\title{
LIME PRETREATMENT AND ENZYMATIC HYDROLYSIS OF CORN STOVER
}

\author{
A Dissertation \\ by \\ SE HOON KIM

\begin{abstract}
Submitted to the Office of Graduate Studies of Texas A\&M University

in partial fulfillment of the requirements for the degree of

DOCTOR OF PHILOSOPHY
\end{abstract}

May 2004

Major Subject: Chemical Engineering 


\title{
LIME PRETREATMENT AND ENZYMATIC HYDROLYSIS OF CORN STOVER
}

\author{
A Dissertation \\ by \\ SE HOON KIM \\ Submitted to Texas A\&M University \\ in partial fulfillment of the requirements \\ for the degree of \\ DOCTOR OF PHILOSOPHY
}

Approved as to style and content by:

Mark T. Holtzapple

(Chair of Committee)

Charles J. Glover

(Member)
Richard R. Davison

(Member)

Cady R. Engler

(Member)

Kenneth R. Hall

(Head of Department)

May 2004

Major Subject: Chemical Engineering 


\begin{abstract}
Lime Pretreatment and Enzymatic Hydrolysis of Corn Stover. (May 2004)

Se Hoon Kim, B.S., Seoul National University, Republic of Korea;

M.S., Seoul National University, Republic of Korea

Chair of Advisory Committee: Dr. Mark T. Holtzapple
\end{abstract}

Renewable energy sources, such as lignocellulosic biomass, are environmentally friendly because they emit less pollution without contributing net carbon dioxide to the atmosphere. Among lignocellulosic biomass, corn stover is a very useful feedstock to economically produce environmentally friendly biofuels.

Corn stover was pretreated with an excess of calcium hydroxide $(0.5 \mathrm{~g}$ $\mathrm{Ca}(\mathrm{OH})_{2} / \mathrm{g}$ raw biomass) in non-oxidative and oxidative conditions at $25,35,45$, and $55^{\circ} \mathrm{C}$. The optimal condition is $55^{\circ} \mathrm{C}$ for 4 weeks with aeration, determined by yields of glucan and xylan. The overall yields of glucose (g glucan hydrolyzed/100 g original glucan) and xylose (g xylan hydrolyzed/100 g original xylan) were 91.3 and 51.8 at 15 FPU/g cellulose, respectively. Furthermore, when considering the dissolved fragments of glucan and xylan in the pretreatment liquors, the overall yields of glucose and xylose were 93.2 and 79.5 at $15 \mathrm{FPU} / \mathrm{g}$ cellulose, respectively. The pretreatment liquor has no inhibitory effect on ethanol fermentation using Saccharomyces cerevisiae $\mathrm{D}_{5} \mathrm{~A}$.

At the recommended condition, only $0.073 \mathrm{~g} \mathrm{Ca}(\mathrm{OH})_{2}$ was consumed per $\mathrm{g}$ of raw corn stover. Under extensive delignification conditions, $87.5 \%$ of the initial lignin was removed. Extensive delignfication required oxidative treatment and additional lime consumption. Deacetylation quickly reached a plateau within 1 week.

Delignification highly depended on temperature and the presence of oxygen. Lignin and hemicellulose were selectively removed, but cellulose was not affected by lime pretreatment in mild temperatures $\left(25-55^{\circ} \mathrm{C}\right)$.

The delignification kinetic models of corn stover were empirically determined by 
three simultaneous first-order reactions. The activation energies for the oxidative delignification were estimated as 50.15 and $54.21 \mathrm{~kJ} / \mathrm{mol}$ in the bulk and residual phases, respectively.

Crystallinity slightly increased with delignification because amorphous components (lignin, hemicellulose) were removed. However, the increased crystallinity did not negatively affect the 3-d sugar yield of enzyme hydrolysis. Oxidative lime pretreatment lowered the acetyl and lignin contents to obtain high digestibility, regardless of crystallinity.

The enzymatic digestibility of lime-treated biomass was affected by the change of structural features (acetylation, lignification, and crystallization) resulting from the treatment. The non-linear models for 3-d hydrolysis yields of glucan and xylan were empirically established as a function of the residual lignin fraction for the corn stover pretreated with lime and air. 
To my parents

wife

and my beloved child 


\section{ACKNOWLEDGMENTS}

First, I would like to thank my research advisor, Dr. Mark T. Holtzapple.

Second, I would like to thank my committee members, Dr. Richard Davison, Dr. Cady Engler, and Dr. Charles Glover, for their valuable input to my research. I also express my gratitude to Mr. Randy Marek, Engineering Technician, for his assistance in making the reactor systems of my research and great guidance for using those machines. Special thanks go to Cesar Granda, Xhu Li, Jonathan O’Dwyer, Frank Agbogbo, and Zhihong $\mathrm{Hu}$ for their collaborations on this project. I would also like to acknowledge all other members of Dr. Holtzapple's group, who have shared much time with me in the laboratory, contributed to my understanding of diverse cultures and helped me adapt to life in the United States.

Third, I would like to thank all the members of the Consortium for Applied Fundamentals and Innovation (CAFI) funded by the United States Department of Agriculture (USDA), including Dartmouth College, Auburn University, Purdue University, Michigan State University, the National Renewable Energy Laboratory (NREL). Working with other people from various institutes provided a great opportunity to improve my communication skills and understanding of the whole picture of renewable energy programs in the United States.

Finally, I would like to dedicate my Ph.D. degree to my parents for their unconditional love. I thank my wife, daughter, and son for their support and encouragement to complete the Ph.D. program. Every achievement of my graduate study comes with their deep love. 


\section{TABLE OF CONTENTS}

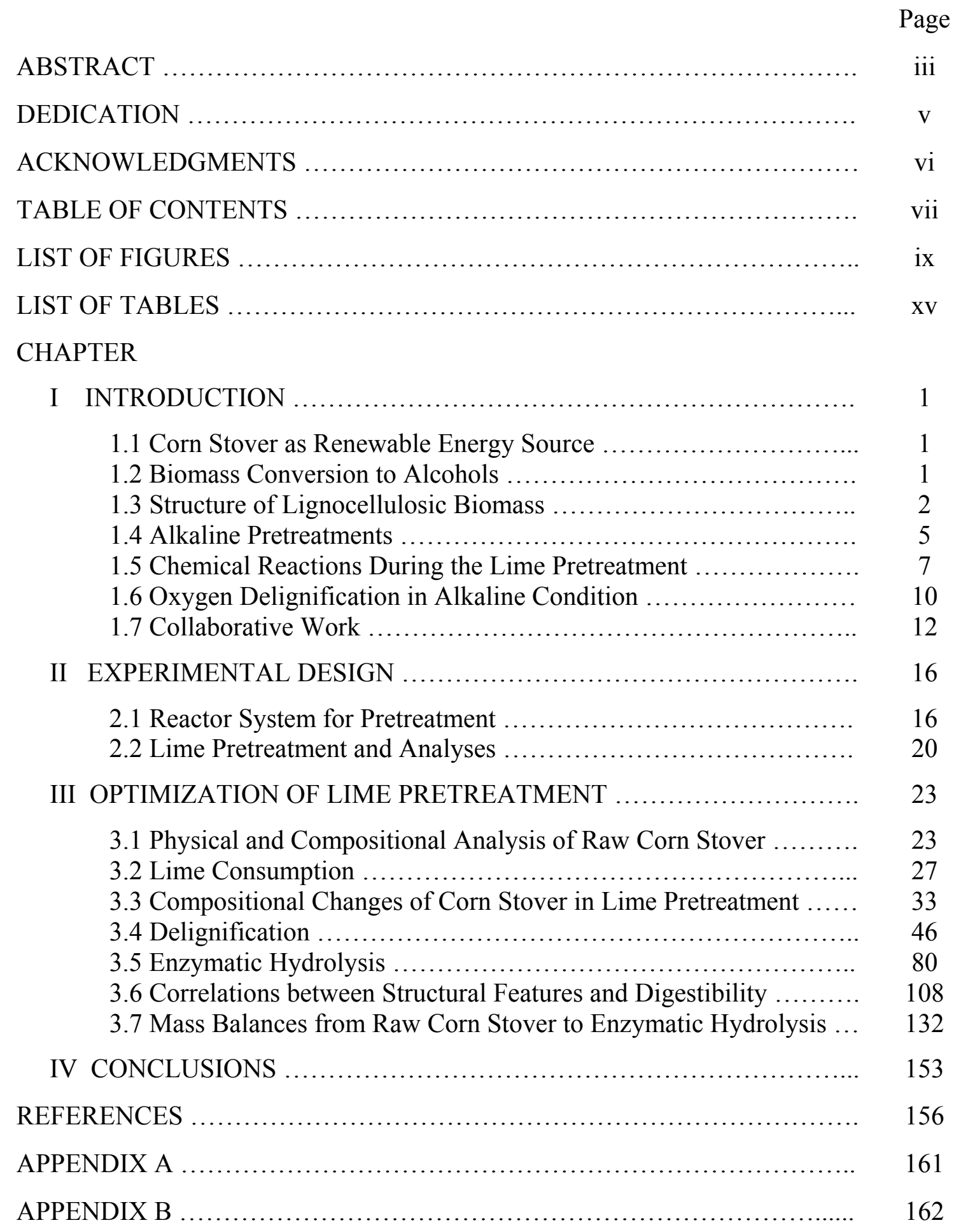


APPENDIX C ......................................................... 163

APPENDIX D ....................................................... 165

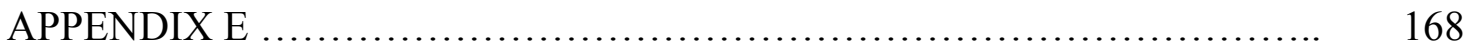

APPENDIX F .................................................. 171

APPENDIX G ....................................................... 173

APPENDIX H ..................................................... 175

APPENDIX I ........................................................ 180

APPENDIX J .......................................................... 183

APPENDIX K .................................................... 186

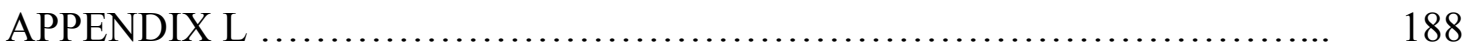

APPENDIX M ................................................... 190

APPENDIX N ........................................................ 192

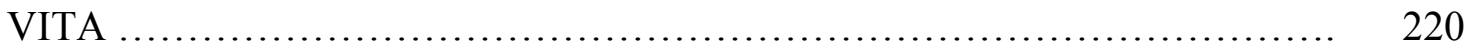




\section{LIST OF FIGURES}

FIGURE

Page

1 Mode of action of cellulolytic enzymes

2 Schematic diagram of biomass conversion to alcohols: (a) ethanol process; (b) MixAlco process ................................... 4

3 Cellulose degradation in alkaline conditions ....................... 8

4 Xylan degradation in alkaline conditions .......................... 9

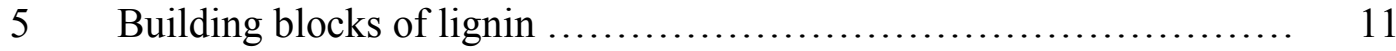

$6 \quad$ Cleavage of (a) $\alpha$-aryl and (b) $\beta$-aryl ether linkages in alkaline conditions

$7 \quad$ Alkaline cleavage of carbon-carbon bonds ....................... 14

8 Schematic diagram of the jacketed reactor for lime pretreatment ...... 17

9 Schematic diagram of the jacketed reactor system for lime pretreatment in the non-oxidative $\left(\mathrm{N}_{2}\right.$ supply) and oxidative (air supply) conditions

10 Photographs of reactor system to pretreat corn stover with lime: (a) front view; (b) side view; (c) head part of water tank; (d) temperature control blocks

11 Particle size distribution of raw corn stover

12 Profiles of the specific lime consumption as a function of pretreatment time in the non-oxidative condition (a) and in the oxidative condition with $\mathrm{CO}_{2}$ scrubbing (b)

13 Profiles of the specific lime consumption in the non-oxidative (----), oxidative with natural air $(\boldsymbol{O})$ and with $\mathrm{CO}_{2}$-scrubbed air $(\boldsymbol{\Delta})$ at $25^{\circ} \mathrm{C}$

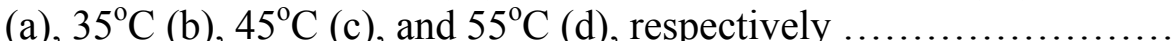

14 The fractional changes of lignin solubilized as a function of the weight fraction of lime consumed in the non-oxidative condition $(\boldsymbol{\Delta})$ and oxidative condition with $\mathrm{CO}_{2}$ scrubbing $(\mathbf{O})$

15 Mass profiles of total solid, holocellulose (glucan + xylan), lignin (Klason lignin + acid-soluble lignin), crude proteins, ash, and others in the non-oxidative lime pretreatment at $25^{\circ} \mathrm{C}(\mathrm{a}), 35^{\circ} \mathrm{C}(\mathrm{b}), 45^{\circ} \mathrm{C}(\mathrm{c})$, and $55^{\circ} \mathrm{C}(\mathrm{d})$, respectively 
16 Mass profiles of total solid, holocellulose (glucan + xylan), lignin (Klason lignin + acid-soluble lignin), crude proteins, ash, and others in the oxidative lime pretreatment at $25^{\circ} \mathrm{C}(\mathrm{a}), 35^{\circ} \mathrm{C}(\mathrm{b}), 45^{\circ} \mathrm{C}(\mathrm{c})$, and $55^{\circ} \mathrm{C}(\mathrm{d})$, respectively

17 Pretreatment yields of cellulose, $Y_{\mathrm{G}}$, (a), hemicellulose, $Y_{\mathrm{X}},(\mathrm{b})$, and Klason lignin content $(c)$ in non-oxidative $(\mathbf{O})$ and oxidative $(\bigcirc)$ conditions at $25^{\circ} \mathrm{C}$

18 Pretreatment yields of cellulose, $Y_{\mathrm{G}}$, (a), hemicellulose, $Y_{\mathrm{X}},(\mathrm{b})$, and Klason lignin content $(\mathrm{c})$ in non-oxidative $(\mathbf{O})$ and oxidative $(\mathrm{O})$ conditions at $35^{\circ} \mathrm{C}$

19 Pretreatment yields of cellulose, $Y_{\mathrm{G}}$, (a), hemicellulose, $Y_{\mathrm{X}},(\mathrm{b})$, and Klason lignin content $(c)$ in non-oxidative $(\mathbf{O})$ and oxidative $(O)$ conditions at $45^{\circ} \mathrm{C}$

20 Pretreatment yields of cellulose, $Y_{\mathrm{G}},(\mathrm{a})$, hemicellulose, $Y_{\mathrm{X}},(\mathrm{b})$, and Klason lignin content $(\mathrm{c})$ in non-oxidative $(\mathbf{O})$ and oxidative $(\bigcirc)$ conditions at $55^{\circ} \mathrm{C}$

21 Three stages of delignification in wood pulping process ..............

22 Delignification of lignocellulosic biomass described in three stages (initial, bulk, and residual) simultaneously

23 Profiles of Klason lignin content in non-oxidative (a) and oxidative (b) lime pretreatment at $25,35,45$, and $55^{\circ} \mathrm{C}$

24 Profiles of acid-soluble lignin content in non-oxidative (a) and oxidative (b) lime pretreatment at $25,35,45$, and $55^{\circ} \mathrm{C}$

25 Klason lignin content $(L)$ versus the pretreatment yield of total solids $\left(Y_{\mathrm{T}}\right)$ recovered after the non-oxidative lime pretreatment at (a) 25, (b) 35 , (c) 45 , and (d) $55^{\circ} \mathrm{C}$

26 Klason lignin content $(L)$ versus the pretreatment yield of total solids $\left(Y_{\mathrm{T}}\right)$ recovered after the oxidative lime pretreatment at (a) 25, (b) 35, (c) 45 , and (d) $55^{\circ} \mathrm{C}$

27 Effect of temperature $\left({ }^{\circ} \mathrm{C}\right)$ on the selectivity of delignification $\left(\triangle L / \triangle Y_{\mathrm{T}}\right.$ ) in non-oxidative (a) and oxidative (b) pretreatment with lime for 4 weeks. Bar symbols represent standard errors $(-)$........

28 Effect of temperature $\left({ }^{\circ} \mathrm{C}\right)$ on the selectivity of delignification $\left(\triangle L / \triangle Y_{\mathrm{T}}\right.$ ) in non-oxidative (a) and oxidative (b) pretreatment with lime for 16 weeks. Bar symbols represent standard errors $(-)$....... 
29 Effect of aeration on the selectivity of delignification $\left(\triangle L / \triangle Y_{\mathrm{T}}\right)$ for 4 and 16 weeks in lime-pretreatment. Bar symbols represent standard errors $(-)$

30 The yields of holocellulose, $Y_{\mathrm{GX}}$, (a), glucan, $Y_{\mathrm{G}}$, (b), and xylan, $Y_{\mathrm{X}}$, (c) versus the residual insoluble lignin $\left(W_{\mathrm{L}}\right)$ of corn stover pretreated with lime in non-oxidative $(\boldsymbol{O})$ and oxidative $(\boldsymbol{\Delta})$ conditions, respectively

31 Comparison of the curve fits for delignification kinetics of the nonoxidative pretreatment at (a) 25 , (b) 35 , (c) 45 , and (d) $55^{\circ} \mathrm{C}$, using Equation 5 (-----), Equation 6 (- - ), and Equation 7 (-- -), respectively

32 Comparison of the curve fits for delignification kinetics of the nonoxidative pretreatment at (a) 25 , (b) 35 , (c) 45 , and (d) $55^{\circ} \mathrm{C}$, using Equation 5 (-----), Equation 6 (- - ), and Equation 7 (-- -), respectively

33 Arrhenius plots $\ln k$ versus 1000/T for Equation 5 as the delignification model in the non-oxidative (a) and oxidative (b) conditions

34 Arrhenius plots $\ln k$ versus 1000/T for Equation 6 as the delignification model in the non-oxidative (a) and oxidative (b) conditions

35 Arrhenius plots $\ln k$ versus $1000 / T$ for Equation 7 as the delignification model in the non-oxidative (a) and oxidative (b) conditions

36 Delignification profiles of bulk $\left(W_{\mathrm{L} 2}\right)$ and residual $\left(W_{\mathrm{L} 3}\right)$ phases plotted from Equation 6, where $W_{\mathrm{L} 2}=a_{2} \cdot \exp \left(-k_{2} \cdot t\right)$ and $W_{\mathrm{L} 3}=a_{3} \cdot \exp (-$ $\left.k_{3} \cdot t\right)$, in the non-oxidative (---) and oxidative $(-)$ pretreatment. The circle symbol shows the experimental data for the non-oxidative $(O)$ and oxidative (O) pretreatment, at (a) 25 , (b) 35 , (c) 45 , and (d) $55^{\circ} \mathrm{C}$, respectively

37 Sugar yield profiles of the untreated corn stover (first batch) according to cellulase loading at the enzyme reaction times: 1,5 , and $72 \mathrm{~h} . \ldots . .$.

383 -d sugar yields of the treated corn stover in non-oxidative condition for 16 weeks at 25 and $55^{\circ} \mathrm{C}$

39 Relative 3-d sugar yields of the treated corn stover in non-oxidative condition for 15 weeks at $25^{\circ} \mathrm{C}$ 
40 Aeration effect on 3-d sugar yields of the treated corn stover at (a) 25, (b) 35 , (c) 45 , and (d) $55^{\circ} \mathrm{C}$ after 16 -week pretreatment with lime ......

41 Hydrolysis yield from cellulose to glucose in 3-d enzyme hydrolysis of the corn stover treated with lime at (a) 25, (b) 35, (c) 45, and (d) $55^{\circ} \mathrm{C}$ in non-oxidative $(\mathbf{O})$ and oxidative $(\boldsymbol{\Delta})$ conditions, when the enzyme loading is $15 \mathrm{FPU} / \mathrm{g}$ cellulose

42 Hydrolysis yield from hemicellulose to xylose in 3-d enzyme hydrolysis of the corn stover treated with lime at (a) 25 , (b) 35 , (c) 45 , and $(\mathrm{d}) 55^{\circ} \mathrm{C}$ in non-oxidative $(\boldsymbol{O})$ and oxidative $(\boldsymbol{\Delta})$ conditions, when the enzyme loading is $15 \mathrm{FPU} / \mathrm{g}$ cellulose

43 The ratio of glucose (g) to xylose $(\mathrm{g}), G / X$, generated in 3-d enzyme hydrolysis of the corn stover treated with lime at (a) 25 and (b) $55^{\circ} \mathrm{C}$ in non-oxidative $(\mathbf{O})$ and oxidative $(\boldsymbol{\Delta})$ conditions, when the enzyme loading rate is $15 \mathrm{FPU} / \mathrm{g}$ cellulose

44 Scheme to determine the sugar yields in each step for optimizing lime pretreatment conditions

45 Overall yields of glucan to glucose (a) and of xylan to xylose (b) at $25^{\circ} \mathrm{C}$ in non-oxidative $(O)$ and oxidative $(\bigcirc)$ pretreatments with lime, when enzyme loading was $15 \mathrm{FPU} / \mathrm{g}$ glucan ...

46 Overall yields of glucan to glucose (a) and of xylan to xylose (b) at $35^{\circ} \mathrm{C}$ in non-oxidative $(O)$ and oxidative $(\bigcirc)$ pretreatments with lime, when enzyme loading was $15 \mathrm{FPU} / \mathrm{g}$ glucan

47 Overall yields of glucan to glucose (a) and of xylan to xylose (b) at $45^{\circ} \mathrm{C}$ in non-oxidative $(O)$ and oxidative $(O)$ pretreatments with lime,

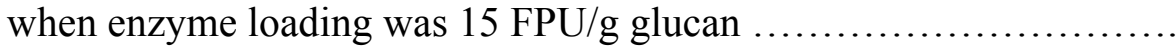

48 Overall yields of glucan to glucose (a) and of xylan to xylose (b) at $55^{\circ} \mathrm{C}$ in non-oxidative $(O)$ and oxidative $(O)$ pretreatments with lime, when enzyme loading was $15 \mathrm{FPU} / \mathrm{g}$ glucan

49 Overall yields for (a) glucose $\left(Y_{\mathrm{g}}^{\mathrm{T}}\right)$ and for $(\mathrm{b})$ xylose $\left(Y_{\mathrm{x}}^{\mathrm{T}}\right)$ in corn stover pretreated oxidatively with lime at $55^{\circ} \mathrm{C}$ and then enzymatically hydrolyzed at $2.1(\mathbf{O}), 15(\mathbf{\Delta}), 60(\mathbf{\square}) \mathrm{FPU} / \mathrm{g}$ cellulose of cellulase, respectively

50 Overall yields for $(\bigcirc)$ glucose $\left(Y_{\mathrm{g}}^{\mathrm{T}}\right)$ and for $(\bigcirc)$ xylose $\left(Y_{\mathrm{x}}^{\mathrm{T}}\right)$ in corn stover pretreated at the optimal condition ( 4 week, $55^{\circ} \mathrm{C}$, and aeration) and then enzymatically hydrolyzed for $3 \mathrm{~d}$ 
51 Hydrolysis efficiency of Spezyme CP (cellulase) on $\alpha$-cellulose and pure xylan at $5 \mathrm{FPU} / \mathrm{g}$ cellulose and $5 \mathrm{FPU} / \mathrm{g}$ xylan of enzyme loadings, respectively. Substrate concentration was $10 \mathrm{~g} / \mathrm{L}$

52 X-ray diffraction pattern of corn stover

53 Deacetylation of the pretreated corn stover with lime at (a) 25, (b) 35, (c) 45 , and (d) $55^{\circ} \mathrm{C}$ in non-oxidative $(\bigcirc)$ and oxidative $(\mathbf{O})$ conditions

54 The profiles of deacetylation ( $\square$ ) and delignification ( $)$ during the lime pretreatment in non-oxidative (a) and in oxidative (b) condition at $25^{\circ} \mathrm{C}$

55 The profiles of deacetylation $(\boldsymbol{\square})$ and delignification $(\boldsymbol{O})$ during the lime pretreatment in non-oxidative (a) and in oxidative (b) condition at $35^{\circ} \mathrm{C}$

56 The profiles of deacetylation ( $\square$ ) and delignification ( $)$ during the lime pretreatment in non-oxidative (a) and in oxidative (b) condition at $45^{\circ} \mathrm{C}$

57 The profiles of deacetylation ( $\square$ ) and delignification ( $)$ during the lime pretreatment in non-oxidative (a) and in oxidative (b) condition at $55^{\circ} \mathrm{C}$

58 Distribution of deacetylation, delignification, and 3-d sugar yield $\left(Y_{\mathrm{gx}}\right)$ in enzyme hydrolysis for the corn stover treated with lime ..............

59 Effect of delignification on the hydrolysis yields of glucan (a) and xylan (b) in 3-d enzyme digestibility at $15 \mathrm{FPU} / \mathrm{g}$ cellulose

60 Correlation of delignification with holocellulose (glucan and xylan) content (a) and with the ratio of glucan to xylan (b) of lime-pretreated solid in non-oxidative $(\boldsymbol{A})$ and oxidative $(\boldsymbol{O})$ conditions

61 Correlation of crystallinity with delignification (a) and glucan content (b) of lime-pretreated corn stover in non-oxidative $(\square)$ and oxidative

(a) conditions

$62 \quad 3-d$ hydrolysis yield of holocellulose as a function of lignin content in lime-treated woody biomass with air (Chang et al. 2000) ...............

63 Correlations between the weight fraction of the residual lignin $\left(W_{\mathrm{L}}\right)$ and 3-d hydrolysis yields: (a) $Y_{\mathrm{g}}$; (b) $Y_{\mathrm{x}}$; (c) $Y_{\mathrm{gx}}$, for corn stover pretreated with lime and air. The enzyme loading rate is $15 \mathrm{FPU} / \mathrm{g}$ cellulose. The solid lines show plots of non-linear regressions using Equations 25, 26, and 24, respectively 
FIGURE Page

64 Products of alkaline wet oxidation of corn stover .................... 134

65 Weight percents of cellulose (a) and hemicelluose (b) degraded and undegraded in the pretreatment liquor, and recovered in the solid pretreated with lime at $55^{\circ} \mathrm{C}$ in oxidative condition, respectively ...... 138

66 Weight percents of cellulose (a) and hemicelluose (b) digested and undigested in the recovered solid pretreated with lime at $55^{\circ} \mathrm{C}$ in oxidative condition, respectively, when the enzyme loading rate is 15 and $60 \mathrm{FPU} / \mathrm{g}$ cellulose in $3-\mathrm{d}$ enzyme hydrolysis .....................

67 The relative digestibility of glucan in enzyme hydrolysis of $\alpha$ cellulose $(\mathbf{\Delta})$ and the corn stover $(\mathbf{O})$ pretreated with lime at the optimal condition $\left(55^{\circ} \mathrm{C}, 4\right.$ weeks, and aeration), and relative digestibility of xylan $(\mathrm{O})$ for the pretreated corn stover at (a) 15 and (b) $60 \mathrm{FPU} / \mathrm{g}$ cellulose, respectively $\ldots \ldots \ldots \ldots \ldots \ldots \ldots \ldots \ldots \ldots \ldots . . \ldots \ldots \ldots$

68 Mass fractions from raw corn stover to enzyme hydrolysis ............ 144

69 Cultivation of Saccharomyces cerevisiae $\mathrm{D}_{5} \mathrm{~A}$ in YPD basal medium at $37^{\circ} \mathrm{C}$ : OD $(\mathbf{O})$, glucose concentration $(\mathbf{\Delta})$, and ethanol

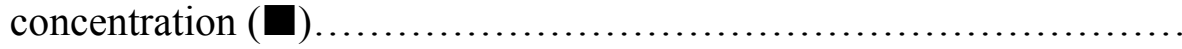

70 Cross-sectional view of pretreatment and fermentation pile 


\section{LIST OF TABLES}

TABLE Page

1 Pretreatment technologies of lignocellulosic biomass ............... 6

2 Water partial pressure and the corresponding oxygen partial pressure in saturated air as a function of temperature at normal atmospheric conditions (Perry et al., 1984)

3 Experimental conditions and the operational parameters for pretreatment

4 The particle size distribution of the first and second batches of corn stover

Compositions of raw corn stover

$6 \quad$ Mineral content of raw corn stover ................................ 26

$7 \quad$ The recovery yield of total mass $\left(Y_{\mathrm{M}}\right)$ from column disassembly ...... 36

8 Slopes $\left(\triangle L / \triangle Y_{\mathrm{T}}\right)$ of Klason lignin content $(L, \mathrm{~g}$ Klason lignin/100 $\mathrm{g}$ raw biomass) versus the pretreatment yield of total solids $\left(Y_{\mathrm{T}}\right.$, g solid recovered/100 $\mathrm{g}$ raw biomass) to compare the ease of delignification at different temperatures in non-oxidative and oxidative limepretreatments, respectively

9 Slopes $\left(\triangle L / \triangle Y_{\mathrm{T}}\right)$ of Klason lignin content $(L, \mathrm{~g}$ Klason lignin/100 $\mathrm{g}$ raw biomass) versus the pretreatment yield of total solids $\left(Y_{\mathrm{T}}\right.$, g solid recovered/100 g raw biomass) to compare the ease of delignification in non-oxidative and oxidative lime-pretreatments, respectively ........

10 Results of parameter estimation for reaction rate constants, $k_{i}(i=1,2$, and 3), obtained from regression analyses of delignification kinetic data in the non-oxidative lime pretreatments

11 Results of parameter estimation for constants, $a_{i}(i=1,2$, and 3$)$, obtained from regression analyses of delignification kinetic data in the non-oxidative lime pretreatments ................................

12 Results of parameter estimation for reaction rate constants, $k_{i}(i=1,2$, and 3), obtained from regression analyses of delignification kinetic data in the oxidative lime pretreatments ..........................

13 Results of parameter estimation for constants, $a_{i}(i=1,2$, and 3$)$, obtained from regression analyses of delignification kinetic data in the oxidative lime pretreatments 
14 Correlation analysis between delignification data for the first and second batches of corn stover ................................... 73

15 Activation energies for delignification modeled in Equation 6 ........ 73

16 Comparison of lignin contents of untreated corn stover in both nonoxidative and oxidative conditions without lime addition

17 The hydrolysis yield of cellulose and hemicellulose to glucose $\left(Y_{\mathrm{g}}\right)$ and xylose $\left(Y_{x}\right)$, and the ratio of glucose to xylose $(G / X)$ in 3-d enzymatic hydrolysis at $15 \mathrm{FPU} / \mathrm{g}$ cellulose of enzyme loading .........

18 The maximal overall yields of glucose $\left(Y_{\mathrm{g}}^{\mathrm{T}}, \mathrm{g}\right.$ glucan hydrolyzed/g glucan in raw biomass) and xylose $\left(Y_{\mathrm{x}}^{\mathrm{T}}, \mathrm{g}\right.$ xylan hydrolyzed/g xylan in raw biomass) for each pretreatment with lime, when the enzyme loading is $15 \mathrm{FPU} / \mathrm{g}$ cellulose ..................................

19 The average levels of deacetylation (g acetyl group removed/100 g acetyl group in raw biomass) for corn stover treated with lime

20 Comparison of deacetylation (g acetyl group removed/100 g acetyl group in raw biomass) between lime-free and lime pretreatments at $10^{\text {th }}$ and $8^{\text {th }}$ week, respectively

21 Parameters of correlations for 3-d hydrolysis yields of glucan $\left(Y_{\mathrm{g}}, \mathrm{g}\right.$ glucan hydrolyzed/100 g glucan in treated biomass) and xylan $\left(Y_{\mathrm{x}}, \mathrm{g}\right.$ xylan hydrolyzed/100 g xylan in treated biomass) .

22 The weight percents of cellulose and hemicellulose degraded and undegraded in the pretreatment liquor, and recovered in the solid stover treated with lime at $55^{\circ} \mathrm{C}$ with aeration for 4 and 8 weeks

23 The weight percents of cellulose and hemicellulose digested and undigested in the recovered solid corn stover treated with lime at $55^{\circ} \mathrm{C}$ with aeration for 4 and 8 weeks, when the enzyme loading rate is 15 and $60 \mathrm{FPU} / \mathrm{g}$ cellulose, respectively, in 3-d enzyme digestibility ......

24 Mass balances from raw corn stover (RC) to enzyme hydrolysis (ER and $\mathrm{EH}$ ) of the pretreated corn stover (in Figure 68 ) at $55^{\circ} \mathrm{C}$ with

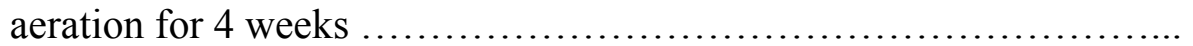

25 Mass balances from raw corn stover (RC) to enzyme hydrolysis (ER and $\mathrm{EH}$ ) of the pretreated corn stover (in Figure 68 ) at $55^{\circ} \mathrm{C}$ with aeration for 8 weeks

26 Yields of glucose and xylose in the pretreatment and the overall process, when the enzyme loading is $15 \mathrm{FPU} / \mathrm{g}$ cellulose 
TABLE Page

27 Yields of glucose and xylose in the pretreatment and the overall process, when the enzyme loading is $60 \mathrm{FPU} / \mathrm{g}$ cellulose ............. 148

28 Fermentability of the pretreatment liquor collected in the non-

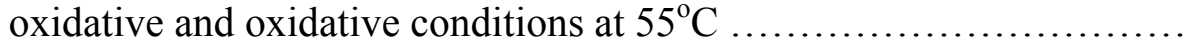




\section{CHAPTER I \\ INTRODUCTION}

\subsection{Corn Stover as Renewable Energy Source}

Many environmental problems - such as greenhouse gases and pollution of air, water, and soil - originate from fossil fuels. Fossil fuels release greenhouse gases, like carbon dioxide, that contribute to global warming. Carbon dioxide from fossil fuel combustion accounted for nearly $80 \%$ of global warming in the 1990s (Hileman 1999 and 2003 Inventory of U.S Greenhouse Gas Emissions and Sinks). However, renewable energy sources, such as lignocellulosic biomass, are environmentally friendly because they emit less pollution without contributing net carbon dioxide to the atmosphere.

Another reason to consider biomass as an energy source is to address the growing amounts of lignocellulosic waste generated from the agricultural and industrial sectors. Large amounts of corn stover are available as an environmentally friendly raw material for industry. In 2002, the United States produced 153 million tons of corn stover, corresponding to $43 \%$ of all agricultural residues (Hettenhaus et al. 2000 and Kadam et al. 2003). In spite of the large quantities, currently only $6 \%$ of stover is collected, mostly for animal feeding and bedding. Some stover is grazed, but all or part of corn stover is left on the field as a cover (Sokhansanj et al. 2002).

Among lignocellulosic biomass, corn stover is a very useful feedstock to economically produce environmentally friendly biofuels.

\subsection{Biomass Conversion to Alcohols}

Three major components of lignocellulosic biomass, such as corn stover, are cellulose, hemicellulose, and lignin. Cellulose and hemicellulose are not directly available for bioconversion because of their intimate association with lignin (Williams et

This dissertation follows the style and format of Biotechnology and Bioengineering 
al. 1982, Ingram et al. 1995, and Holtzapple et al. 1997).

To increase the enzymatic digestibility of lignocellulosic biomass, it is treated mechanically (e.g., ball milling) or chemically (e.g., acid/alkali treatment). The treated biomass then is enzymatically hydrolyzed to sugars by cellulase and hemicellulase. The resulting sugars are fermented to ethanol by yeast fermentation (Hahn et al. 1996). This process needs cellulase enzyme complexes to convert biomass to sugars ('saccharification'). Cellulase is a group of enzymes that synergistically hydrolyzes cellulose (Reczey et al. 1996) (Figure 1). The classical cellulase system includes endoglucanase, exoglucanase, and cellobiase (or $\beta$-glucosidase). Endoglucanse randomly attacks at $\beta-1,4-D-g l u c a n$ chains in amorphous regions of cellulose or the surface of microfibrils. Exoglucanase releases cellobiose from the non-reducing ends of $\beta$-D-glucan chains. Cellobiase hydrolyzes cellobiose to glucose (Jeewon 1997). Simultaneous saccharification and fermentation (SSF) has been proposed as an industrial process that merges saccharification and fermentation.

Alternatively, biomass can be converted to mixed acids by a mixed-culture fermentation using the MixAlco process, (Holtzapple et al. 1997), as shown in Figure 2. The latter process converts lignocellulosic biomass directly into carboxylate salts using rumen or marine microorganisms. The carboxylate salts are thermally converted to ketones, and then hydrogenated to produce mixed $\left(\mathrm{C}_{2}-\mathrm{C}_{13}\right)$ alcohols (Holtzapple et al. 1997).

\subsection{Structure of Lignocellulosic Biomass}

Cellulose is a linear polysaccharide of glucose residues connected by $\beta-1,4$ linkages. Native crystalline cellulose is insoluble and occurs as fibers of densely packed, hydrogen-bonded, anhydroglucose chains of 15 to 10,000 glucose units. Its density and complexity resists hydrolysis without preliminary chemical or mechanical degradation or swelling. In nature, cellulose is usually associated with other polysaccharides such as xylan or lignin. It is the skeletal basis of plant cell walls (Holtzapple 1993a). 


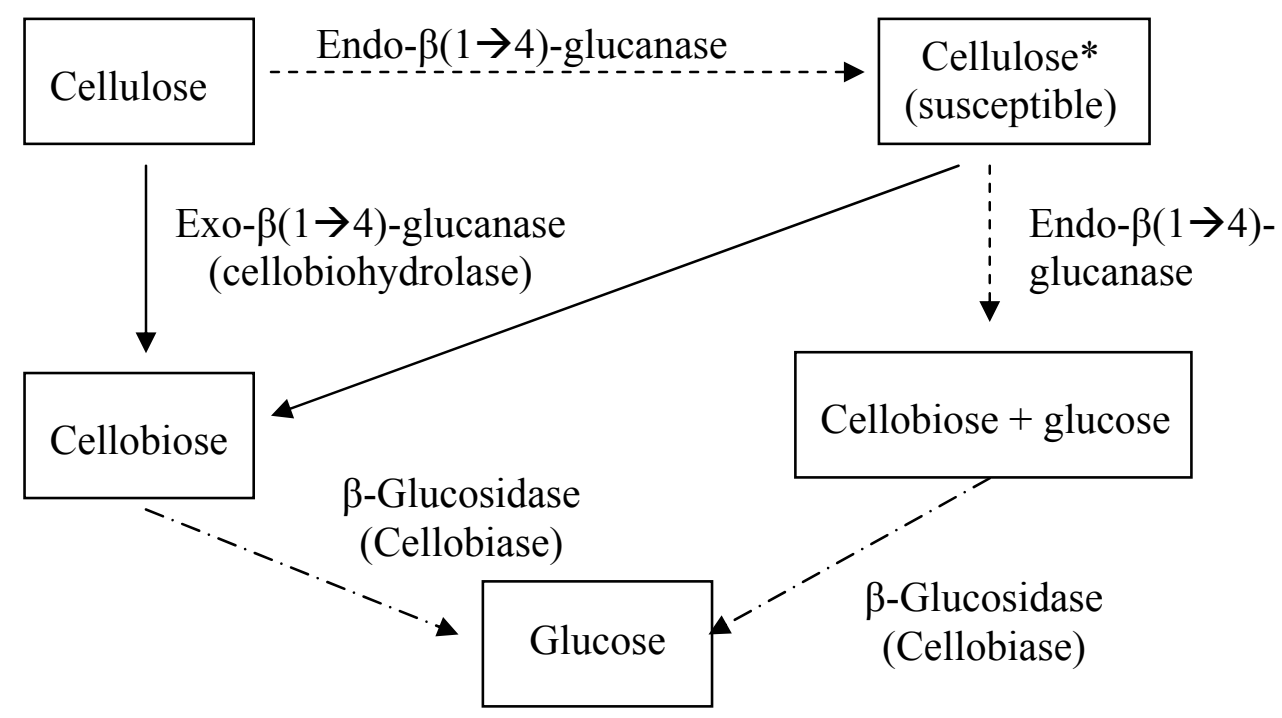

Figure 1. Mode of action of cellulolytic enzymes. 


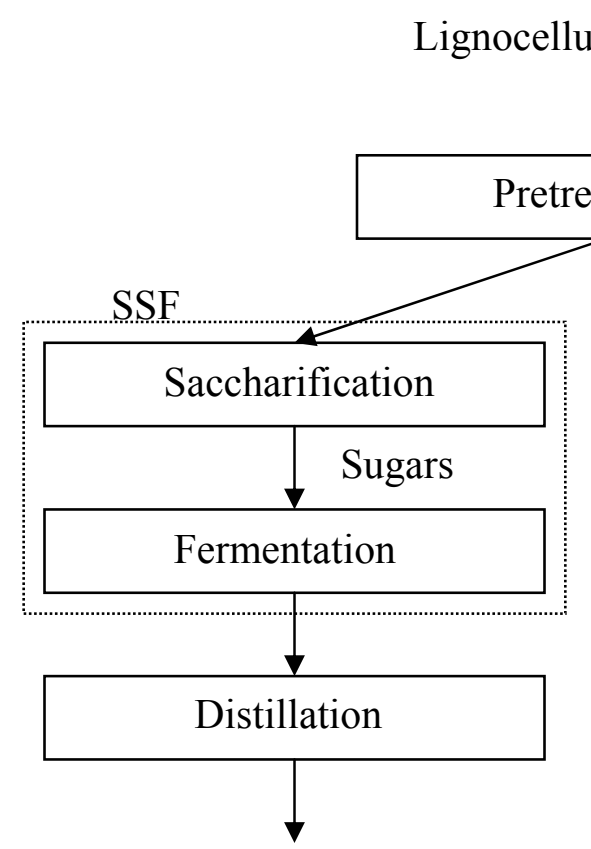

Ethanol

(a)

(b)

Figure 2. Schematic diagram of biomass conversion to alcohols: (a) ethanol process; (b) MixAlco process. 
Hemicellulose consists of short, highly branched chains of sugars, mainly xylose. It contains five-carbon sugars (D-xylose and L-arabinose), six-carbon sugars (D- glucose, D-galactose, and D-mannose), and uronic acid (Holtzapple 1993b). Native xylan is highly substituted with acetic acid, for example, $35-70 \%$ of xylose is acetylated in hardwoods and grasses. Its branched nature renders hemicellulose amorphous and relatively easy to hydrolyze to its constituent sugars. As the acetyl xylan fraction becomes increasingly deacetylated, it becomes more digestible, which in turn makes the cellulose fraction more accessible to cellulose enzymes and therefore more digestible (Mitchell et al. 1990).

Cellulose and hemicellulose are the most abundant organic sources of food, fuel, and chemicals (Ingram et al. 1995). However, its usefulness depends upon its digestibility to glucose and xylose.

Lignin is a highly cross-linked phenylpropylene polymer (Holtzapple 1993c). It plays an important role in cell wall structure as a permanent bonding agent among plant cells. It is always associated with hemicellulose in the cell wall (Sarkanen et al. 1971).

\subsection{Alkaline Pretreatments}

As shown in Figure 2, pretreatment of lignocellulosic biomass is a common step for efficient alcohol production. Without pretreatment, biomass digestibility for enzymatic hydrolysis or microbial fermentation is limited due to structural properties, such as lignin content, acetylated hemicellulose, limited surface area, and crystallinity (Kong et al. 1992 and Chang et al. 2000). Many different technologies for biomass pretreatment have been developed (Table 1). Among various technologies, hydrolysis methods with dilute acid or alkali are relatively capital and energy efficient. However, the suitability of the pretreatment technologies can differ from species to species of biomass.

Lime pretreatment technology has been thoroughly studied on various biomass sources such as switchgrass, corn stover, wood, and municipal waste (Chang et al. 1997 


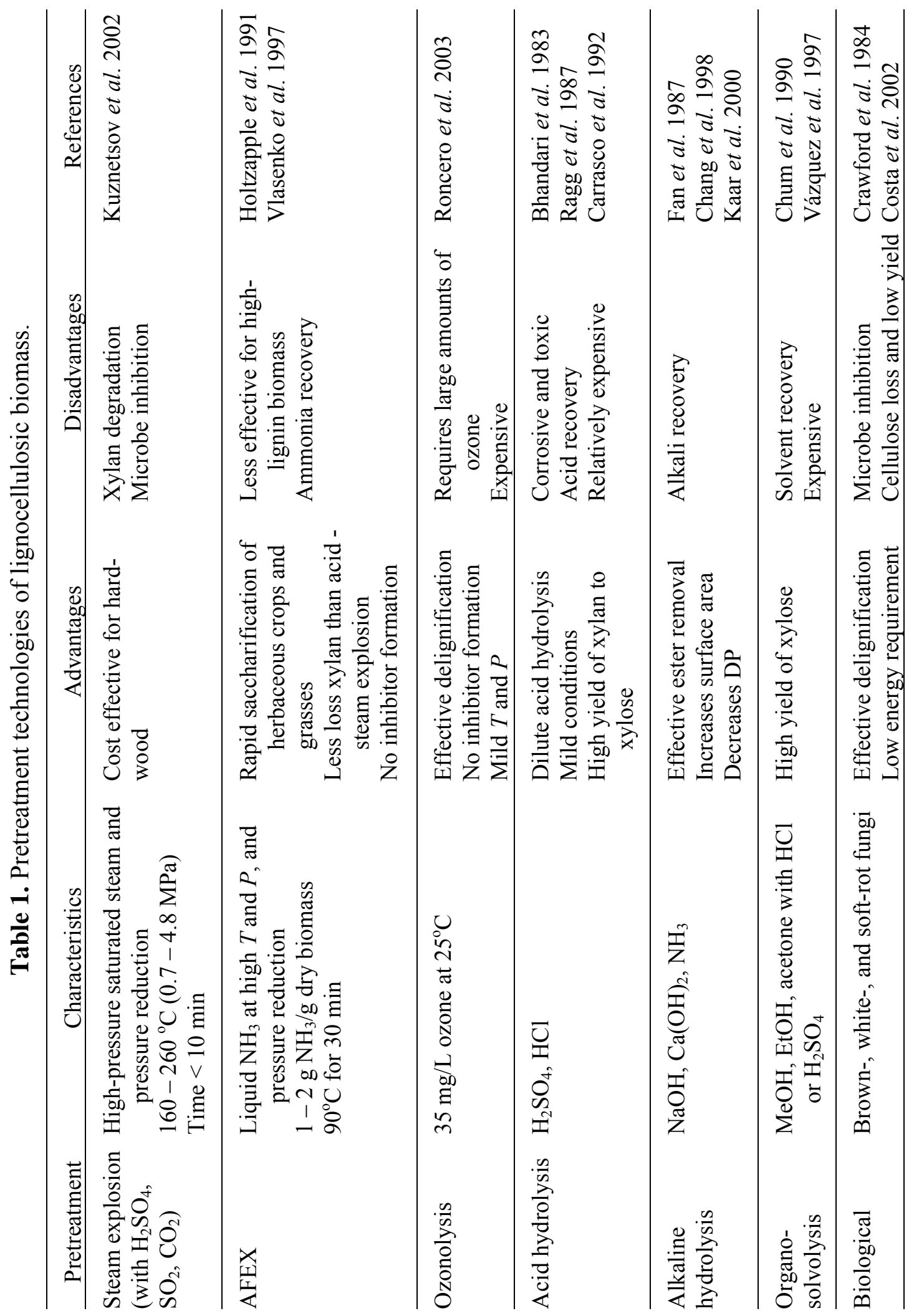


and 1998, Kaar et al. 2000). Lime has the following advantages: it is inexpensive, $\$ 0.06 / \mathrm{kg}$ (Miller, 2001); safe to handle; and can be simply recovered (Chang et al. 1998).

In previous studies on lime pretreatment, the pretreatment conditions were optimized for different types of lignocellulosic materials on the basis of 3-d enzyme digestibility; $120^{\circ} \mathrm{C}$ for $1 \mathrm{~h}$ on bagasse (Chang et al. 1998), $100-120^{\circ} \mathrm{C}$ for $2 \mathrm{~h}$ on switchgrass (Chang et al. 1997), and $120^{\circ} \mathrm{C}$ for $4 \mathrm{~h}$ on corn stover (Kaar et al. 2000) in non-oxidative lime conditions, whereas 14 bar absolute oxygen at $150^{\circ} \mathrm{C}$ for $6 \mathrm{~h}$ on poplar wood and 7.1 bar absolute oxygen at $140^{\circ} \mathrm{C}$ for $3 \mathrm{~h}$ on newspaper (Chang et al. 2001) in oxidative lime conditions. Most cases were optimized at high temperature ranges $\left(100-150^{\circ} \mathrm{C}\right)$ and pure oxygen was used to meet the oxidative treatment. However, the specially designed vessel (e.g., stainless steel tank that resists high pressure and corrosion) and the large amounts of pure oxygen are not economical for low-cost biomass pretreatments at commercial scales.

From this view, in this study, pretreatment conditions were reconsidered and optimized in moderate temperature ranges $\left(25-55^{\circ} \mathrm{C}\right)$ with air instead of pure oxygen.

\subsection{Chemical Reactions During the Lime Pretreatment}

Carbohydrates in the presence of alkali and oxygen undergo both oxidation and alkaline degradation to produce a complex mixture of products (Montgomery 1953, Williams et al. 1982, McGinnis et al. 1984, and Klinke et al. 2002). Hydroxy-carboxylic acids, such as glucoisosaccharinic and xylosaccharinic acids, are formed from the degradation of cellulose and hemicellulose (Figure 3 and 4). The peeling reaction (or endwise depolymerization reaction) is a $\beta$-elimination that begins at the reducing end of the molecule and proceeds along the chain liberating saccharinate molecules (Lai 2001).

The formation of low-molecular-mass fragments, such as glycolic and lactic acids, increases at more severe reaction conditions, i.e., high alkaline concentration or high-temperature conditions (Sjöström 1991). Cellulose is relatively more stable to alkaline wet oxidation (alkali, water, oxygen, high temperature and pressure) than xylan. 


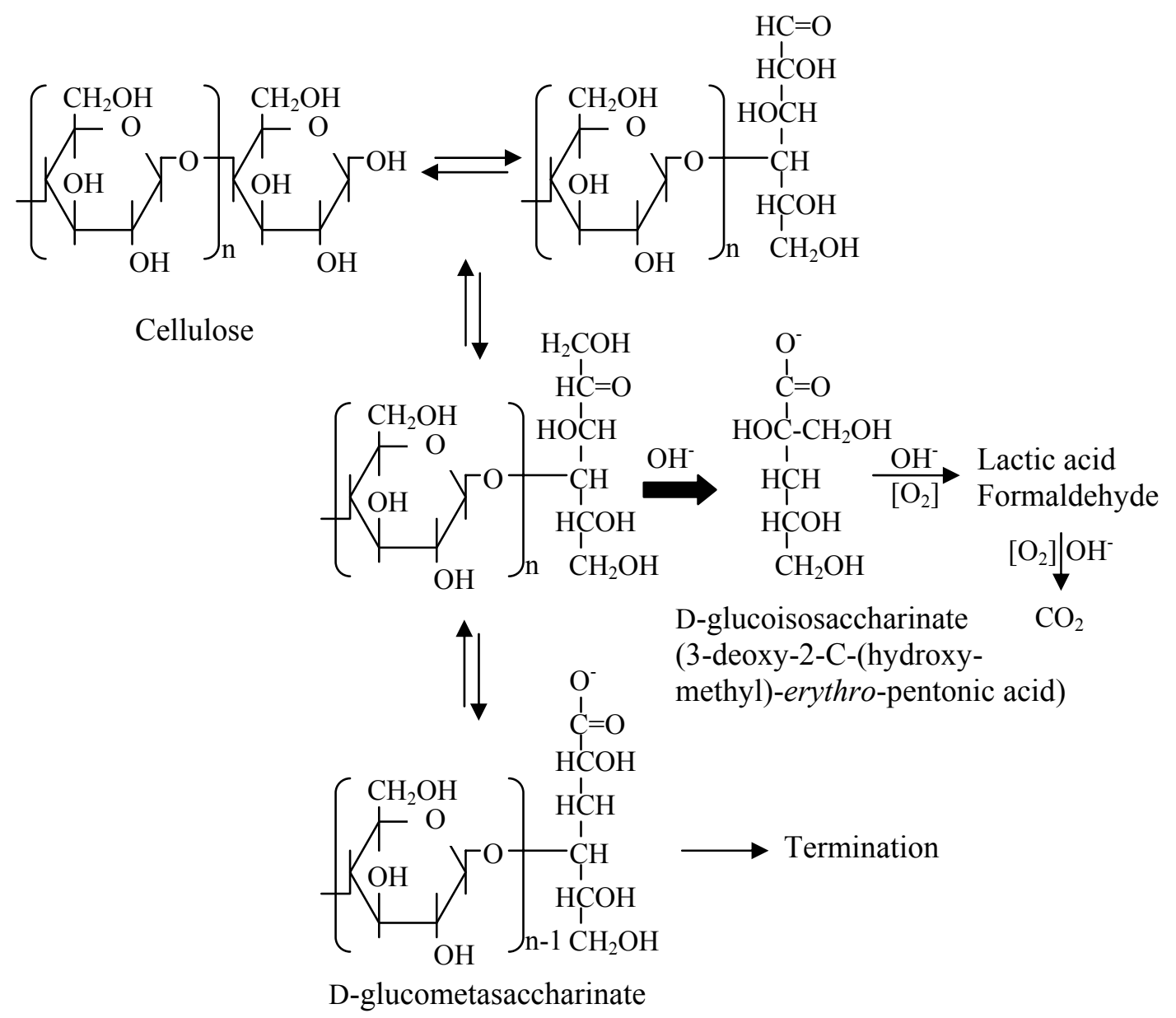

Figure 3. Cellulose degradation in alkaline conditions. 


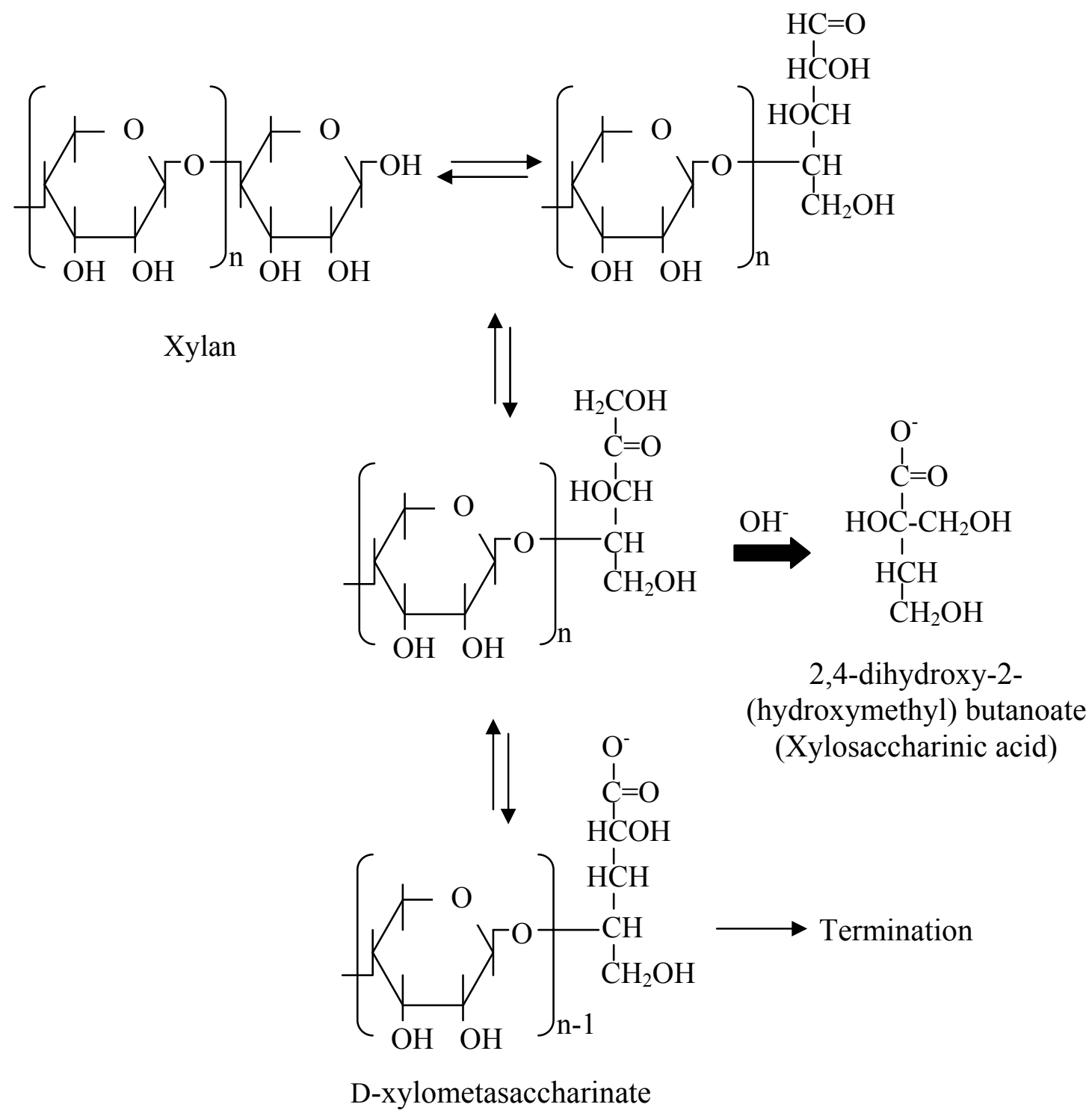

Figure 4. Xylan degradation in alkaline conditions. 
Degradation reactions of cellulose and hemicellulose are limited by the formation of D-glucometasaccharinate and D-xylometasaccharinate, respectively, which terminate or 'cap' the reactions.

Klinke et al. (2002) reported that wheat straw cellulose is efficiently recovered in the solid fraction (96\%) and enzymatically converted to glucose in high yield $(67 \%)$ in alkaline wet oxidation pretreatment, e.g., $195^{\circ} \mathrm{C}, 10 \mathrm{~min}, 12$ bar oxygen and $6.5 \mathrm{~g} / \mathrm{L}$ of $\mathrm{Na}_{2} \mathrm{CO}_{3}$. As intermediates in the wet oxidation reaction, monomeric phenols (e.g., 4hydroxybenzaldehyde, syringaldehyde, and vanillin) and furan derivatives (e.g., 5hydroxymethylfurfural (5-HMF) and 2-furfural) are formed from the degradation of lignin, cellulose, and hemicellulose, respectively. Williams et al. (1982) reported that the saccharinic acids reached a maximum about 7 days after treatment of Timothy grass (Phleum pretense) and thereafter decreased due to further degradation to lactic acid and carbon dioxide for a long-term treatment at mild conditions (30 days at $25^{\circ} \mathrm{C}$ ). Some degradation products, such as lactic acid and isosaccharinic acid, in the liquid fraction can be utilized by a mixed-culture of microorganisms after alkaline treatment (Williams et al., 1982).

To perform a total mass balance and determine monosugar yields, it is important to know how much cellulose and hemicellulose can be solubilized or degraded after lime pretreatment. It needs to be confirmed if these degradation products in the liquid hydolyzate inhibit microbial cell growth and alcohol production. If there are inhibitory substances in the pretreated biomass, these must be removed before microbial fermentation.

\subsection{Oxygen Delignification in Alkaline Condition}

In nature, there are three monomer forms (Figure 5) of lignin, which are biosynthesized in plants via the shikimic acid pathway. Coniferyl alcohol is the predominant component found in Gymnosperm (softwood). Both coniferyl and sinapyl 


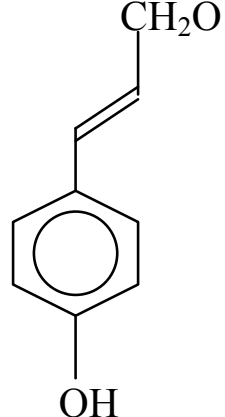

$\mathrm{C}_{9} \mathrm{H}_{10} \mathrm{O}_{2}$

$p$-Coumaryl alcohol

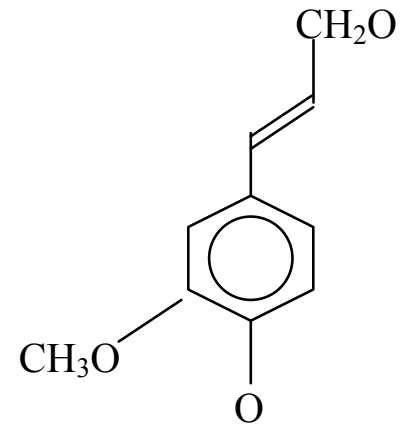

$\mathrm{C}_{9} \mathrm{H}_{9} \mathrm{O}_{2}\left(\mathrm{OCH}_{3}\right.$

Coniferyl alcohol

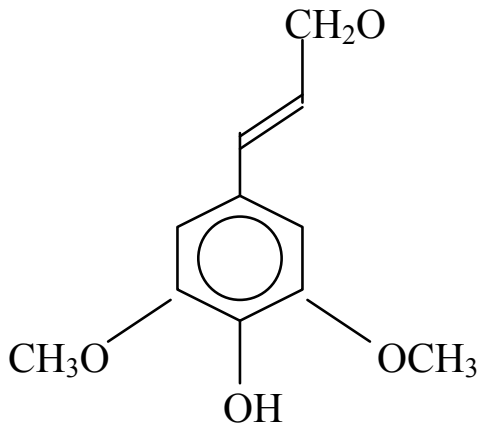

$\mathrm{C}_{9} \mathrm{H}_{8} \mathrm{O}_{2}\left(\mathrm{OCH}_{3}\right)$

Sinapyl alcohol

Figure 5. Building blocks of lignin. 
alcohols are the building blocks of Angiosperm (hardwood). Grass and forage-type lignins are usually composed of all three (Shiraishi et al., 2001).

Generally, the oxidation potential of phenolic groups in lignin is much lower than those of undissociated phenol and phenol ether. This is the reason why oxygen delignification is usually performed under alkaline conditions. The most probable initial step is an outer-sphere one-electron transfer from phenolate to oxygen in an alkaline environment:

$$
\mathrm{PhO}^{-}+\mathrm{O}_{2} \leftrightarrows\left[\mathrm{PhO} \bullet+\cdot \mathrm{O}_{2}^{-}\right] \rightarrow \mathrm{PhO} \bullet+{ }^{-} \mathrm{O}_{2} \bullet
$$

and then superoxide radical $\left(\mathrm{O}_{2}^{\bullet}\right)$ can penetrate into fibers. Hydroxyl radical $(\mathrm{HO} \bullet)$ may be formed from a superoxide-driven reaction catalyzed by mononuclear transition metal ion species such as $\mathrm{Mn}, \mathrm{Fe}$, and $\mathrm{Cu}$ and added to $\pi$-electron system of the aromatic ring in lignin (Kleinert 1966, Goring 1971, and Argyropoulos 2001).

For example, phenolic $\alpha$-aryl groups are removed by cleaving ether linkages, and $\beta$-aryl groups are removed by a neighboring group participating in the type of reaction shown in Figure 6. Carbon-carbon bonds are cleaved by the aldol type of reaction shown in Figure 7 (Gierer 1985 and Shiraishi et al. 2001).

Due to the reversibility of the addition steps, condensation reactions (e.g., dimer formation) can occur from the competition between external nucleophiles in the liquor and internal nucleophiles in phenolic and enolic structures. In general, condensation reactions make new carbon-carbon bonds and counteract lignin fragmentation.

The limitation of oxygen delignification is the low activity of oxygen. Thus, high temperature and $\mathrm{pH}$ are required to obtain a reasonable rate, but these conditions favor carbohydrate degradation. Therefore, oxygen delignification conditions need to be optimized under milder conditions.

\subsection{Collaborative Work}

This research was performed as a member of Consortium for Applied Fundamentals and Innovation (CAFI) funded by the United State Department of 


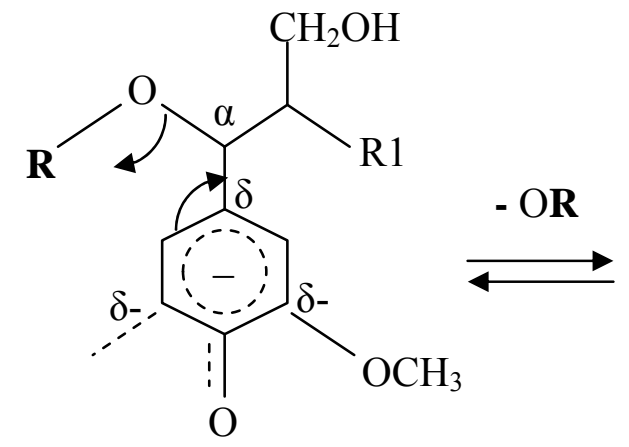

$\mathbf{R}=\mathrm{H}$, Aryl, Alkyl

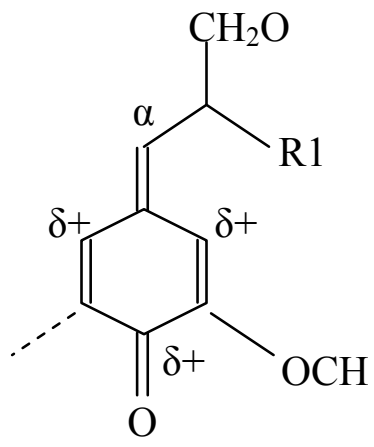

Enone intermediate

(a)
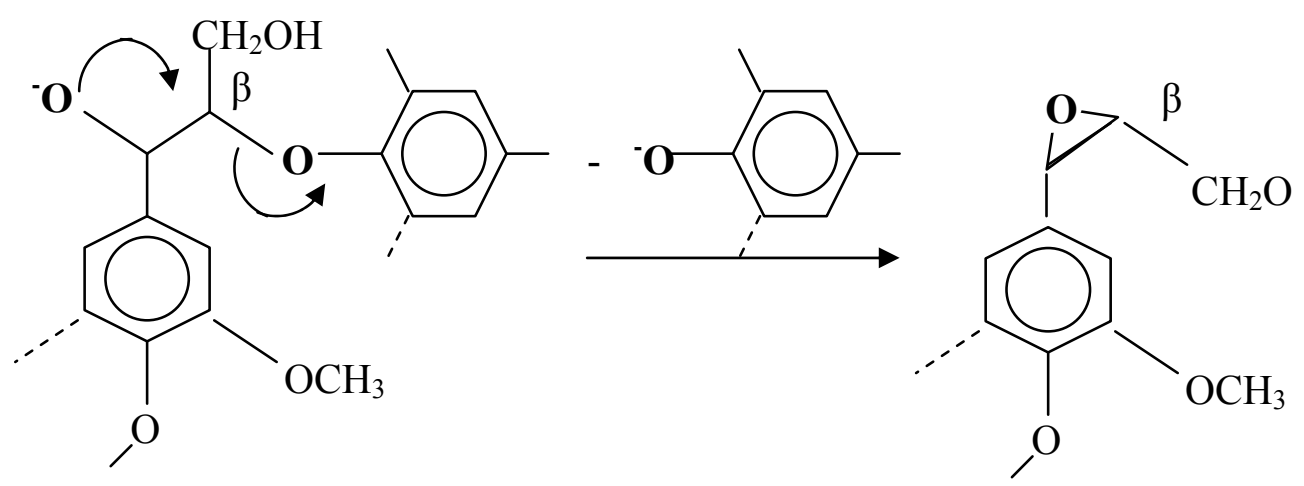

Oxirane intermediate

(b)

Figure 6. Cleavage of (a) $\alpha$-aryl and (b) $\beta$-aryl ether linkages in alkaline conditions. 

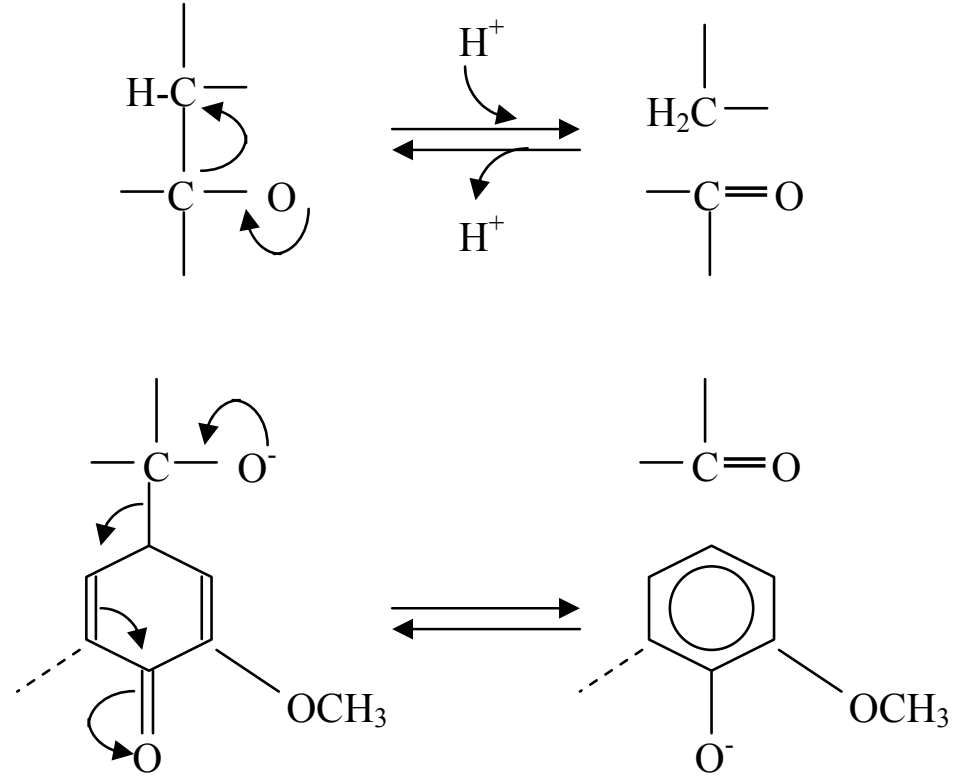

Figure 7. Alkaline cleavage of carbon-carbon bonds. 
Agriculture (USDA) including Dartmouth College, Auburn University, Purdue University, Michigan State University, National Renewable Energy Laboratory (NREL), and Texas A\&M University. Each group used different technologies to pretreat corn stover: acid catalyzed-steam explosion, Dartmouth University; liquid ammonia recycled percolation (ARP), Auburn University; controlled $\mathrm{pH}$ pretreatment, Purdue University; ammonia fiber explosion (AFEX), Michigan State University; lime pretreatment, Texas A\&M University.

Texas A\&M University performed the analysis of acetyl group content on the pretreated samples from each group. The results of acetyl determination for each sample are summarized in Table N-40 in Appendix N. 


\section{CHAPTER II \\ EXPERIMENTAL DESIGN}

\subsection{Reactor System for Pretreatment}

Lignocellulosic substrate was pretreated with lime (calcium hydroxide) in the presence of water. Four sets of packed-bed PVC columns $(\mathrm{D} \times \mathrm{L}=1$ inch $\times 17$ inches $)$ in Figure 8 were used for the lime-pretreatment reaction at 25 (ambient temperature), 35, 45 , and $55^{\circ} \mathrm{C}$. Each set has two subsets, with and without aeration, to achieve oxidative and non-oxidative conditions, respectively. The total number of columns for each subset is 10 , which allowed several different run times to be evaluated. Three sets of columns with water jackets were operated at three different temperatures $\left(35,45\right.$, and $\left.55^{\circ} \mathrm{C}\right)$ by the water heating and circulating system, as shown in Figures 9 and 10.

The water heating and circulating system has two parts: temperature controller and water circulator. The temperature controller contains a temperature controller (1/16 DIN, OMEGA), a thermocouple (KTSS-18G-18, OMEGA), a heating element (1.5 kW, $120 \mathrm{~V})$, a solid-state relay (RSSDN-25A, Idec Co.), fuses (12.5 A and $1 / 4 \mathrm{~A})$, and a main switch. The water circulator consists of a centrifugal pump (3/4 hp, TEEL, U.S.A.), a water tank (8 gallon, Nalgene Co., U.S.A.), a manifold having one input and 20 output fittings, and return pipelines.

Air supplied by the Cater-Mattil compressor was preheated and saturated in the cylinder within the water tank and then distributed to each column by the air-manifold having one input and 10 output fittings. Compressed nitrogen gas (Praxair Co., College Station, TX) was used to make the non-oxidative condition and supplied to each column by the $\mathrm{N}_{2}$-manifold after preheating and saturation.

The whole reactor system was operated continuously at each temperature by purging nitrogen and air before the pretreatment reactions. Additionally, the air was scrubbed of carbon dioxide by passing it through a lime-water slurry in a bottle. 


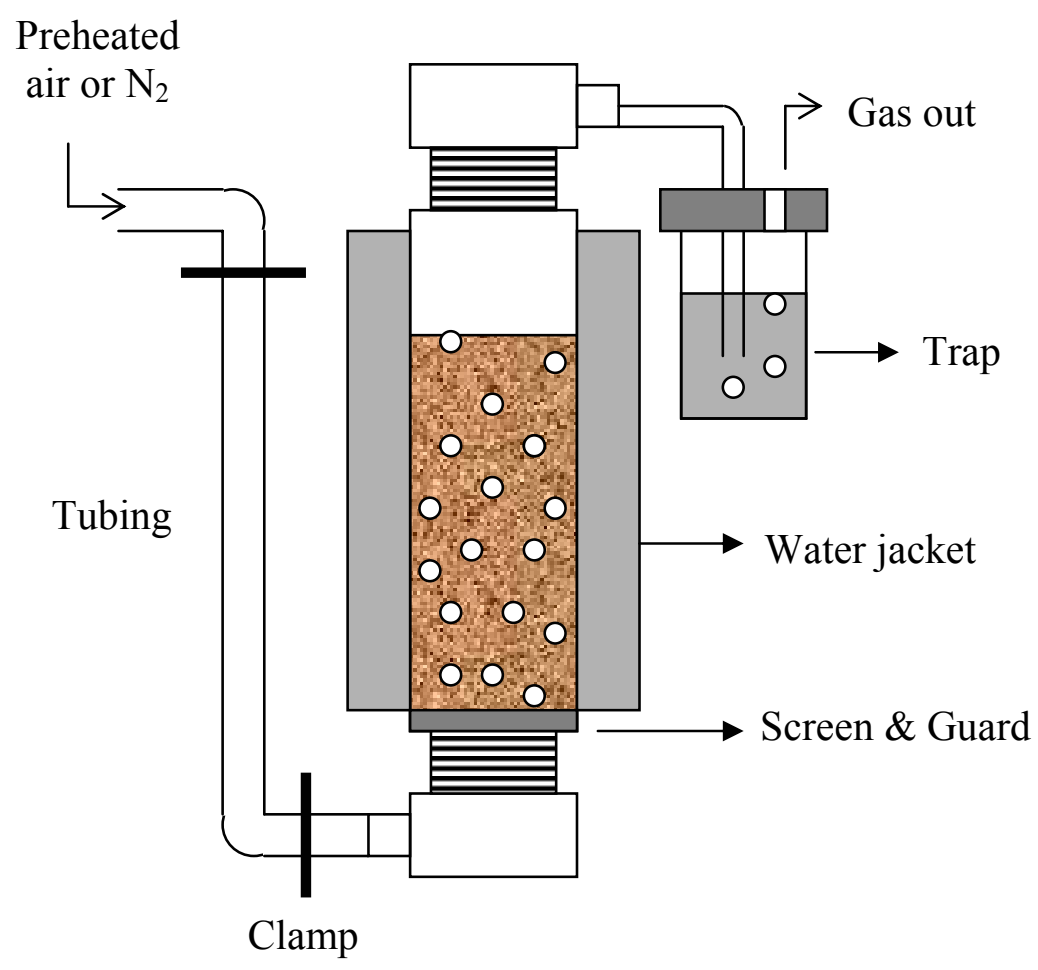

Figure 8. Schematic diagram of the jacketed reactor for lime pretreatment. 


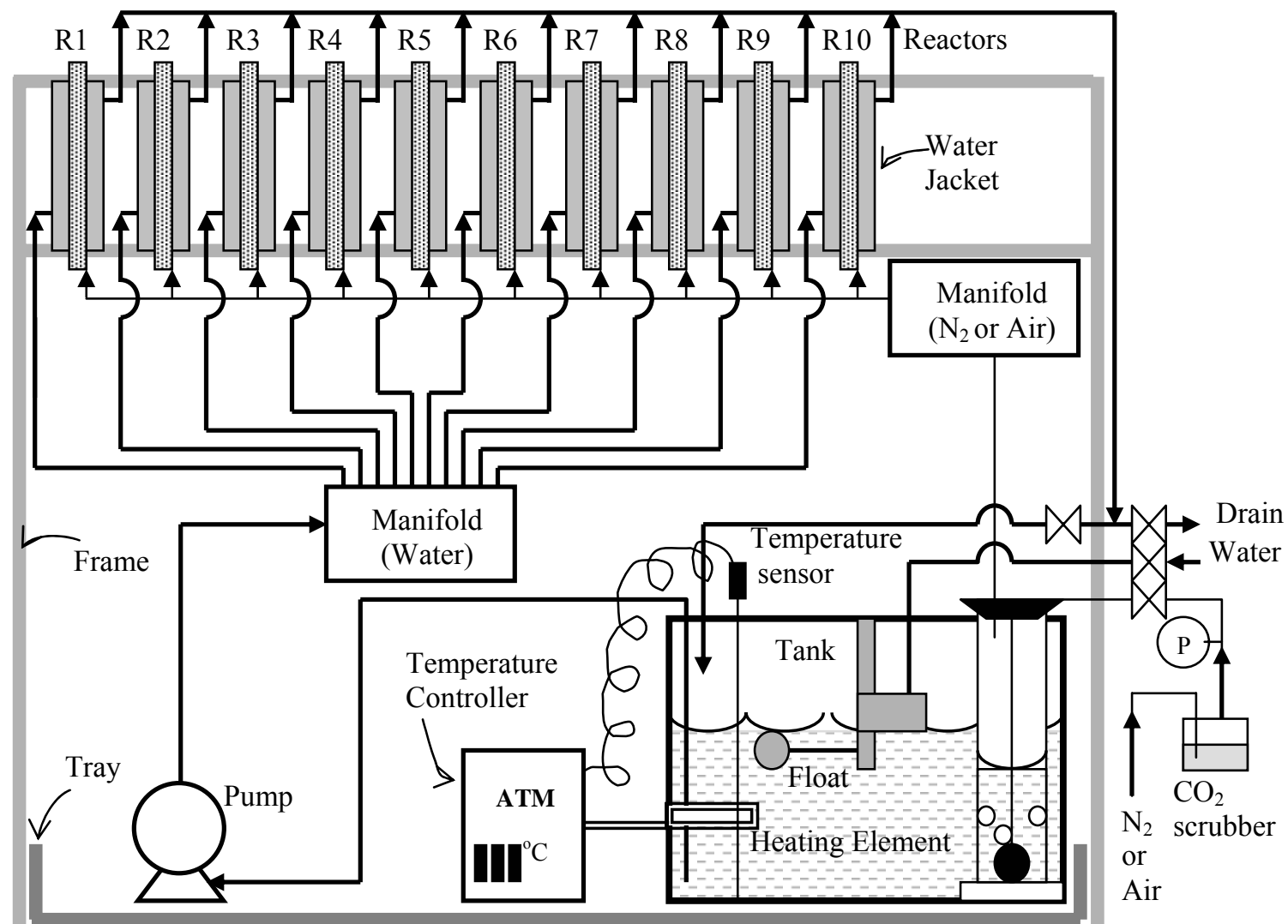

Figure 9. Schematic diagram of the jacketed reactor system for lime pretreatment in the non-oxidative $\left(\mathrm{N}_{2}\right.$ supply) and oxidative (air supply) conditions. 

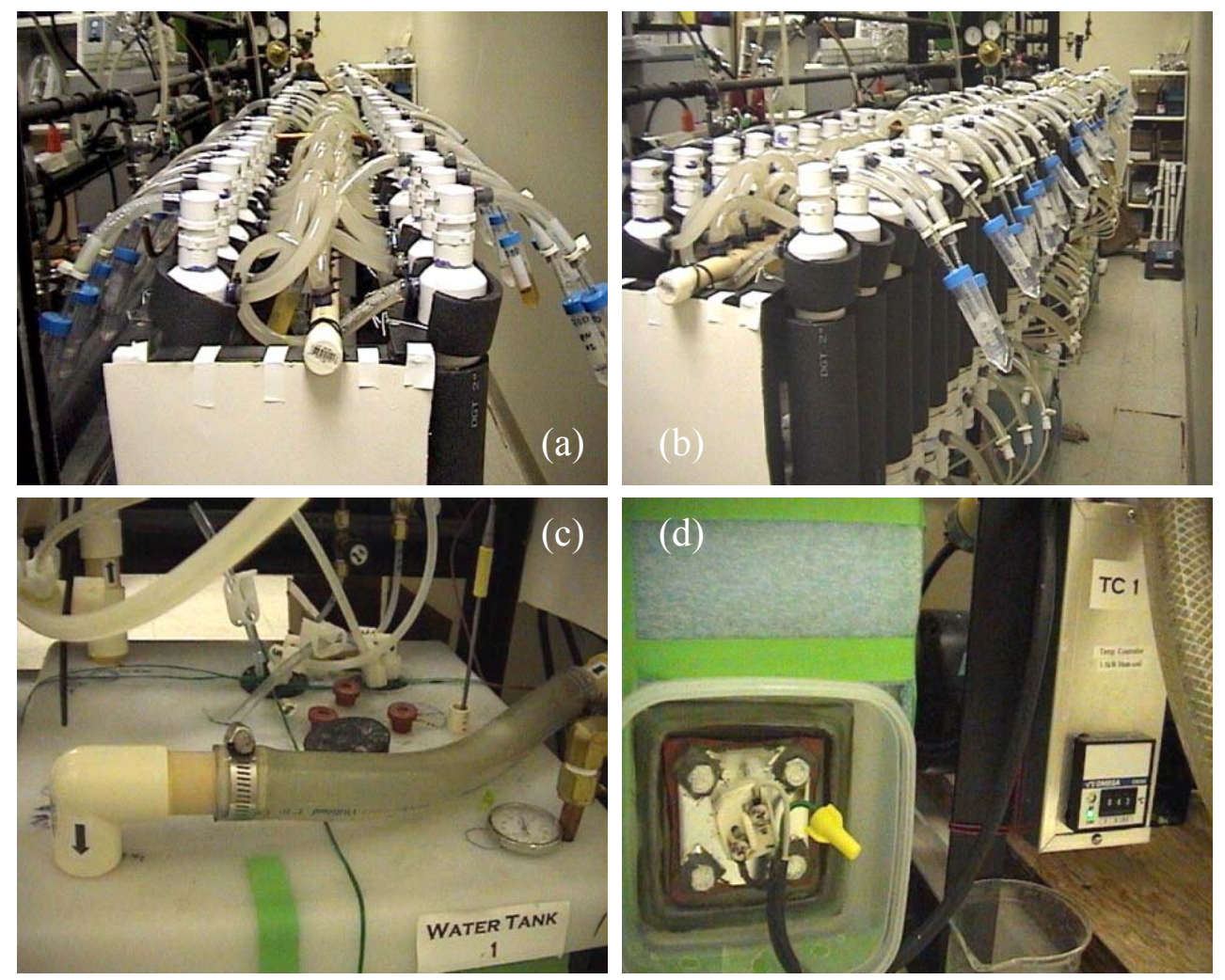

Figure 10. Photographs of reactor system to pretreat corn stover with lime:

(a) front view; (b) side view; (c) head part of water tank; (d) temperature control blocks. 
This prevents carbon dioxide in the air from reacting with lime in the biomass, an unproductive reaction that makes calcium carbonate.

To reduce costs, air was used instead of pure oxygen. At moderate temperatures $\left(<70^{\circ} \mathrm{C}\right)$, the partial pressure of oxygen is not significantly reduced by the water vapor (Table 2). The flow rate of gases (nitrogen and air) was estimated by the number of bubbles generated per unit time, and controlled by clamping the inlet gas tubing. For instance, if two bubbles were generated every second in the outlet gas trap and the I.D. of the outlet end was $3.5 \mathrm{~mm}$, then the gas flow rate was about $2.7 \mathrm{~mL} / \mathrm{min}$. In this study, the gas flow rate was controlled in $2.7-4.0 \mathrm{~mL} / \mathrm{min}$.

\subsection{Lime Pretreatment and Analyses}

Raw biomass (15.0 g dry weight of corn stover), calcium hydroxide (7.5 g dry weight), and distilled water $(150 \mathrm{~mL})$ were transferred into a reactor after thoroughly being mixed using a spatula. After the pretreatment time elapsed, the reactors were moved out of the system randomly and cooled down to ambient temperature. Samples were then collected for various analyses. Details are described in Appendix A, "Lime pretreatment procedures." Experimental conditions and key parameters for operation are summarized in Table 3.

Lime was used in excess to maintain the alkaline $\mathrm{pH}(\geq 12.0)$ and to determine the actual amounts of lime consumed during the long-term pretreatment. Distilled water was utilized for all pretreatment experiments and for washing the biomass. The gas flow rate was measured from the number of bubble generated per unit time using the bubble indicator (gas trap in Figure 8)

The moisture content and dry weight of biomass were determined as described in NREL Standard Procedure No. 01, "Determination of total solid/moisture in biomass." The amount of unreacted lime in the biomass slurry was determined to estimate the lime consumption during the pretreatment (Appendix C, "Determination of lime unreacted after pretreatment"). The weight loss of biomass untreated and treated with lime was 
Table 2. Water partial pressure and the corresponding oxygen partial pressure in saturated air as a function of temperature at normal atmospheric conditions (Perry et al., 1984).

\begin{tabular}{|c|c|c|}
\hline $\begin{array}{c}\text { Temperature } \\
\left({ }^{\circ} \mathrm{C}\right)\end{array}$ & Water Partial Pressure (atm) & $\begin{array}{c}\text { Oxygen Partial Pressure } \\
(\mathrm{atm})\end{array}$ \\
\hline 50 & 0.121 & 0.184 \\
60 & 0.197 & 0.169 \\
70 & 0.308 & 0.145 \\
80 & 0.468 & 0.112 \\
90 & 0.692 & 0.065 \\
95 & 0.834 & 0.035 \\
\hline
\end{tabular}

Table 3. Experimental conditions and the operational parameters for pretreatment.

\begin{tabular}{|l|c|}
\hline \multicolumn{1}{|c|}{ Parameter } & Condition \\
\hline $\begin{array}{l}\text { Lime loading rate } \\
\left(\mathrm{g} \mathrm{Ca}(\mathrm{OH})_{2} / \mathrm{g} \text { dry biomass }\right)\end{array}$ & 0.5 \\
\hline $\begin{array}{l}\text { Water loading rate } \\
\left(\mathrm{g} \mathrm{H}_{2} \mathrm{O} / \mathrm{g} \text { dry biomass }\right)\end{array}$ & 10.0 \\
\hline Temperature $\left({ }^{\circ} \mathrm{C}\right)$ & $25,35,45,55$ \\
\hline Oxidation & Air versus nitrogen \\
\hline Pretreatment time (weeks) & $0-16$ \\
\hline
\end{tabular}


determined to estimate the recovery yields of biomass and holocellulose (glucan + xylan), and to make the mass balances described in Appendix D, "Biomass washing procedure." Details for other analytical methods are mentioned in each section and appendix. 


\section{CHAPTER III \\ OPTIMIZATION OF LIME PRETREATMENT}

\subsection{Physical and Compositional Analysis of Raw Corn Stover}

\section{Introduction}

In this study, raw corn stover was directly used for lime pretreatment. The corn stover was ground by the supplier to reduce the particle size. To identify the physical and compositional properties of corn stover, the particle size distributions and compositions were analyzed for two different batches, which were harvested from fields at different times.

\section{Materials and Methods}

Corn stover was supplied from NREL (National Renewable Energy Laboratory, Boulder, $\mathrm{CO}$ ) in two different batches (Source: BioMass AgriProducts, Harlan, IA). The stover was already washed, dried, and milled to pass $1 / 4$-inch round screen before being delivered to our laboratory.

Raw corn stover (100 g dry weight) was consecutively sieved with seven different sizes of USA standard testing sieves. The particle size distribution was determined as the weight percent of each collection.

The contents of cellulose and hemicellulose in fresh corn stover were analyzed by HPLC using HPX-87P column and refractive index (RI) detector, as described in Appendix H, "Determination of carbohydrates in biomass." Protein (or total nitrogen) content was estimated using LECO CHN-600 Determinator (Soil, Water and Forage Testing Laboratory, Texas A\&M University, TX). Lignin (Klason and acid-soluble) contents and acetyl group content were determined as described in Appendix I and G, 
respectively. Ash content was determined as the amount of inorganic residue left after ignition at $575 \pm 15^{\circ} \mathrm{C}$ (NREL Standard Method No. 005).

\section{Results and Discussion}

In the consecutive sieves, about $3.0 \%(\mathrm{w} / \mathrm{w})$ dry weight of corn stover was lost. The weight contents for each fraction are summarized in Table 4.

The portion of large particles ( $\geq 0.6 \mathrm{~mm}$ ), Mesh No. $4-30$, of the second batch was about $4.4 \%$ smaller than that of the first batch. The major portion of particles ( $>58$ $(\mathrm{w} / \mathrm{w}) \%)$ was large particles $(\geq 0.85 \mathrm{~mm})$ and the portion of smaller particles $(\leq 0.425$ $\mathrm{mm})$, Mesh No. 40 - 100, was less than $21(\mathrm{w} / \mathrm{w}) \%$. However, the particle size distribution between two different batches was not significantly different, as shown in Figure 11.

The major components of corn stover were glucan, xylan, and lignin. The weight percent of each component is listed in Table 5. The ratios of glucan to xylan were 38/21 (1.8) and 36/21 (1.7), for the first and second batch of corn stover, respectively. Other hemicelluloses such as arabinan, mannan, and galactan were present in small amounts (less than 3.6\%). Lignin was contained in approximately $21 \%$ of raw corn stover in this study, which was $3 \%$ higher than in data from NREL. Other minor components were crude proteins, acetyl groups, and extractives. Mineral components such as phosphorous $(\mathrm{P})$, potassium $(\mathrm{K})$, calcium $(\mathrm{Ca})$, magnessium $(\mathrm{Mg})$, sodium $(\mathrm{Na})$, and trace metals $(\mathrm{Zn}$, $\mathrm{Fe}, \mathrm{Cu}, \mathrm{Mn}$ ) are contained less than $2.5 \%$ (Table 6).

\section{Conclusion}

The major portion of particles $(>58(\mathrm{w} / \mathrm{w}) \%)$ in raw corn stover was large particles $(\geq 0.85 \mathrm{~mm})$, but the particle size distribution between two different batches was not significantly different.

The major components of corn stover were glucan, xylan, and lignin. 
Table 4. The particle size distribution of the first and second batches of corn stover.

\begin{tabular}{|c|c|c|c|}
\hline \multirow{2}{*}{$\begin{array}{c}\text { The Range of } \\
\text { Mesh Numbers }\end{array}$} & \multicolumn{2}{|c|}{ Weight Contents (w/w)\% } & \multirow{2}{*}{$\begin{array}{c}\text { a) Difference } \\
(\mathrm{w} / \mathrm{w}) \%\end{array}$} \\
\cline { 2 - 3 } & First Batch & Second Batch & 0.75 \\
\hline$<100$ & $3.75 \pm 0.62$ & $4.49 \pm 0.24$ & 0.58 \\
\hline $100-80$ & $1.22 \pm 0.36$ & $1.80 \pm 0.30$ & 1.17 \\
\hline $80-50$ & $5.67 \pm 0.76$ & $6.84 \pm 0.28$ & 1.26 \\
\hline $50-40$ & $6.69 \pm 0.47$ & $7.95 \pm 0.14$ & 0.65 \\
\hline $40-30$ & $8.79 \pm 1.17$ & $9.44 \pm 0.41$ & -0.96 \\
\hline $30-20$ & $12.4 \pm 0.72$ & $11.4 \pm 0.92$ & -3.43 \\
\hline $20-4$ & $61.5 \pm 3.34$ & $58.1 \pm 1.06$ & \\
\hline
\end{tabular}

a) Difference of mean $=$ Content of second batch - Content of first batch Error band $( \pm)$ indicates 1 standard deviation

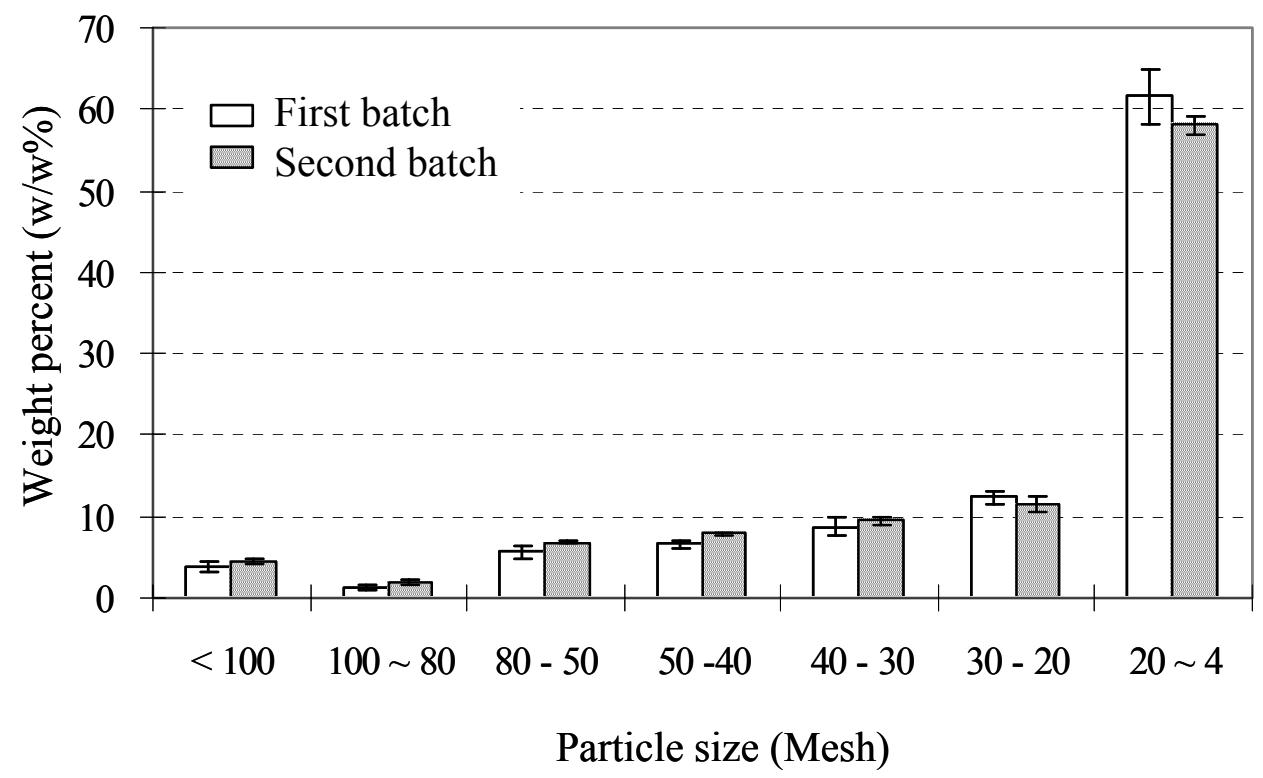

Figure 11. Particle size distribution of raw corn stover. 
Table 5. Compositions of raw corn stover.

\begin{tabular}{|c|c|c|c|c|}
\hline \multirow{2}{*}{$\begin{array}{c}\text { Components } \\
\text { (g/100 g raw biomass) }\end{array}$} & \multicolumn{2}{|c|}{$\begin{array}{l}\text { First batch of } \\
\text { corn stover }\end{array}$} & \multicolumn{2}{|c|}{$\begin{array}{c}\text { Second batch of } \\
\text { corn stover }\end{array}$} \\
\hline & TAMU $^{1)}$ & NREL $^{2)}$ & TAMU $^{1)}$ & $\mathrm{NREL}^{2)}$ \\
\hline Glucan & 37.5 & 37.5 & 36.1 & 36.1 \\
\hline Xylan & 20.8 & 20.8 & 21.4 & 21.4 \\
\hline Lignin & 21.4 & 17.6 & 20.8 & 17.2 \\
\hline K. Lignin ${ }^{3)}$ & 19.6 & - & 17.2 & - \\
\hline A. Lignin ${ }^{4)}$ & 1.8 & - & 3.6 & - \\
\hline Crude proteins & 3.4 & 2.9 & 3.5 & 4.0 \\
\hline Ash & 9.5 & 6.7 & 6.9 & 7.1 \\
\hline \multicolumn{5}{|l|}{ Others } \\
\hline Arabinan & 3.4 & 2.7 & 3.6 & 3.5 \\
\hline Mannan & - & 0.8 & - & 1.8 \\
\hline Galactan & - & 1.6 & - & 2.5 \\
\hline Acetyl & 2.2 & 2.2 & 3.2 & 3.2 \\
\hline Uronic acid & - & - & - & 3.6 \\
\hline Non-structural sugars & - & - & - & 1.2 \\
\hline
\end{tabular}

1) Analysis in Texas A\&M University

2) Data from NREL

3) Klason lignin

4) Acid-soluble lignin

Table 6. Mineral content ${ }^{1)}$ of raw corn stover.

\begin{tabular}{ccc}
\hline $\begin{array}{c}\text { Components } \\
(\mathrm{g} / 100 \mathrm{~g} \text { raw biomass })\end{array}$ & $\begin{array}{c}\text { First batch of corn } \\
\text { stover }\end{array}$ & $\begin{array}{c}\text { Second batch of corn } \\
\text { stover }\end{array}$ \\
\hline $\mathrm{P}$ & 0.0900 & 0.1300 \\
$\mathrm{~K}$ & 0.5600 & 0.5100 \\
$\mathrm{Ca}$ & 0.5800 & 0.8500 \\
$\mathrm{Mg}$ & 0.2000 & 0.2400 \\
$\mathrm{Na}$ & 0.0900 & 0.1399 \\
$\mathrm{Zn}$ & 0.0023 & 0.0025 \\
$\mathrm{Fe}$ & 0.9932 & 0.2811 \\
$\mathrm{Cu}$ & 0.0020 & 0.0008 \\
$\mathrm{Mn}$ & 0.0099 & 0.0198 \\
\hline Total & 2.5276 & 2.1741
\end{tabular}

1) Based on dry weight at $105^{\circ} \mathrm{C}$. 


\subsection{Lime Consumption}

\section{Introduction}

Calcium hydroxide, $\mathrm{Ca}(\mathrm{OH})_{2}$, was used as the sole alkali to pretreat corn stover. The amount of lime consumed depended on the conditions, such as temperature and aeration. During the pretreatment, $\mathrm{OH}^{-}$reacted with many different functional groups in lignocellulosic biomass, e.g., phenolics and ethers in lignin, acetyls and the end groups of cellulose and hemicellulose, and oxygen molecules in air. Calcium ion, $\mathrm{Ca}^{2+}$, can react with carbon dioxide to form calcium carbonate, which gradually deposits in the lignocellulosic matrix. Carbon dioxide may be generated from delignification and degradation of cellulose and hemicellulose or it can be present in the air if air is purged through the biomass. Using Scanning Electron Microscopy (SEM), López et al. (2000) reported that the surface of sugarcane bagasse was modified by the deposition of calcium in the fiber matrix, whereas it was not affected by the sodium hydroxide treatment. Behera et al. (1996) showed that the lignocellulosic fibers of Calotropis procera became porous after delignification. From these previous results, calcium may protect cellulose more efficiently than hemicellulose from degradation by peeling reactions. Relatively high recovery yield of glucan can be explained in this way (data shown in Section 3.3).

The unproductive reaction of calcium to form calcium carbonate can be efficiently avoided by $\mathrm{CO}_{2}$ scrubbing of the inlet air. By this method, lime consumption is reduced which benefits the process economics.

Lime consumption was determined by titration for different conditions and the effectiveness of $\mathrm{CO}_{2}$ scrubbing was reported in this study.

\section{Materials and Methods}

Lime (calcium hydroxide) was purchased from Fisher, Catalog No. C97-3. Via titration, certified 5- $\mathrm{N} \mathrm{HCl}$ was used to determine the remaining amounts of lime in the 
treated biomass mixture.

The amounts of lime consumed during the pretreatment at each condition were determined by $\mathrm{pH}$ neutralization with a standard solution of acid, 5-N HCl, as described in Appendix C, "Determination of lime unreacted after pretreatment."

In the case of oxidative pretreatment, air was scrubbed of carbon dioxide by passing it through a lime-water slurry in a bottle. Periodically, the $\mathrm{pH}$ of the lime solution was measured, and more lime was added into the bottle if its $\mathrm{pH}$ was below 9 .

\section{Results and Discussion}

During the non-oxidative lime treatment, less than $0.1 \mathrm{~g} \mathrm{Ca}(\mathrm{OH})_{2} / \mathrm{g}$ raw biomass was consumed during 16 weeks. The maximum specific lime consumption was $0.058 \mathrm{~g}$ $\mathrm{Ca}(\mathrm{OH})_{2} / \mathrm{g}$ raw biomass at $55^{\circ} \mathrm{C}$. The specific lime consumption tended to increase, as temperature increased (Figure 12 (a)).

In the case of the oxidative lime pretreatment, the amount of lime consumed significantly increased as temperature increased (Figure 12 (b)). Without $\mathrm{CO}_{2}$ scrubbing at $55^{\circ} \mathrm{C}$, the specific lime consumption was $0.195 \mathrm{~g} \mathrm{Ca}(\mathrm{OH})_{2} / \mathrm{g}$ raw biomass for 4 weeks and further increased to $0.319 \mathrm{~g} \mathrm{Ca}(\mathrm{OH})_{2} / \mathrm{g}$ raw biomass for 16 weeks. Between the nonoxidative and oxidative treatment, the difference of the specific lime consumption became larger as temperature increased.

In the oxidative pretreatment, when comparing with the results without $\mathrm{CO}_{2}$ scrubbing (see Figure 13), lime consumption was effectively reduced by scrubbing $\mathrm{CO}_{2}$ out of the air. The specific lime consumption $\left(\mathrm{g} \mathrm{Ca}(\mathrm{OH})_{2} / \mathrm{g}\right.$ raw biomass) was reduced down to 0.047 at 4 weeks and 0.097 at 16 weeks at $25^{\circ} \mathrm{C}$, and 0.073 at 4 weeks and 0.176 at 16 weeks at $55^{\circ} \mathrm{C}$, respectively. The reduction of lime consumption was more significant at higher temperature. Thus, carbon dioxide can be effectively removed from the air by $\mathrm{CO}_{2}$ scrubbing.

In alkaline pretreatment, the lignin in lignocellulosic biomass is solubilized by the action of hydroxide ion, $\mathrm{OH}^{-}$. As shown in Figure 14, more lime is needed to get 


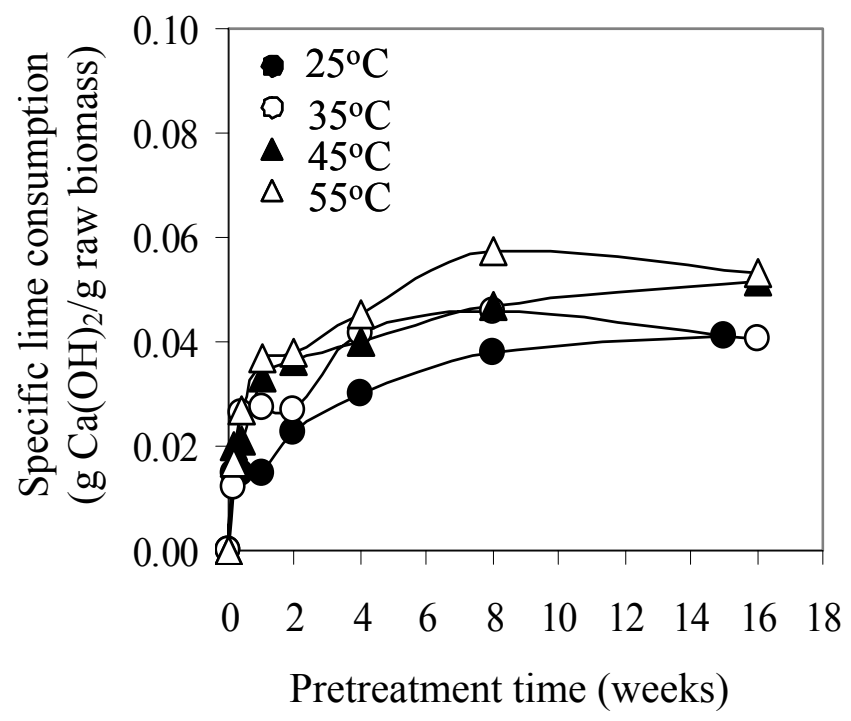

(a)

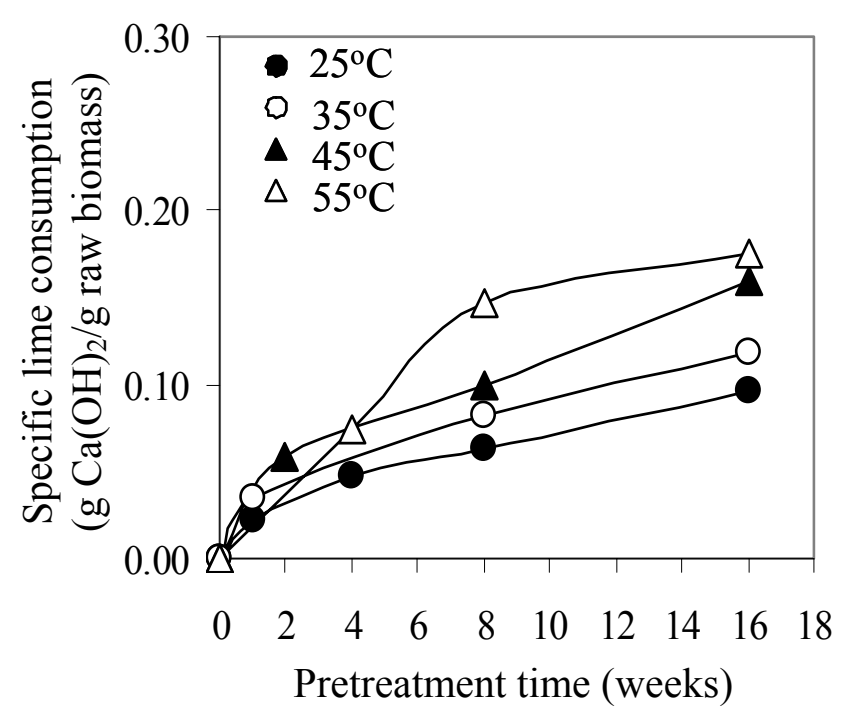

(b)

Figure 12. Profiles of the specific lime consumption as a function of pretreatment time in the non-oxidative condition (a) and in the oxidative condition with $\mathrm{CO}_{2}$ scrubbing (b). 


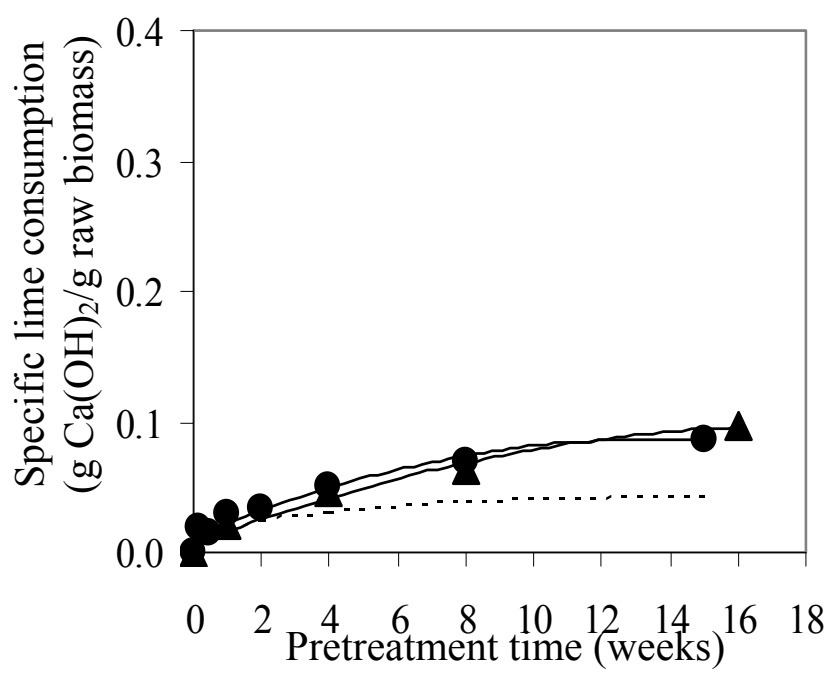

(a)

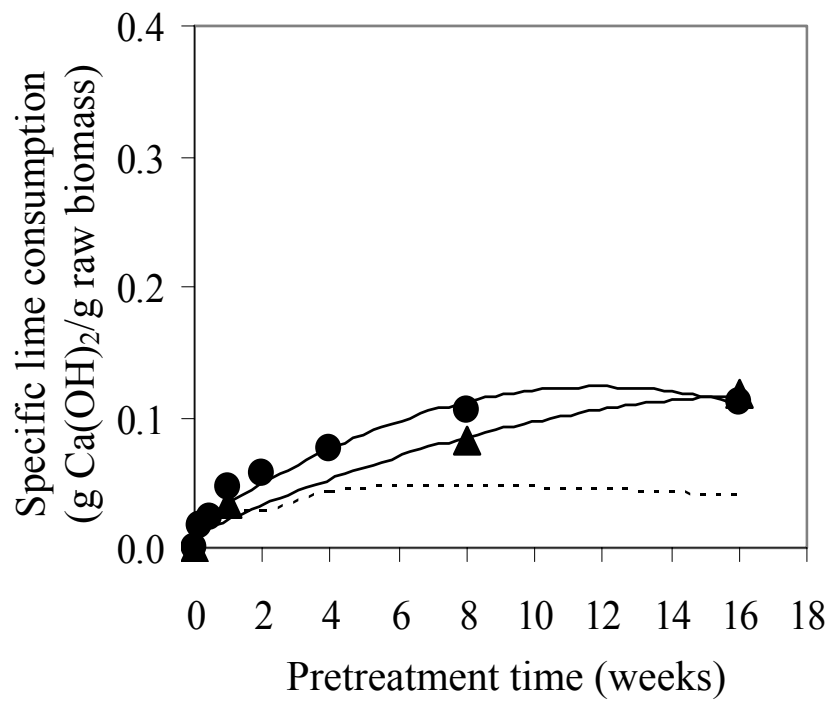

(b)

Figure 13. Profiles of the specific lime consumption in the nonoxidative (----), oxidative with natural air $(\mathbf{O})$ and with $\mathrm{CO}_{2}$-scrubbed air $(\boldsymbol{\Delta})$ at $25^{\circ} \mathrm{C}(\mathrm{a}), 35^{\circ} \mathrm{C}(\mathrm{b}), 45^{\circ} \mathrm{C}$ (c), and $55^{\circ} \mathrm{C}(\mathrm{d})$, respectively. 


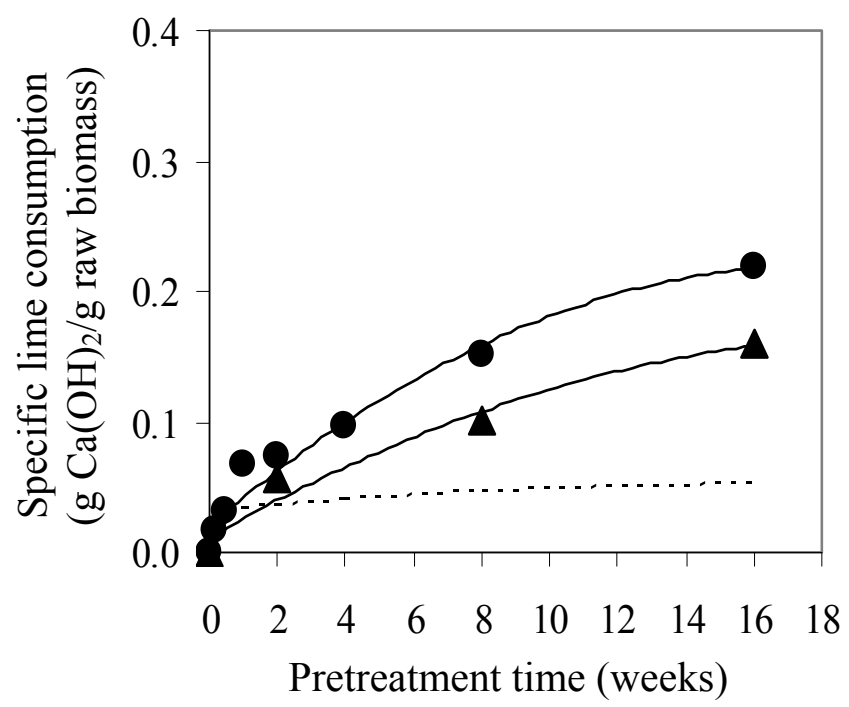

(c)

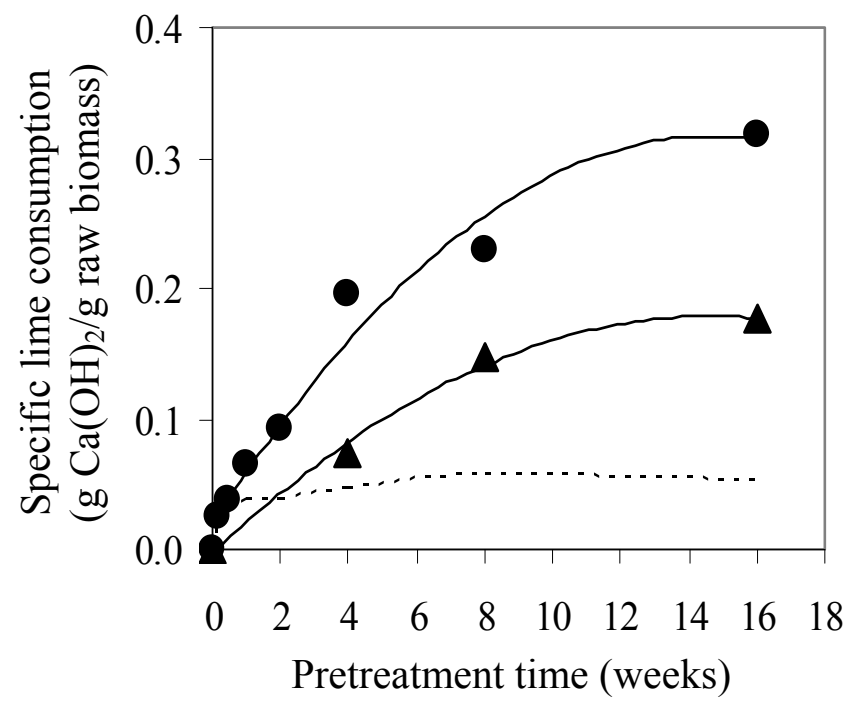

(d)

Figure 13. Continued. 


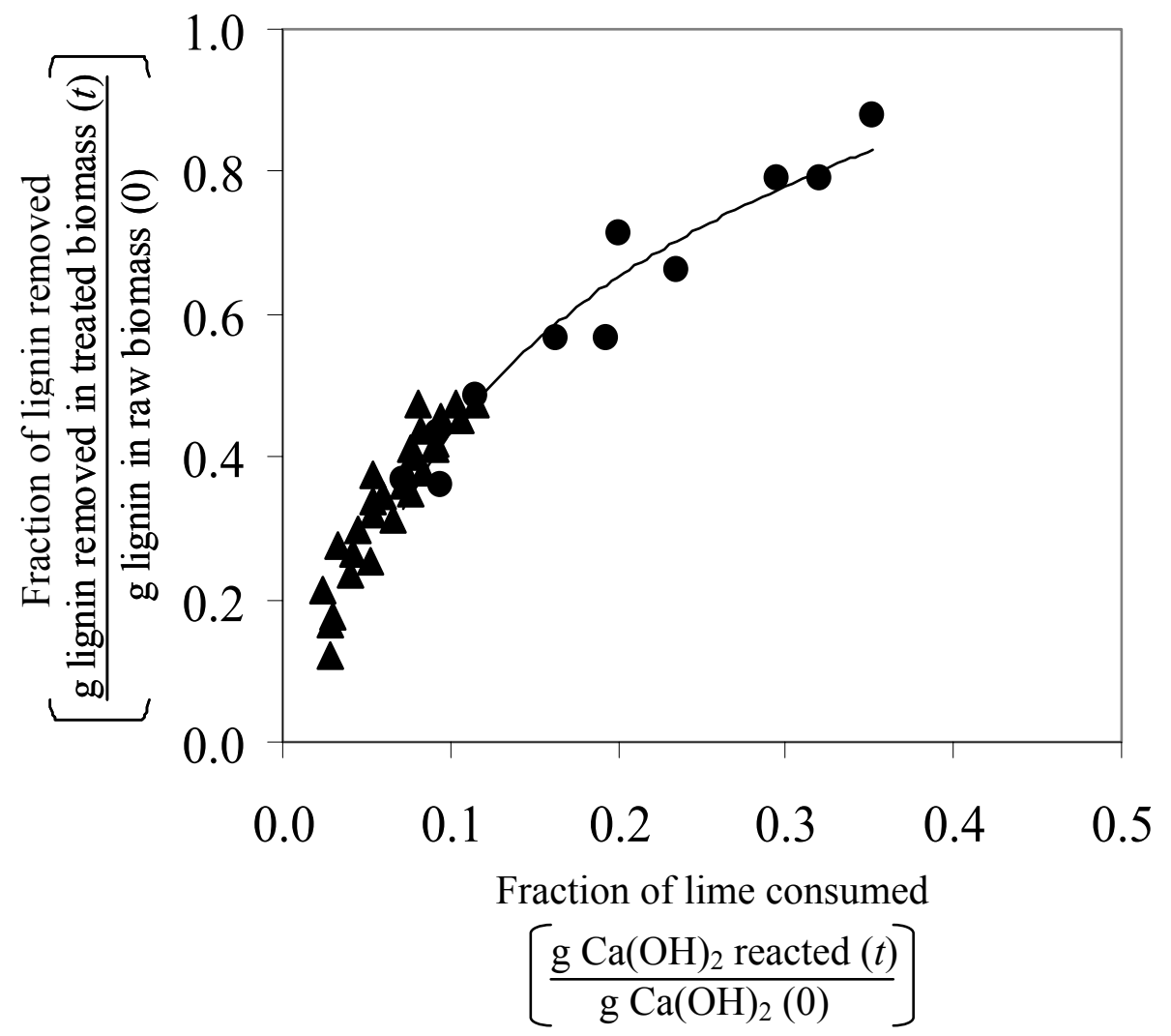

Figure 14. The fractional changes of lignin solubilized as a function of the weight fraction of lime consumed in the non-oxidative condition $(\boldsymbol{\Delta})$ and oxidative condition with $\mathrm{CO}_{2}$ scrubbing (O). 
more delignification.

Delignification was estimated as follows:

Delignification $=$ the fraction of original lignin removed

$$
\begin{aligned}
& =\frac{\mathrm{g} \text { lignin removed in treated biomass }}{\mathrm{g} \text { lignin in raw biomass }} \\
& =1-\frac{\mathrm{g} \text { lignin remained in treated biomass }}{\mathrm{g} \text { lignin in raw biomass }}
\end{aligned}
$$

In the lower range of lime consumption $(\leq 0.1 \mathrm{~g}$ lime consumed $(t) / \mathrm{g}$ lime $(0))$, approximately $50 \%$ of the original lignin in raw biomass was removed easily. This phenomenon was independent of the presence of oxygen. However, removing the remaining fraction of the lignin required oxidative treatment with additional consumption of lime.

\section{Conclusion}

The specific lime consumption ( $\mathrm{g} \mathrm{Ca}(\mathrm{OH})_{2} / \mathrm{g}$ raw biomass) tended to increase, as temperature increased.

More lime was consumed in oxidative conditions than in non-oxidative conditions due to more delignification in oxidative condition.

\subsection{Compositional Changes of Corn Stover in Lime Pretreatment}

\section{Introduction}

The weight fractions of each biomass component changed due to the solubilization of components during the alkaline pretreatment. Mass balances were performed to determine how much biomass was solubilized by the lime pretreatment.

Biomass was harvested from each reactor into the centrifuge bottle. Some small portions of biomass were retained inside of the column reactor when the column was 
disassembled to collect the wet biomass. The recovery yield of total mass $\left(Y_{\mathrm{M}}\right)$ was determined to check the reproducibility of the harvesting and washing steps.

During lime pretreatment, some portions of holocellulose (glucan and xylan) were removed by the action of hydroxide ions ('peeling reaction') in addition to the delignification reaction. It is most desirable if the holocellulose remains in the lignocellulosic fiber matrix, and lignin is removed as much as possible. To determine the optimal conditions, the pretreatment yield of holocelluose $\left(Y_{\mathrm{GX}}\right)$ needs to be determined from the mass balances at different lime pretreatments. Selectivity data also need to be considered between lignin removal and holocelluose degradation.

\section{Materials and Methods}

The pretreated corn stover at each pretreatment condition was repeatedly washed with fresh distilled water until the filtered water became colorless, as described in Appendix D, "Biomass washing procedure." The total dry weight of the sample was measured before and after pretreatment and wash.

The contents of cellulose and hemicellulose in the pretreated corn stover were analyzed by HPLC using the HPX-87P column and RI detector, as described in Appendix H, "Determination of carbohydrates in biomass." Protein (or total nitrogen) content was determined by the Soil, Water and Forage Testing Laboratory, Texas A\&M University, TX. Lignin (Klason and acid-soluble) contents and acetyl group content were determined as described in Appendix I and G, respectively. Ash content was determined by NREL Standard Method No. 005.

To determine the reproducibility of the recovery yield during the harvest of wet biomass from the reactor, the six mixtures containing $15 \mathrm{~g}$ dry weight of raw corn stover, $7.5 \mathrm{~g}$ of lime, and $150 \mathrm{~mL}$ of water individually were loaded inside each column reactor. After 1-h incubation at ambient temperature, the reactors were disassembled. From each reactor, the wet biomass and lime mixture was harvested carefully into 1-L centrifuge bottles using sufficient amounts of distilled water. Without washing, the residual lime 
concentration was directly determined by titrating with $5-\mathrm{N} \mathrm{HCl}$. The titrated biomass was then centrifuged and washed several times as described in Appendix D. In addition to the standard deviation, the mean of the solid recovery yield was determined. The coefficient of variation was determined by the following formula:

$$
\text { Coefficient of variation }(\%)=\frac{\text { Standard deviation }}{\text { Mean }} \times 100(\%)
$$

The pretreatment yields of holocellulose $\left(Y_{\mathrm{GX}}\right)$, glucan $\left(Y_{\mathrm{G}}\right)$, and xylan $\left(Y_{\mathrm{X}}\right)$ were estimated by measuring glucan and xylan contents before and after lime pretreatment using HPLC. The selectivity was estimated from the correlation between the lignin removal and the holocellulose degradation.

\section{Results and Discussions}

The recovery yield of total mass $\left(Y_{\mathrm{M}}\right)$ in the harvest step itself was $96.21 \pm 1.69$ (g solid recovered/100 g raw biomass). The coefficient of variation was $1.75 \%$. Thus, approximately $3.8 \%$ of the wet biomass was lost during the harvest and washing steps (see Table 7). The weight loss might become from the partial solubilization of corn stover (e.g., ash dissolution) and the incomplete mass transfer from the inner reactor. However, the variation of mass loss is negligible among reactors in harvesting and washing the biomass slurry. These results show that the solid handling procedures are very reproducible. The recovery yield was not used in any of the mass balances reported later, or any other calculations.

In most cases, there was a rapid decrease of total solids caused mostly by delignification in the first week. After 2 week, the loss of the solid fraction was not significant in the non-oxidative pretreatment with lime (Figure 15).

As temperature increased, in the oxidative lime pretreatment, the solid weight loss became more significant after 1 week (see Figure 16). 
Table 7. The recovery yield of total mass $\left(Y_{\mathrm{M}}\right)$ from column disassembly.

\begin{tabular}{|c|c|c|c|c|c|}
\hline $\begin{array}{l}\text { Reactor } \\
\text { number }\end{array}$ & $\begin{array}{c}\text { Raw corn } \\
\text { stover } \\
\text { (g) }\end{array}$ & $\begin{array}{c}\text { Solid } \\
\text { content } \\
(\%)\end{array}$ & $\begin{array}{l}\text { Initial dry } \\
\text { weight of } \\
\text { stover } \\
\text { (g) }\end{array}$ & $\begin{array}{l}\text { The dry } \\
\text { weight of } \\
\text { solid } \\
\text { harvested } \\
\text { and washed } \\
\text { (g) }\end{array}$ & $\begin{array}{c}Y_{\mathrm{M}} \\
\text { (g solid } \\
\text { recovered/100 } \\
\text { g raw } \\
\text { biomass) }\end{array}$ \\
\hline 1 & 15.66 & 95.7 & 14.99 & 14.24 & 95.04 \\
\hline 2 & 15.66 & 95.7 & 14.99 & 14.09 & 94.00 \\
\hline 3 & 15.66 & 95.7 & 14.65 & 14.65 & 97.73 \\
\hline 4 & 15.66 & 95.9 & 14.77 & 14.77 & 98.35 \\
\hline 5 & 15.66 & 95.9 & 14.32 & 14.32 & 95.35 \\
\hline 6 & 15.66 & 95.9 & 14.54 & 14.54 & 96.82 \\
\hline \multicolumn{5}{|c|}{ Mean } & 96.21 \\
\hline \multicolumn{5}{|c|}{ Standard deviation } & 1.69 \\
\hline \multicolumn{5}{|c|}{ Coefficient of variation (\%) } & 1.75 \\
\hline
\end{tabular}




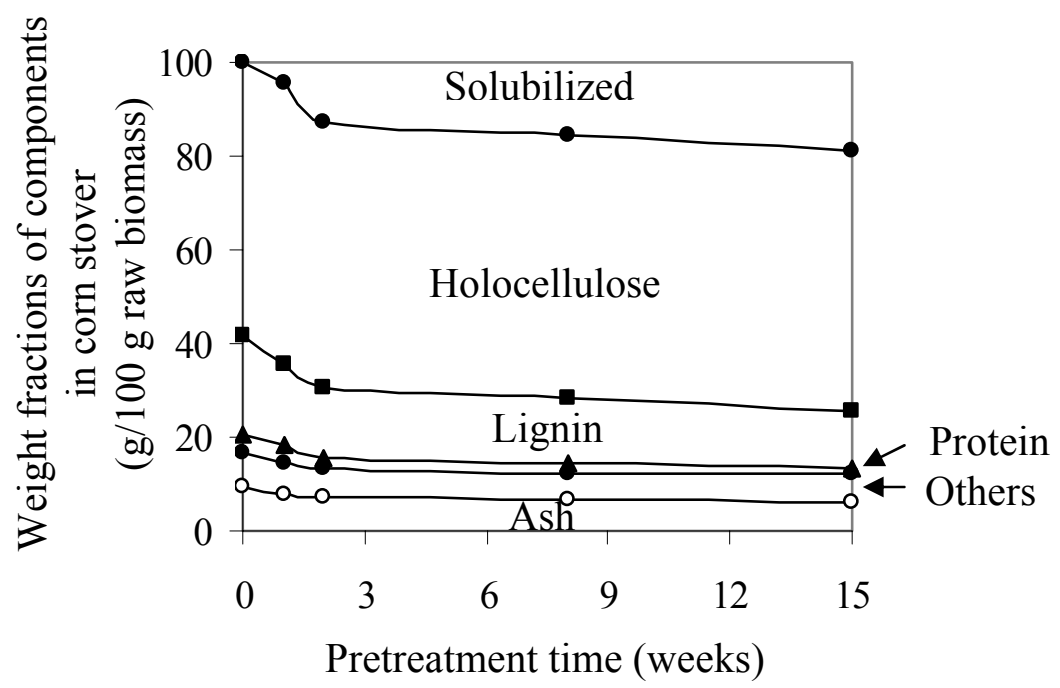

(a)

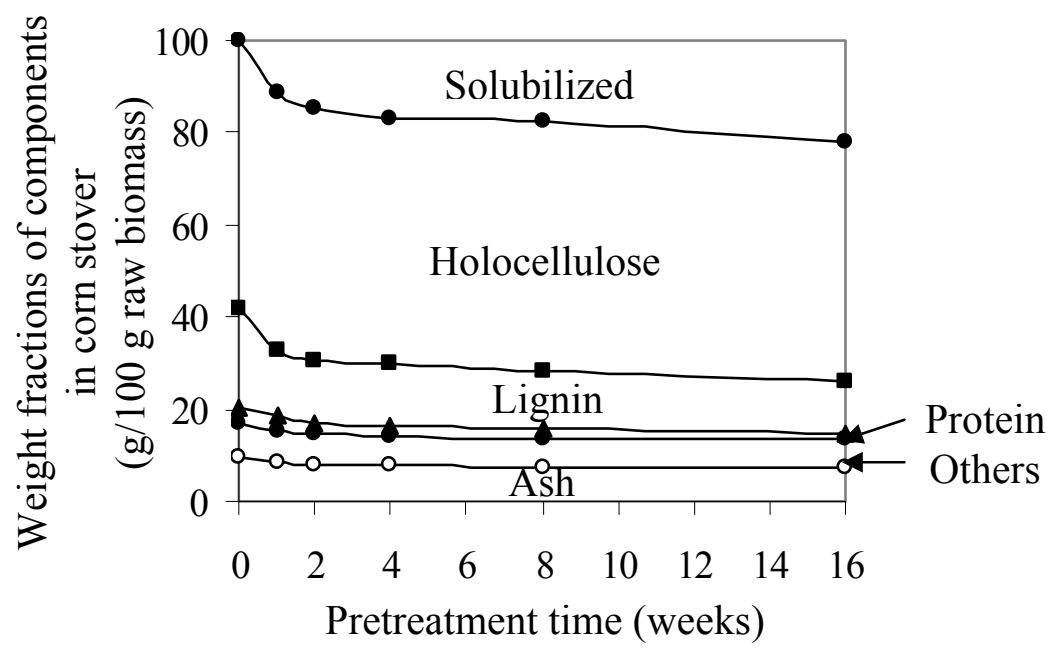

(b)

Figure 15. Mass profiles of total solid, holocellulose (glucan + xylan), lignin (Klason lignin + acid-soluble lignin), crude proteins, ash, and others in the non-oxidative lime pretreatment at $25^{\circ} \mathrm{C}(\mathrm{a}), 35^{\circ} \mathrm{C}(\mathrm{b}), 45^{\circ} \mathrm{C}$ (c), and $55^{\circ} \mathrm{C}(\mathrm{d})$, respectively. 


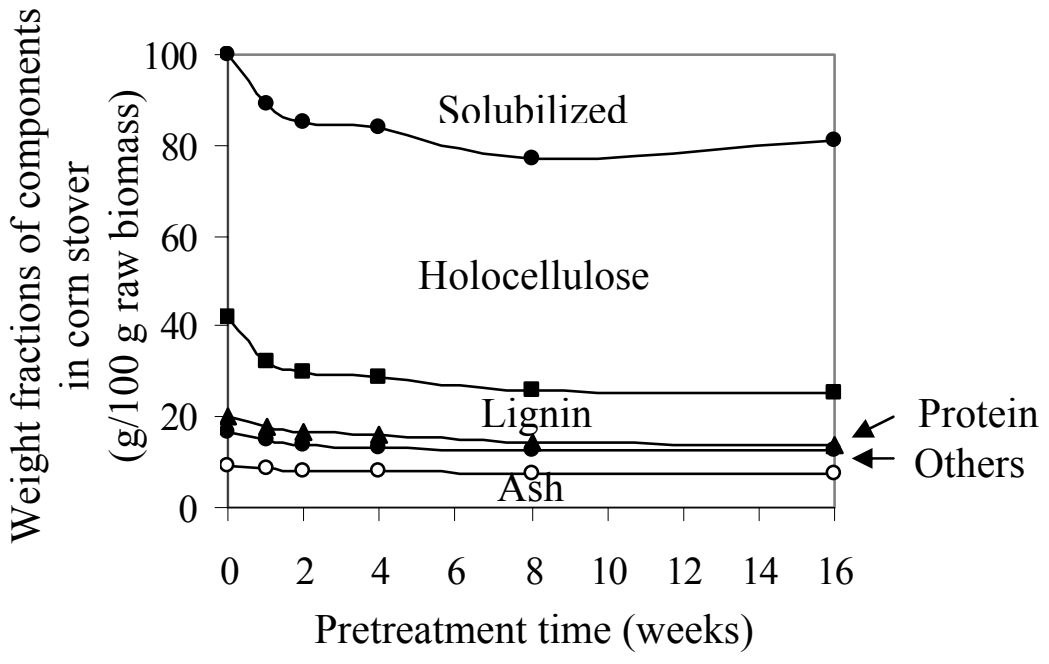

(c)

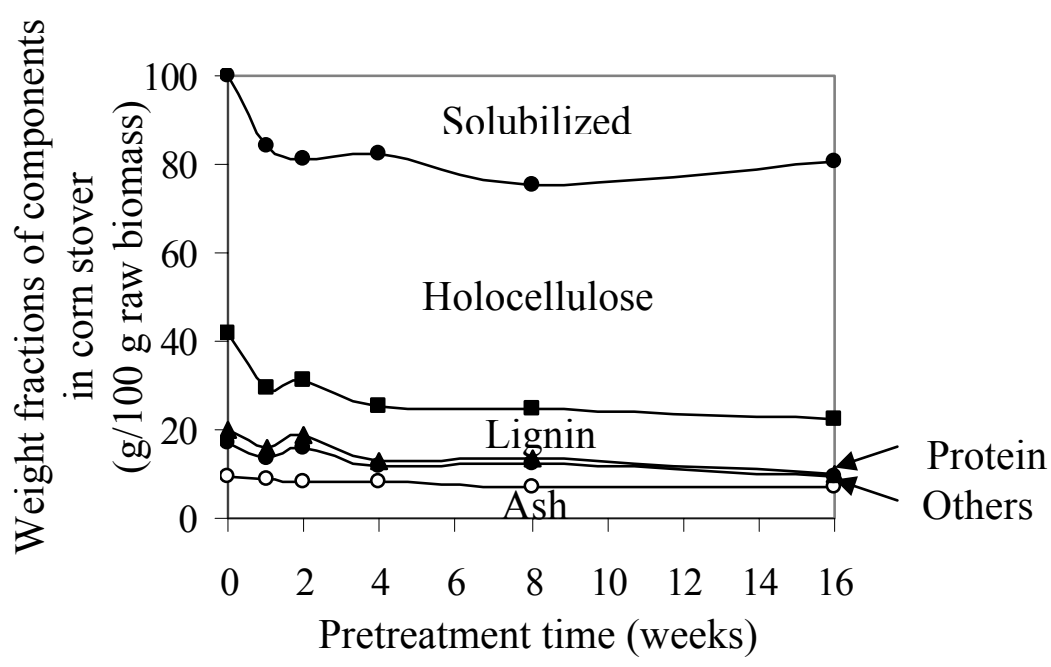

(d)

Figure 15. Continued. 


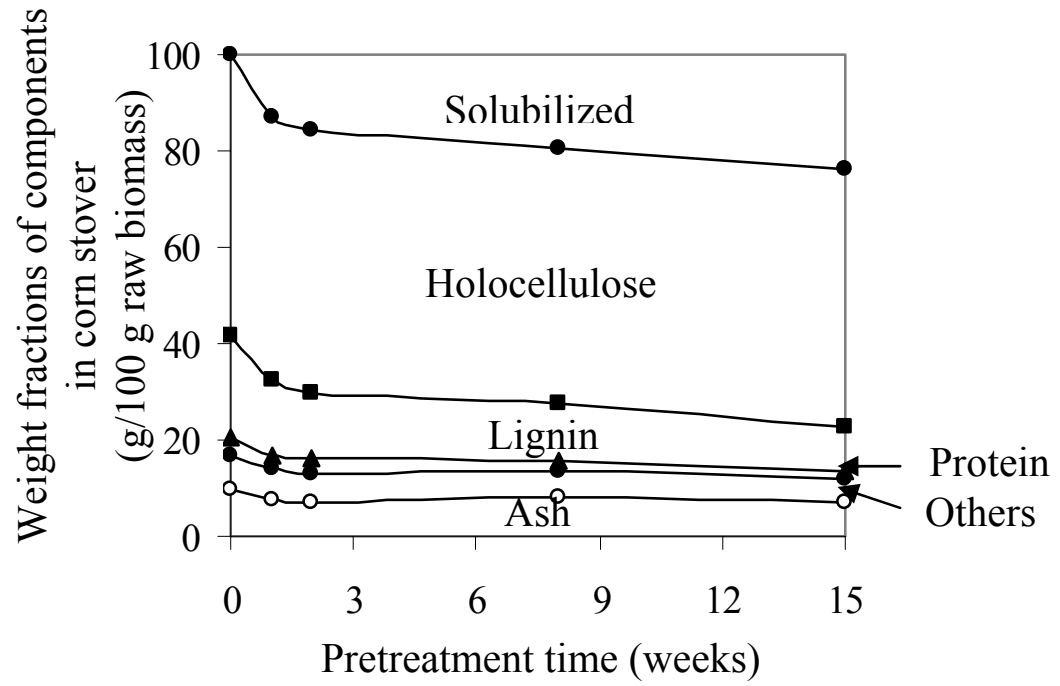

(a)

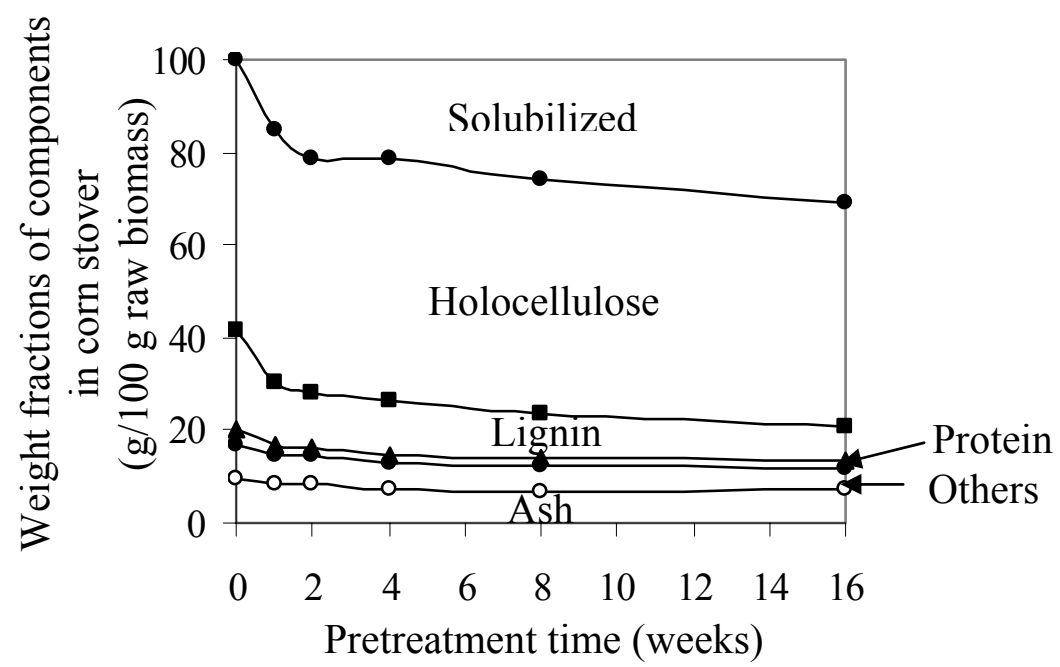

(b)

Figure 16. Mass profiles of total solid, holocellulose (glucan + xylan), lignin (Klason lignin + acid-soluble lignin), crude proteins, ash, and others in the oxidative lime pretreatment at $25^{\circ} \mathrm{C}(\mathrm{a}), 35^{\circ} \mathrm{C}(\mathrm{b}), 45^{\circ} \mathrm{C}(\mathrm{c})$, and $55^{\circ} \mathrm{C}(\mathrm{d})$, respectively. 


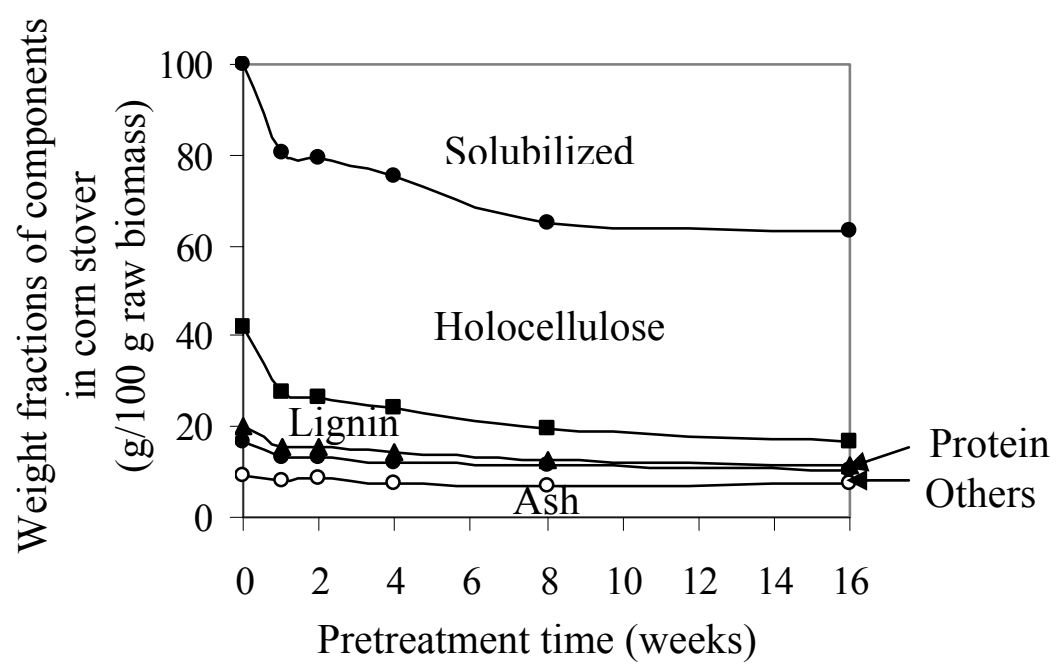

(c)

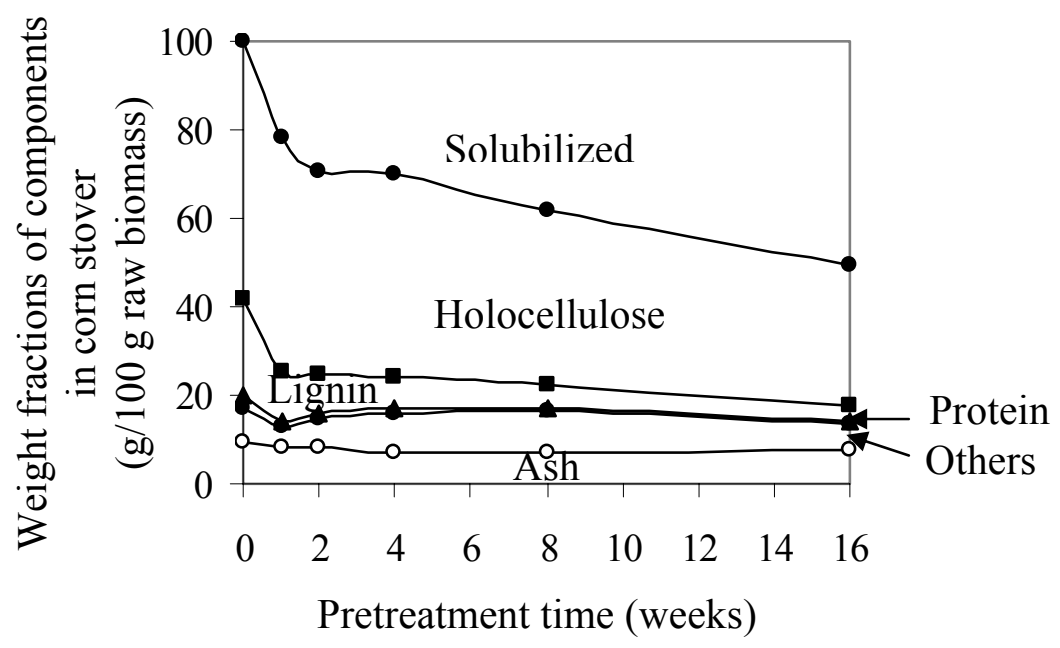

(d)

Figure 16. Continued. 
The degradation of holocellulose, especially xylan, occurred more severely after 4- and 8-week pretreatments at 55 and $45^{\circ} \mathrm{C}$, respectively. However, the glucan fraction was relatively more stable than xylan (Figures $17-20$ ). For instance, after 16 weeks at $55^{\circ} \mathrm{C}, 93.7 \%$ of glucan and $79.3 \%$ of xylan remained in the non-oxidatively treated corn stover, whereas $71.0 \%$ of glucan and only $50.3 \%$ of xylan was recovered in the oxidatively treated corn stover. At $55^{\circ} \mathrm{C}$ in oxidative condition, almost all glucan and more than $67 \%$ of xylan was recovered at 4 weeks, but the degradations of glucan and xylan was significant after 8 weeks.

At each temperature, the pretreatment yields of total solid $\left(Y_{\mathrm{T}}\right)$, holocellulose $\left(Y_{\mathrm{GX}}\right)$, glucan $\left(Y_{\mathrm{G}}\right)$, and xylan $\left(Y_{\mathrm{X}}\right)$ in the non-oxidatively treated corn stover were superior to those in the oxidatively treated corn stover at each temperature. Therefore, the non-oxidative condition has higher recovery of glucan and xylan than the oxidative condition because cellulose and hemicellulose are not degraded easily in the former condition. However, more than $50 \%$ of the lignin still remained in the pretreated corn stover after the non-oxidative lime treatment, which can negatively affect the conversion of glucan and xylan to glucose and xylose in the enzymatic hydrolysis reactions using cellulases.

\section{Conclusions}

More holocellulose (glucan and xylan) can be recovered in the non-oxidative lime pretreatment of corn stover; however, the lignin cannot be removed efficiently compared to the oxidative lime treatment.

The optimal condition for lime pretreatment should be determined by comparing the pretreatment yields, as well as the enzymatic hydrolysis of polysaccharides to monomeric sugars in the saccharification for each condition. This is the topic of Section 3.5 Enzymatic Hydrolysis. 

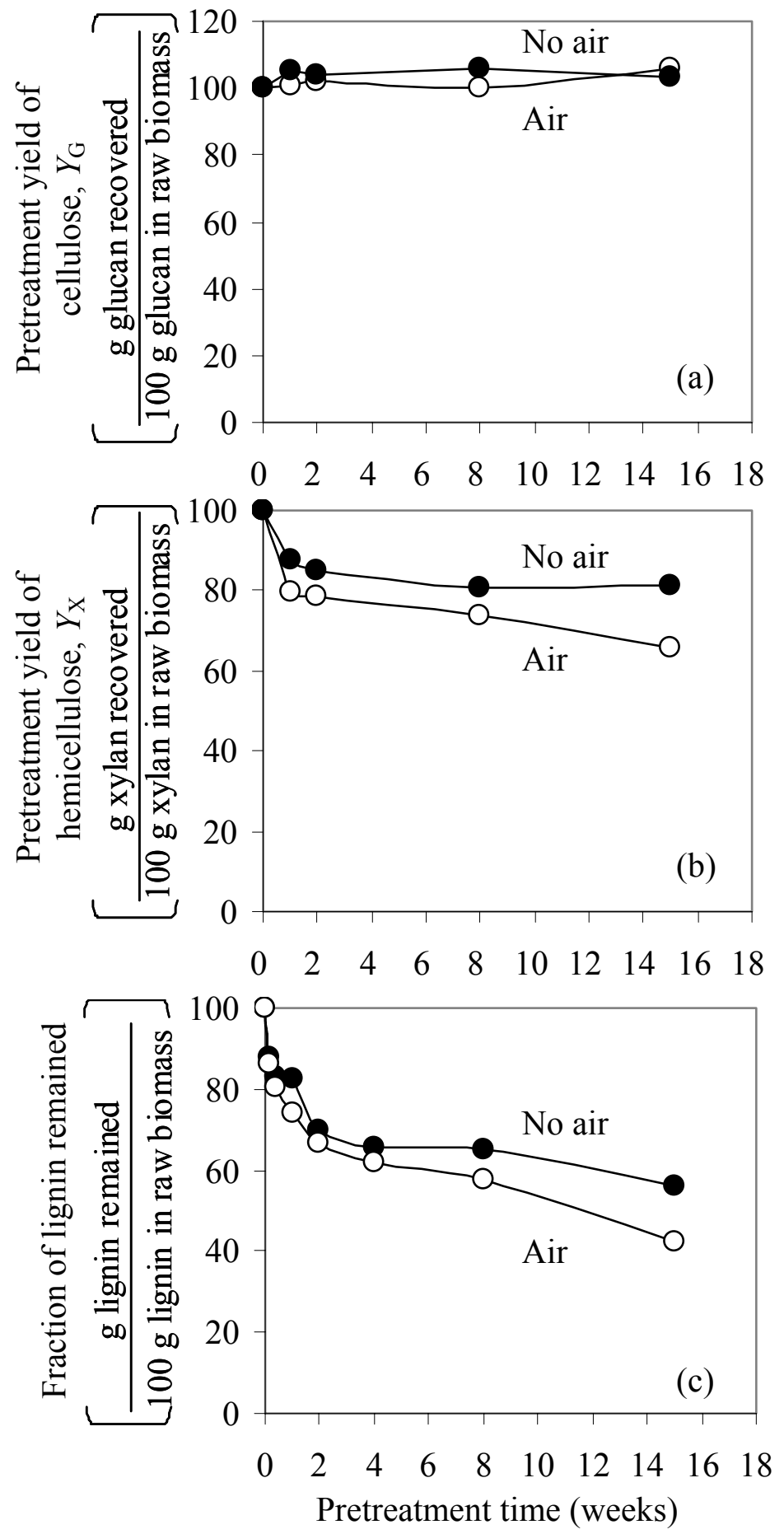

Figure 17. Pretreatment yields of cellulose, $Y_{\mathrm{G}}$, (a), hemicellulose, $Y_{\mathrm{X}},(\mathrm{b})$, and Klason lignin content (c) in non-oxidative (O) and oxidative $(\mathrm{O})$ conditions at $25^{\circ} \mathrm{C}$. 

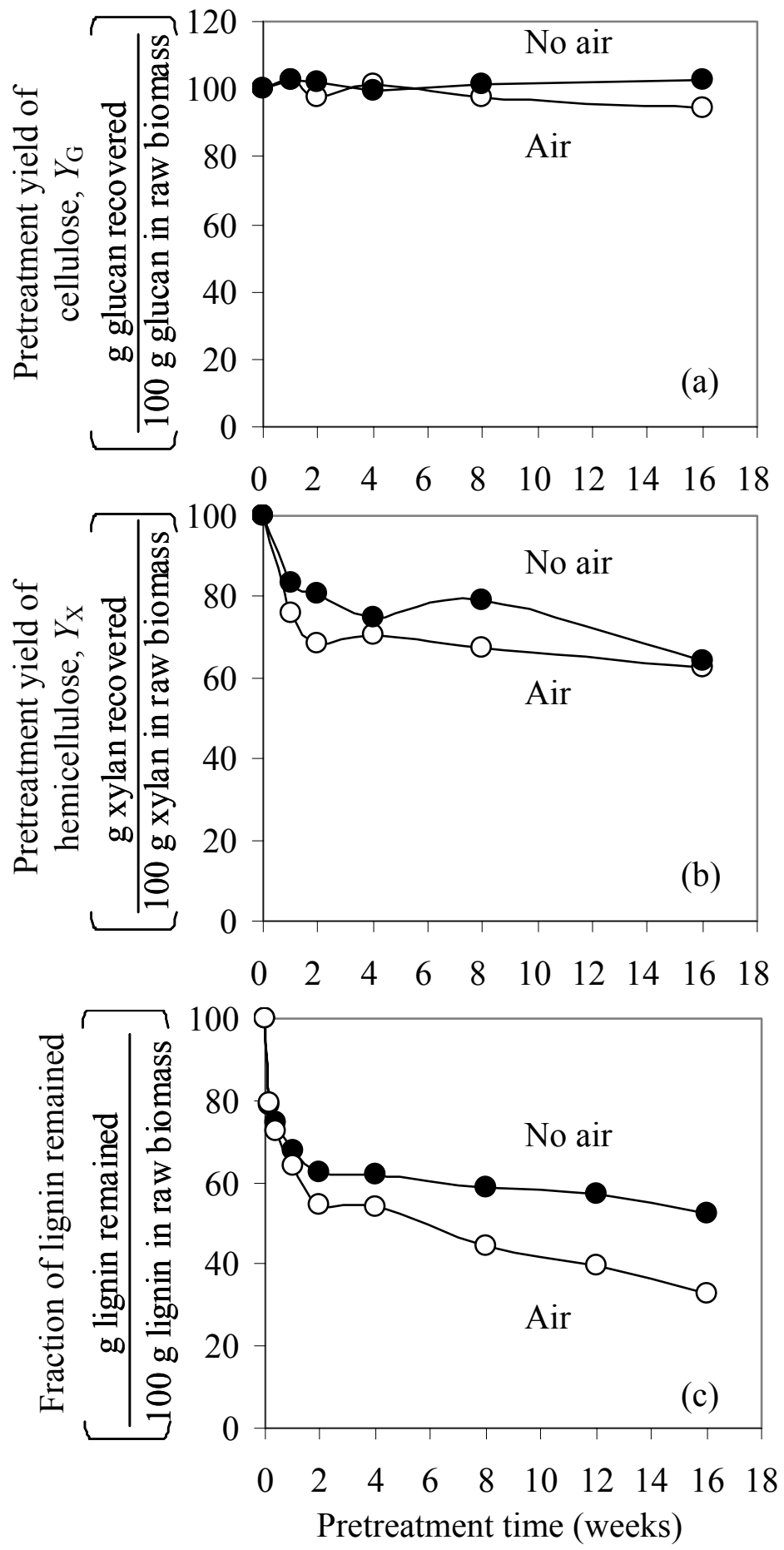

Figure 18. Pretreatment yields of cellulose, $Y_{\mathrm{G}},(\mathrm{a})$, hemicellulose, $Y_{\mathrm{X}}$, (b), and Klason lignin content (c) in non-oxidative (O) and oxidative $(O)$ conditions at $35^{\circ} \mathrm{C}$. 

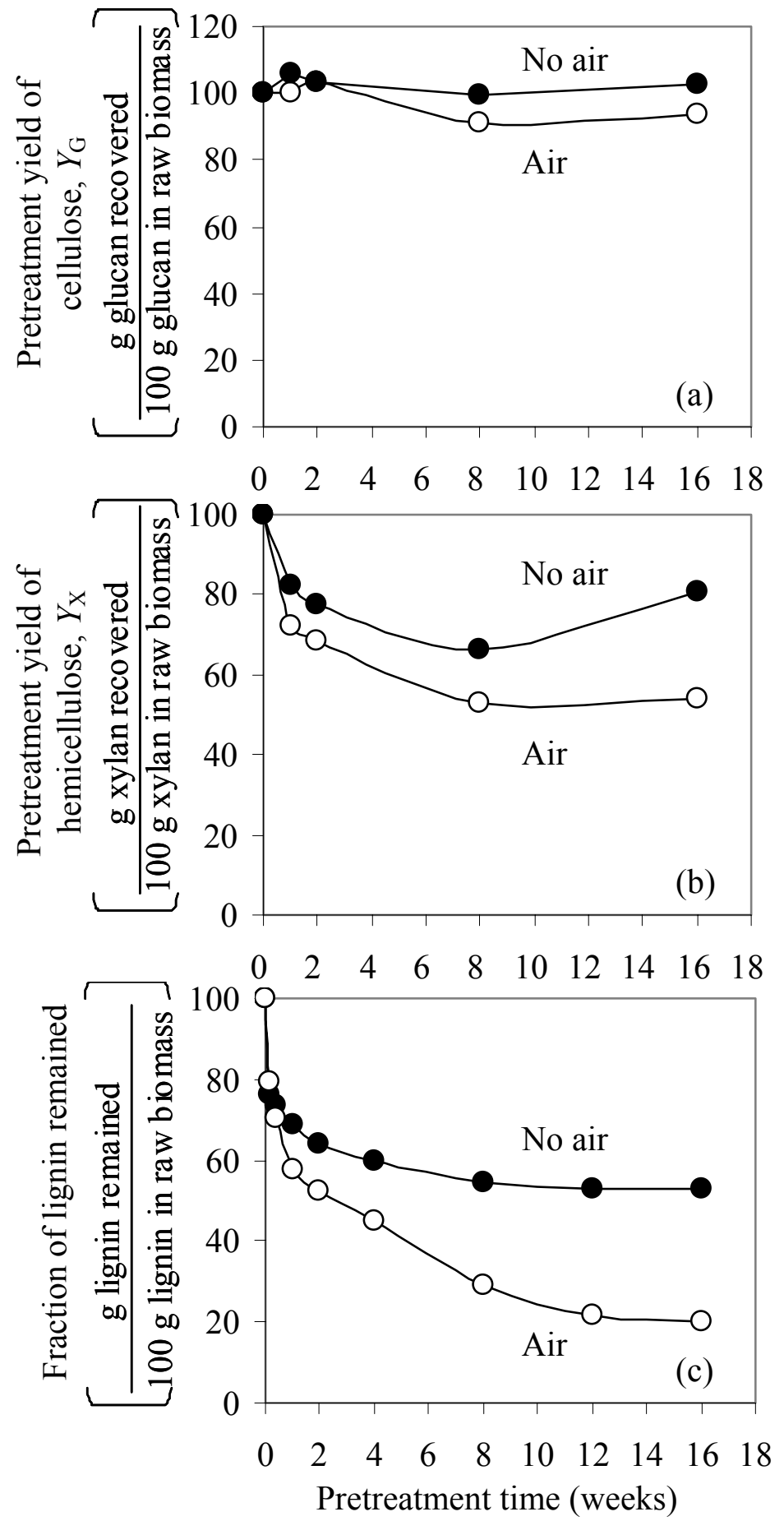

Figure 19. Pretreatment yields of cellulose, $Y_{\mathrm{G}}$, (a), hemicellulose, $Y_{\mathrm{X}},(\mathrm{b})$, and Klason lignin content (c) in non-oxidative $(\mathbf{O})$ and oxidative $(\mathrm{O})$ conditions at $45^{\circ} \mathrm{C}$. 

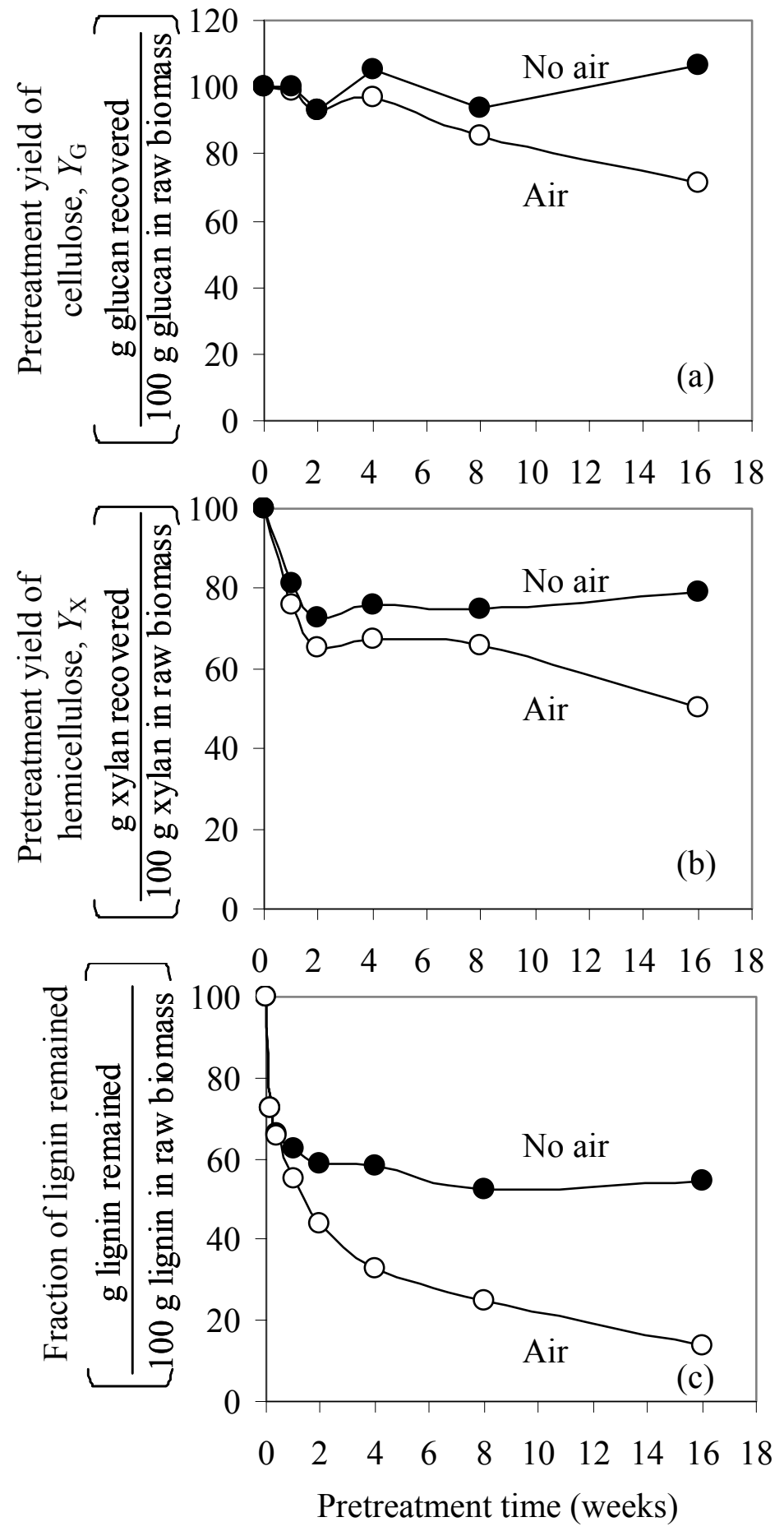

Figure 20. Pretreatment yields of cellulose, $Y_{\mathrm{G}}$, (a), hemicellulose, $Y_{\mathrm{X}},(\mathrm{b})$, and Klason lignin content (c) in non-oxidative $(\mathbf{O})$ and oxidative $(O)$ conditions at $55^{\circ} \mathrm{C}$. 


\subsection{Delignification}

\section{Introduction}

Lignin is a highly cross-linked phenylpropylene polymer (Holtzapple 1993c). It plays an important role in cell wall structure as a permanent bonding agent between plant cells. It is always associated with hemicellulose in the cell wall (Sarkanen et al. 1971).

In biomass pulping, the delignification mechanism can be described using the following stages: initial, bulk, and residual (Aurell 1964, Dolk et al. 1989, Chiang et al. 1990, and DeGroot 1994) as depicted in Figures 21 and 22. During the initial delignification stage in alkaline pulping with sodium hydroxide, phenolic $\alpha$-O-4-linkages in lignin and some phenolic $\beta$-O-4-linkages are cleaved (Gierer et al. 1980 and 1985). In the bulk stage, the major reaction is the cleavage of non-phenolic $\beta$-O-4-linkages (Gierer and Norén 1980). During the residual delignification stage, carbon-carbon linkages in lignin are cleaved and carbohydrates are degraded (DeGroot 1994).

Delignification has been described in three different stages (initial, bulk, and residual) for wood pulping, which can be mathematically expressed as the result of three simultaneous first-order reactions (Gierer 1980 and Dolk et al. 1989). The general equation for delignification kinetics in kraft pulping is described with:

$$
W_{\mathrm{L}}=a_{1} \bullet \exp \left(-k_{1} \bullet t\right)+a_{2} \bullet \exp \left(-k_{2} \bullet t\right)+a_{3} \bullet \exp \left(-k_{3} \bullet t\right)
$$

where, $W_{\mathrm{L}}$ : the fraction of the residual lignin (g lignin remaining/g lignin in raw biomass)

$a_{1}$ : the maximum fraction of lignin fragments released in the initial stage

$a_{2}$ : the maximum fraction of lignin fragments released in the bulk stage

$a_{3}$ : the maximum fraction of lignin fragments released in the residual stage

$k_{1}, k_{2}, k_{3}$ : the reaction rate constants for the initial, bulk, and residual

delignification stage, respectively. 


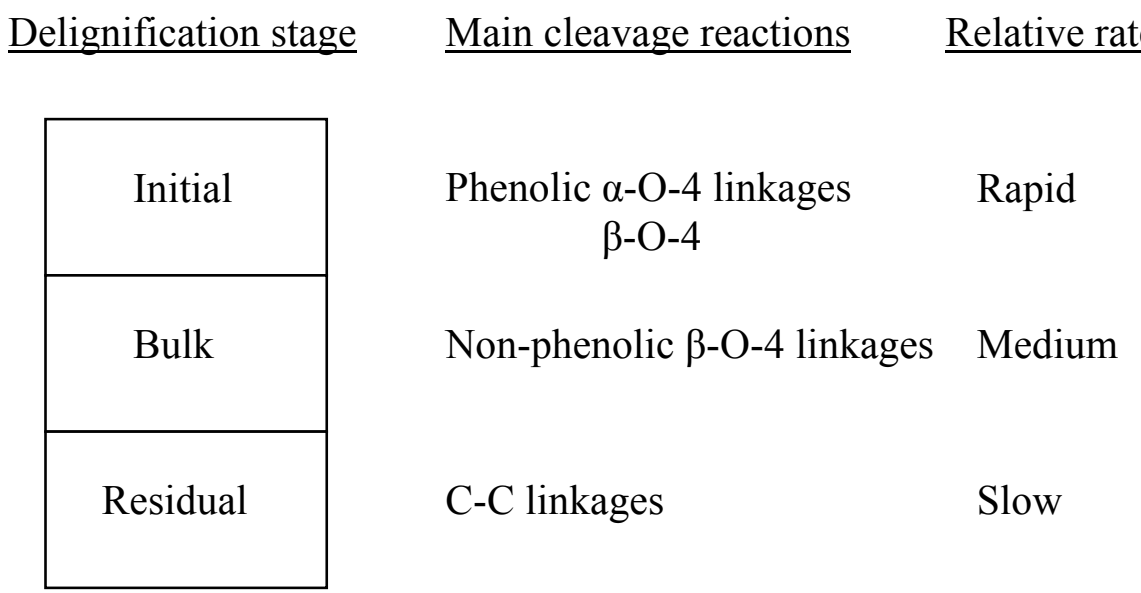

Figure 21. Three stages of delignification in wood pulping process.

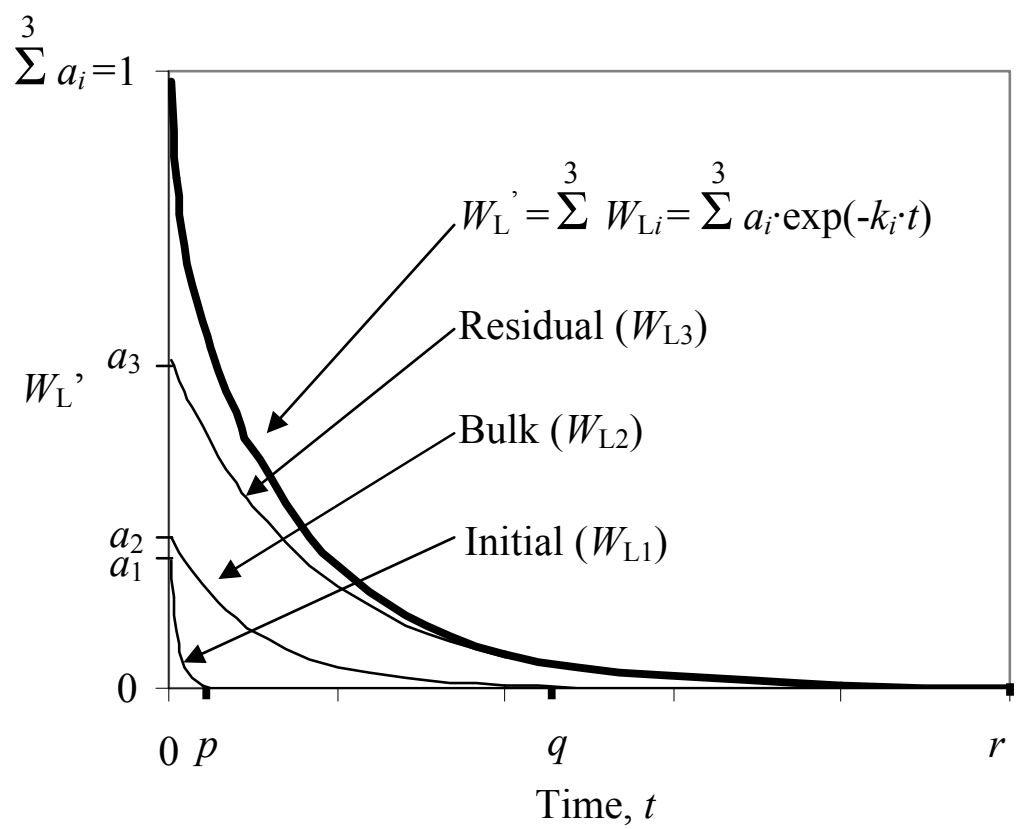

Figure 22. Delignification of lignocellulosic biomass described in three stages (initial, bulk, and residual) simultaneously. 
This equation is subjected to the constraint that

$$
a_{1}+a_{2}+a_{3}=1
$$

because $W_{\mathrm{L}}=1$ at $t=0$.

In Figure 22, Equation 3 may be expressed as follows:

$$
\begin{array}{ll}
W_{\mathrm{L}}=a_{1} \bullet \exp \left(-k_{1} \bullet t\right)+a_{2} \bullet \exp \left(-k_{2} \bullet t\right)+a_{3} \bullet \exp \left(-k_{3} \bullet t\right) & 0 \leq t \leq r \\
W_{\mathrm{L}}=a_{1} \bullet \exp (-\infty \bullet t)+a_{2} \bullet \exp \left(-k_{2} \bullet t\right)+a_{3} \bullet \exp \left(-k_{3} \bullet t\right) & p \leq t \leq r \\
W_{\mathrm{L}}=a_{1} \bullet \exp (-\infty \bullet t)+a_{2} \bullet \exp (-\infty \bullet t)+a_{3} \bullet \exp \left(-k_{3} \bullet t\right) & q \leq t \leq r
\end{array}
$$

where $t$ is the time period during which data were collected.

In Equation 5, the kinetic equation shows that the entire data set is sufficient to describe the initial, bulk, and residual delignification stages. In Equation 6, the data set has information only about the bulk and residual delignification stages; the initial stage was completed because the first time sample occurred after $p$. In Equation 7, the data set has information only about the residual delignification stage; the initial and bulk delignification stages were completed because the first sample occurred after $q$.

In this study, the delignification reactions occur at low temperatures $(25,35,45$, and $55^{\circ} \mathrm{C}$ ), compared with the high-temperature conditions for kraft pulping (more than $\left.150^{\circ} \mathrm{C}\right)$. Also, in this study, calcium hydroxide, $\mathrm{Ca}(\mathrm{OH})_{2}$, was the delignification chemical, compared to sodium hydroxide, $\mathrm{NaOH}$, which is used as the dominant alkali in kraft pulping.

The delignification model was used to analyze the data in this study. The parameters, such as $a_{i}$ and $k_{i}(i=1,2$, and 3), were estimated and compared between non-oxidative and oxidative pretreatments with lime. Based on the kinetic parameters of delignification, the activation energy $\left(E_{\mathrm{a}}\right)$ was estimated for each pretreatment.

Additionally, it was determined if the lignin can be removed in non-oxidative or oxidative condition without lime. Non-oxidative treatment without lime was used to identify the temperature effect on delignification. Oxidative treatment without lime was used to identify the combined effect of temperature and aeration on delignification. 


\section{Materials and Methods}

Dry corn stover $(15 \mathrm{~g})$ was pretreated with lime in non-oxidative and oxidative conditions, as described in Appendix A, "Lime pretreatment procedure." Klason (acidinsoluble) lignin content and acid-soluble lignin contents were determined, as described in Appendix I, "Determination of lignin (acid-insoluble and -soluble contents in biomass)." The pretreatment yield of solids was determined by neutralizing the pretreated biomass with acid $(5-\mathrm{N} \mathrm{HCl})$ to $\mathrm{pH} 7.0$, washing with distilled water, oven drying at $45^{\circ} \mathrm{C}$ for $48 \mathrm{~h}$. Thus, the dry weight obtained was used to calculate the pretreatment yield of solids ( $Y_{\mathrm{T}}$, g solids recovered/100 $\mathrm{g}$ raw biomass).

The fraction of residual lignin $\left(W_{\mathrm{L}}\right)$ was determined as:

$$
W_{\mathrm{L}}=\frac{L \cdot Y_{\mathrm{T}}}{L_{\mathrm{o}}}
$$

where $L$ and $L_{\mathrm{o}}$ are the Klason lignin content of the treated biomass and the Klason lignin content of the fresh biomass at time zero, respectively, and $Y_{\mathrm{T}}$ is the pretreatment yield of the total solids determined after the lime pretreatment. Acid-soluble lignin content was not included in this study for delignification kinetics, because it varied greatly and interfered with the accurate estimation of delignification at lower lignin contents.

To identify the effect of aeration-only on delignification, $15.0 \mathrm{~g}$ dry weight of corn stover and $150 \mathrm{~mL}$ of distilled water were loaded in column reactors, which were operated using the procedure described in Appendix A, except that no lime was added. Non-oxidative and oxidative conditions without lime were achieved by purging nitrogen gas and air during the 10 -week operation at 25 and $55^{\circ} \mathrm{C}$, respectively.

\section{Results and Discussions}

\section{Effect of Lime Pretreatment on Lignin}

The Klason and acid-soluble lignin contents in the fresh biomass were $19.62 \pm$ 0.31 (g Klason lignin/100 g raw biomass) and 1.80 \pm 0.12 (g acid-soluble lignin/100 g 
raw biomass), respectively. Because only the Klason lignin content is being modeled, $L_{\mathrm{o}}$ $=19.62$ (g Klason lignin/100 g lignin in raw biomass).

After non-oxidative lime pretreatment, the Klason lignin content decreased from 19.6 down to $13 \mathrm{~g}$ Klason lignin/100 g treated biomass. Delignification occurred significantly within the first 2 weeks of treatment, but did not depend on temperature after around 4 weeks (Figure 23 (a)).

On the other hand, during oxidative pretreatment, the Klason lignin content decreased significantly throughout the entire treatment time. Delignification depended on temperature at this condition (Figure 23 (b)). For 16 weeks in the oxidative lime pretreatment, the Klason lignin content decreased down to 10.5 and $4.3 \mathrm{~g}$ Klason lignin/100 g treated biomass at 25 and $55^{\circ} \mathrm{C}$, respectively.

During the non-oxidative lime pretreatment, the acid-soluble lignin content in the pretreated corn stover decreased from 1.8 to $1.2 \mathrm{~g}$ acid-soluble lignin/100 $\mathrm{g}$ treated biomass. The reduction tendency of acid-soluble lignin was similar to that of Klason lignin (Figure $24(\mathrm{a})$ ).

In the case of oxidative pretreatment, however, the acid-soluble lignin contents in the pretreated corn stover started to decrease for the first 2 weeks, but gradually recovered after 2 weeks, even though the increase was relatively small compared with Klason lignin contents. The recovering rate of acid-soluble lignin also increased as temperature increased, as shown in Figure 24 (b). There may be a conversion of Klason lignin to acid-soluble lignin due to lime pretreatment.

During the 16-week lime pretreatment, non-oxidative delignification removed up to $43.6,46.3,48.4$, and $47.7 \mathrm{~g}$ lignin removed/100 $\mathrm{g}$ lignin in raw biomass at 25, 35, 45, and $55^{\circ} \mathrm{C}$, respectively. Oxidative delignification, however, more efficiently removed up to $57.8,66.2,80.9$, and $87.5 \mathrm{~g}$ lignin removed/100 $\mathrm{g}$ lignin in raw biomass at 25, 35, 45, and $55^{\circ} \mathrm{C}$, respectively during the same period. 


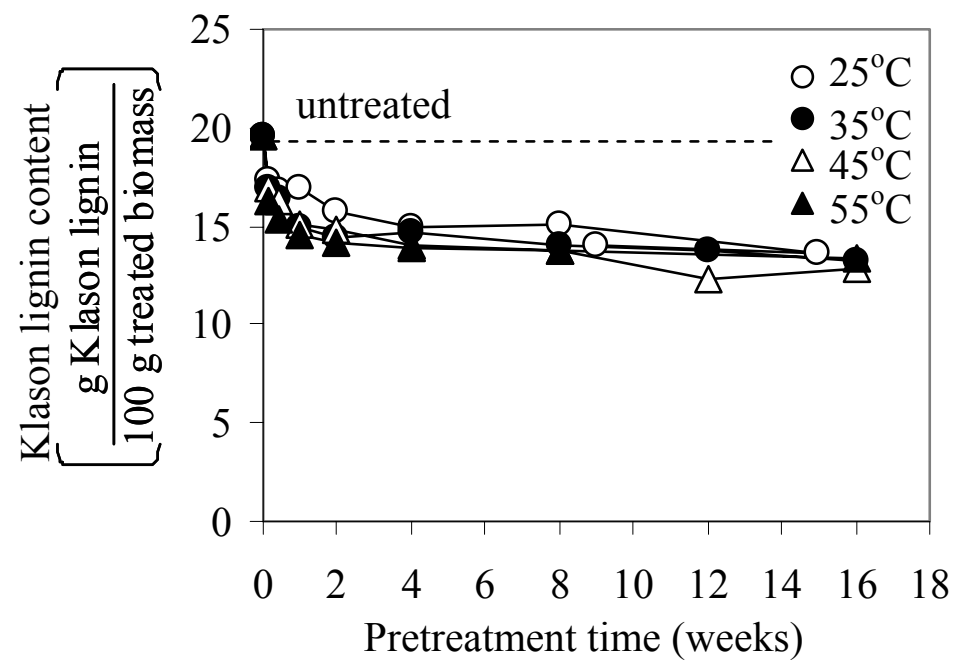

(a)

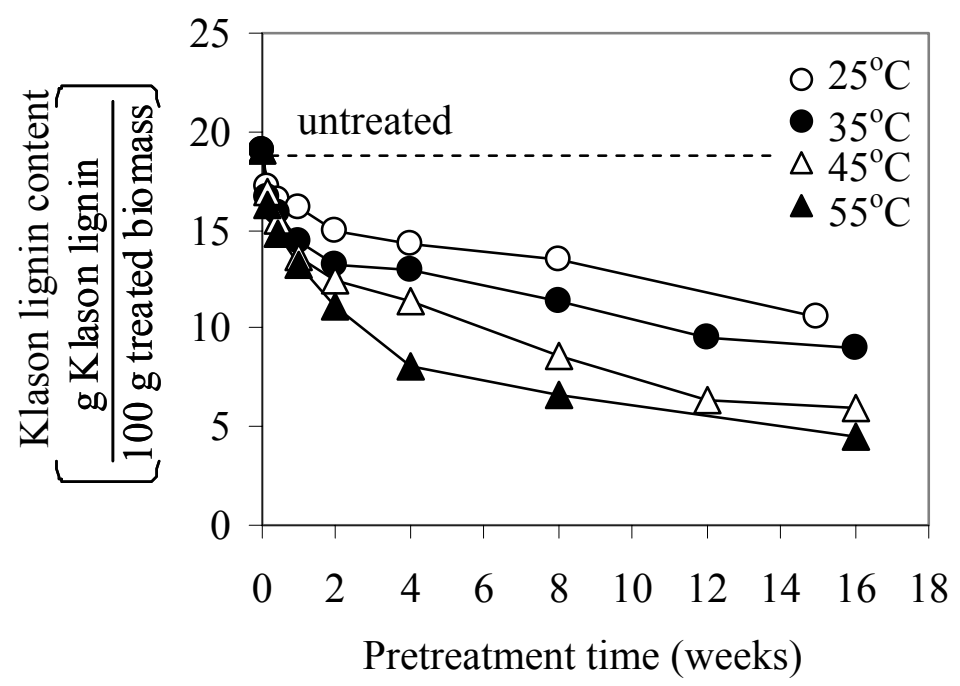

(b)

Figure 23. Profiles of Klason lignin content in non-oxidative (a) and oxidative (b) lime pretreatment at $25,35,45$, and $55^{\circ} \mathrm{C}$. 


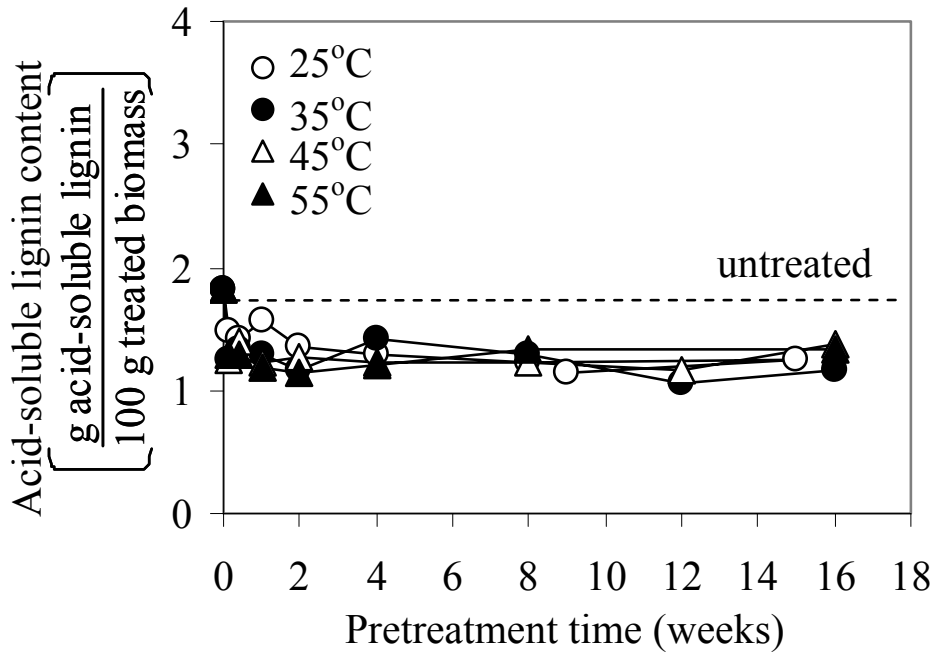

(a)

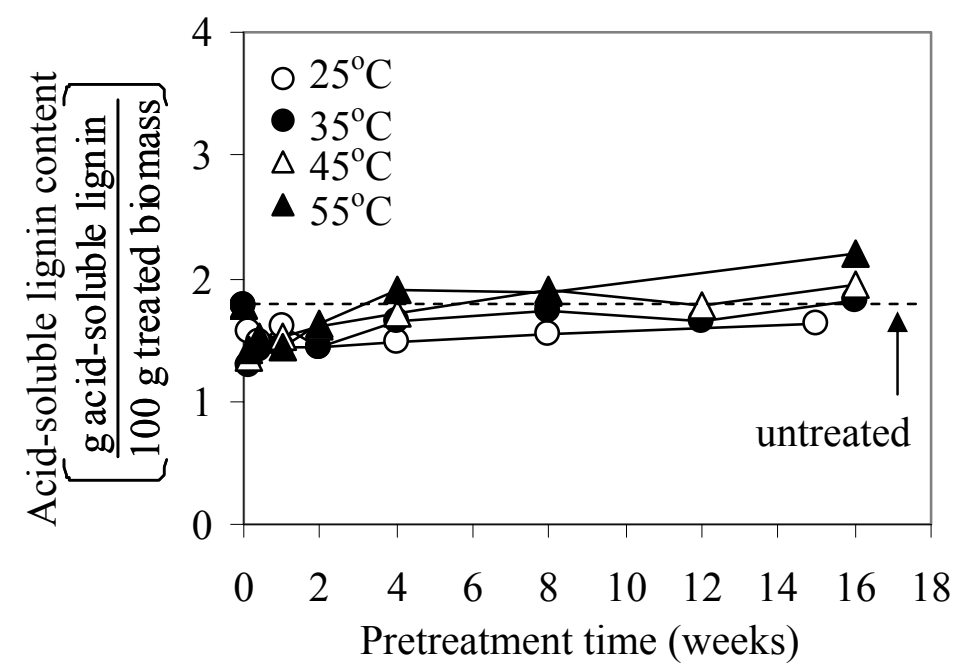

(b)

Figure 24. Profiles of acid-soluble lignin content in non-oxidative (a) and oxidative (b) lime pretreatment at $25,35,45$, and $55^{\circ} \mathrm{C}$. 


\section{Delignification Selectivity}

The lignin of corn stover started to be removed from the beginning of lime pretreatment and depended linearly on the pretreatment yield of total solid (the first batch of corn stover) as shown in Figures 25 and 26. The slope of linear plot between Klason lignin content ( $L$, g Klason lignin/100 g raw biomass) and the pretreatment yield of total solids ( $Y_{\mathrm{T}}, \mathrm{g}$ solid recovered/100 $\mathrm{g}$ raw biomass) indicates the ease (selectivity) of delignification. As shown in Table 8 and Figure 27, for 4 weeks of lime pretreatment, the delignification selectivities tended to increase, as temperature increased. In the nonoxidative case, the selectivity tended to increase with temperatures from 25 to $35^{\circ} \mathrm{C}$; above $35^{\circ} \mathrm{C}$, there is no temperature effect. In oxidative case, the selectivity tended to slightly increase with temperatures in the entire range $\left(25-55^{\circ} \mathrm{C}\right)$. As shown in Table 8 and Figure 28, for 16 weeks of non-oxidative lime pretreatment, the selectivity shows a similar pattern. There is a relatively rapid increase from 25 to $35^{\circ} \mathrm{C}$; above $35^{\circ} \mathrm{C}$, there is no temperature effect. For 16 weeks of oxidative lime pretreatment, there is no effect of temperatures. Statistically, however, the effect of temperature on the delignification selectivity was not significant, because $95 \%$ confidence intervals (C.I.) were overlapped at different temperatures. Table 9 and Figure 29 show the mean delignification selectivies at each condition (4 or 16 weeks, non-oxidative or oxidative) are higher in oxidative lime pretreatment than in non-oxidative lime pretreatment. When the treatment time increased from 4 to 16 weeks, in oxidative conditions, the delignification selectivites tended to decrease due to more extensive solubilization of solids, whereas in non-oxidative conditions, it did not change.

\section{Kinetics of Delignification}

Holocellulose (glucan + xylan) was much more recovered than lignin; more than $80 \%$ of holocellulose $\left(Y_{\mathrm{GX}} \geq 0.8\right)$ was recovered when $70 \%$ of the lignin was removed $\left(W_{\mathrm{L}} \leq 0.3\right)$.

However, the removal of holocellulose rapidly increased after $25.5 \%$ of lignin removal, as shown in Figure 30 (a). In holocellulose, glucan was much less degradable 


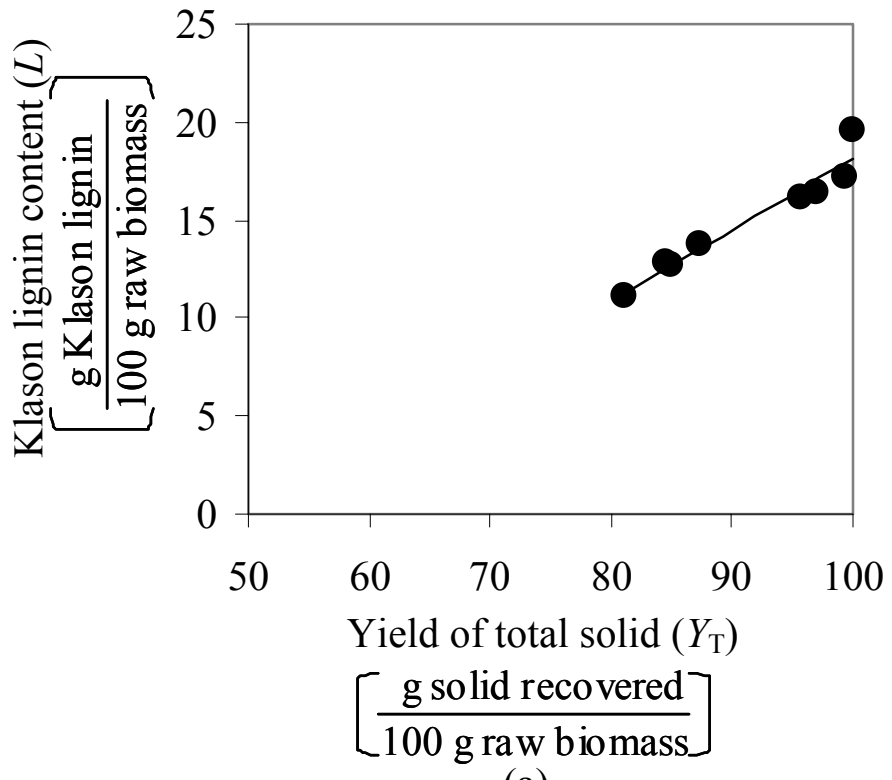

(a)

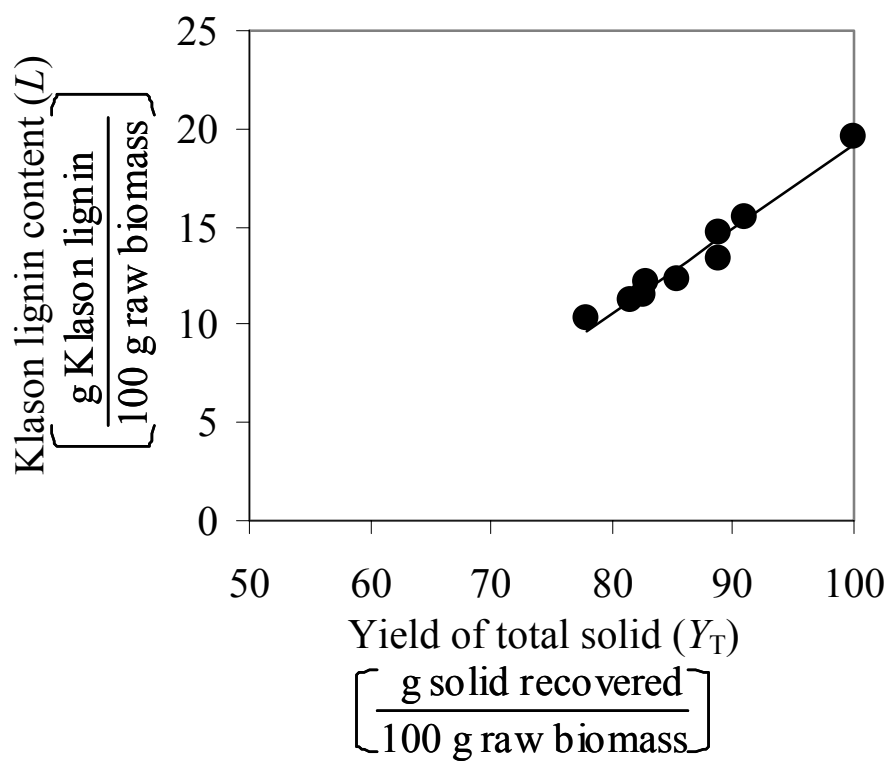

(b)

Figure 25. Klason lignin content $(L)$ versus the pretreatment yield of total solids $\left(Y_{\mathrm{T}}\right)$ recovered after the non-oxidative lime pretreatment at (a) 25 , (b) 35 , (c) 45 , and (d) $55^{\circ} \mathrm{C}$. 


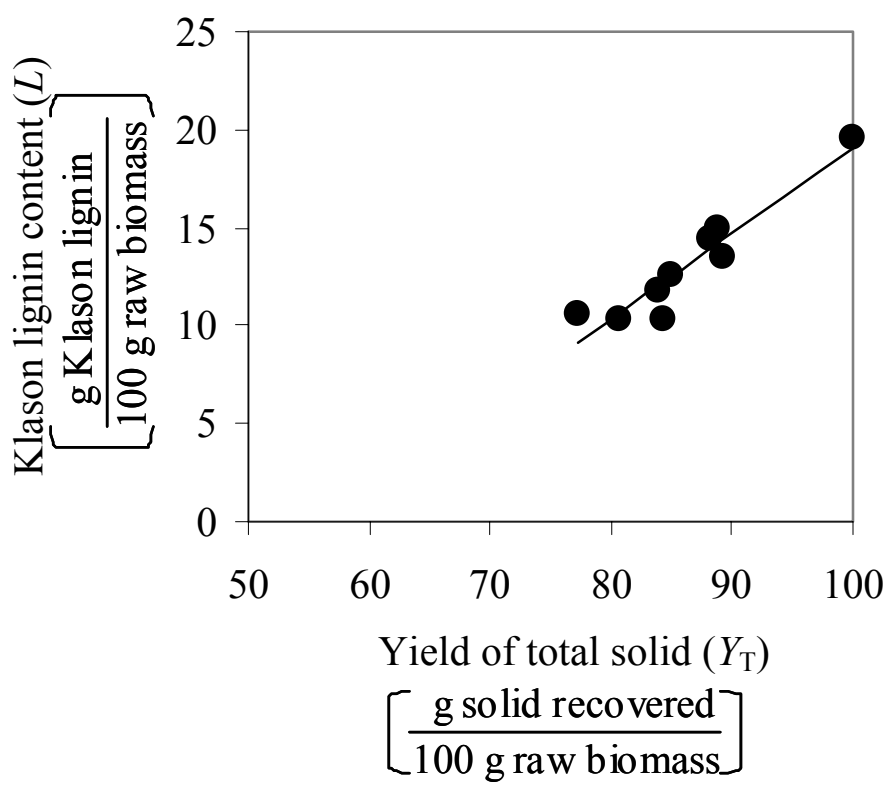

(c)

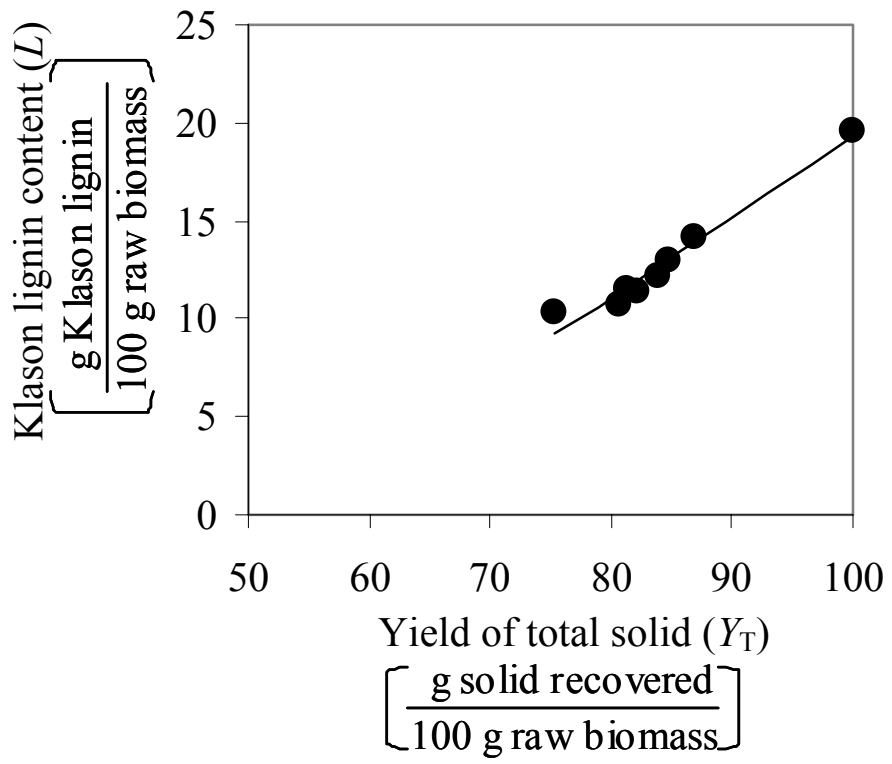

(d)

Figure 25. Continued. 


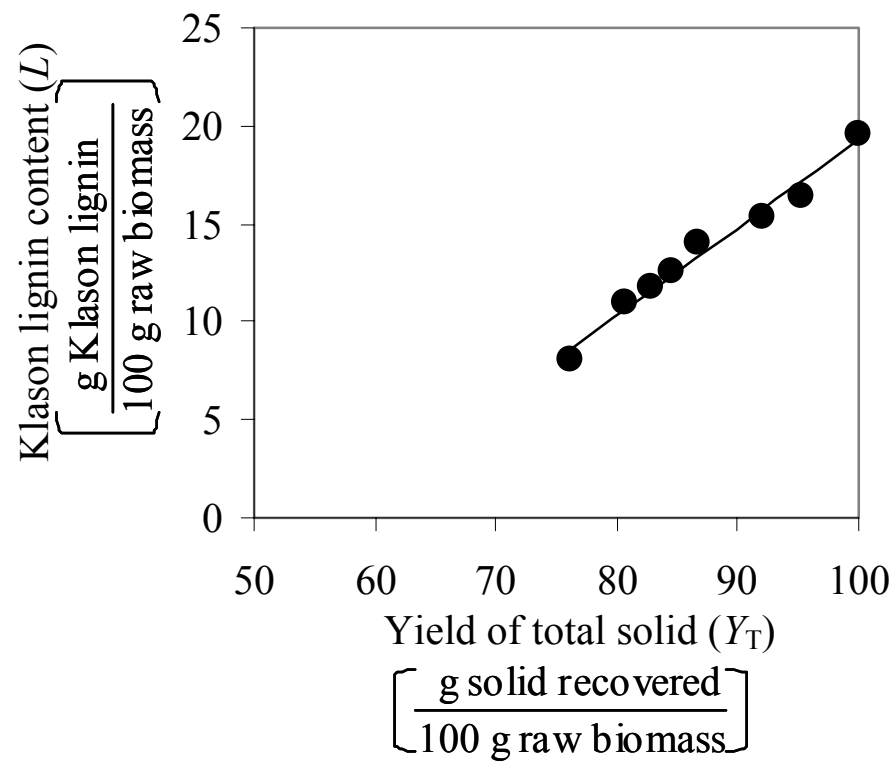

(a)

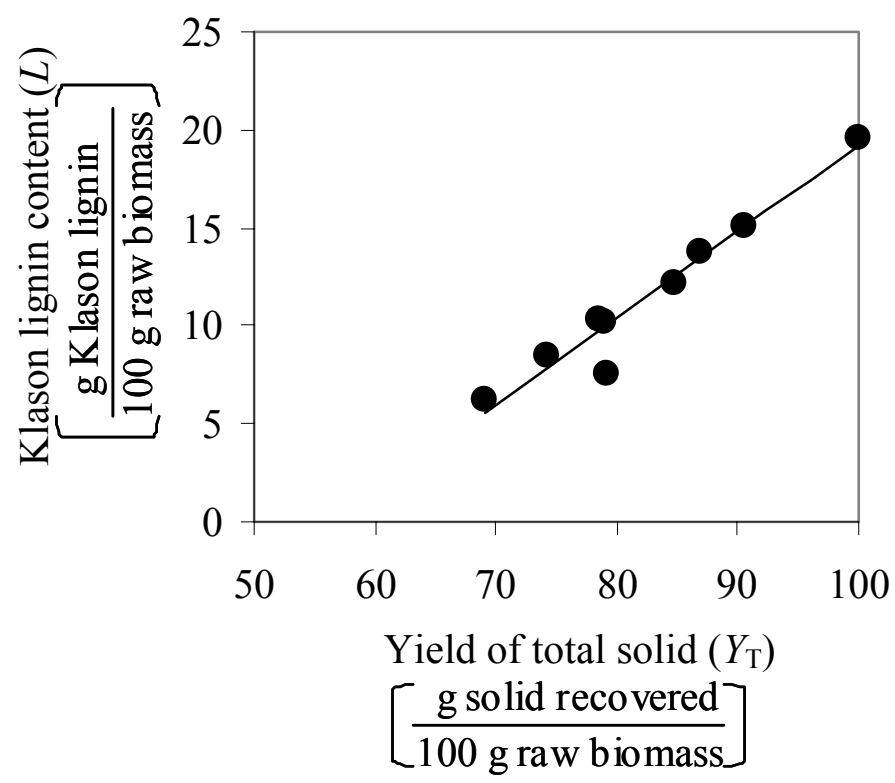

(b)

Figure 26. Klason lignin content $(L)$ versus the pretreatment yield of total solids $\left(Y_{\mathrm{T}}\right)$ recovered after the oxidative lime pretreatment at (a) 25 , (b) 35 , (c) 45 , and (d) $55^{\circ} \mathrm{C}$. 


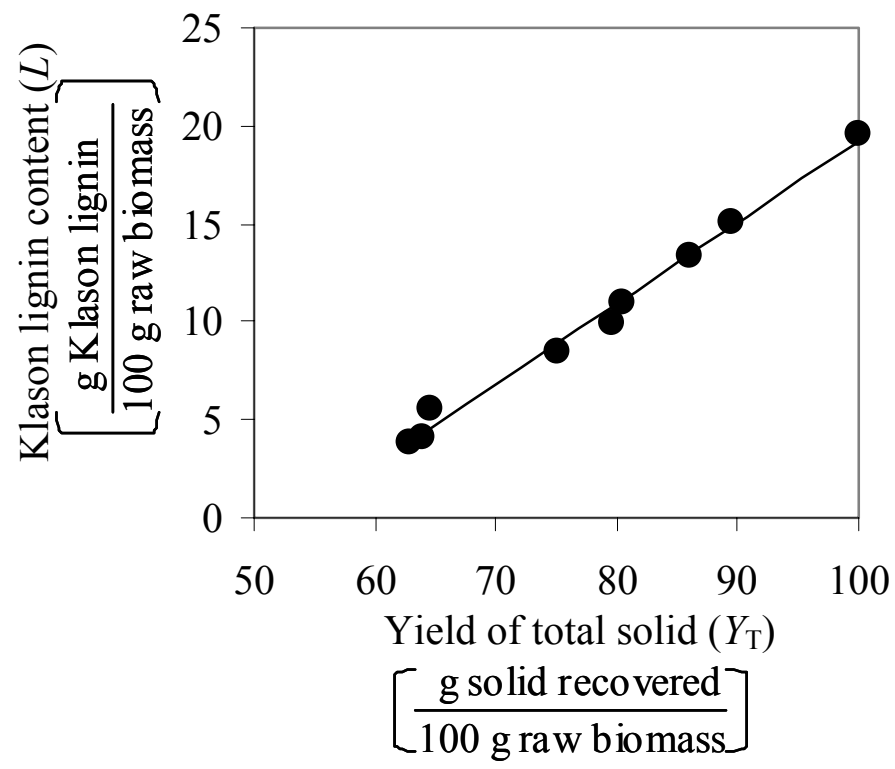

(c)

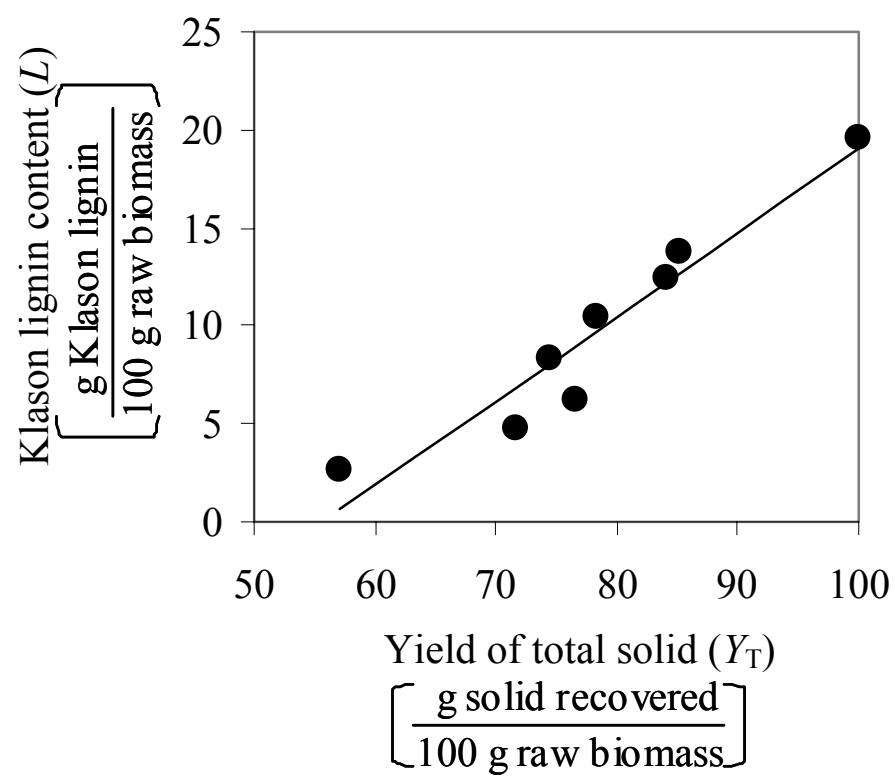

(d)

Figure 26. Continued. 
Table 8. Slopes $\left(\triangle L / \triangle Y_{\mathrm{T}}\right)^{1)}$ of Klason lignin content $(L, \mathrm{~g}$ Klason lignin/100 g raw biomass) versus the pretreatment yield of total solids $\left(Y_{\mathrm{T}}\right.$, g solid recovered/100 g raw biomass) to compare the ease of delignification at different temperatures in non-oxidative and oxidative lime-pretreatments, respectively.

\begin{tabular}{|c|c|c|c|c|c|c|c|c|c|}
\hline Time $^{2)}$ & \multirow{2}{*}{$\begin{array}{c}\text { Temp } \\
(\text { weeks })\end{array}$} & \multicolumn{3}{|c|}{ Non-oxidative pretreatment } & \multicolumn{4}{c|}{ Oxidative pretreatment } \\
\cline { 2 - 10 } & Slope & $\pm \mathrm{SE}^{3)}$ & $\pm \mathrm{CI}^{4)}$ & $\mathrm{R}^{2}$ & Slope & $\pm \mathrm{SE}^{3)}$ & $\pm \mathrm{CI}^{4)}$ & $\mathrm{R}^{2}$ \\
\hline \multirow{4}{*}{4} & 25 & 0.366 & 0.065 & 0.180 & 0.888 & 0.419 & 0.037 & 0.104 & 0.969 \\
\cline { 2 - 10 } & 35 & 0.461 & 0.049 & 0.135 & 0.958 & 0.438 & 0.019 & 0.054 & 0.992 \\
\cline { 2 - 10 } & 45 & 0.477 & 0.050 & 0.140 & 0.947 & 0.456 & 0.015 & 0.042 & 0.996 \\
\cline { 2 - 10 } & 55 & 0.447 & 0.020 & 0.055 & 0.992 & 0.479 & 0.069 & 0.193 & 0.925 \\
\hline \multirow{4}{*}{16} & 25 & 0.366 & 0.039 & 0.095 & 0.937 & 0.447 & 0.027 & 0.066 & 0.979 \\
\cline { 2 - 10 } & 35 & 0.428 & 0.031 & 0.073 & 0.965 & 0.441 & 0.041 & 0.097 & 0.943 \\
\cline { 2 - 10 } & 45 & 0.437 & 0.058 & 0.137 & 0.890 & 0.416 & 0.015 & 0.036 & 0.991 \\
\cline { 2 - 10 } & 55 & 0.410 & 0.034 & 0.083 & 0.961 & 0.428 & 0.054 & 0.132 & 0.913 \\
\hline
\end{tabular}

1) Slopes calculated from Figures 25 and 26

2) Pretreatment time

3) $\mathrm{SE}=$ Standard errors from linear regression analysis in Execl

4) $\mathrm{CI}=95 \%$ confidence interval from linear regression analysis in Execl 


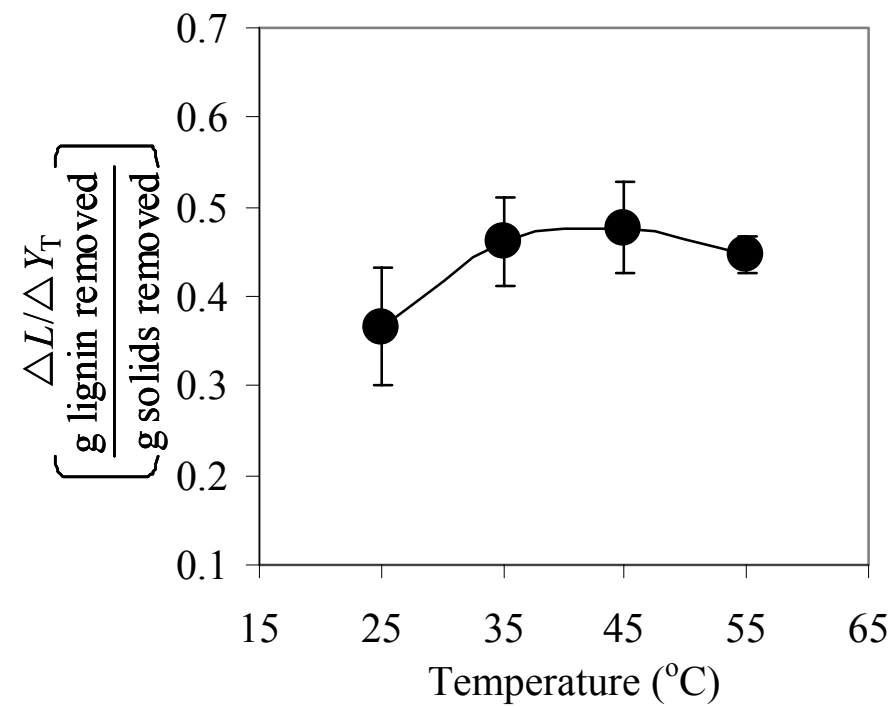

(a)

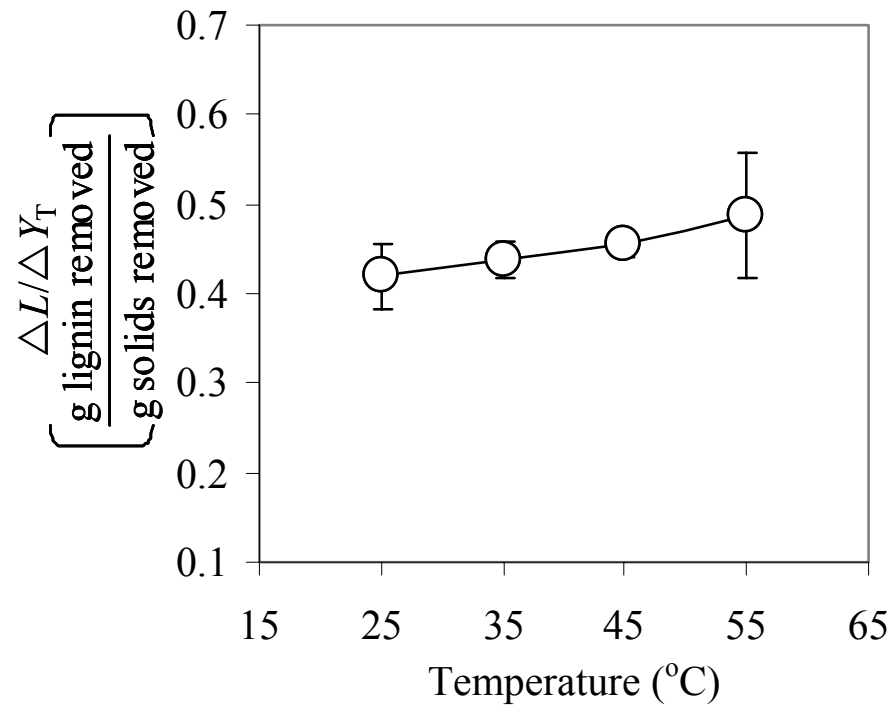

(b)

Figure 27. Effect of temperature $\left({ }^{\circ} \mathrm{C}\right)$ on the selectivity of delignification $\left(\triangle L / \triangle Y_{\mathrm{T}}\right)$ in non-oxidative (a) and oxidative (b) pretreatment with lime for 4 weeks. Bar symbols represent standard errors ( - ). 


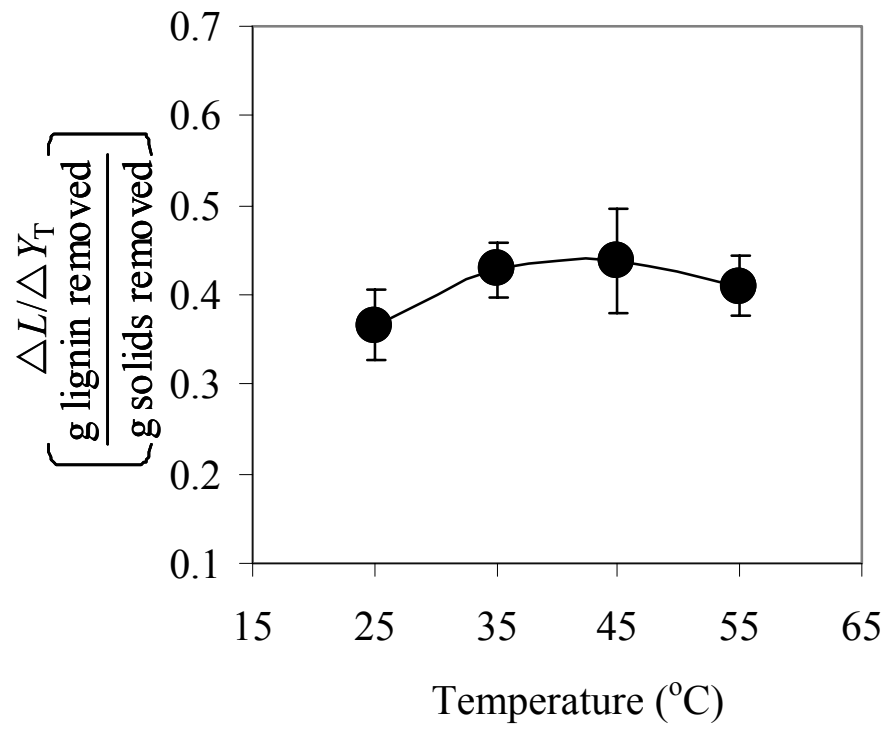

(a)

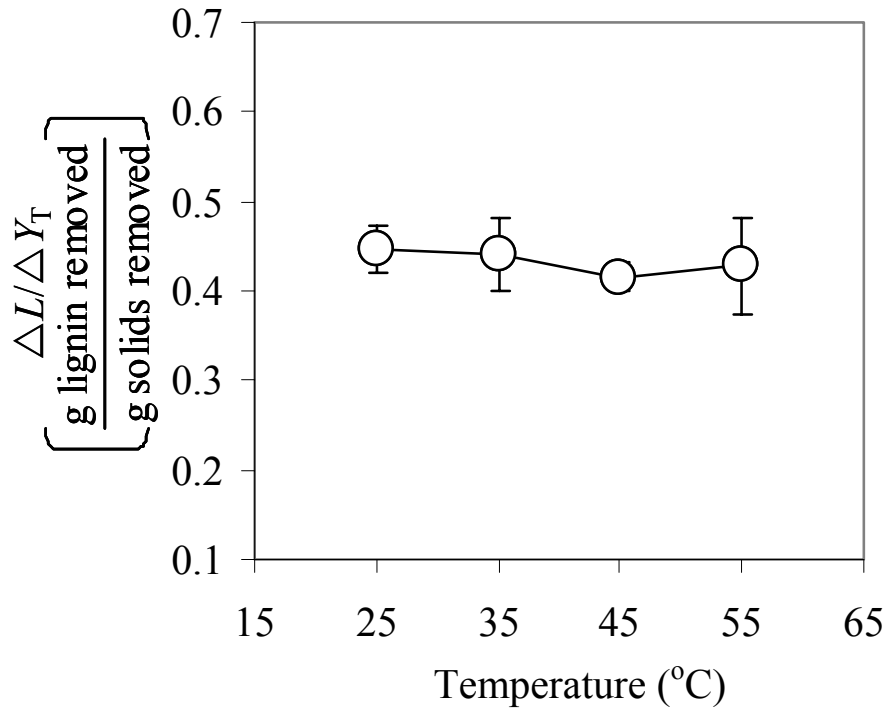

(b)

Figure 28. Effect of temperature $\left({ }^{\circ} \mathrm{C}\right)$ on the selectivity of delignification $\left(\triangle L / \triangle Y_{\mathrm{T}}\right)$ in non-oxidative (a) and oxidative (b) pretreatment with lime for 16 weeks. Bar symbols represent standard errors $(-)$. 
Table 9. Slopes $\left(\triangle L / \triangle Y_{\mathrm{T}}\right)^{1)}$ of Klason lignin content $(L, \mathrm{~g}$ Klason lignin/100 $\mathrm{g}$ raw biomass) versus the pretreatment yield of total solids $\left(Y_{\mathrm{T}}\right.$, g solid recovered/100 g raw biomass) to compare the ease of delignification in nonoxidative and oxidative lime-pretreatments, respectively.

\begin{tabular}{|c|c|c|c|c|c|}
\hline $\begin{array}{c}\text { Time } \\
\text { (weeks) }\end{array}$ & $\begin{array}{c}\text { Lime- } \\
\text { pretreatment }\end{array}$ & Slope & $\pm \mathrm{SE}^{3)}$ & $\pm \mathrm{CI}^{4)}$ & $\mathrm{R}^{2}$ \\
\hline \multirow{2}{*}{4} & $\begin{array}{c}\text { Non- } \\
\text { oxidative }\end{array}$ & 0.366 & 0.026 & 0.055 & 0.912 \\
\cline { 2 - 6 } & Oxidative & 0.449 & 0.026 & 0.055 & 0.939 \\
\hline \multirow{2}{*}{16} & $\begin{array}{c}\text { Non- } \\
\text { oxidative }\end{array}$ & 0.360 & 0.022 & 0.045 & 0.903 \\
\cline { 2 - 6 } & Oxidative & 0.413 & 0.020 & 0.040 & 0.939 \\
\hline
\end{tabular}

1) Slopes calculated from data of non-oxidative and oxidative treatments, separately

2) Pretreatment time

3) $\mathrm{SE}=\mathrm{Standard}$ errors from linear regression analysis in Execl

4) $\mathrm{CI}=95 \%$ confidence interval from linear regression analysis in Execl

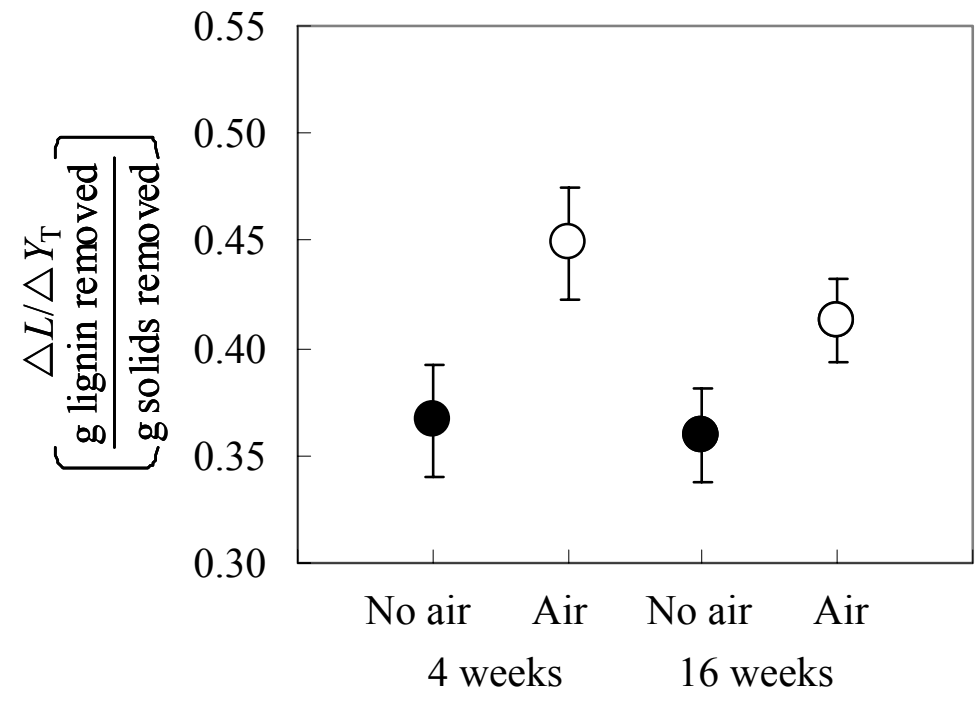

Figure 29. Effect of aeration on the selectivity of delignification $\left(\triangle L / \triangle Y_{\mathrm{T}}\right)$ for 4 and 16 weeks in lime-pretreatment. Bar symbols represent standard errors $(-)$. 

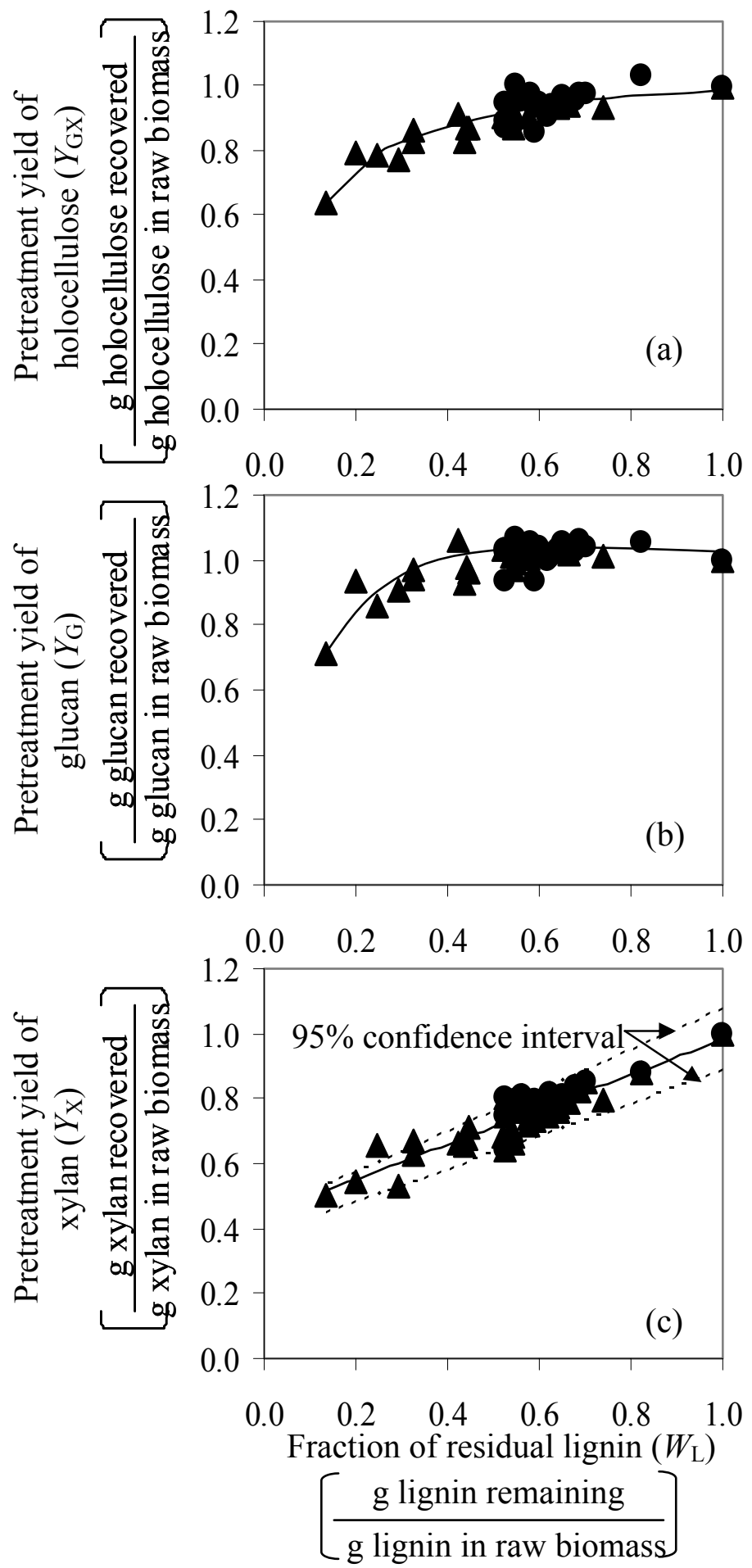

Figure 30. The yields of holocellulose, $Y_{\mathrm{GX}},(\mathrm{a})$, glucan, $Y_{\mathrm{G}}$, (b), and xylan, $Y_{\mathrm{X}}$, (c) versus the residual insoluble lignin $\left(W_{\mathrm{L}}\right)$ of corn stover pretreated with lime in non-oxidative $(O)$ and oxidative $(\boldsymbol{\Delta})$ conditions, respectively. 
than xylan. More than $80 \%$ of initial glucan $\left(Y_{\mathrm{G}}=0.8 \mathrm{~g}\right.$ glucan recovered $/ \mathrm{g}$ glucan in raw biomass) was recovered whereas only 55\% of initial xylan $\left(Y_{\mathrm{X}}=0.55 \mathrm{~g}\right.$ xylan recovered/g xylan in raw biomass) remained when $80 \%$ lignin was removed $\left(W_{\mathrm{L}}=0.2 \mathrm{~g}\right.$ lignin remaining/g lignin in raw biomass) in Figure 30 (b) and (c). As shown in Figure 30 (c), xylan removal showed a linear relationship with lignin removal: slope $\left(\triangle Y_{\mathrm{X}} / \triangle W_{\mathrm{L}}\right)=0.566 \pm 0.028(\mathrm{~g}$ xylan removed/g lignin removed $)$ and $y$-intercept $\left(Y_{\mathrm{X}}\right.$ at $\left.W_{\mathrm{L}}=0\right)=0.419 \pm 0.017(\mathrm{~g}$ xylan recovered/g xylan in raw biomass $)\left(\mathrm{R}^{2}=0.9443\right)$.

Wood delignification in alkaline (sodium hydroxide) pulping has been well described using a three-term first-order model in high temperature ranges $\left(120-180^{\circ} \mathrm{C}\right)$. The delignifying portions $\left(a_{i}, i=1,2\right.$, or 3$)$ due to the chemical reactions in the initial, bulk, and residual phases were 16,78, and 6\% for western hemlock wood (Dolk et al. 1989) and 18.8, 71.4, and 3.8\% for Douglas-fir wood (Chiang et al. 1990), respectively. The activation energies for each phase were $80-86,120-130$, and $110-117 \mathrm{~kJ} / \mathrm{mol}$, which were calculated from the Arrhenius equation:

$$
\ln k_{i}=\ln A_{i}-E_{a i} / R T, \text { for } i=1,2 \text {, or } 3
$$

where $A_{i}=$ pre-exponential factor $(1 / \mathrm{min})$ for $i$-th phase

$E_{a i}=$ activation energy $(\mathrm{J} / \mathrm{mol})$ for $i$-th phase

$R=$ ideal gas constant, 8.314 Joule $/(\mathrm{mol} \cdot \mathrm{K})$

$T=$ absolute temperature $(\mathrm{K})$.

Bagasse delignification with $\mathrm{Na}_{2} \mathrm{O}$ in the range of $100-165^{\circ} \mathrm{C}$ occurred in only two delignification phases: bulk and residual phases, instead of three phases (Sabatier et al. 1993). As temperature decreased from 165 to $100^{\circ} \mathrm{C}, a_{2}$ for bulk-phase delignification decreased from 0.8 to 0.64 , but $a_{3}$ for residual-phase delignification increased from 0.2 to 0.36 . In other words, as temperature was lowered, the major portion of delignification tended to move from the bulk to the residual phase. The activation energy $\left(E_{a}\right)$ for delignification of dried bagasse was $42 \mathrm{~kJ} / \mathrm{mol}$ in the bulk phase, which corresponds to ca. 1/3 of $E_{a}$ for Douglas-fir wood in kraft pulping (Chiang et al. 1990). The initial delignification is believed to occur very rapidly in the beginning of alkaline pulping, e.g., 
during the heating up periods, in most cases.

In this study, the delignification of corn stover with calcium hydroxide in the low ranges of temperature $\left(25-55^{\circ} \mathrm{C}\right)$ was different from previous studies on wood and bagasse. Nonlinear regressions and parameter estimations were performed using SAS, Polymath, and Excel programs based on the minimization of root mean squares and the following constraints: $0 \leq a_{i} \leq 1, a_{i}\left(25^{\circ} \mathrm{C}\right)=a_{i}\left(35^{\circ} \mathrm{C}\right)=a_{i}\left(45^{\circ} \mathrm{C}\right)=a_{i}\left(55^{\circ} \mathrm{C}\right)$, and $k_{i} \geq 0$ for $i=1,2$, and 3 . These statistical analyses were performed on the residual (Klason) lignin fractions $\left(W_{\mathrm{L}}\right)$ with respect to pretreatment times at each temperature for the nonoxidatively and oxidatively treated corn stovers.

The model parameters ( $a_{i}$ and $k_{i}, i=1,2$, and 3 ) were estimated using the delignification data $\left(W_{\mathrm{L}}\right)$ of the first batch of corn stover treated with lime at each condition. To test the model applicability, the predicted values for $W_{\mathrm{L}}$ were compared with the delignification data of the second batch at each condition. The results of nonlinear regression analyses are summarized in Tables $10-13$. The $a_{1}$ for the initial delignification stage in Equation 6 can be calculated by Equation 4, $a_{1}=1-\left(a_{2}+a_{3}\right)$, where $a_{2}$ and $a_{3}$ can be obtained from the nonlinear regression method using the data for $p \leq t$. The values of $a_{1}$ and $a_{2}$ in Equation 5 can be calculated only in the form of $a_{1}+a_{2}$ $=1-a_{3}$, where $a_{3}$ is obtained from the nonlinear regression method using the data for $q$ $\leq t$

Curve fits of the predicted $W_{\mathrm{L}}$ compared to the experimental data are shown in Figure 31 (for the non-oxidative pretreatment) and Figure 32 (for the oxidative pretreatment). For $n=1$ (one finite term model as Equation 7), the model did not fit the experimental data as indicated by the large values of the root mean square (RMS) residuals. For $n=3$ (three finite-term model, Equation 5), the model showed the best fit due to the smallest RMS residuals (Tables 10 and 12). However, it did not satisfy the initial condition, $a_{1}+a_{2}+a_{3}=1$ (Tables 11 and 13), and showed the poorest linearity between $\ln k_{\mathrm{i}}$ and $1 / T$ (Figure 33) used to calculate the activation energies and the preexponential factors in Equation 9. Considering both the residuals and the linearity of $\ln$

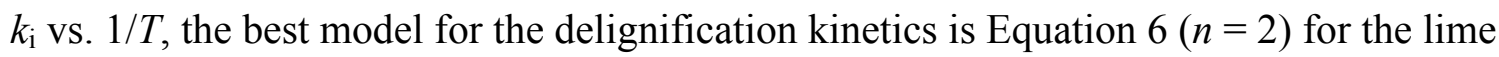


Table 10. Results of parameter estimation for reaction rate constants, $k_{i}(i=1,2$, and 3 ), obtained from regression analyses of delignification kinetic data in the non-oxidative lime pretreatments.

\begin{tabular}{|c|c|c|c|c|c|}
\hline$n^{1)}$ & $\begin{array}{c}\text { Temperature } \\
\left({ }^{\circ} \mathrm{C}\right)\end{array}$ & $k_{1}\left(\min ^{-1}\right)$ & $k_{2}\left(\min ^{-1}\right)$ & $k_{3}\left(\min ^{-1}\right)$ & $\begin{array}{c}\text { Root mean } \\
\text { square } \\
\text { residual }\end{array}$ \\
\hline \multirow{4}{*}{1} & 25 & & & $5.09 \times 10^{-7}$ & 0.2924 \\
\hline & 35 & & & $1.97 \times 10^{-6}$ & 0.1153 \\
\hline & 45 & & & $2.36 \times 10^{-6}$ & 0.1068 \\
\hline & 55 & & & $2.46 \times 10^{-6}$ & 0.1556 \\
\hline \multirow{4}{*}{2} & 25 & & $4.25 \times 10^{-5}$ & $9.14 \times 10^{-7}$ & 0.0779 \\
\hline & 35 & & $2.41 \times 10^{-4}$ & $9.52 \times 10^{-7}$ & 0.0585 \\
\hline & 45 & & $2.69 \times 10^{-4}$ & $1.30 \times 10^{-6}$ & 0.0848 \\
\hline & 55 & & $7.18 \times 10^{-4}$ & $1.28 \times 10^{-6}$ & 0.0686 \\
\hline \multirow{4}{*}{3} & 25 & $2.89 \times 10^{-5}$ & $9.89 \times 10^{-7}$ & $9.03 \times 10^{-7}$ & 0.0833 \\
\hline & 35 & $1.56 \times 10^{-5}$ & $8.62 \times 10^{-7}$ & $1.04 \times 10^{-6}$ & 0.0330 \\
\hline & 45 & $1.57 \times 10^{-4}$ & $2.96 \times 10^{-6}$ & $1.93 \times 10^{-7}$ & 0.0580 \\
\hline & 55 & $5.36 \times 10^{-4}$ & $7.12 \times 10^{-7}$ & $1.75 \times 10^{-6}$ & 0.0643 \\
\hline
\end{tabular}

1) $n=$ the number of finite terms at the equations of delignification kinetic model: $n=$ 1 for Equation $7 ; n=2$ for Equation $6 ; n=3$ for Equation 5 .

Table 11. Results of parameter estimation for constants, $a_{i}(i=1,2$, and 3$)$, obtained from regression analyses of delignification kinetic data in the non-oxidative lime pretreatments.

\begin{tabular}{|c|c|c|c|c|}
\hline \multirow{2}{*}{$n^{1)}$} & $a_{1}$ & $a_{2}$ & $a_{3}$ & \multirow{2}{*}{ Sum } \\
\cline { 2 - 4 } & \multicolumn{2}{|c|}{ (g lignin remaining/g lignin in raw biomass) } & \\
\hline 1 & & & 0.71 & 0.71 \\
\hline 2 & & 0.28 & 0.63 & 0.91 \\
\hline 3 & 0.22 & 0.29 & 0.35 & 0.85 \\
\hline
\end{tabular}

1) $n=$ the number of finite terms at the equations of delignification kinetic model: $n=$ 1 for Equation $7 ; n=2$ for Equation $6 ; n=3$ for Equation 5 . 
Table 12. Results of parameter estimation for reaction rate constants, $k_{i}(i=1,2$, and 3 ), obtained from regression analyses of delignification kinetic data in the oxidative lime pretreatments.

\begin{tabular}{|c|c|c|c|c|c|}
\hline \multirow{3}{*}{$n^{1)}$} & $\begin{array}{c}\text { Temperature } \\
\left({ }^{\circ} \mathrm{C}\right)\end{array}$ & $k_{1}\left(\mathrm{~min}^{-1}\right)$ & $k_{2}\left(\mathrm{~min}^{-1}\right)$ & $k_{3}\left(\mathrm{~min}^{-1}\right)$ & $\begin{array}{c}\text { Root mean } \\
\text { square } \\
\text { residual }\end{array}$ \\
\hline \multirow{3}{*}{1} & 35 & & & $2.13 \times 10^{-6}$ & 0.2884 \\
\cline { 2 - 6 } & 45 & & & $4.37 \times 10^{-6}$ & 0.1777 \\
\cline { 2 - 6 } & 55 & & & $8.88 \times 10^{-6}$ & 0.1780 \\
\hline \multirow{3}{*}{2} & 25 & & $3.39 \times 10^{-5}$ & $1.58 \times 10^{-6}$ & 0.0782 \\
\cline { 2 - 6 } & 35 & & $1.24 \times 10^{-4}$ & $3.19 \times 10^{-6}$ & 0.0408 \\
\cline { 2 - 6 } & 45 & & $1.49 \times 10^{-4}$ & $7.39 \times 10^{-6}$ & 0.0512 \\
\hline \multirow{3}{*}{3} & 25 & $8.59 \times 10^{-5}$ & $2.80 \times 10^{-6}$ & $2.50 \times 10^{-6}$ & 0.0475 \\
\hline \multirow{3}{*}{3} & 35 & $2.65 \times 10^{-4}$ & $1.44 \times 10^{-5}$ & $9.49 \times 10^{-7}$ & 0.0533 \\
\cline { 2 - 6 } & 45 & $2.92 \times 10^{-4}$ & $3.37 \times 10^{-6}$ & $2.04 \times 10^{-5}$ & 0.0420 \\
\cline { 2 - 6 } & 55 & $5.30 \times 10^{-4}$ & $4.44 \times 10^{-6}$ & $3.67 \times 10^{-5}$ & 0.0423 \\
\hline
\end{tabular}

1) $n=$ the number of finite terms at the equations of delignification kinetic model: $n=$ 1 for Equation 7; $n=2$ for Equation 6; $n=3$ for Equation 5.

Table 13. Results of parameter estimation for constants, $a_{i}(i=1,2$, and 3$)$, obtained from regression analyses of delignification kinetic data in the oxidative lime pretreatments.

\begin{tabular}{|c|c|c|c|c|}
\hline \multirow{2}{*}{$n^{1)}$} & $a_{1}$ & $a_{2}$ & $a_{3}$ & \multirow{2}{*}{ Sum } \\
\cline { 2 - 4 } & \multicolumn{2}{|c|}{ (g lignin remaining/g lignin in raw biomass) } & \\
\hline 1 & & & 0.65 & 0.65 \\
\hline 2 & & 0.27 & 0.57 & 0.85 \\
\hline 3 & 0.21 & 0.30 & 0.37 & 0.88 \\
\hline
\end{tabular}

1) $n=$ the number of finite terms at the equations of delignification kinetic model: $n=$ 1 for Equation 7; $n=2$ for Equation 6; $n=3$ for Equation 5 . 


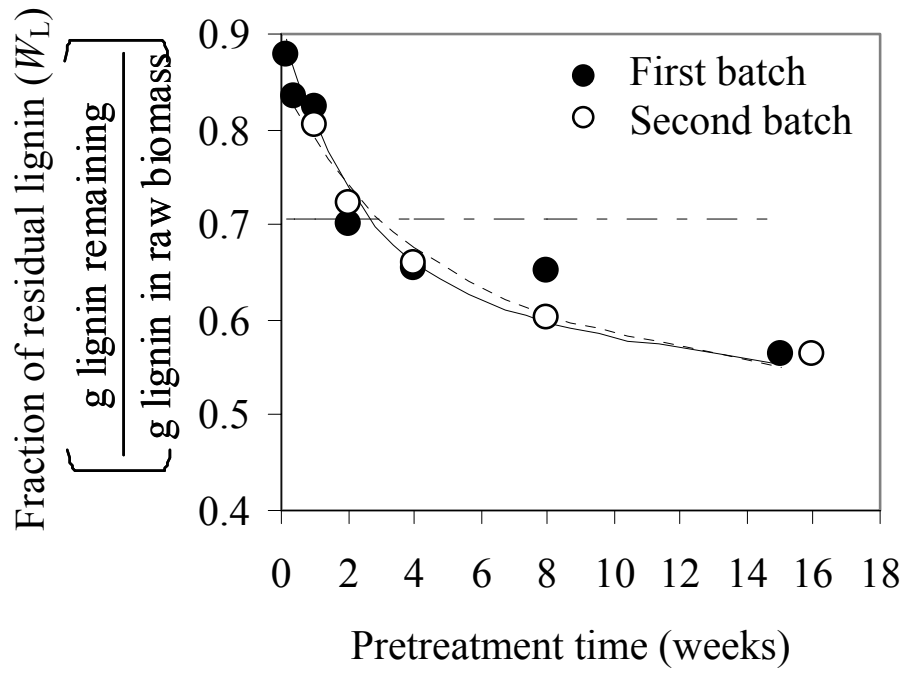

(a)

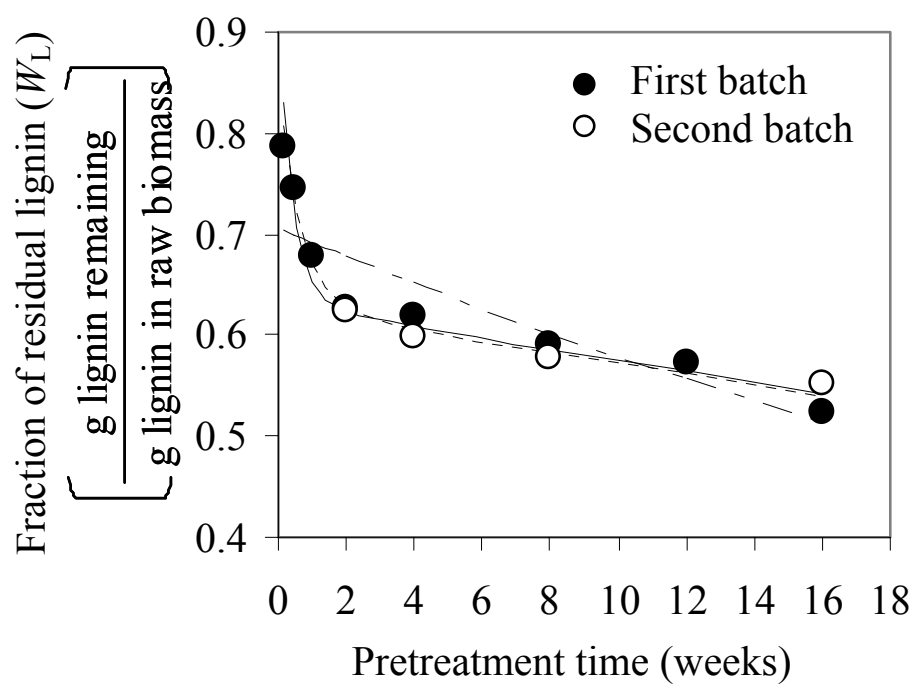

(b)

Figure 31. Comparison of the curve fits for delignification kinetics of the non-oxidative pretreatment at (a) 25, (b) 35, (c) 45, and (d) $55^{\circ} \mathrm{C}$, using Equation 5 (-----), Equation $6(-)$, and Equation 7 (-- ), respectively. 


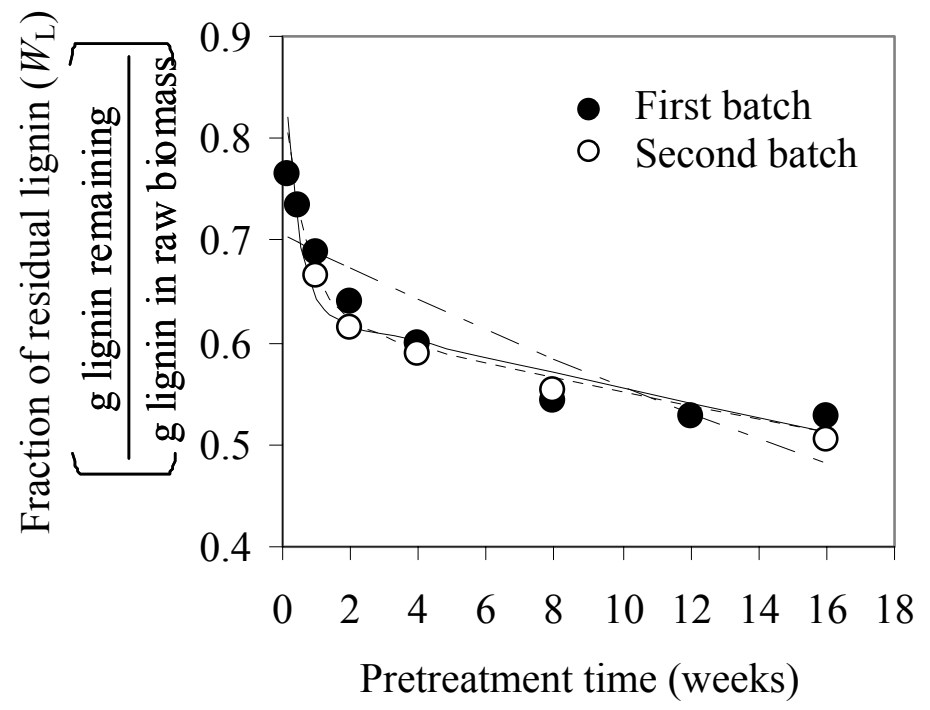

(c)

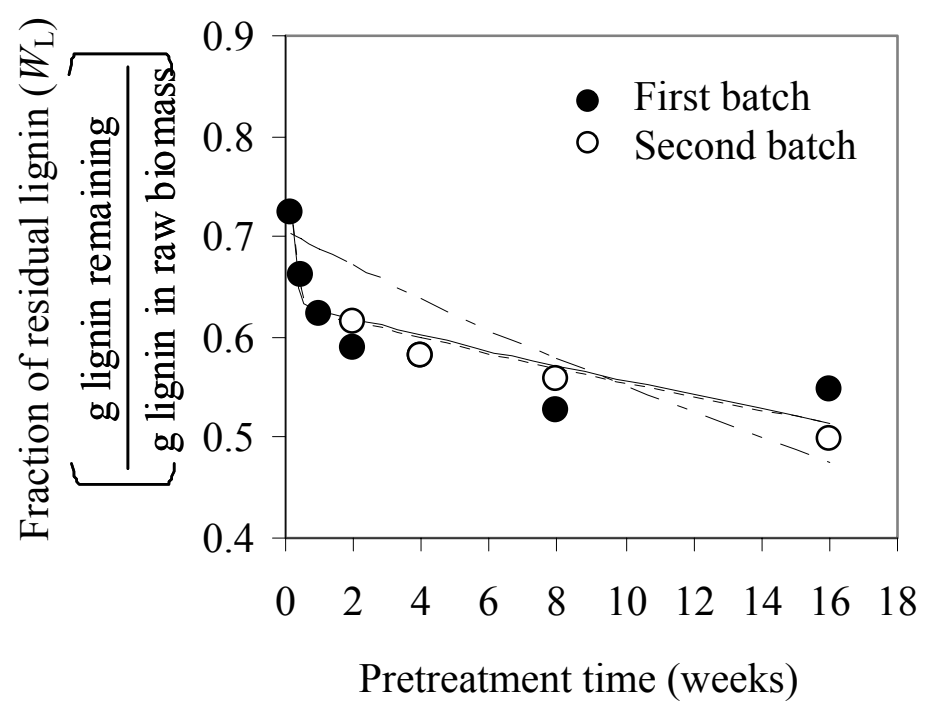

(d)

Figure 31. Continued. 


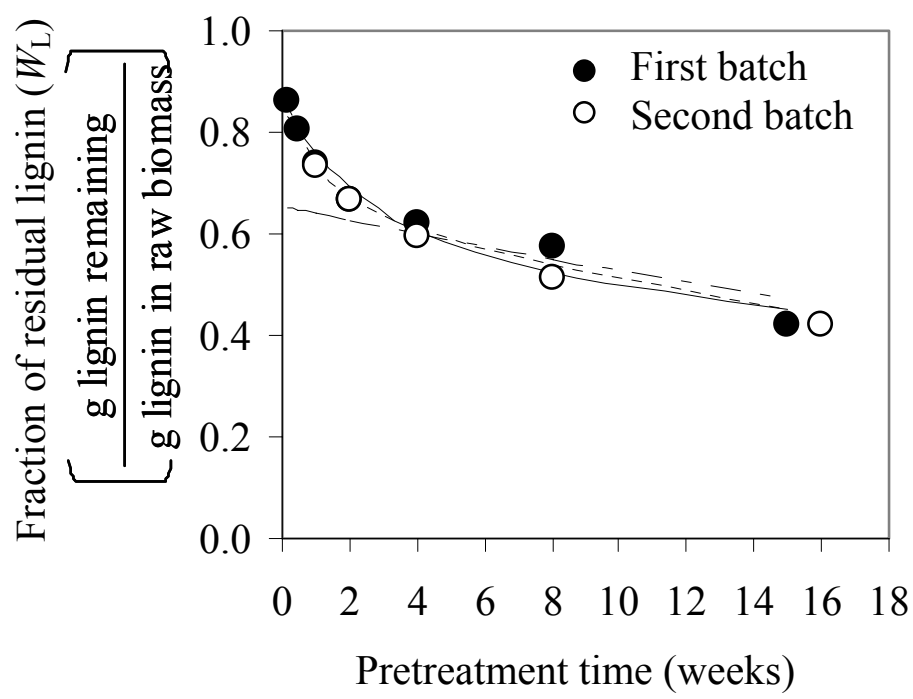

(a)

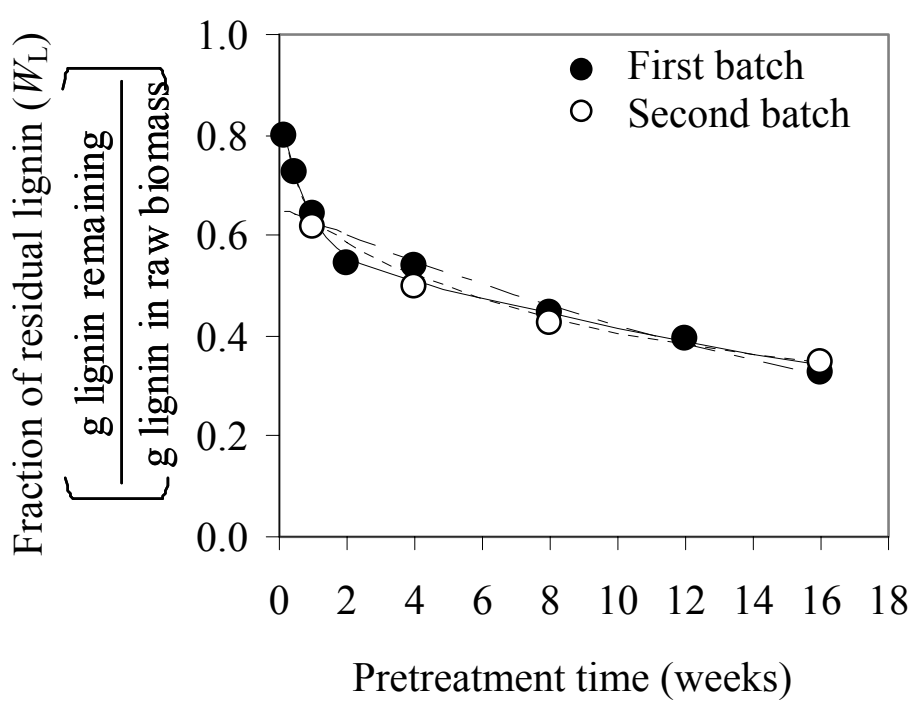

(b)

Figure 32. Comparison of the curve fits for delignification kinetics of the non-oxidative pretreatment at (a) 25 , (b) 35 , (c) 45 , and (d) $55^{\circ} \mathrm{C}$, using Equation 5 (-----), Equation $6(-)$, and Equation 7 (-- ), respectively. 


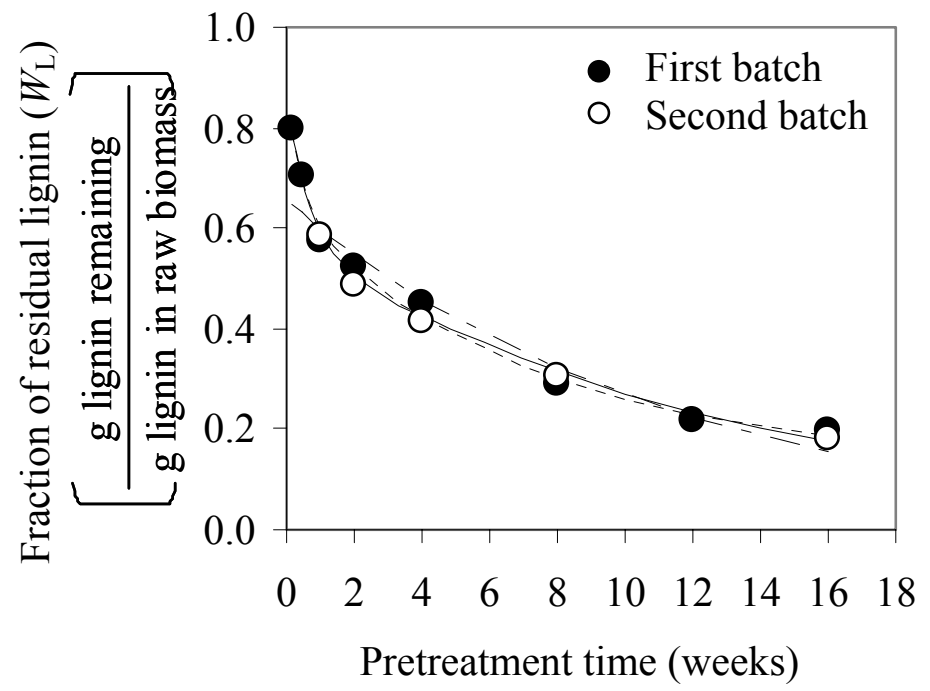

(c)

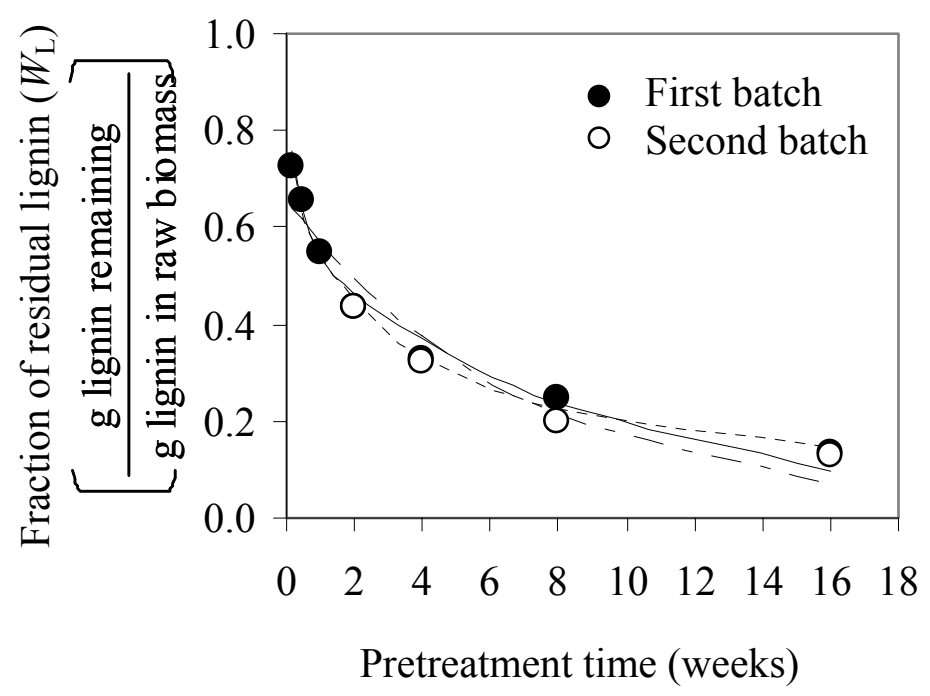

(d)

Figure 32. Continued. 

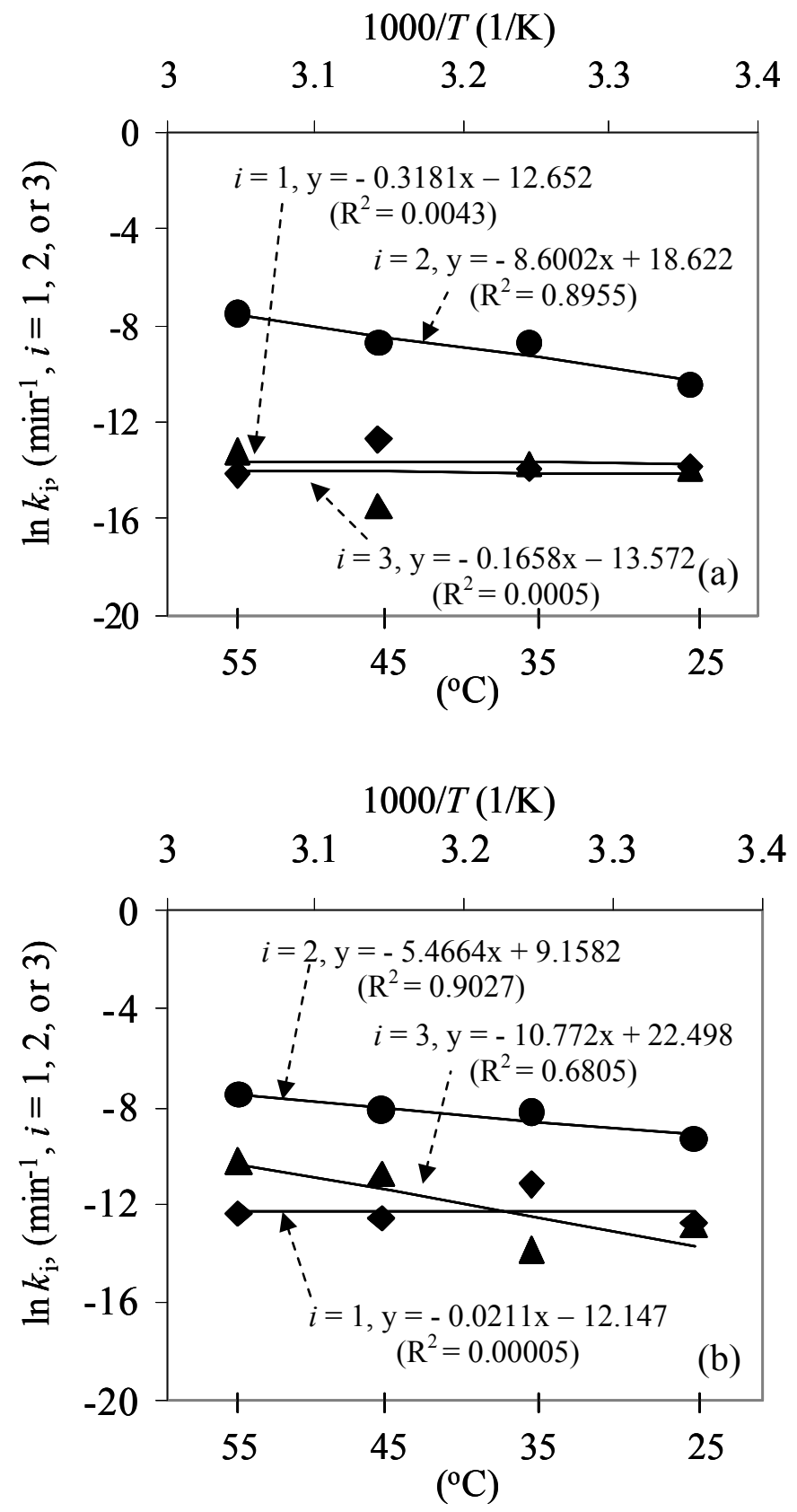

Figure 33. Arrhenius plots $\ln k$ versus $1000 / T$ for Equation 5 as the delignification model in the non-oxidative (a) and oxidative (b) conditions. 
pretreatment in both non-oxidative and oxidative conditions as follows:

and

$$
W_{\mathrm{L}}=\underbrace{0.09 \bullet \exp (-\infty \bullet t)}_{\text {Initial }}+\underbrace{0.28 \bullet \exp \left(-k_{2} \bullet t\right.}_{\text {Bulk }}+\underbrace{0.63 \bullet \exp \left(-k_{3} \bullet t\right)}_{\text {Residual }} \text { (Non-oxidative) (10) }
$$

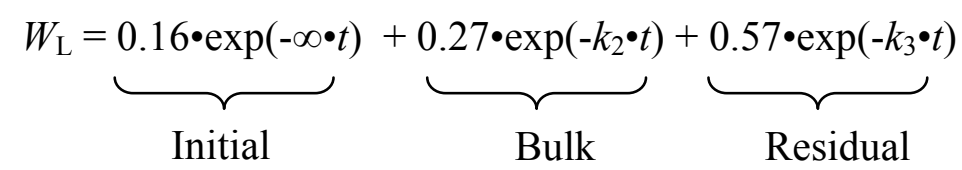

(Oxidative) (11)

In Equations 10 and $11, k_{1} \rightarrow \infty$, which means that the initial delignification is too fast to be detected at the first time of sampling $(p \leq t)$ in Figure 22 .

Of the Klason lignin, 9\% was removed in the initial phase in non-oxidative lime pretreatment, whereas $16 \%$ was removed in the initial phase of the oxidative lime pretreatment. Clearly, lignin removal in the initial phase was promoted by the presence of oxygen.

The major fraction of lignin was removed in the residual phase in the lower temperatures $\left(25-55^{\circ} \mathrm{C}\right): 63 \%$ for the non-oxidative pretreatment and $57 \%$ for the oxidative pretreatment. The delignification characteristics (e.g., $a$ 's) at the lower temperatures in this study are significantly different from the results at higher temperature $\left(\geq 100^{\circ} \mathrm{C}\right)$ in previous studies, e.g., $a_{1}=0.16$ (initial), $a_{2}=0.78$ (bulk), and $a_{3}=0.06$ (residual) for delignification of western hemlock wood in sodium hydroxide pretreatment (Dolk et al. 1989). In our study, the delignified fraction of the bulk phase was almost the same for both non-oxidative and oxidative conditions.

The delignification models established for the first batch of corn stover in both non-oxidative and oxidative conditions were well correlated with the experimental data for the second batch of corn stover, as shown in Table 14 and Figures 31 and 32. The kinetic model of delignification for the oxidative lime pretreatment was relatively more accurate than for the non-oxidative pretreatment.

From the Arrhenius plot $\ln k_{i}\left(\mathrm{~min}^{-1}, i=1,2\right.$, or 3$)$ versus $1 / T\left(\mathrm{~K}^{-1}\right)$ in Figures 33 -35, activation energies for both (bulk, $i=2$, and residual, $i=3$ ) phases in Equation 6 were determined most accurately, as summarized in Table 15. 
Table 14. Correlation analysis ${ }^{1)}$ between delignification data for the first and second batches of corn stover.

\begin{tabular}{|c|c|c|}
\hline Temperature $\left({ }^{\circ} \mathrm{C}\right)$ & $\begin{array}{c}\text { Non-oxidative } \\
\text { pretreatment }\end{array}$ & $\begin{array}{c}\text { Oxidative } \\
\text { pretreatment }\end{array}$ \\
\hline 25 & 0.9590 & 0.9742 \\
\hline 35 & 0.9300 & 0.9892 \\
\hline 45 & 0.9780 & 0.9901 \\
\hline 55 & 0.6684 & 0.9876 \\
\hline
\end{tabular}

1) Correlation analysis between two populations by Excel.

Table 15. Activation energies for delignification modeled in Equation 6.

\begin{tabular}{|c|c|c|c|c|}
\hline \multirow{2}{*}{ Pretreatment } & \multirow{2}{*}{$i^{1)}$} & \multicolumn{3}{|c|}{ Activation energy, $E_{\mathrm{a} i}(\mathrm{~kJ} / \mathrm{mol})$} \\
\cline { 3 - 5 } & & Corn stover & Wood pulping $^{2)}$ & Baggase $^{3)}$ \\
\hline \multirow{2}{*}{ Non-oxidative } & 2 & 70.24 & - & - \\
\cline { 2 - 5 } & 3 & 10.74 & - & - \\
\hline \multirow{2}{*}{ Oxidative } & 2 & 50.15 & $120-130$ & 42.0 \\
\cline { 2 - 5 } & 3 & 54.21 & $110-117$ & - \\
\hline
\end{tabular}

1) $i=2$ for bulk and 3 for residual delignification, respectively

2) The average ranges in the previous studies (Dolk et al. 1989 and Chiang et al. 1990) on kraft delignification of woods

3) The estimated value from the report of Sabatier et al. (1993) 

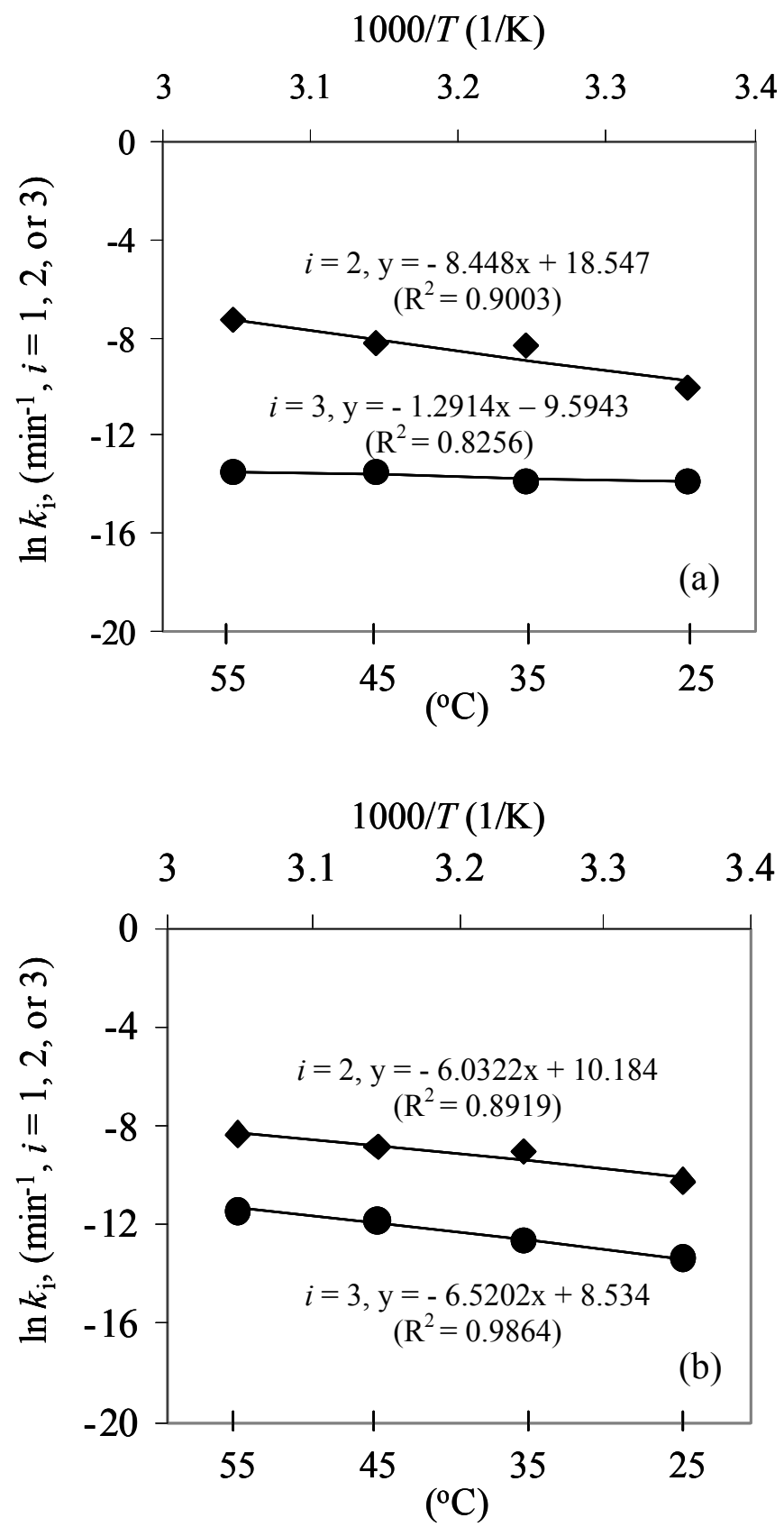

Figure 34. Arrhenius plots $\ln k$ versus $1000 / T$ for Equation 6 as the delignification model in the non-oxidative (a) and oxidative (b) conditions. 

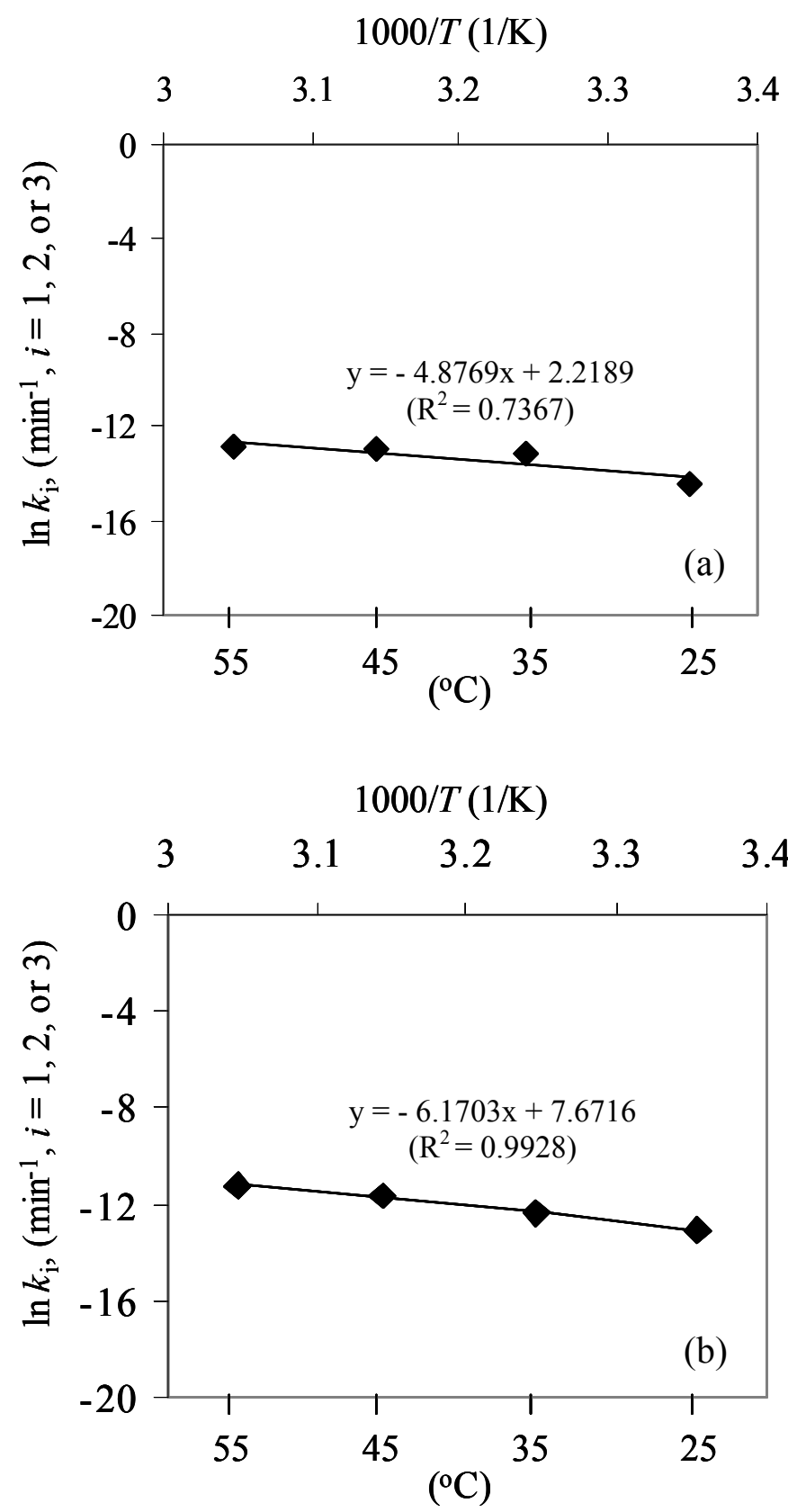

Figure 35. Arrhenius plots $\ln k$ versus $1000 / T$ for Equation 7 as the delignification model in the non-oxidative (a) and oxidative (b) conditions. 
The activation energies for the oxidative pretreatment were more accurately estimated than in the non oxidative pretreatment, because the linear regression values

$\left(\mathrm{R}^{2}\right)$ for the data of the oxidative pretreatment were better. The activation energies of the bulk and residual phases $\left(E_{\mathrm{a} 2}\right.$ and $\left.E_{\mathrm{a} 3}\right)$ were estimated as 50.15 and $54.21 \mathrm{~kJ} / \mathrm{mol}$ respectively in the oxidative pretreatment. These values are similar to $E_{\mathrm{a}}$ for bagasse, but much smaller than the $E_{\mathrm{a}}$ for wood (see Table 15). Delignification of corn stover showed similar kinetic properties with bagasse. For lignin removal in alkaline conditions, corn stover and bagasse may have a more favorable structure than wood because of the lower activation energy for delignification.

Furthermore, the oxidative lime pretreatment of corn stover enhanced the removal of lignin in the bulk and residual phases, and was more effective in removing lignin in the residual phase. As shown in Figure 36, the time for removing lignin from the bulk phase decreased as the temperature increased in both conditions.

In the oxidative pretreatment, the delignification rate (slope) of the residual phase increased, as the temperature increased.

\section{Effect of the Oxidative Condition without Lime for Delignification}

In lime-free treatments, the Klason lignin content of corn stover was not affected by oxidative or non-oxidative conditions, regardless of temperature. As shown in Table 16 , only the acid-soluble lignin contents of the solid fraction slightly decreased as temperature increased from 25 to $55^{\circ} \mathrm{C}$ after the 10 -week incubation. At a given temperature, aeration alone did not affect the contents of Klason or acid-soluble lignin.

\section{Conclusions}

The lignin of corn stover was removed more efficiently in the oxidative lime pretreatment than in the non-oxidative lime pretreatment. As temperature increased from 25 to $55^{\circ} \mathrm{C}$, the removal efficiency of lignin increased more in the oxidative condition than in the non-oxidative condition. At $55^{\circ} \mathrm{C}$, the Klason lignin content in the solid 


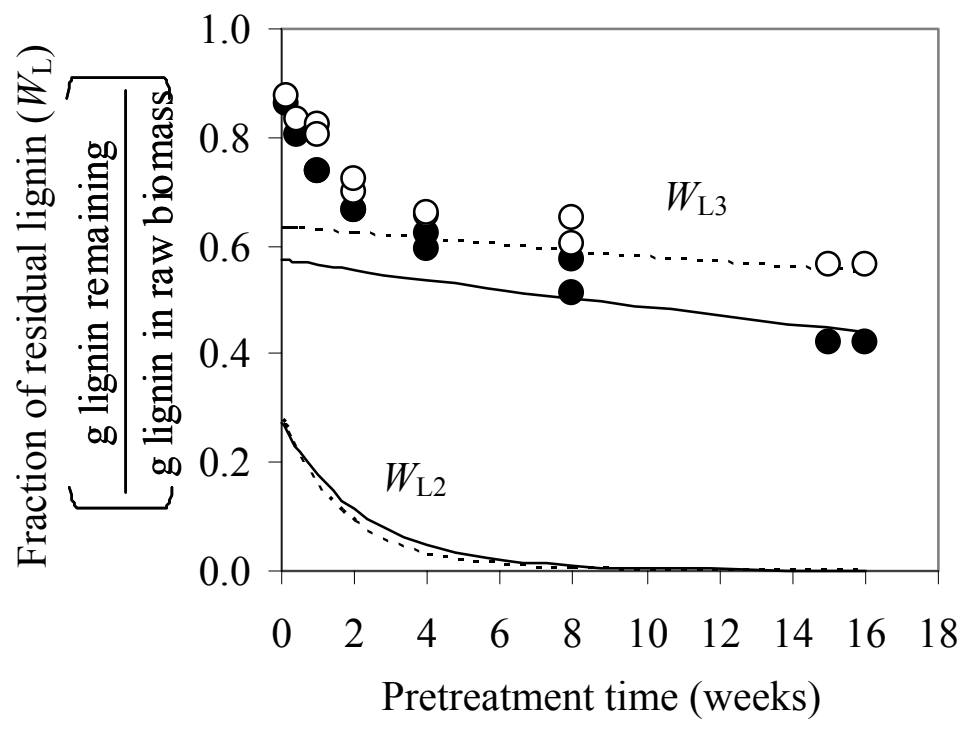

(a)

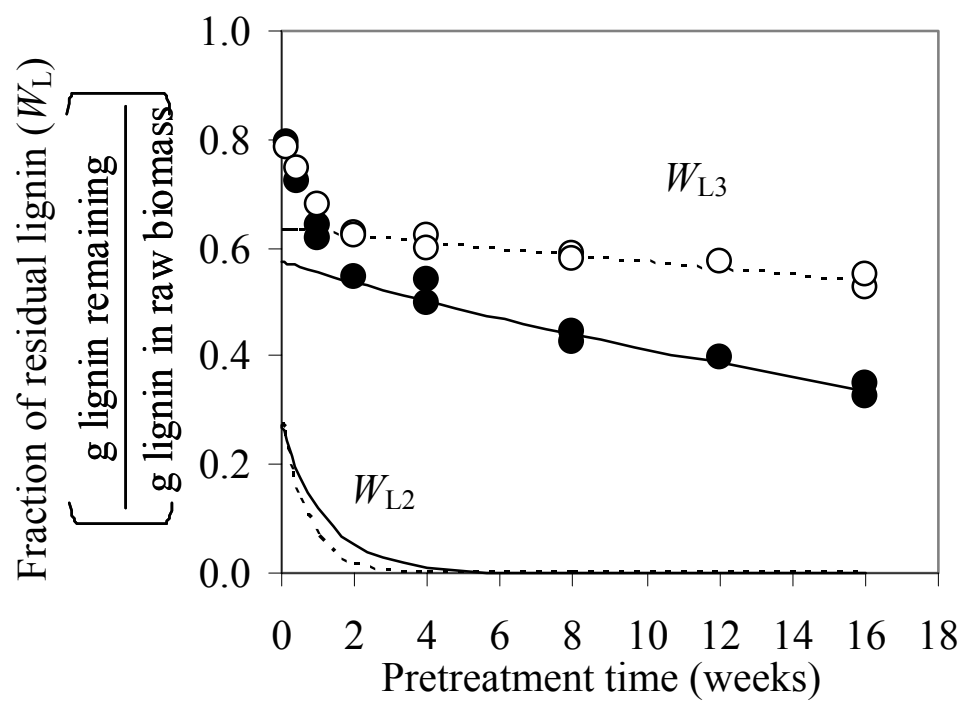

(b)

Figure 36. Delignification profiles of bulk $\left(W_{\mathrm{L} 2}\right)$ and residual $\left(W_{\mathrm{L} 3}\right)$ phases plotted from Equation 6, where $W_{\mathrm{L} 2}=a_{2} \cdot \exp \left(-k_{2} \cdot t\right)$ and $W_{\mathrm{L} 3}=$ $a_{3} \cdot \exp \left(-k_{3} \cdot t\right)$, in the non-oxidative (----) and oxidative (-) pretreatment. The circle symbol shows the experimental data for the non-oxidative $(\bigcirc)$ and oxidative $(O)$ pretreatment, at (a) 25 , (b) 35 , (c) 45 , and (d) $55^{\circ} \mathrm{C}$, respectively. 


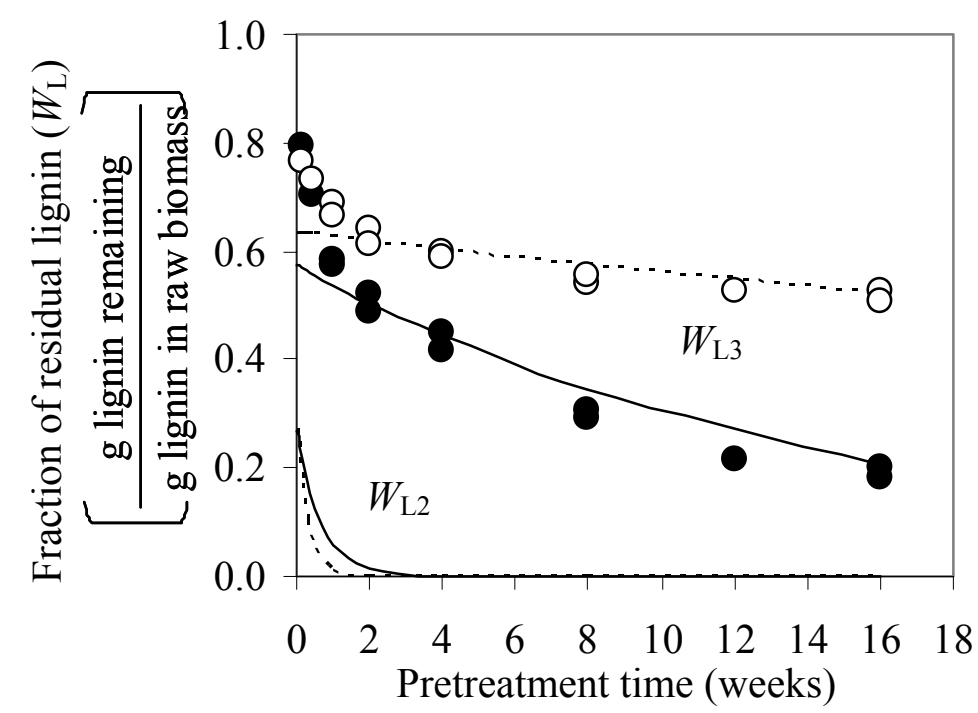

(c)

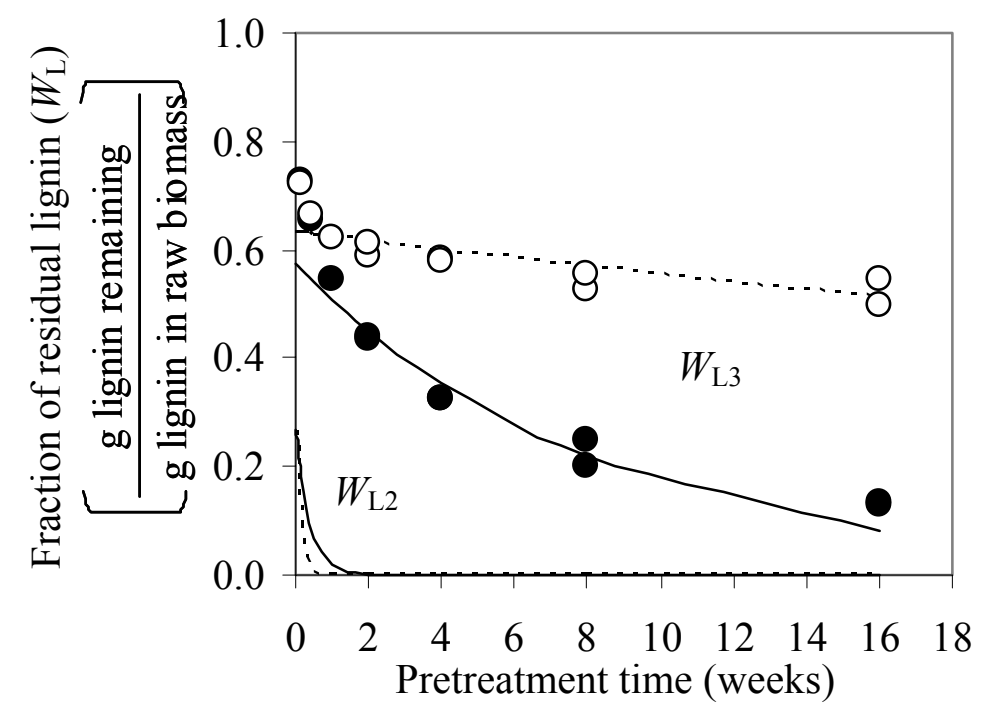

(d)

Figure 36. Continued. 
Table 16. Comparison of lignin contents of untreated corn stover in both nonoxidative and oxidative conditions without lime addition. ${ }^{1)}$

\begin{tabular}{|c|c|c|c|c|}
\hline Condition & $\begin{array}{c}\text { Temperature } \\
\left({ }^{\circ} \mathrm{C}\right)\end{array}$ & $\begin{array}{c}\text { Klason lignin } \\
\text { (g Klason } \\
\text { lignin/100 } \mathrm{g} \\
\text { treated } \\
\text { biomass })\end{array}$ & $\begin{array}{c}\text { Acid-soluble } \\
\text { lignin } \\
\text { (g acid-soluble } \\
\text { lignin/100 } \mathrm{g} \\
\text { treated } \\
\text { biomass) }\end{array}$ & $\begin{array}{c}\text { Total lignin } \\
\text { content } \\
\text { (g lignin/100 } \mathrm{g} \\
\text { treated } \\
\text { biomass) }\end{array}$ \\
\hline \multirow{2}{*}{$\begin{array}{c}\text { Non- } \\
\text { oxidative }\end{array}$} & 25 & 19.34 & 2.00 & 21.34 \\
\cline { 2 - 5 } Oxidative & 55 & 19.90 & 1.64 & 21.54 \\
\cline { 2 - 5 } & 55 & 19.27 & 2.01 & 21.28 \\
\hline Control $^{2)}$ & - & 18.72 & 1.55 & 20.27 \\
\hline Raw $^{3)}$ & - & 19.50 & 2.49 & 21.00 \\
\hline
\end{tabular}

1) The first batch of corn stover was used and the operation time was 10 weeks.

2) The first batch of untreated washed only corn stover.

3) Raw corn stover untreated. 
decreased from $19.62 \pm 0.29$ to $4.7 \pm 0.25 \mathrm{~g}$ Klason lignin $/ 100 \mathrm{~g}$ treated biomass in the oxidative lime pretreatment but only $12.95 \pm 0.49 \mathrm{~g}$ Klason lignin/100 g treated biomass in the non-oxidative pretreatment.

The delignification selectivity is more enhanced due to the oxidative lime pretreatment.

The delignification kinetic model for corn stover was empirically established as the two finite terms of the first-order reaction corresponding to the bulk and residual phases of delignification in both non-oxidative and oxidative lime pretreatments from 25 to $55^{\circ} \mathrm{C}$. In the beginning of lime pretreatment, the lignin of the initial phase was easily removed. As temperature increased, the time period and the portion of delignification in the bulk phase decreased. Also, the rate of delignification in the residual phase increased more rapidly in the oxidative condition.

The activation energies for delignification reactions were estimated as 50.15 and $54.21 \mathrm{~kJ} / \mathrm{mol}$ in the bulk and residual phases, respectively, in the oxidative lime pretreatment, which are similar to the kraft delignification of bagasse and much less than in kraft delignifications of wood.

Without lime, temperature and aeration did not delignify corn stover.

\subsection{Enzymatic Hydrolysis}

\section{Introduction}

The cellulose and hemicellulose in lime-treated biomass are more digestible than in untreated biomass (Chang et al. 2000 and Kaar et al. 2000). The enzymatic digestibility of biomass is affected by the pretreatment methods (e.g., acid and alkaline treatments) and the structural modification of the biomass (e.g., lignin content, acetyl group content, and crystallinity). Delignification, deacetylation, and decrystallization of lignocellulosic biomass are correlated with surface area or accessibility of cellulase enzymes to cellulose and hemicellulose in the fiber matrix. 
In previous studies on lime pretreatment, the pretreatment conditions were optimized for different types of lignocellulosic materials on the basis of 3-d enzyme digestibility; $120^{\circ} \mathrm{C}$ for $1 \mathrm{~h}$ on bagasse (Chang et al. 1998), $100-120^{\circ} \mathrm{C}$ for $2 \mathrm{~h}$ on switchgrass (Chang et al. 1997), and $120^{\circ} \mathrm{C}$ for $4 \mathrm{~h}$ on corn stover (Kaar et al. 2000) in non-oxidative lime treatment, whereas 14 bar absolute oxygen at $150^{\circ} \mathrm{C}$ for $6 \mathrm{~h}$ on poplar wood and 7.1 bar absolute oxygen at $140^{\circ} \mathrm{C}$ for $3 \mathrm{~h}$ on newspaper (Chang et al. 2001) in oxidative lime treatment. Most cases were optimized in high temperature ranges (100 $150^{\circ} \mathrm{C}$ ) and pure oxygen was used for the oxidative treatment. Klinke et al. (2002) reported that cellulose in wheat straw is efficiently recovered in the solid fraction (96\%) and enzymatically converted to glucose in high yield (67\%) in alkaline wet oxidation pretreatment, e.g., $195^{\circ} \mathrm{C}, 10 \mathrm{~min}, 12$ bar oxygen and $6.5 \mathrm{~g} / \mathrm{L}$ of $\mathrm{Na}_{2} \mathrm{CO}_{3}$.

In this study, corn stover was pretreated with lime in non-oxidative and oxidative conditions at lower temperature ranges $\left(25-55^{\circ} \mathrm{C}\right)$ for a long term (up to 4 months). The efficiency of enzymatic hydrolysis should be evaluated to determine the optimal condition for corn stover treated with this new method.

\section{Materials and Methods}

Substrates for the enzyme reaction were the untreated washed-only, the nonoxidatively lime-treated, and the oxidatively lime-treated corn stovers. The untreated washed-only corn stover was used as the control for comparing the enzymatic digestibility of the treated corn stovers. The substrate (cellulose) concentration was 10 g/L. Cellulase enzyme (Spezyme CP, Lot 301-00348-257) was kindly provided by NREL. $\beta$-Glucosidase (Novozyme 188, $250 \mathrm{CBU} / \mathrm{g}$ of activity) was added to completely convert cellobiose to glucose, i.e., $40 \mathrm{CBU} / \mathrm{g}$ cellulose. Cellulase was added at the specific loading rates, FPU per unit mass of biomass (i.e., 0, 2, 10, 20, 40, and 120 FPU/g cellulose), as described in Appendix E, "Enzymatic hydrolysis", and its activity was periodically determined by the filter paper unit per $\mathrm{mL}$ as described in the NREL standard procedure No. 06, "Measurements of cellulase activities." Citrate buffer (1.0 M, 
$\mathrm{pH}$ 4.8) and sodium azide solution ( $(\mathrm{w} / \mathrm{w}) \%$ ) were used to keep constant $\mathrm{pH}$ and prevent microbial contamination, respectively.

The concentration of sugars (glucose and xylose) was determined by the DNS method in Appendix F and the HPLC method using Aminex HPX-87P column (BioRad, U.S.A.) and RI detector (RefractoMonitor ${ }^{\circledR}$ III, Model 1109, LDC/MiltonRoy, U.S.A.). The sugar concentration determined by the DNS method was reported as the equivalent amounts of reducing sugar (glucose) per unit biomass. The operating conditions for HPLC analysis are described in Appendix H, "Determination of carbohydrates in biomass."

\section{Results and Discussions}

\section{Enzymatic Hydrolysis of Untreated Washed only Corn Stover}

Sugar yields increased rapidly at the beginning of enzymatic hydrolysis reaction, and then leveled off to an asymptote in about $72 \mathrm{~h}$. As enzyme (cellulase) loading increased from 1 to $20 \mathrm{FPU} / \mathrm{g}$ dry biomass, the sugar yield increased rapidly and then gradually reached a maximum (Figure 37). For a given substrate and enzyme loading, the 3-d sugar yield can be used to approximate the ultimate sugar yield.

The 3-d enzyme digestibility of untreated corn stover was 114, 153, and $193 \mathrm{mg}$ equiv. glucose/g dry biomass at 1, 5, and $60 \mathrm{FPU} / \mathrm{g}$ dry biomass corresponding to 2.7, 13.3, and 160.0 FPU/g cellulose of enzyme loading, respectively. Enzyme hydrolysis profiles fit well to the following equation:

$$
Y=A \cdot \ln (X)+B
$$

where $Y=$ sugar yield (mg equivalent glucose/g dry biomass)

$X=$ cellulase loading (FPU/g dry biomass)

$A$ and $B$ are empirical constants 

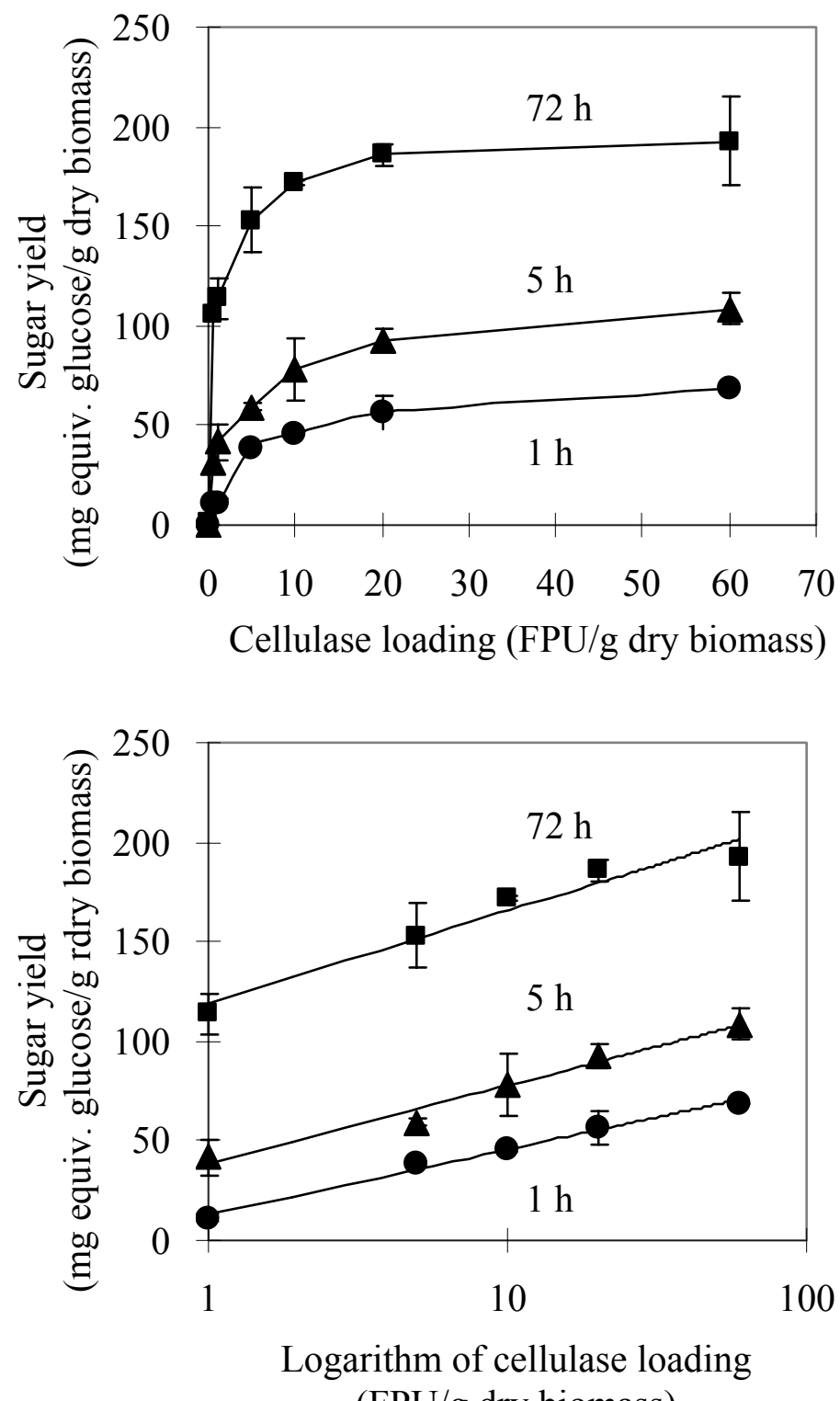

(FPU/g dry biomass)

Figure 37. Sugar yield profiles of the untreated corn stover (first batch) according to cellulase loading at the enzyme reaction times: 1,5 , and $72 \mathrm{~h}$. 
This equation is identical to the simplified model equation derived from the assumption of high enzyme loading in the HCH-1 model (Holtzapple et al. 1984 and 1994):

$$
-\frac{d G}{d t}=\frac{\kappa G E i}{\alpha+\phi G+\varepsilon E}
$$

where $G=$ cellulose concentration

$E=$ enzyme concentration

$\kappa, \alpha$, and $\varepsilon=$ parameters describing the degree of substrate reactivity

$\phi=$ fraction of cellulose sites that are free $(\phi \cong 1)$

$i=$ inhibition parameter $(i \rightarrow 1$ at high activity of cellobiase $)$

Generally, the linear plot of Equation 11 shifts upward as $i \rightarrow 1$.

\section{Enzymatic Hydrolysis of the Treated Corn Stover}

The enzymatic digestibility of corn stover increased dramatically due to lime pretreatment. It also depended on temperature, time, and the presence of oxygen.

During the 16-week non-oxidative lime pretreatment, the 3-d enzyme digestibility increased 3-fold higher than of the untreated corn stover over the entire range of cellulase concentration (Figure 38). Without air, the $3-\mathrm{d}$ sugar yield at $55^{\circ} \mathrm{C}$ was only $9.0 \pm 1.6$ (mg equiv. glucose $/ g$ raw biomass) higher than at $25^{\circ} \mathrm{C}$. For non-oxidative lime pretreatment, the temperature effect on enzyme digestibility of corn stover was not very significant.

Usually the 3-d enzyme digestibility increased dramatically for the first few weeks of pretreatment and increased slowly for the remaining treatment time. Interestingly, after a 4-week lime pretreatment, the 3-d enzyme digestibility of nonoxidatively lime treated corn stover at $25^{\circ} \mathrm{C}$ reached ca. $80 \%$ and $90 \%$ of the final (15 week) sugar yield (mg equiv. glucose/g raw biomass) at 2.1 and $125.6 \mathrm{FPU} / \mathrm{g}$ cellulose of cellulase loadings, respectively (Figure 39). Similar trends were observed at different temperatures and also in the oxidative pretreatments. 


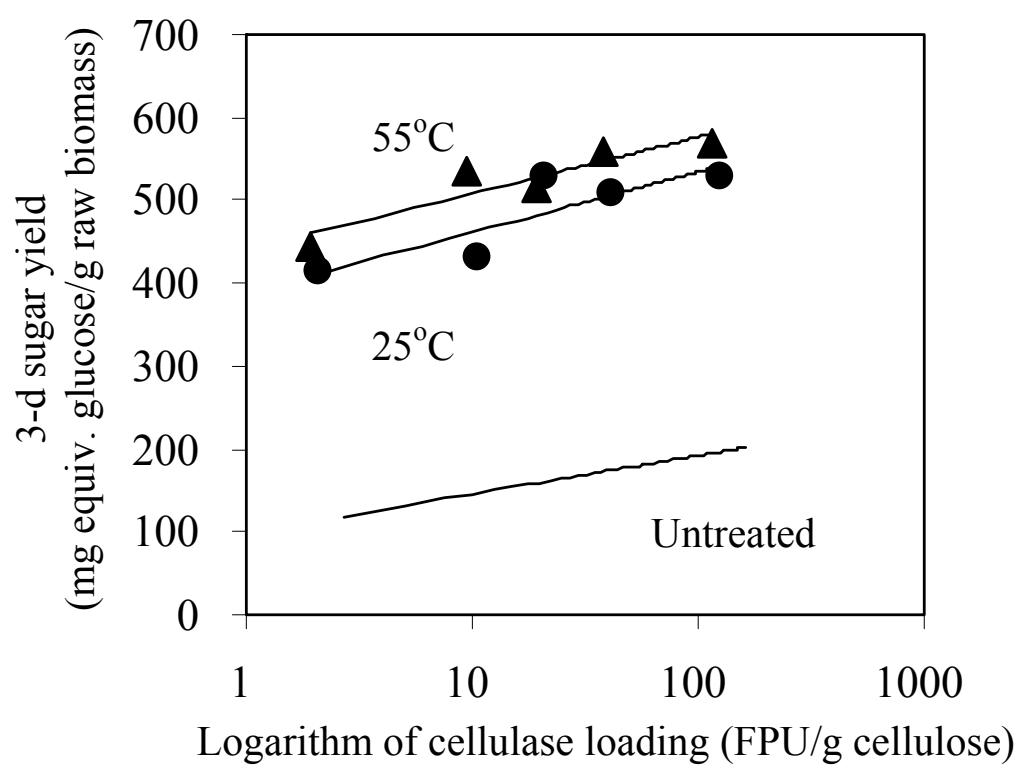

Figure 38. 3-d sugar yields of the treated corn stover in nonoxidative condition for 16 weeks at 25 and $55^{\circ} \mathrm{C}$.

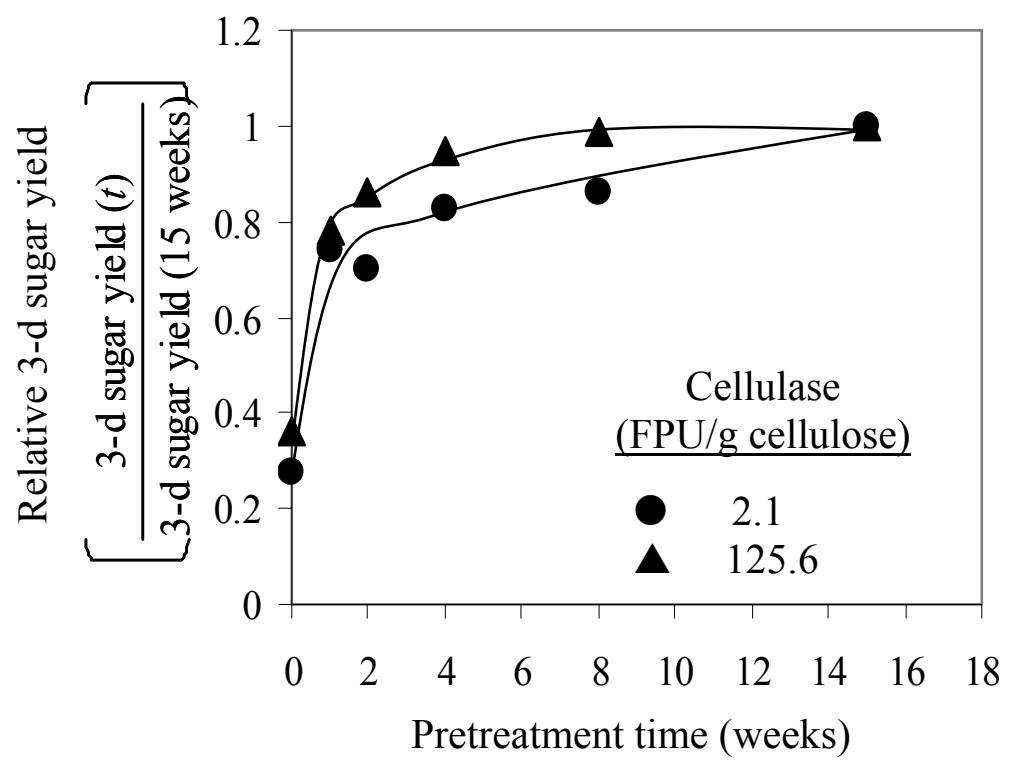

Figure 39. Relative 3-d sugar yields of the treated corn stover in non-oxidative condition for 15 weeks at $25^{\circ} \mathrm{C}$. 
The enzymatic digestibility of corn stover can be significantly improved by oxidative lime pretreatment. Aeration was more effective on 3-d enzyme digestibility at higher temperature, $55^{\circ} \mathrm{C}$, as shown in Figure 40 .

Due to delignification, deacetylation, and solubilization of extractive components, the compositions of the treated biomass differ from the original compositions. The compositional changes depend on pretreatment time, temperature, lime, and oxidation condition, as described in Section 3.3.

Enzymatic hydrolysis was performed for the samples to determine the conversion yields of cellulose and hemicellulose to glucose and xylose respectively, using enzyme loading of 15 and $60 \mathrm{FPU} / \mathrm{g}$ cellulose.

\section{Hydrolysis Yields of Cellulose/Hemicellulose to Glucose/Xylose}

Cellulose and hemicellulose are hydrolyzed by the action of enzymes as follows:

$$
\begin{array}{cc}
{\left[\mathrm{C}_{6} \mathrm{H}_{10} \mathrm{O}_{5}\right]_{n}+n \cdot \mathrm{H}_{2} \mathrm{O} \rightarrow} & n \cdot \mathrm{C}_{6} \mathrm{H}_{12} \mathrm{O}_{6} \\
\text { Cellulose } & \text { Glucose } \\
M w 162.2 & M w 180.2 \\
& \\
{\left[\mathrm{C}_{5} \mathrm{H}_{8} \mathrm{O}_{4}\right]_{n}+n \cdot \mathrm{H}_{2} \mathrm{O} \rightarrow} & n \cdot \mathrm{C}_{5} \mathrm{H}_{10} \mathrm{O}_{5} \\
\text { Hemicellulose } & \text { Xylose } \\
M w 132.1 & M w 150.1
\end{array}
$$

Therefore, the hydrolysis yield from cellulose to glucose $\left(Y_{\mathrm{g}}\right)$ and from hemicellulose to xylose $\left(Y_{\mathrm{x}}\right)$ can be determined by the following equations, respectively:

$$
\begin{aligned}
\text { Hydrolysis yield for glucose }\left(Y_{\mathrm{g}}\right) & =\left[\frac{\mathrm{g} \text { glucose }}{\mathrm{g} \text { cellulose }}\right] \times\left[\frac{162.2}{180.2}\right] \\
& =\frac{\mathrm{g} \text { of cellulose hydrolyzed }}{\mathrm{g} \text { of cellulose in the pretreated biomass }}
\end{aligned}
$$




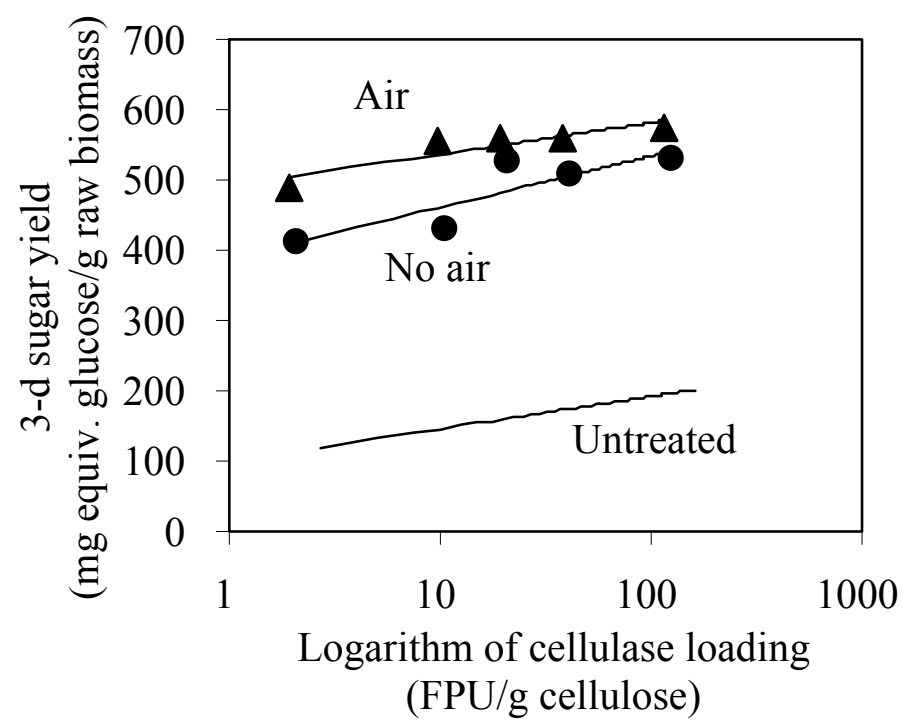

(a)

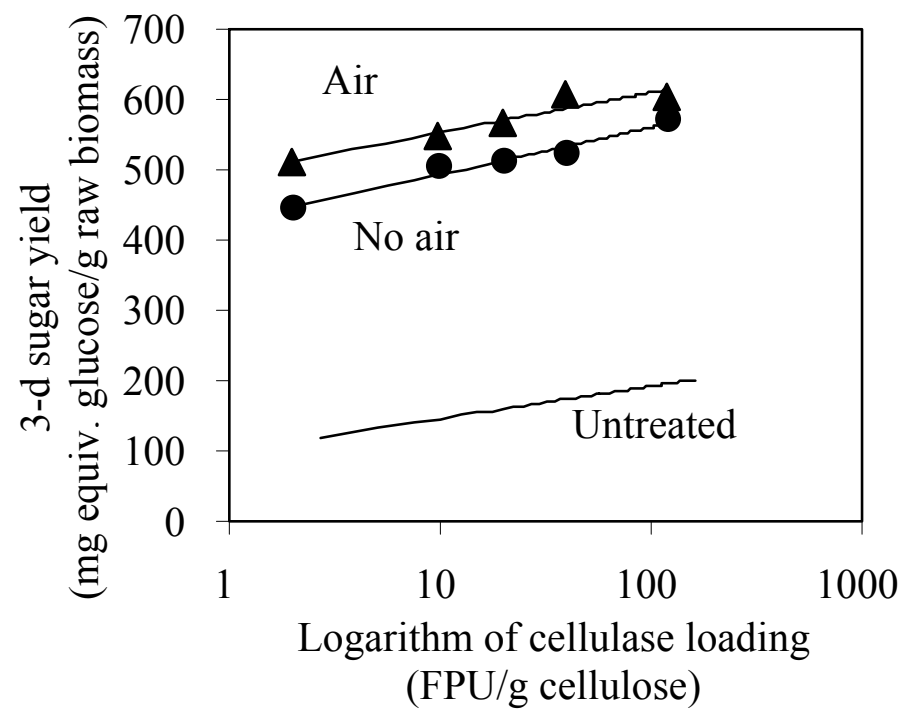

(b)

Figure 40. Aeration effect on 3-d sugar yields of the treated corn stover at (a) 25 , (b) 35 , (c) 45 , and (d) $55^{\circ} \mathrm{C}$ after 16-week pretreatment with lime. 


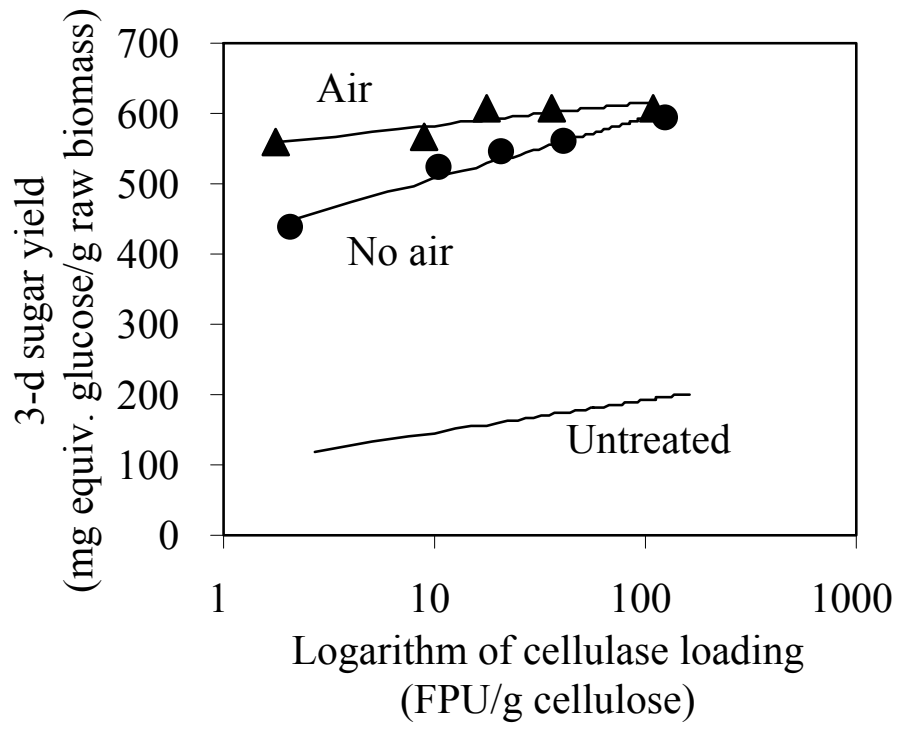

(c)

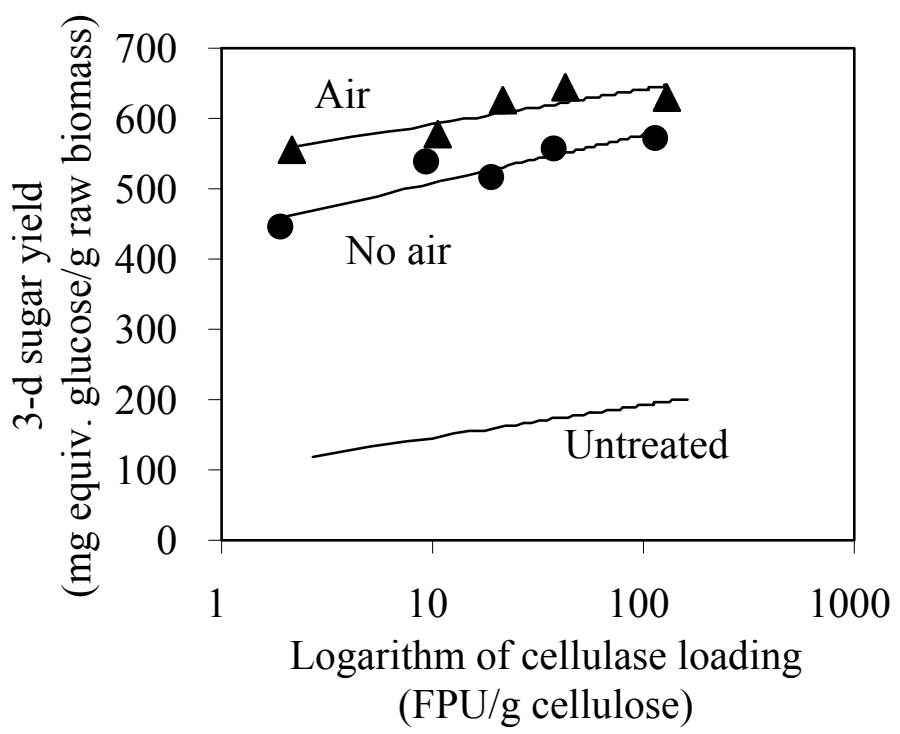

(d)

Figure 40. Continued. 
$\begin{aligned} \text { Hydrolysis yield for xylose }\left(Y_{\mathrm{x}}\right) & =\left[\frac{\mathrm{g} \text { xylose }}{\mathrm{g} \text { hemicellulose }}\right] \times\left[\frac{132.1}{150.1}\right] \\ & =\frac{\mathrm{g} \text { of hemicellulose hydrolyzed }}{\mathrm{g} \text { of hemicellulose in the pretreated biomass }}\end{aligned}$

With $25^{\circ} \mathrm{C}$ non-oxidative lime pretreatment, when the enzyme loading was 15 FPU/g cellulose, the hydrolysis yield for glucose $\left(Y_{\mathrm{g}}\right.$, g glucan hydrolyzed/g glucan in treated biomass) rapidly increased from 0.26 to 0.55 within 2 weeks and slightly increased up to 0.64 for the remaining pretreatment (Figure 41 (a)). With aeration at the same condition, the profile of $Y_{\mathrm{g}}$ was not significantly different from the result with no aeration.

However, at higher temperatures (i.e., $55^{\circ} \mathrm{C}$ ), the $Y_{\mathrm{g}}$ profiles with and without aeration were significantly different, as shown in Figure 41 (d). The $Y_{\mathrm{g}}$ in the nonoxidative pretreatment reached a maximum $(0.77 \mathrm{~g}$ glucan hydrolyzed $/ \mathrm{g}$ glucan in treated biomass) after 8 weeks, whereas the oxidative pretreatment achieved more than 0.93 after 4 weeks.

At $60 \mathrm{FPU} / \mathrm{g}$ cellulose, $Y_{\mathrm{g}}$ was enhanced, but its profiles were similar to the results obtained at $15 \mathrm{FPU} / \mathrm{g}$ cellulose. When the enzyme loading was $60 \mathrm{FPU} / \mathrm{g}$ cellulose, $Y_{\mathrm{g}}$ reached $0.98 \mathrm{~g}$ glucan hydrolyzed/g glucan in treated biomass at $55^{\circ} \mathrm{C}$ in the oxidative lime pretreatment after 4 week.

On the other hand, the hydrolysis yield for xylose $\left(Y_{\mathrm{x}},\right)$ rapidly increased within a few weeks in the same manner as $Y_{\mathrm{g}}$ but the maximal values were respectively 0.76 and $0.72 \mathrm{~g}$ xylan hydrolyzed $/ \mathrm{g}$ xylan in treated biomass for the non-oxidative and oxidative pretreatment at $55^{\circ} \mathrm{C}$ for 4 weeks, when the enzyme loading was $15 \mathrm{FPU} / \mathrm{g}$ cellulose (Figure 42).

Interestingly, the ratio of glucose to xylose $(G / X, \mathrm{~g}$ glucose generated/g xylose generated) that was enzymatically hydrolyzed increased with respect to pretreatment time, temperature, and oxidation condition, as shown in Figure 43. The $G / X$ increased from 1.83 at 0 week ('untreated') to 2.31 and 2.92 in the non-oxidative and oxidative 


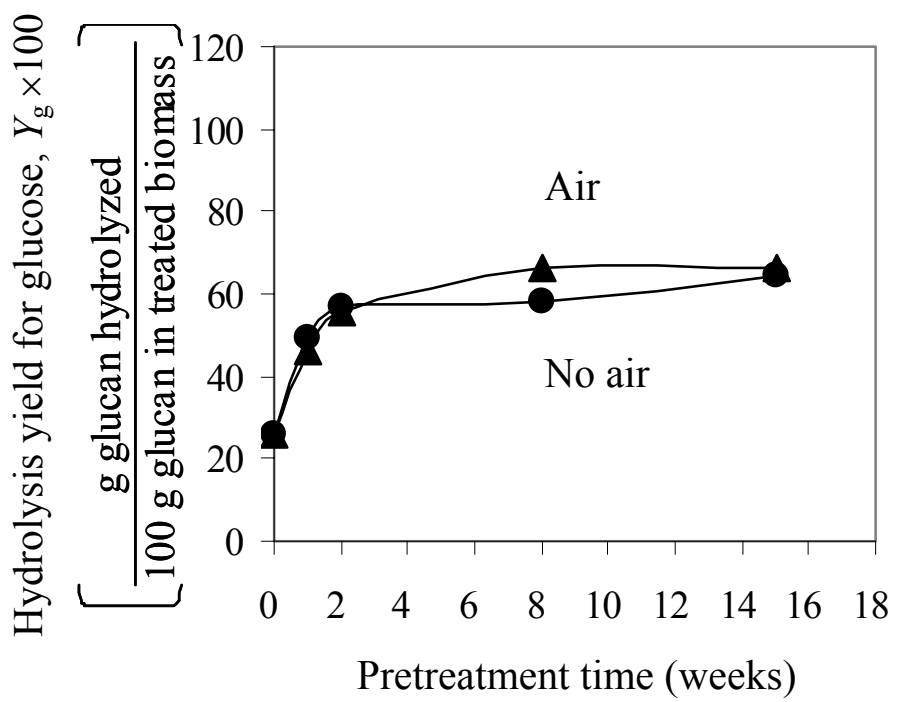

(a)

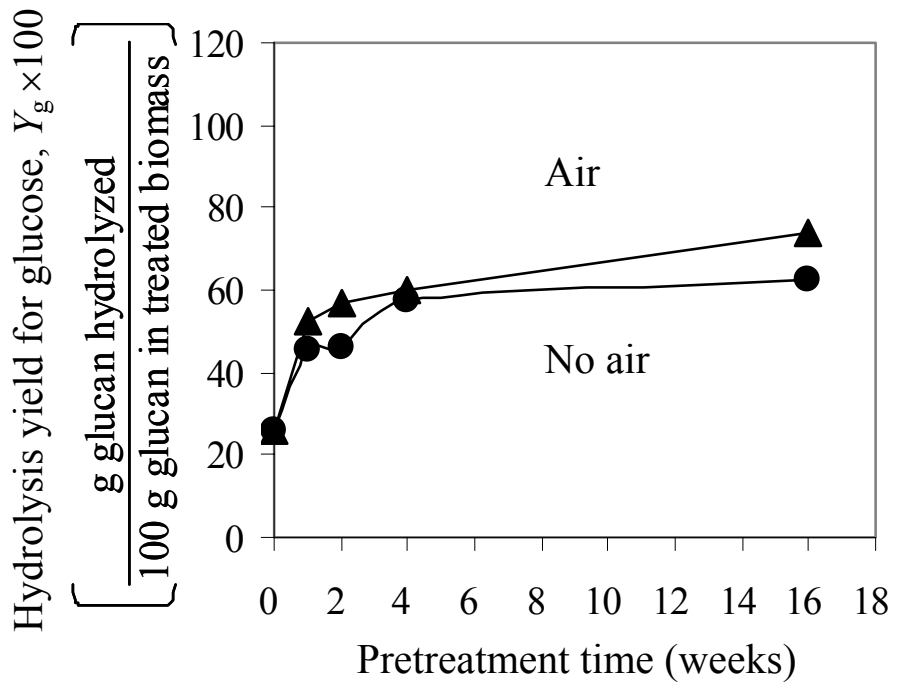

(b)

Figure 41. Hydrolysis yield from cellulose to glucose in 3-d enzyme hydrolysis of the corn stover treated with lime at (a) 25, (b) 35 , (c) 45 , and (d) $55^{\circ} \mathrm{C}$ in non-oxidative $(\mathbf{O})$ and oxidative $(\boldsymbol{A})$ conditions, when the enzyme loading is $15 \mathrm{FPU} / \mathrm{g}$ cellulose. 


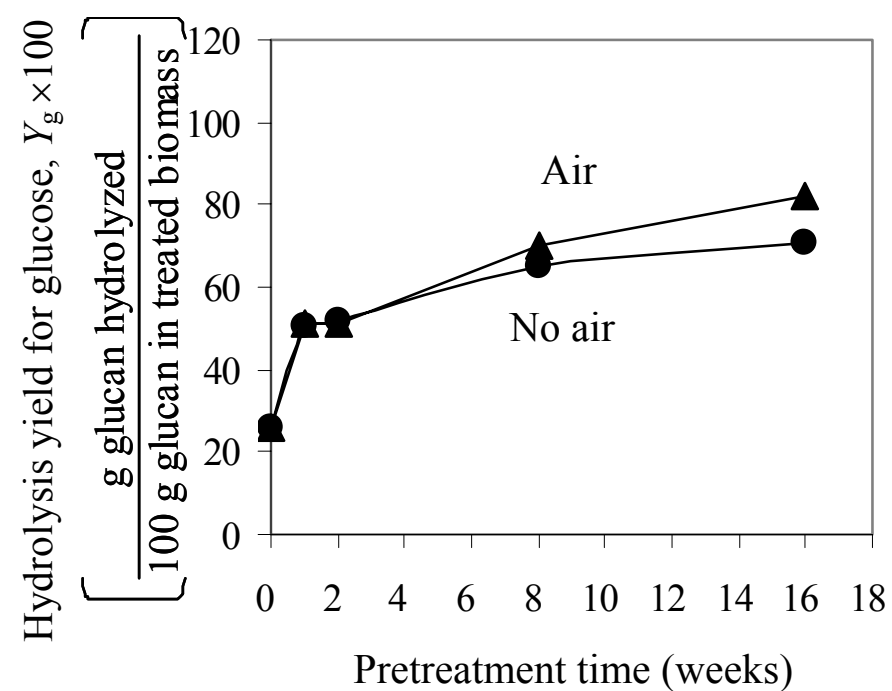

(c)

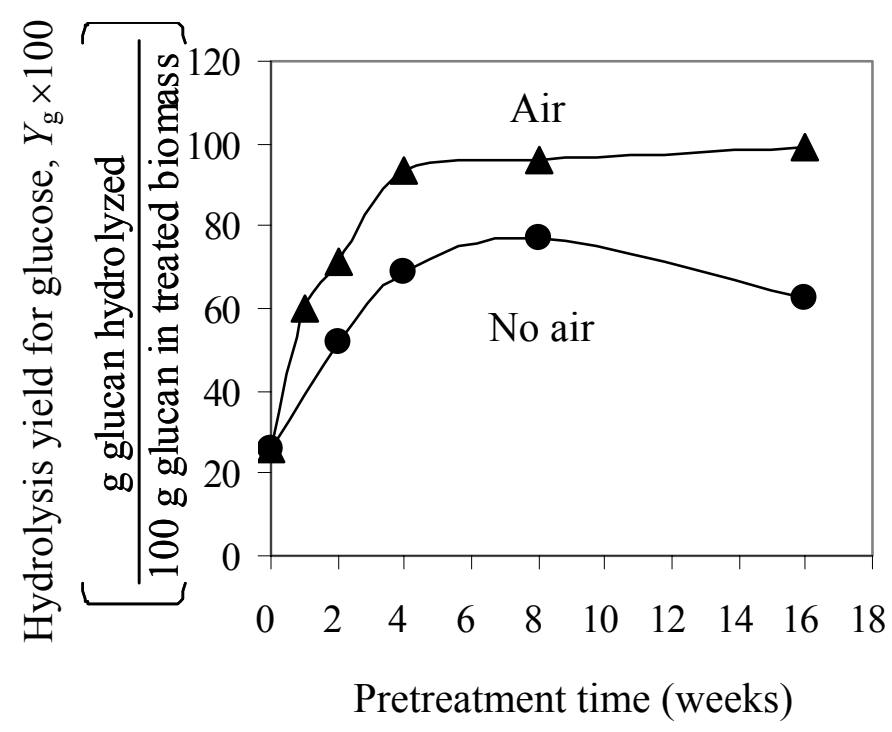

(d)

Figure 41. Continued. 


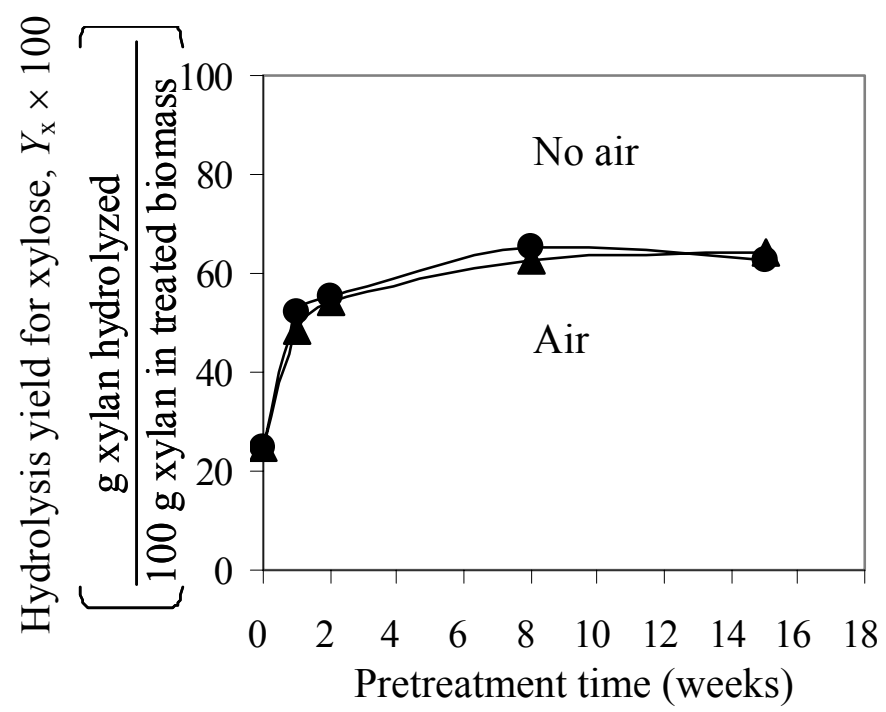

(a)

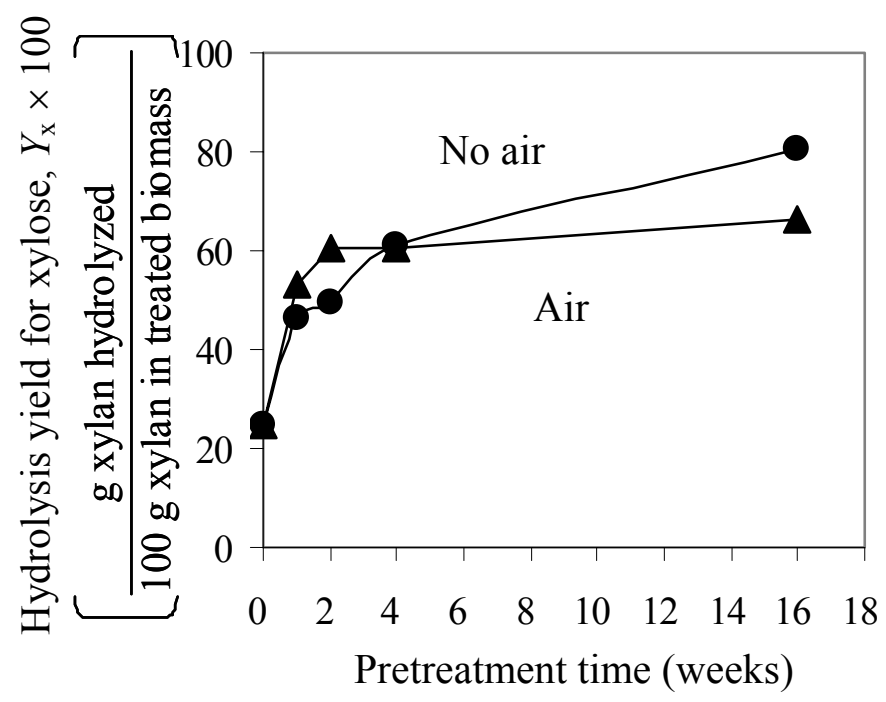

(b)

Figure 42. Hydrolysis yield from hemicellulose to xylose in 3-d enzyme hydrolysis of the corn stover treated with lime at (a) 25, (b) 35 , (c) 45 , and (d) $55^{\circ} \mathrm{C}$ in non-oxidative $(\mathbf{O})$ and oxidative $(\boldsymbol{A})$ conditions, when the enzyme loading is $15 \mathrm{FPU} / \mathrm{g}$ cellulose. 


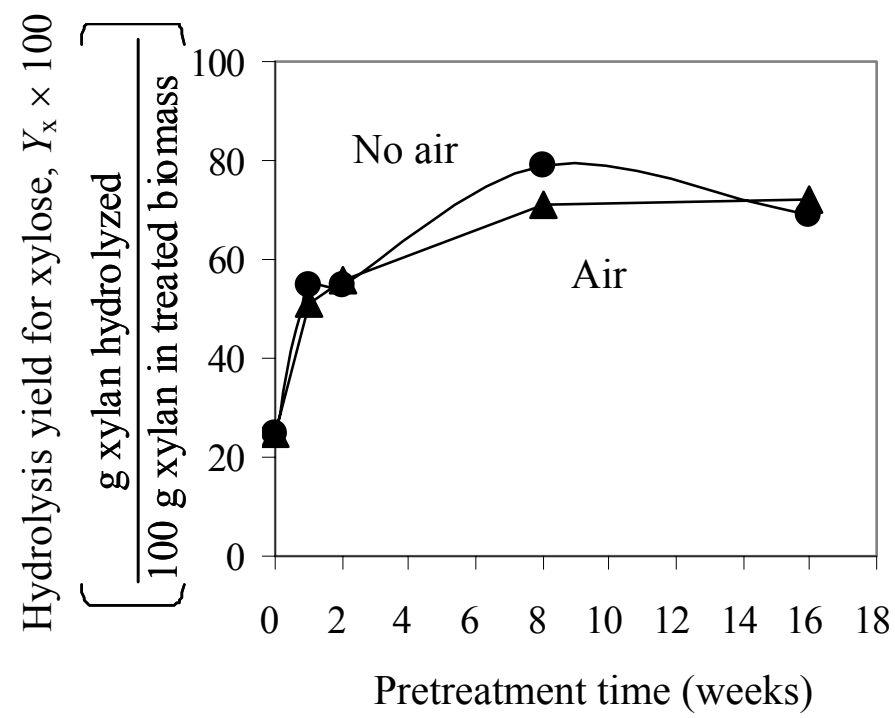

(c)

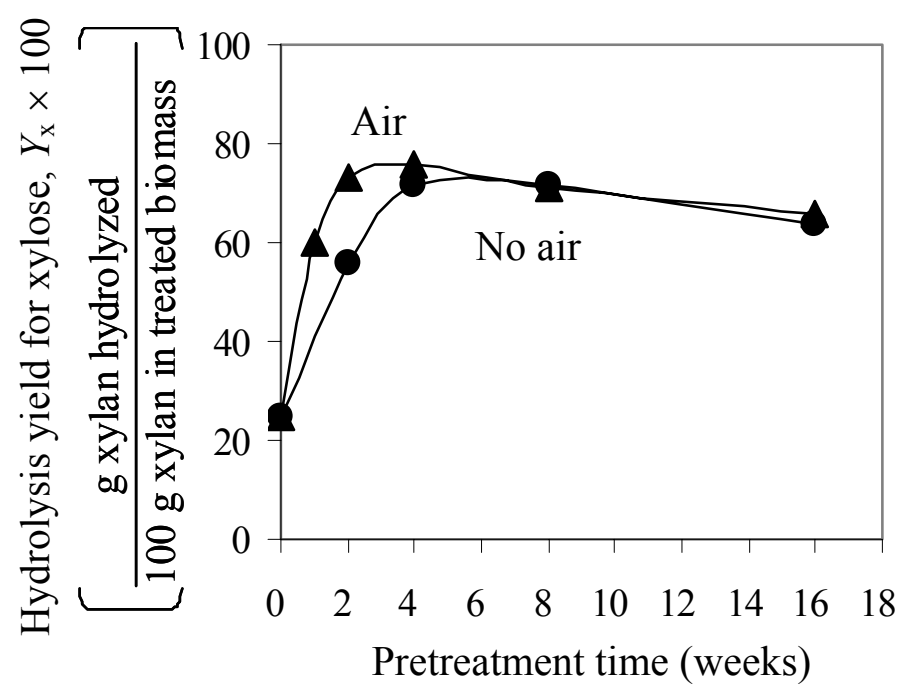

(d)

Figure 42. Continued. 


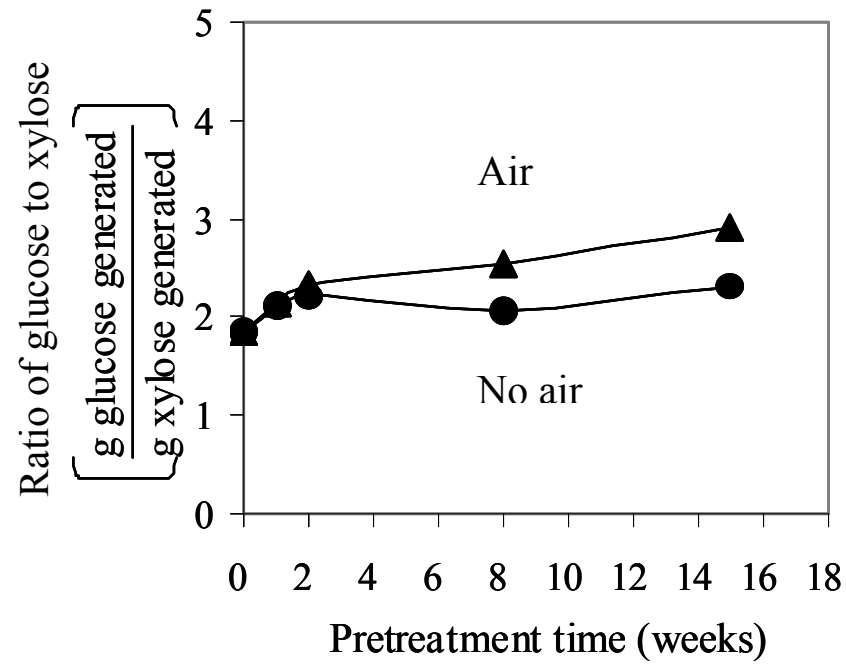

(a)

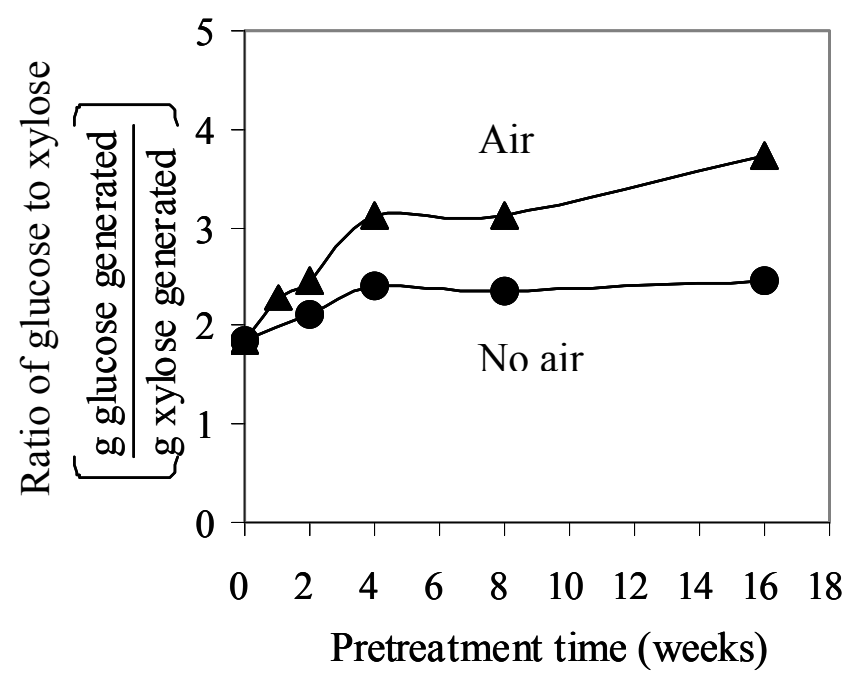

(b)

Figure 43. The ratio of glucose (g) to xylose $(\mathrm{g}), G / X$, generated in 3-d enzyme hydrolysis of the corn stover treated with lime at (a) 25 and (b) $55^{\circ} \mathrm{C}$ in non-oxidative $(\boldsymbol{O})$ and oxidative $(\boldsymbol{\Delta})$ conditions, when the enzyme loading rate is $15 \mathrm{FPU} / \mathrm{g}$ cellulose. 
pretreatment at $25^{\circ} \mathrm{C}$ for 16 weeks, respectively. The $G / X$ in non-oxidative lime pretreatment showed a relatively constant value compared with the ratio obtained from the oxidative treatment after 4 weeks. In the oxidative lime pretreatment, the $G / X$ increased as temperature increased, because xylan was more destroyed due to more extensive delignification.

At higher temperatures in the oxidative lime preteatment, cellulose is much more digestible than hemicellulose as pretreatment time elapsed.

In Table 17, the hydrolysis yields $\left(Y_{\mathrm{g}}\right.$ and $\left.Y_{\mathrm{x}}\right)$ and the $G / X$ values are summarized for the pretreatment in non-oxidative and oxidative conditions at 25 and $55^{\circ} \mathrm{C}$, respectively, when the lime-treated corn stover was hydrolyzed enzymatically using 15 FPU/g cellulose. All values of $Y_{\mathrm{g}}, Y_{\mathrm{x}}$, and $G / X$ are listed in Table N-11 - N-18 in Appendix N.

\section{Overall Yields of Glucose and Xylose}

To evaluate the optimal condition for the lime pretreatment of corn stover, overall yields of glucose $\left(Y_{\mathrm{g}}^{\mathrm{T}}\right)$ and xylose $\left(Y_{\mathrm{x}}^{\mathrm{T}}\right)$ have to be considered, because the final concentrations of mono-sugars (glucose and xylose) depend on the pretreatment yield of cellulose $\left(Y_{\mathrm{G}}\right)$ and hemicellulose $\left(Y_{\mathrm{X}}\right)$ in the lime pretreatment and also the hydrolysis yield of glucose $\left(Y_{\mathrm{g}}\right)$ and xylose $\left(Y_{\mathrm{x}}\right)$ in enzyme hydrolysis (saccharification), as shown in Figure 44.

The overall yields of cellulose and hemicellulose in raw corn stover to glucose $\left(Y_{\mathrm{g}}^{\mathrm{T}}\right)$ and xylose $\left(Y_{\mathrm{x}}^{\mathrm{T}}\right)$ in the enzyme hydrolyzate were calculated as follows:

The overall yield for glucose $\left(Y_{\mathrm{g}}^{\mathrm{T}}\right)=Y_{\mathrm{G}} \times Y_{\mathrm{g}}=\frac{\mathrm{g} \text { of glucan hydrolyzed }}{\mathrm{g} \text { of glucan in raw biomass }}$

$$
=\left[\frac{\text { g glucan recovered }(\mathrm{B})}{\text { g glucan in raw biomass }(\mathrm{A})}\right] \times\left[\frac{\mathrm{g} \text { glucose }(\mathrm{C})}{\mathrm{g} \text { glucan }(\mathrm{B})}\right] \times\left[\frac{162.2}{180.2}\right]
$$


Table 17. The hydrolysis yield of cellulose and hemicellulose to glucose $\left(Y_{\mathrm{g}}\right)$ and xylose $\left(Y_{\mathrm{x}}\right)$, and the ratio of glucose to xylose $(G / X)$ in 3-d enzymatic hydrolysis at $15 \mathrm{FPU} / \mathrm{g}$ cellulose of enzyme loading.

\begin{tabular}{|c|c|c|c|}
\hline \multicolumn{2}{|c|}{ Pretreatment temperature $\left({ }^{\circ} \mathrm{C}\right)$} & 25 & 55 \\
\hline \multicolumn{2}{|c|}{ Pretreatment time (weeks) } & 8 & 8 \\
\hline \multirow{3}{*}{ No aeration } & $Y_{\mathrm{g}}^{1)}$ & 0.58 & 0.77 \\
\hline & $Y_{\mathrm{x}}^{2)}$ & 0.65 & 0.72 \\
\hline & $G / X^{3)}$ & 2.05 & 2.38 \\
\hline \multirow{3}{*}{ Aeration } & $Y_{\mathrm{g}}$ & 0.67 & $\begin{array}{c}0.96 \\
(0.93)^{*}\end{array}$ \\
\hline & $Y_{\mathrm{x}}$ & 0.63 & $\begin{array}{c}0.71 \\
(0.76)^{*}\end{array}$ \\
\hline & $G / X$ & 2.55 & $\begin{array}{c}3.12 \\
(3.14)^{*}\end{array}$ \\
\hline
\end{tabular}

1) $Y_{\mathrm{g}}$ is hydrolysis yield of cellulose to glucose in 3-d enzymatic hydrolysis (g glucan hydrolyzed/g glucan in treated biomass)

2) $Y_{\mathrm{x}}$ is hydrolysis yield of hemicellulose to xylose in 3-d enzymatic hydrolysis (g xylan hydrolyzed/g xylan in treated biomass)

3) $G / X$ is the ratio of glucose to xylose generated in 3-d enzymatic hydrolysis (g glucose generated/g xylose generated)

* ( ): values at 4 weeks 


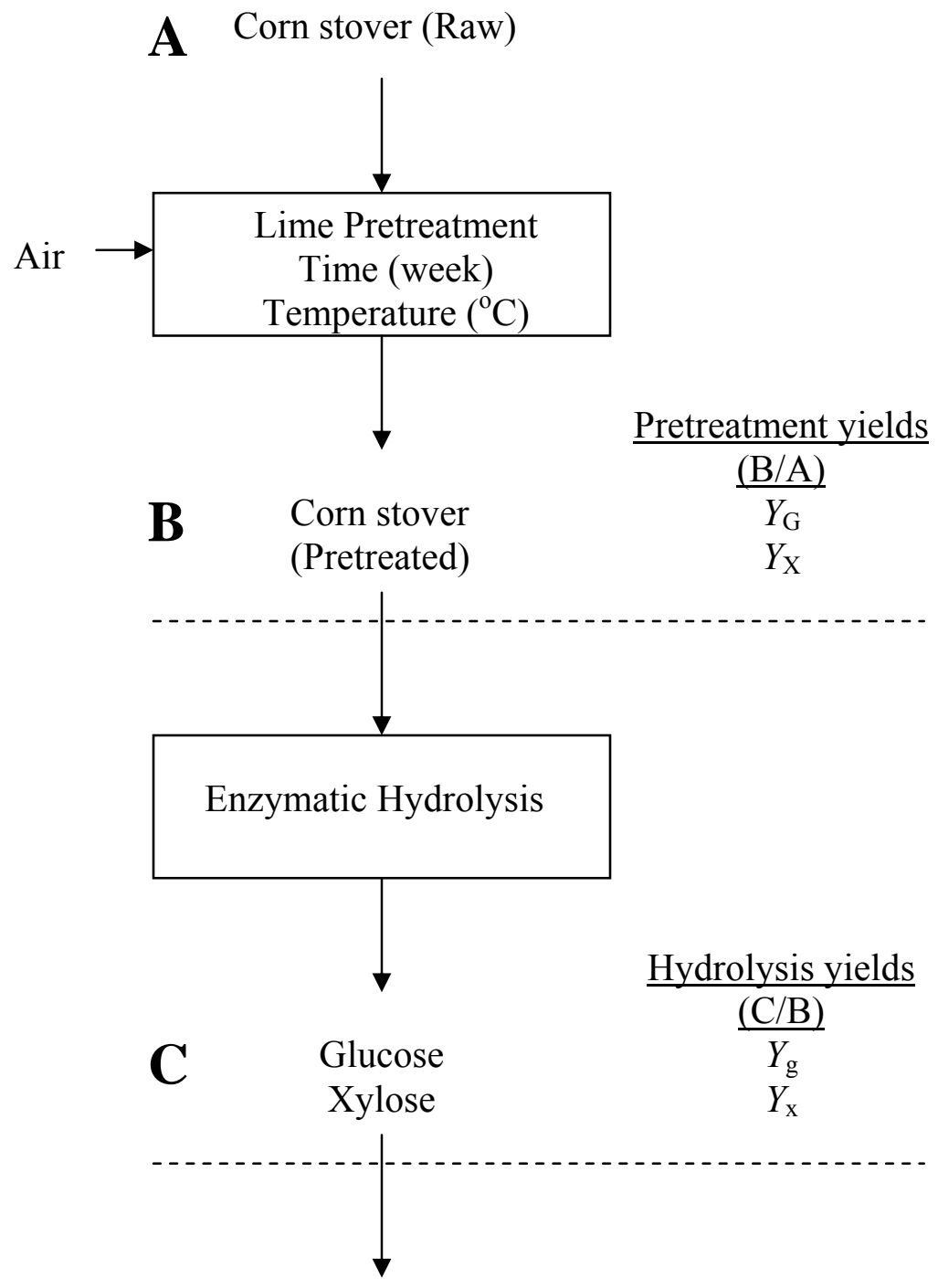

$\underline{\text { Overall yields }}$

$$
\frac{(\mathrm{C} / \mathrm{A})}{Y_{\mathrm{g}}^{\mathrm{T}}}
$$

Figure 44. Scheme to determine the sugar yields in each step for optimizing lime pretreatment conditions. 
The overall yield for xylose $\left(Y_{\mathrm{x}}^{\mathrm{T}}\right)=Y_{\mathrm{X}} \times Y_{\mathrm{x}}=\frac{\mathrm{g} \text { of xylan hydrolyzed }}{\mathrm{g} \text { of xylan in raw biomass }}$ $=\left[\frac{\mathrm{g} \text { xylan recovered }(\mathrm{B})}{\mathrm{g} \text { xylan in raw biomass }(\mathrm{A})}\right] \times\left[\frac{\mathrm{g} \text { xylose }(\mathrm{C})}{\mathrm{g} \text { xylan }(\mathrm{B})}\right] \times\left[\frac{132.1}{150.1}\right]$

As shown in Figures $45-48$, the overall yield of cellulose $\left(Y_{\mathrm{g}}^{\mathrm{T}}\right)$ increased rapidly during the first 2 weeks and gradually in the remaining period of lime pretreatment and was not significantly different between the non-oxidative and oxidative conditions below $45^{\circ} \mathrm{C}$. However, at $55^{\circ} \mathrm{C}$ for 4 weeks, $Y_{\mathrm{g}}^{\mathrm{T}}$ increased up to 0.75 and 0.91 g glucan hydrolyzed/g glucan in raw biomass in non-oxidative and oxidative lime pretreatments, respectively, at $15 \mathrm{FPU} / \mathrm{g}$ cellulose. At $55^{\circ} \mathrm{C}$ after 4 weeks, $Y_{\mathrm{g}}^{\mathrm{T}}$ tended to decrease in both pretreatments.

The overall yield of hemicellulose $\left(Y_{\mathrm{x}}^{\mathrm{T}}\right)$ was higher in the non-oxidative pretreatment than in the oxidative pretreatment. $Y_{\mathrm{x}}^{\mathrm{T}}$ was maximized around 4 weeks at $55^{\circ} \mathrm{C}$ in both non-oxidative and oxidative conditions.

In Table 18, the maximal values of $Y_{\mathrm{g}}^{\mathrm{T}}$ and $Y_{\mathrm{x}}^{\mathrm{T}}$ are summarized for each pretreatment condition, when the enzyme loading was $15 \mathrm{FPU} / \mathrm{g}$ cellulose.

When the enzyme loading was increased to $60 \mathrm{FPU} / \mathrm{g}$ cellulose, $Y_{\mathrm{g}}^{\mathrm{T}}$ (g glucan hydrolyzed/g glucan in raw biomass) and $Y_{\mathrm{x}}^{\mathrm{T}}(\mathrm{g}$ xylan hydrolyzed/g xylan in raw biomass) at the optimal condition $\left(55^{\circ} \mathrm{C}, 4\right.$ week, and aeration) were more enhanced to 0.96 and 0.54 , respectively. At lower enzyme loadings, i.e., $2.1 \mathrm{FPU} / \mathrm{g}$ cellulose, $Y_{\mathrm{g}}^{\mathrm{T}}$ and $Y_{\mathrm{x}}^{\mathrm{T}}$ are 0.69 and 0.39 , respectively at this condition. In Figure 49, the profiles of $Y_{\mathrm{g}}^{\mathrm{T}}$ and $Y_{\mathrm{x}}^{\mathrm{T}}$ are compared with respect to the pretreatment time at three different enzyme loadings; 2.1, 15, and $60 \mathrm{FPU} / \mathrm{g}$ cellulose.

At the optimal condition ( 4 weeks, $55^{\circ} \mathrm{C}$, and aeration) for lime pretreatment, the profiles of $Y_{\mathrm{g}}^{\mathrm{T}}$ and $Y_{\mathrm{x}}{ }^{\mathrm{T}}$ are compared with respect to the different enzyme loadings from 2.1 to $60 \mathrm{FPU} / \mathrm{g}$ cellulose (Figure 50 ). 


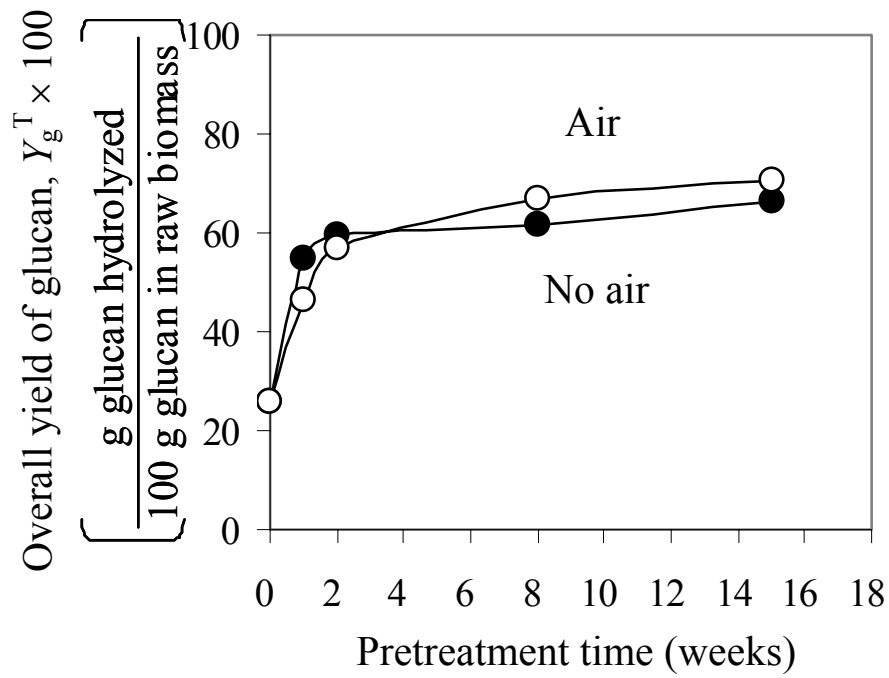

(a)

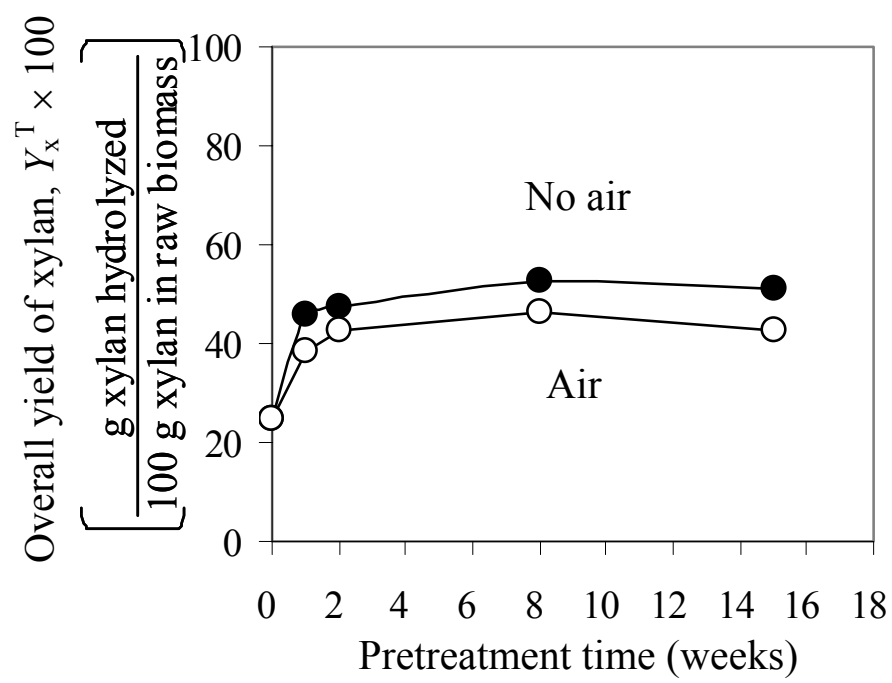

(b)

Figure 45. Overall yields of glucan to glucose (a) and of xylan to xylose (b) at $25^{\circ} \mathrm{C}$ in non-oxidative $(O)$ and oxidative $(O)$ pretreatments with lime, when enzyme loading was 15 FPU/g glucan. 


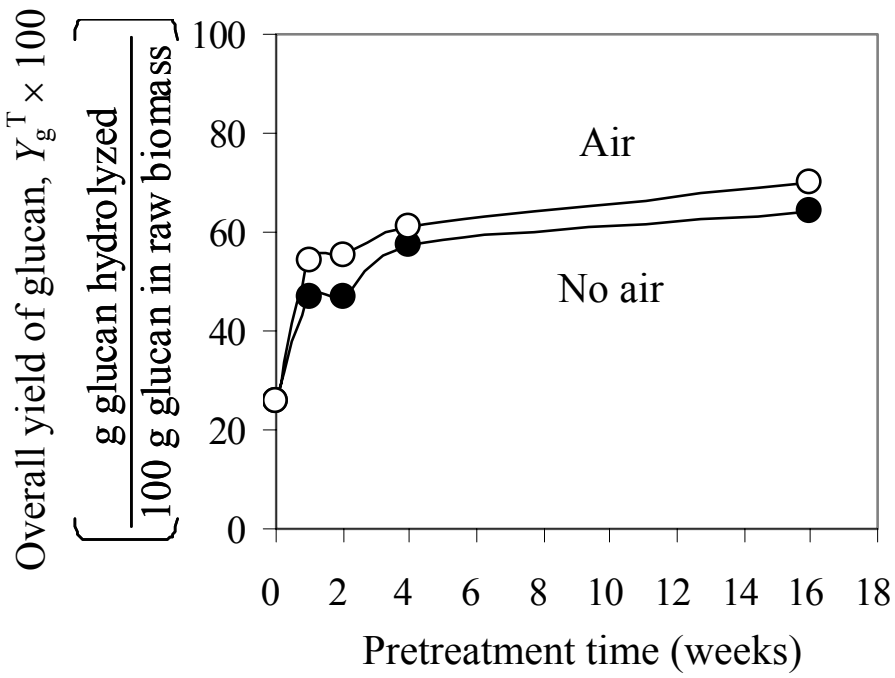

(a)

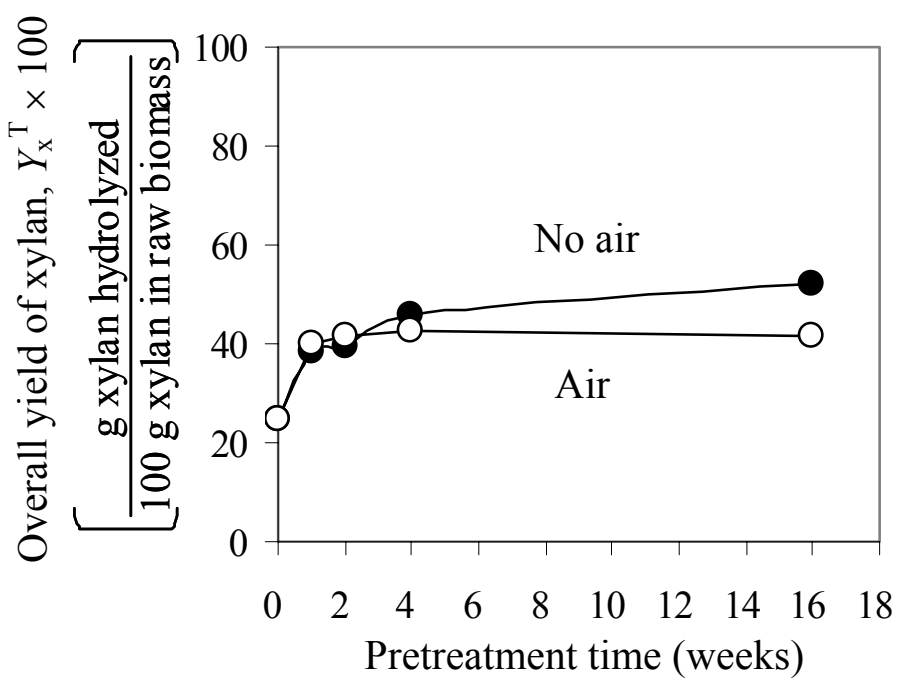

(b)

Figure 46. Overall yields of glucan to glucose (a) and of xylan to xylose (b) at $35^{\circ} \mathrm{C}$ in non-oxidative $(O)$ and oxidative $(\bigcirc)$ pretreatments with lime, when enzyme loading was 15 FPU/g glucan. 


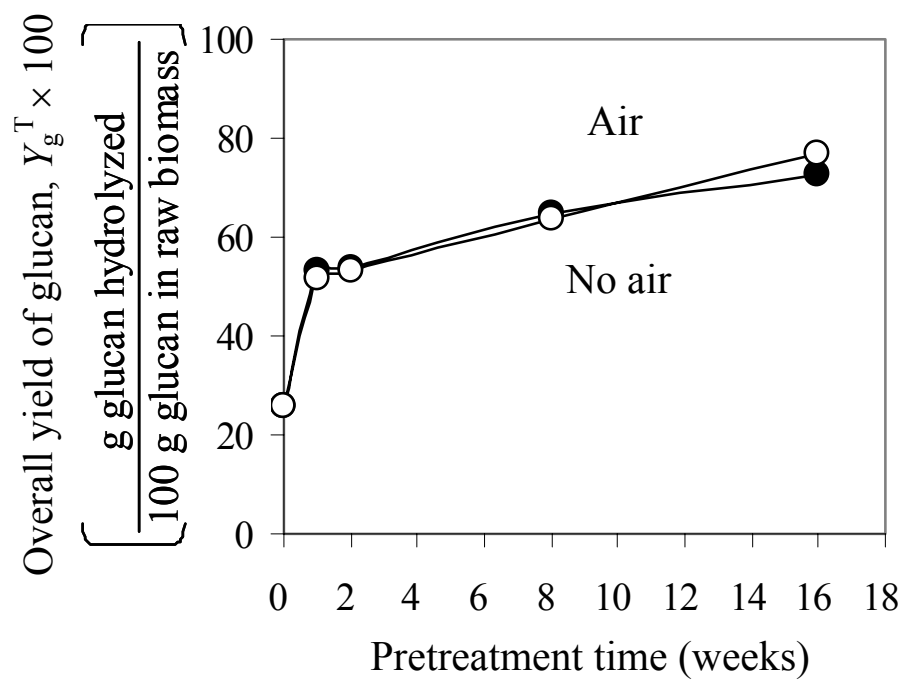

(a)

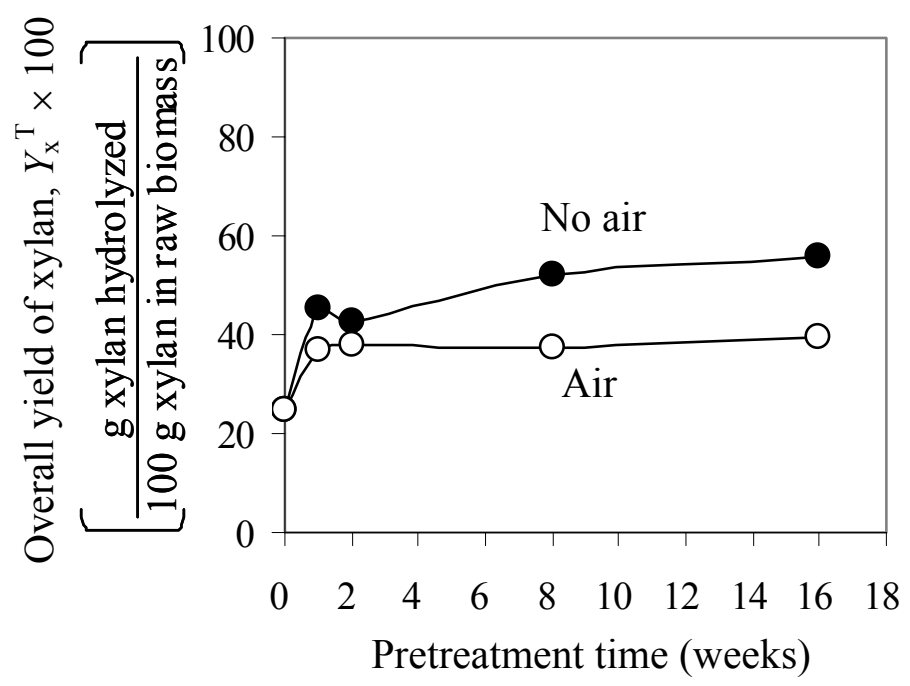

(b)

Figure 47. Overall yields of glucan to glucose (a) and of xylan to xylose (b) at $45^{\circ} \mathrm{C}$ in non-oxidative $(O)$ and oxidative $(O)$ pretreatments with lime, when enzyme loading was 15 FPU/g glucan. 


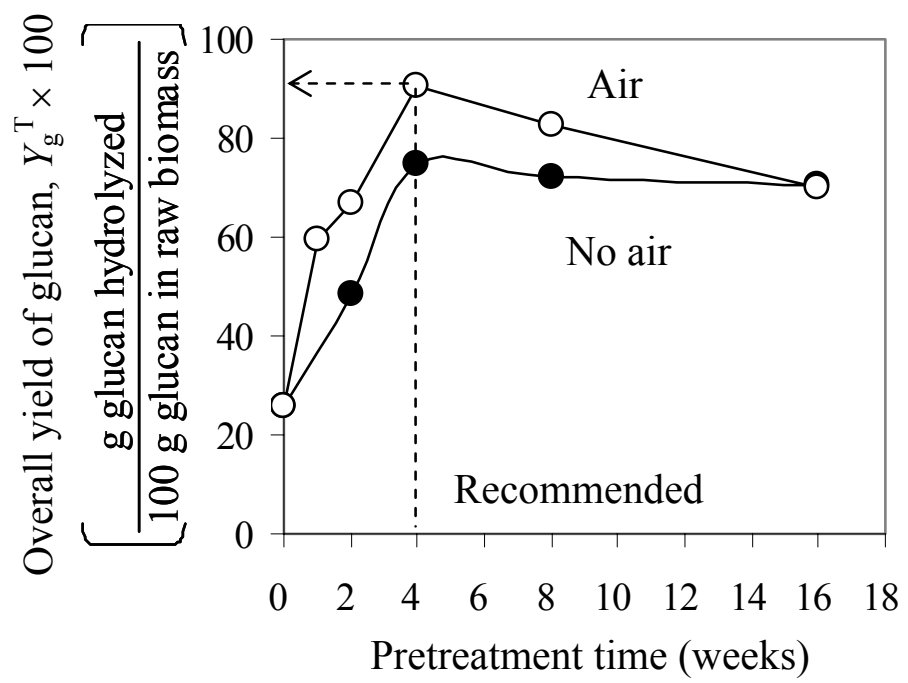

(a)

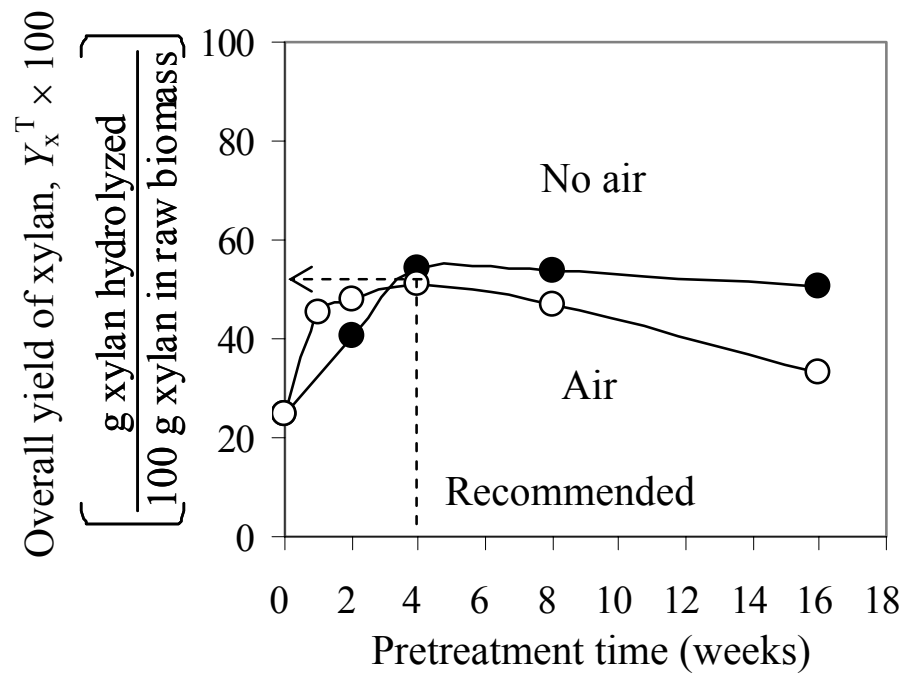

(b)

Figure 48. Overall yields of glucan to glucose (a) and of xylan to xylose (b) at $55^{\circ} \mathrm{C}$ in non-oxidative $(O)$ and oxidative $(O)$ pretreatments with lime, when enzyme loading was 15 FPU/g glucan. 
Table 18. The maximal overall yields of glucose $\left(Y_{\mathrm{g}}^{\mathrm{T}}, \mathrm{g}\right.$ glucan hydrolyzed/g glucan in raw biomass) and xylose $\left(Y_{\mathrm{x}}^{\mathrm{T}}\right.$, g xylan hydrolyzed/g xylan in raw biomass) for each pretreatment with lime, when the enzyme loading is 15 FPU/g cellulose.

\begin{tabular}{|c|c|c|c|c|}
\hline Pretreatment & \multicolumn{2}{|c|}{ Non-oxidative } & \multicolumn{2}{|c|}{ Oxidative } \\
\hline $\begin{array}{c}\text { Temperature } \\
\left({ }^{\circ} \mathrm{C}\right)\end{array}$ & $Y_{\mathrm{g}}^{\mathrm{T}}$ & $Y_{\mathrm{x}}^{\mathrm{T}}$ & $Y_{\mathrm{g}}^{\mathrm{T}}$ & $Y_{\mathrm{x}}^{\mathrm{T}}$ \\
\hline \multirow{2}{*}{25} & 0.67 & 0.53 & 0.70 & 0.46 \\
& $(16)^{*}$ & $(8)$ & $(16)$ & $(8)$ \\
\hline \multirow{2}{*}{35} & 0.64 & 0.52 & 0.70 & 0.43 \\
& $(16)$ & $(16)$ & $(16)$ & $(8)$ \\
\hline \multirow{2}{*}{45} & 0.73 & 0.56 & 0.77 & 0.39 \\
& $(16)$ & $(16)$ & $(16)$ & $(8)$ \\
\hline 55 & 0.75 & 0.54 & 0.91 & 0.51 \\
& $(4)$ & $(4)$ & $(4)$ & $(4)$ \\
\hline
\end{tabular}

* ( ): pretreatment time (weeks) 


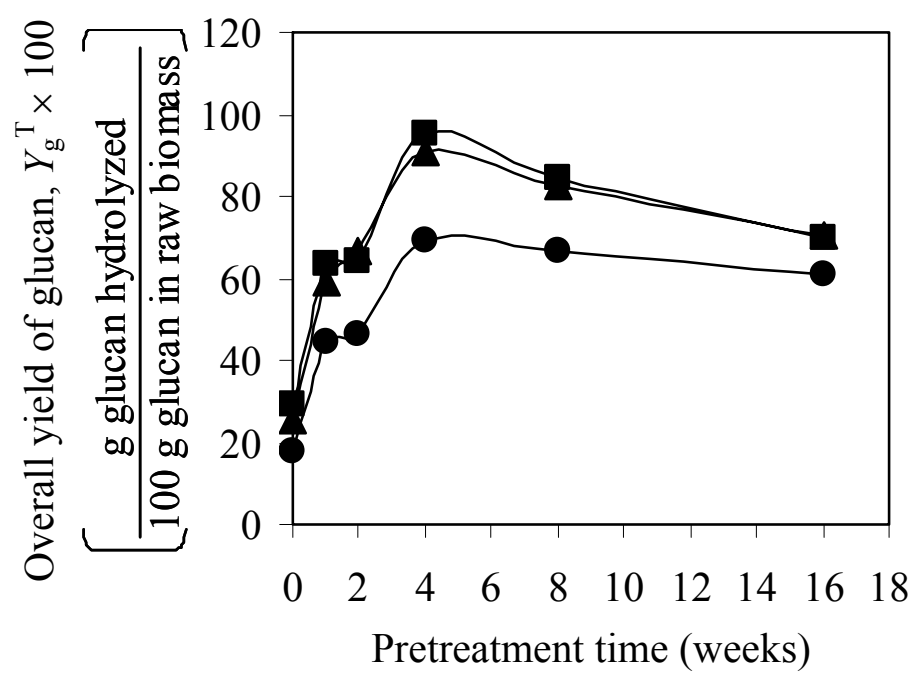

(a)

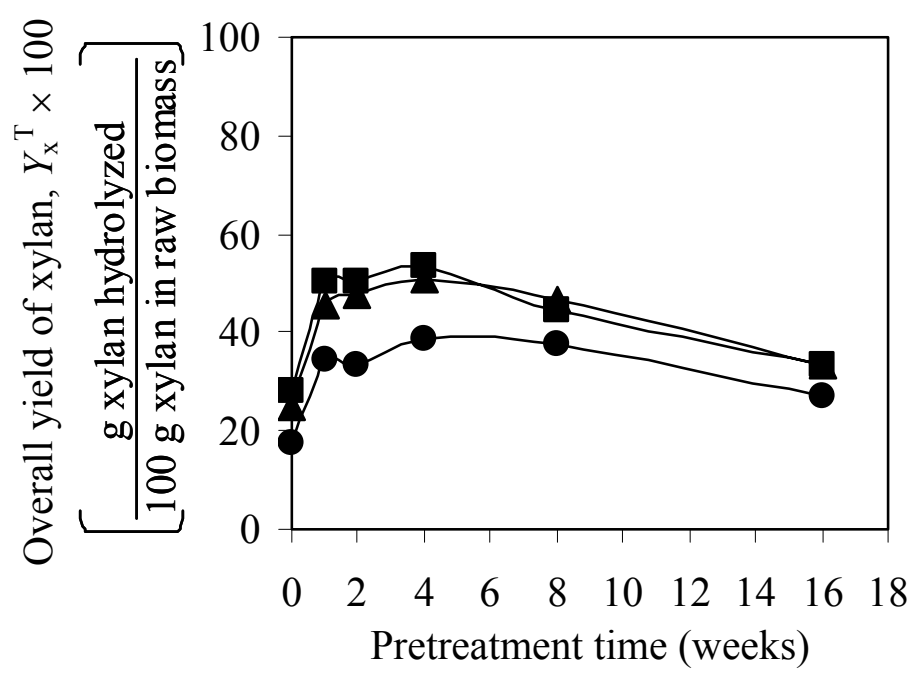

(b)

Figure 49. Overall yields for (a) glucose $\left(Y_{\mathrm{g}}^{\mathrm{T}}\right)$ and for $(\mathrm{b})$ xylose $\left(Y_{\mathrm{x}}^{\mathrm{T}}\right)$ in corn stover pretreated oxidatively with lime at $55^{\circ} \mathrm{C}$ and then enzymatically hydrolyzed at $2.1(\mathbf{O}), 15(\mathbf{\Delta}), 60(\mathbf{a})$ FPU/g cellulose of cellulase, respectively. 


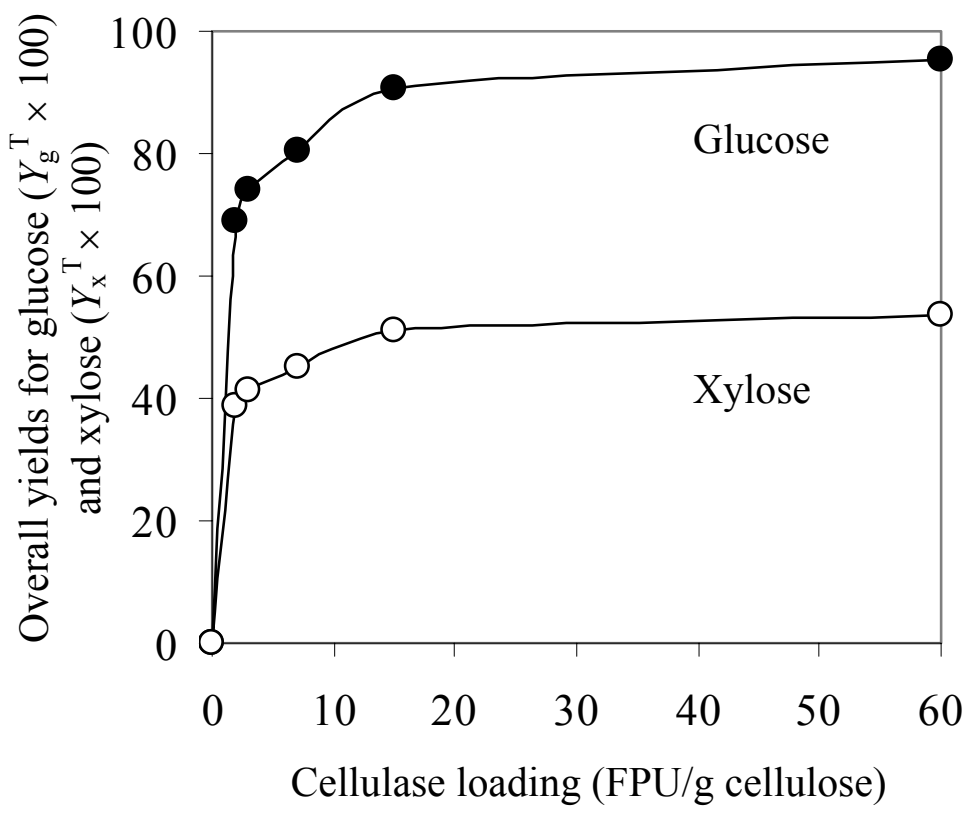

Figure 50. Overall yields for $(\bigcirc)$ glucose $\left(Y_{\mathrm{g}}^{\mathrm{T}}\right)$ and for $(\bigcirc)$ xylose $\left(Y_{\mathrm{x}}^{\mathrm{T}}\right)$ in corn stover pretreated at the optimal condition $\left(4\right.$ week, $55^{\circ} \mathrm{C}$, and aeration) and then enzymatically hydrolyzed for $3 \mathrm{~d}$. 
The conversion of xylan to xylose is relatively lower than the conversion of cellulose to glucose, and is a little higher in the non-oxidative treatment than in the oxidative treatment. Likely, the lower hemicellulose yield results from a low hemicellulase activity in the enzyme preparation; it was optimized for cellulase activity. For example, using Spezyme CP (cellulase) at $5 \mathrm{FPU} / \mathrm{g}$ xylan and $5 \mathrm{FPU} / \mathrm{g}$ cellulose, $59.0 \%$ of the initial xylan (Sigma Catalog No. X-4252, U.S.A.) was hydrolyzed whereas $81.3 \%$ of the initial $\alpha$-cellulose (Sigma Catalog No. C-8002, U.S.A.) was digested during the 96-h of enzyme hydrolysis (see Figure 51).

\section{Conclusions}

The 3-d enzyme digestibility of lime-pretreated corn stover is boosted by the presence of oxygen. Higher temperatures are more favorable because of more rapid delignification, which results in more extensive enzymatic hydrolysis.

The improvement of 3-d enzyme digestibility from non-oxidative to oxidative lime pretreatment depended on the cellulase loading; the lower the cellulase loading, the greater the improvement.

Oxidative lime pretreatment shortened the pretreatment time to reach the maximal enzymatic hydrolysis for corn stover.

The highest overall yield of holocellulose (cellulose and hemicellulose) to monosugars (glucose and xylose) can be achieved when corn stover is treated with lime at $55^{\circ} \mathrm{C}$ for 4 weeks in oxidative conditions, which is the recommended treatment condition.

As temperature increased, the overall yield for glucose proportionally increased. The oxidative pretreatment enhanced the conversion of cellulose to glucose. 


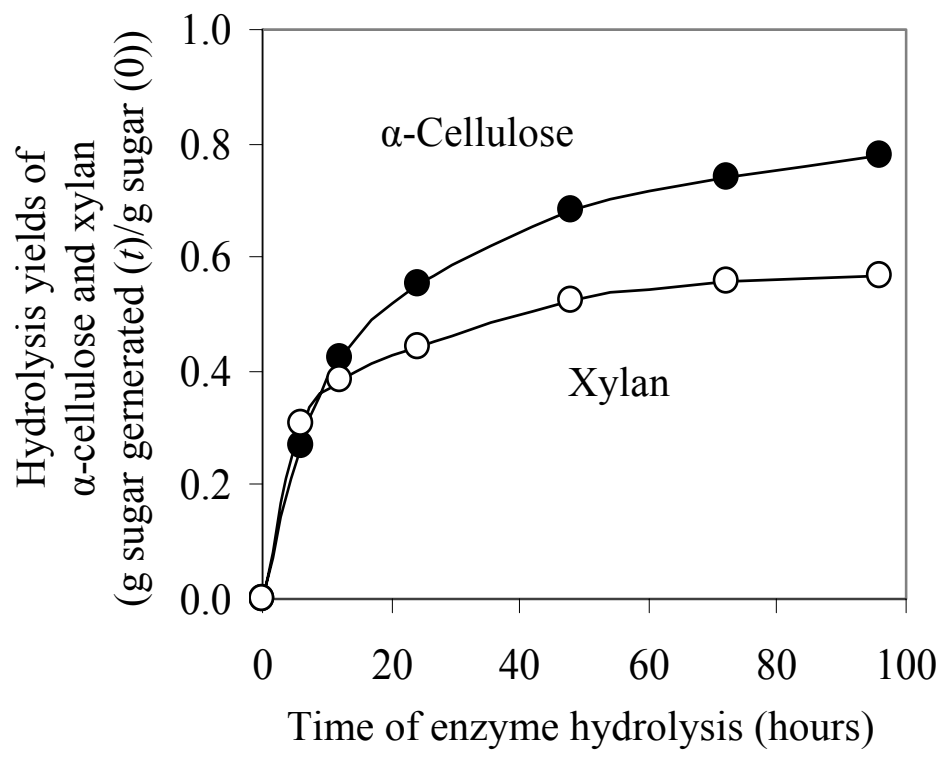

Figure 51. Hydrolysis efficiency of Spezyme CP (cellulase) on $\alpha$-cellulose and pure xylan at $5 \mathrm{FPU} / \mathrm{g}$ cellulose and $5 \mathrm{FPU} / \mathrm{g}$ xylan of enzyme loadings, respectively. Substrate concentration was $10 \mathrm{~g} / \mathrm{L}$. 


\subsection{Correlations between Structural Features and Digestibility}

\section{Introduction}

The digestibility of lime-treated biomass is affected by structural features resulting from the treatment. The key structural features that affect digestibility are the extent of acetylation, lignification, and crystallization.

The removal of amorphous substances (e.g., lignin and acetyl groups of hemicellulose) by delignification and deacetylation increases the crystallinity index. Chang and Holtzapple (2000) reported correlations between enzymatic digestibility and three structural factors: lignin content, crystallinity, and acetyl content. They concluded that (1) extensive delignification is sufficient to obtain high digestibility regardless of acetyl content and crystallinity; (2) delignification and deacetylation remove parallel barriers to enzymatic hydrolysis; and (3) crystallinity significantly affects initial hydrolysis rates but has less effect on ultimate sugar yields. These results indicate that an effective lignocellulose treatment process should remove all the acetyl groups and reduce the lignin content to about $10 \%$ in the treated biomass. Further lignin reduction incurs an extra cost; therefore, it is not justified for enzyme hydrolysis. Lee and Fan (1982) reported that the rate of enzyme hydrolysis depends on enzyme adsorption and the effectiveness of the adsorbed enzymes, instead of the diffusive mass transfer of enzyme.

The aliphatic acyl groups in biomass comprise acetyl and formyl groups, which are combined as $O$-acyl groups with biomass polysaccharides. In hardwoods, the $O$ acetyl groups are combined with the xylose units, whereas in the softwoods, they are combined with the mannose and glucose units of glucomannans (Whistler et al. 1943).

Acetylation sites are maximally 2 positions per anhydroxylose unit. For natural

xylan, the degree of acetylation is approximately 1 . Deacetylation in alkaline solution increases moisture content ('swelling') (Mitchell et al. 1990). 
Kong et al. (1992) reported that alkalis remove acetyl groups from hemicellulose (mainly xylan) thereby reducing the steric hindrance of hydrolytic enzymes and greatly enhancing carbohydrate digestibility. The removal of acetyl groups from xylan is not mainly affected by swelling, because there are no cation effects among several different types of alkalis. They concluded that the sugar yield in enzymatic hydrolysis is directly associated with acetyl group content, and not with the swelling feature.

The acetyl groups of biomass can be cleaved by hydrothermal treatment (autohydrolysis; $\geq 170^{\circ} \mathrm{C}$ in water), because the hydronium ions from water autoionization removes acetyl groups to give acetic acid in the reaction medium (Garrote et al. 2002).

The degree of crystallinity of lignocellulosic biomass has been considered an important factor in resisting enzymatic hydrolysis (Chang et al. 2000, Puri 1984, Rivers et al. 1988). However, it has been reported that the particle size of biomass (excluding big chunks) has no effect on enzymatic conversions of corn stover (Kaar et al. 2000), switchgrass (Chang et al. 2000), and bagasse (Sinitsyn et al. 1991).

In this study, the enzymatic digestibility of untreated and lime-treated corn stovers was correlated with three structural features: acetylation, lignification, and crystallinity. Additionally, the possibility of deacetylation in neutral condition ('autohydrolysis') was tested at mild condition $\left(25-55^{\circ} \mathrm{C}\right)$ for a long-term hydrothermal treatment without lime.

\section{Materials and Methods}

The acetyl content was determined for the untreated and treated corn stovers by the modified apparatus from Whistler and Jeans (1943), as described in Appendix G, "Determination of acetyl groups in biomass." Acetyl groups can be measured by this transesterification method in which the acetyl groups are converted to methyl acetate by transesterification in absolute methanol with sodium methoxide catalyst. The volatile ester is distilled and the amount is determined by the alkali consumed in the 
saponification of the ester in the distillate. The methyl acetate is quantitatively distilled and saponified in standard alkali (Browning 1967).

Delignification and the sugar yield of enzyme hydrolysis were determined for

differently treated and untreated corn stovers, as described in the previous Sections 3.4 and 3.5.

To determine whether or not deacetylation can occur in neutral conditions ('autohydrolysis'), $15 \mathrm{~g}$ dry corn stover was incubated with $150 \mathrm{~mL}$ of distilled water in the reactor without lime at 25 and $55^{\circ} \mathrm{C}$ for 10 weeks with and without aeration, respectively.

Crystallinities of untreated and treated corn stovers was measured by the XRD Laboratory, Department of Geophysics, Texas A\&M University (College Station, TX) using a Rigaku Powder X-ray Diffractometer (Rigaku Denki Co., Japan). The specimen was scanned at $2^{\circ} / \mathrm{min}$ from $2 \theta=10^{\circ}$ to $26^{\circ}$ with a step size of $0.05^{\circ}$.

The definition of crystallinity index is

$$
\mathrm{CrI}=\frac{I_{002}-I_{a m}}{I_{002}} \times 100
$$

where, $I_{002}=$ intensity of the diffraction from the 002 plane at $2 \theta=22.6^{\circ}$ and $I_{a m}=$ intensity of the background scatter measured at $2 \theta=\sim 18.7^{\circ}$ (Segal et al. 1959), as shown in Figure 52.

\section{Results and Discussions}

\section{Effect of Lime Pre treatment on Deacetylation of Corn Stover}

The acetyl content was 2.2 and 3.2\% (g acetyl group/100 g raw biomass) in the first and second batch of raw corn stover, respectively.

Deacetylation was calculated from the weight fraction of the acetyl group removed from the raw corn stover using the following equation:

$$
\text { Deactylation }(\%)=\frac{\mathrm{g} \text { acetyl group removed }}{\mathrm{g} \text { acetyl group in raw corn stover }} \times 100
$$




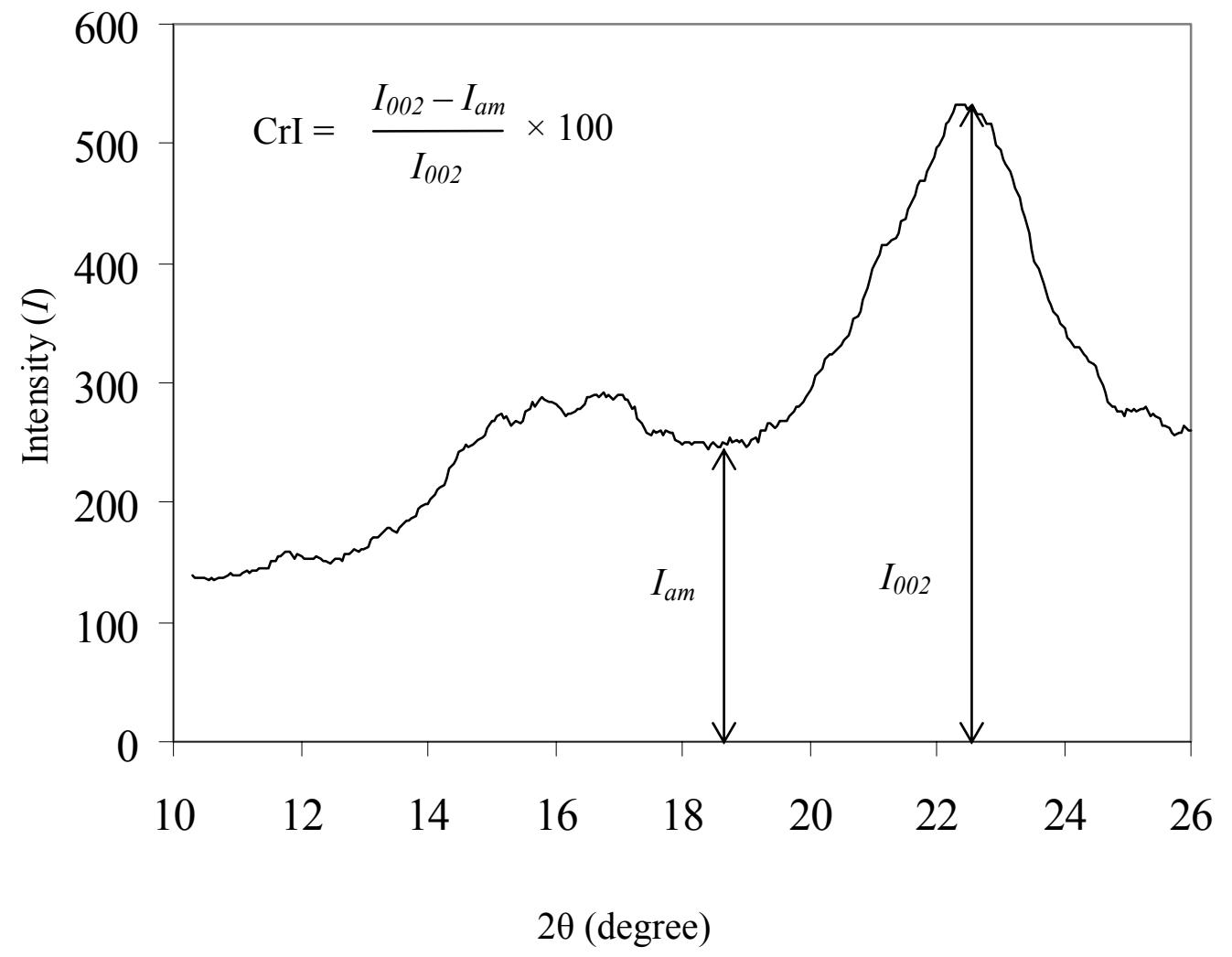

Figure 52. X-ray diffraction pattern of corn stover. 
Deacetylation is a relatively quick reaction because deacetylation levels reached almost maximum values and did not change after 4 weeks for all cases of pretreatment with lime, as shown in Figure 53.

There is no significant influence of temperature on the deacetylation of corn stover treated with lime. Deacetylation at higher temperatures $\left(100^{\circ} \mathrm{C}\right)$ was similar to that at lower temperatures $\left(25-55^{\circ} \mathrm{C}\right)$. For instance, $97.1 \pm 0.3 \%$ of acetyl groups in raw corn stover was removed when the corn stover was pretreated with lime $(0.1 \mathrm{~g}$ $\mathrm{Ca}(\mathrm{OH})_{2} / \mathrm{g}$ raw biomass) at $100^{\circ} \mathrm{C}$ for $2 \mathrm{~h}$, a common lime-treatment condition. Therefore, deacetylation in corn stover occurs mainly from lime pretreatment and does not require oxygen. Oxidative lime pretreatment gives a little higher $(+7 \%)$ deacetylation for the first batch of corn stover than non-oxidative lime treatment does, as listed in Table 19. There was no significant influence on deacetylation between the two different batches of corn stover.

When corn stover was treated hydrothermally without lime at $55^{\circ} \mathrm{C}$ for 10 weeks, deacetylation occurred up to 46.5 and $49.2 \mathrm{~g}$ acetyl group removed/100 g acetyl group in raw biomass in non-oxidative and oxidative conditions, respectively. Furthermore, the acetyl group was removed up to $13.9 \%$, when corn stover was incubated with only water at room temperature for 10 weeks, as shown in Table 20. Thus, deacetylation can occur up to certain levels by autohydrolysis reactions in mild hydrothermal treatment without lime; further, it is not affected by the presence of oxygen.

\section{Effect of Deacetylation and Delignification on 3-d Sugar Yield of Enzyme Hydrolysis}

The acetyl group was removed very quickly regardless of temperature and the oxidation condition, whereas lignin was removed gradually throughout the pretreatment and depended on the pretreatment condition. For example, deacetylation reached a plateau within 1 week and there were no significant differences between the extremes (no aeration at $25^{\circ} \mathrm{C}$ and aeration at $55^{\circ} \mathrm{C}$ ). However, the delignification trends between these two conditions were very different, as shown in Figures $54-57$. 


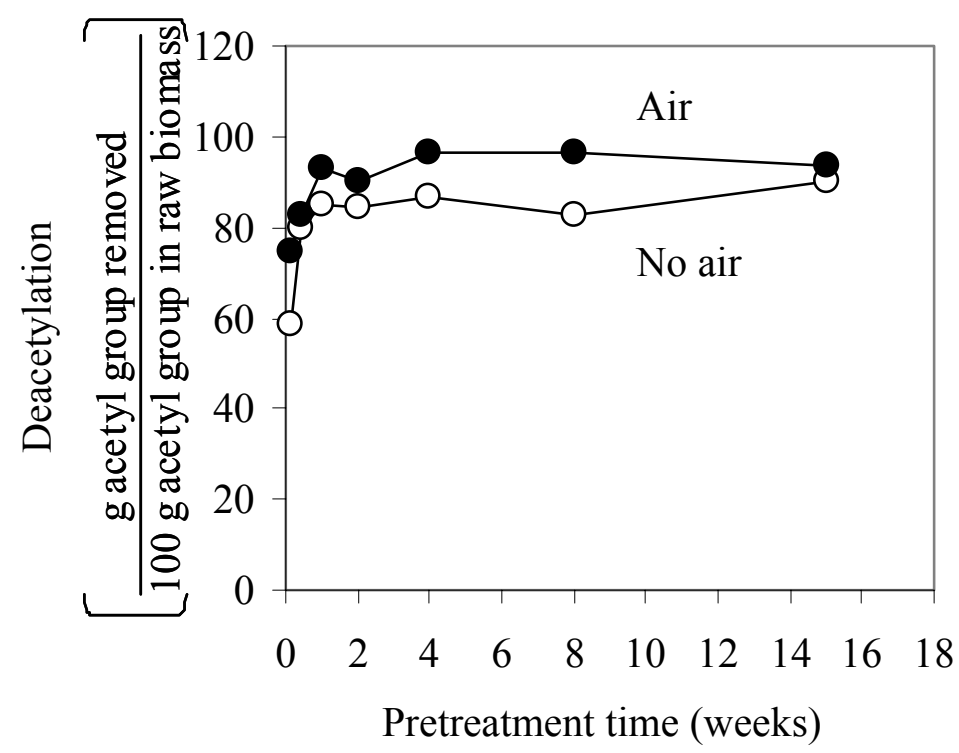

(a)

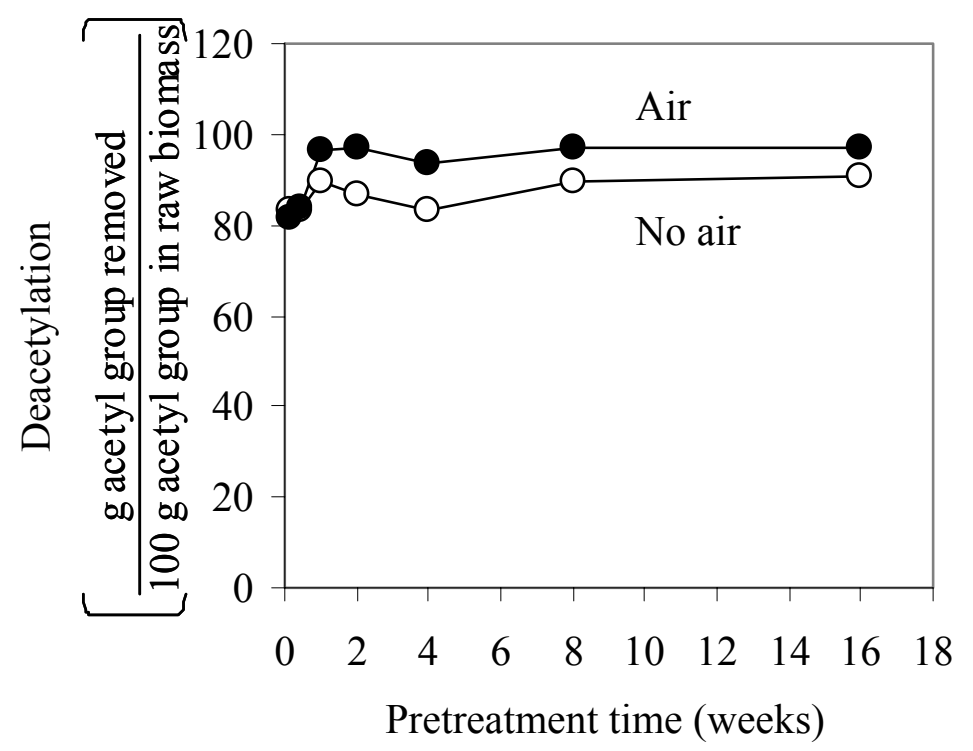

(b)

Figure 53. Deacetylation of the pretreated corn stover with lime at (a) 25, (b) 35 , (c) 45 , and (d) $55^{\circ} \mathrm{C}$ in non-oxidative $(O)$ and oxidative $(\mathbf{O})$ conditions. 


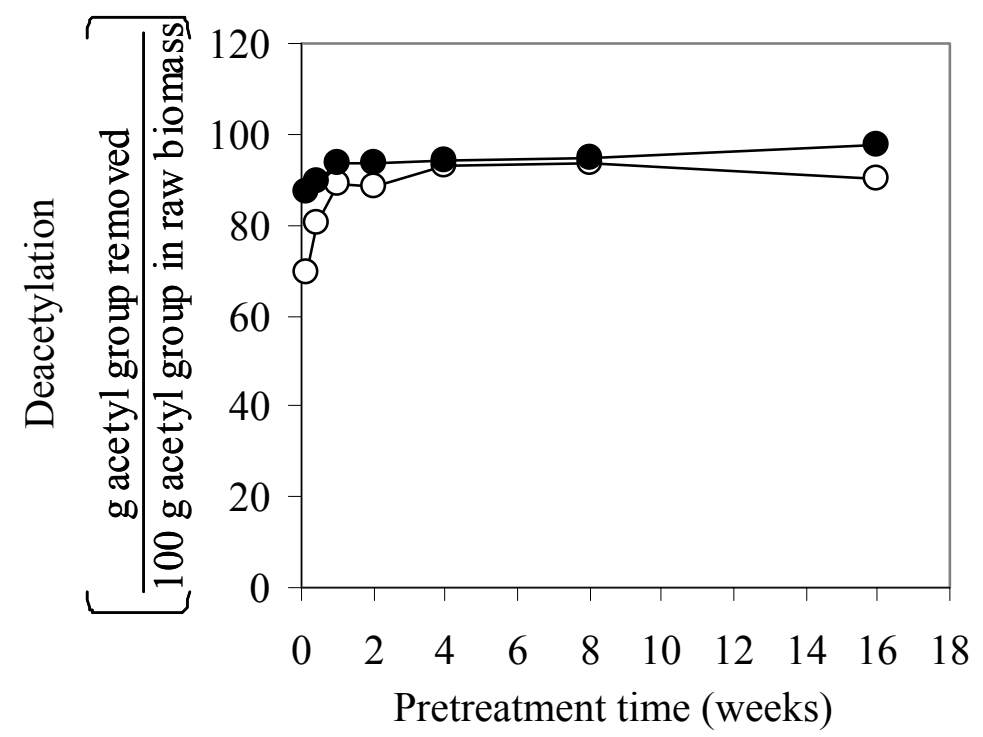

(c)

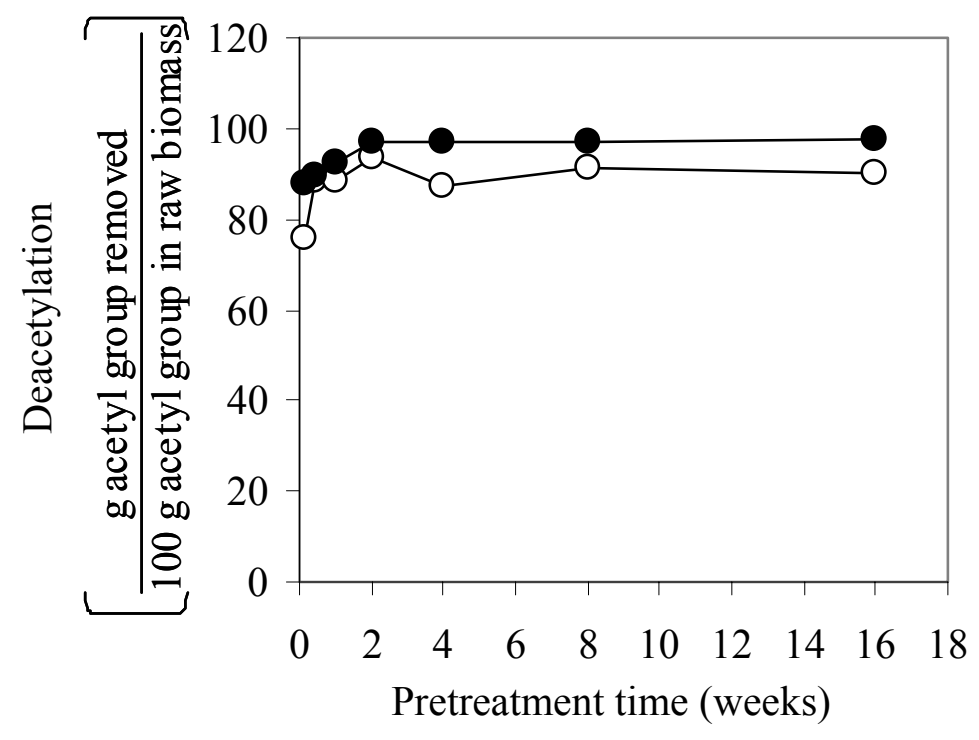

(d)

Figure 53. Continued. 
Table 19. The average levels of deacetylation (g acetyl group removed/100 g acetyl group in raw biomass) for corn stover treated with lime.

\begin{tabular}{|l|c|c|c|c|}
\hline $\begin{array}{l}\text { Lime treatment } \\
\text { condition }\end{array}$ & \multicolumn{2}{|c|}{ Non-oxidative } & \multicolumn{2}{c|}{ Oxidative } \\
\hline $\begin{array}{l}\text { Batch number of } \\
\text { corn stover }\end{array}$ & First batch & Second batch & First batch & Second batch \\
\hline $\begin{array}{l}\text { Average } \\
\text { Deacetylation* }\end{array}$ & $89.1 \pm 3.5$ & $93.8 \pm 1.6$ & $96.1 \pm 1.6$ & $98.0 \pm 1.0$ \\
\hline $\begin{array}{l}\text { Coefficient of } \\
\text { variation (\%) }\end{array}$ & 3.9 & 1.7 & 1.6 & 1.0 \\
\hline
\end{tabular}

* These values are obtained from the data after 4 weeks for each combination of lime treatment condition (non-oxidative or oxidative) and batch types of corn stover (first or second).

- Error band $( \pm)$ indicates 1 standard deviation.

Table 20. Comparison of deacetylation ( $\mathrm{g}$ acetyl group removed/100 $\mathrm{g}$ acetyl group in raw biomass) between lime-free and lime pretreatments at $10^{\text {th }}$ and $8^{\text {th }}$ week, respectively.

\begin{tabular}{|l|c|c|c|c|}
\hline Treatment condition & \multicolumn{2}{|c|}{ Non-oxidative } & \multicolumn{2}{c|}{ Oxidative } \\
\hline Temperature $\left({ }^{\circ} \mathrm{C}\right)$ & 25 & 55 & 25 & 55 \\
\hline Lime-free & $13.9 \pm 4.9$ & $46.7 \pm 4.5$ & $14.5 \pm 7.8$ & $49.2 \pm 3.1$ \\
Lime & $86.5 \pm 3.7$ & $89.6 \pm 2.0$ & $95.7 \pm 1.7$ & $97.3 \pm 0.4$ \\
\hline
\end{tabular}

- Error band $( \pm)$ indicates 1 standard deviation. 


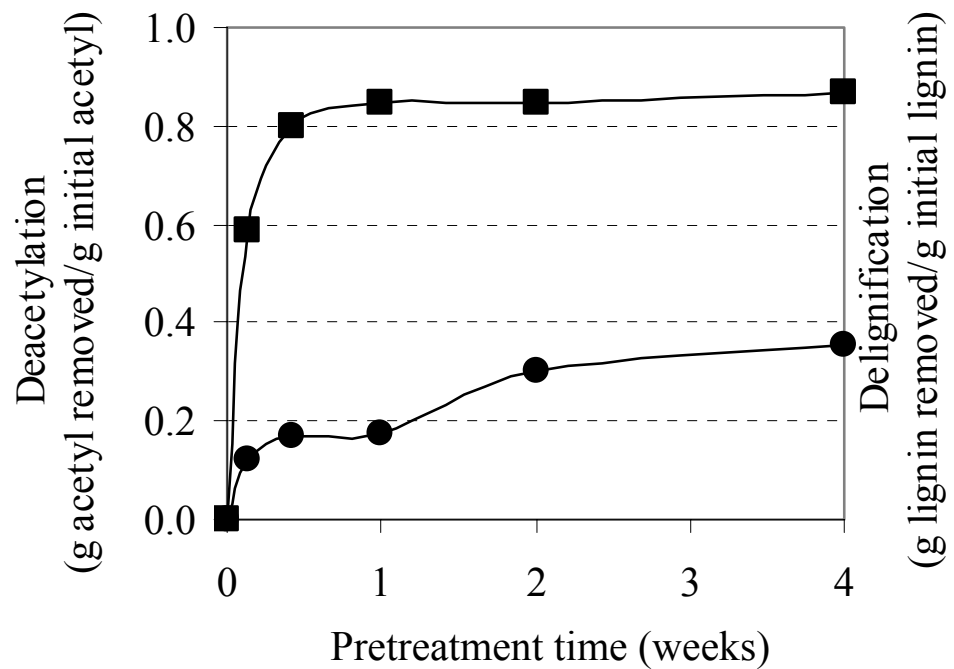

(a)

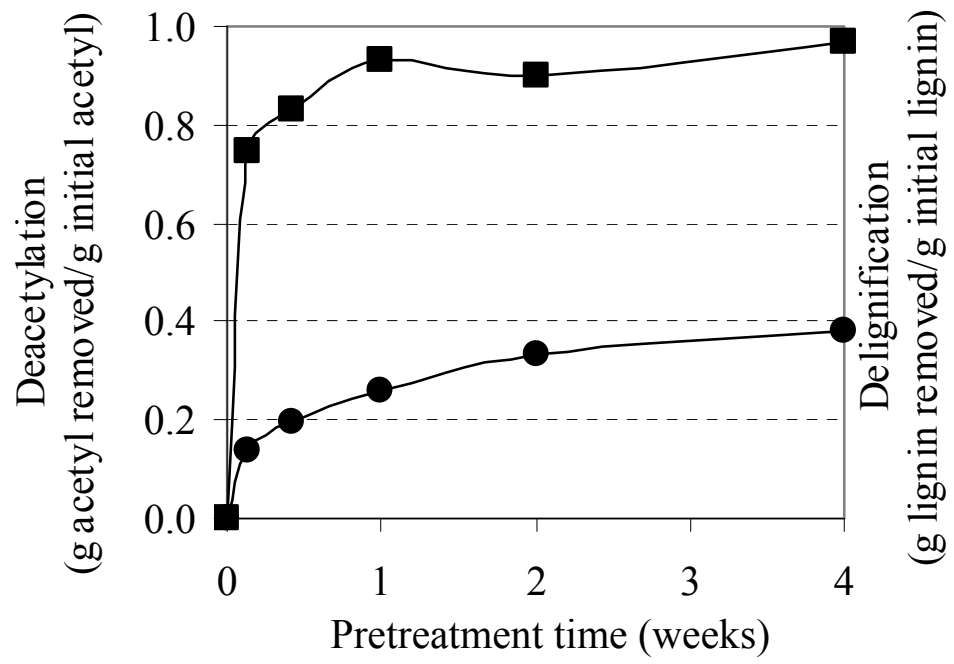

(b)

Figure 54. The profiles of deacetylation ( $\square$ ) and delignification (O) during the lime pretreatment in non-oxidative (a) and in oxidative (b) condition at $25^{\circ} \mathrm{C}$. 


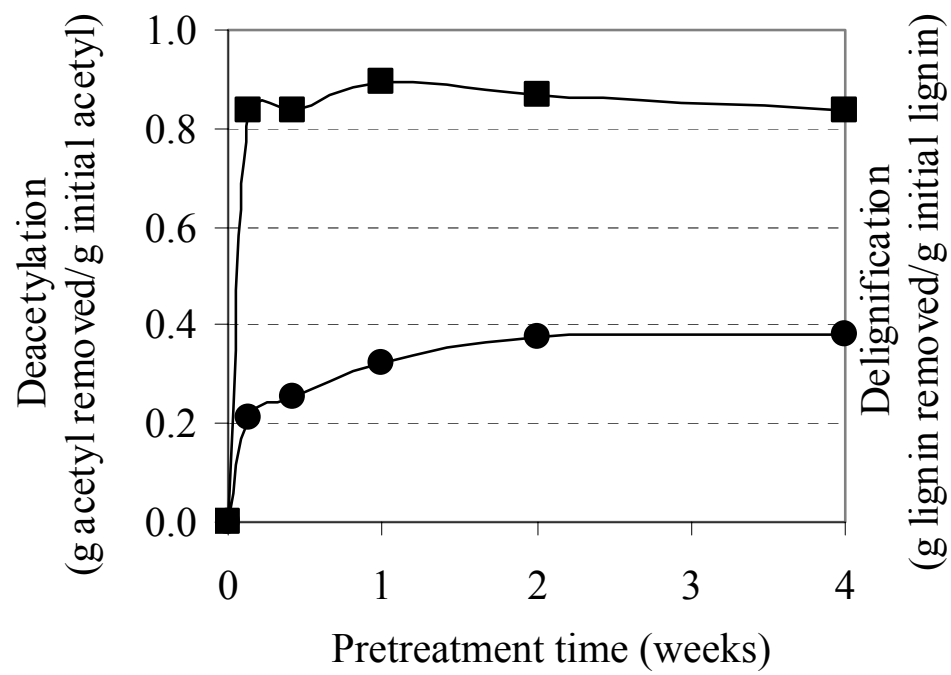

(a)

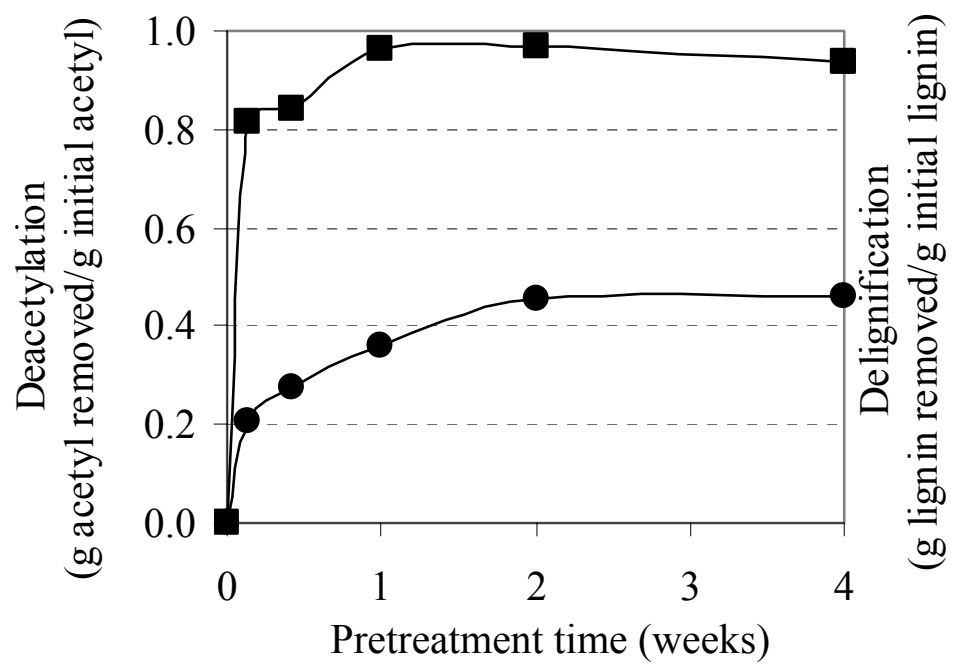

(b)

Figure 55. The profiles of deacetylation ( $\square$ ) and delignification (O) during the lime pretreatment in non-oxidative (a) and in oxidative (b) condition at $35^{\circ} \mathrm{C}$. 


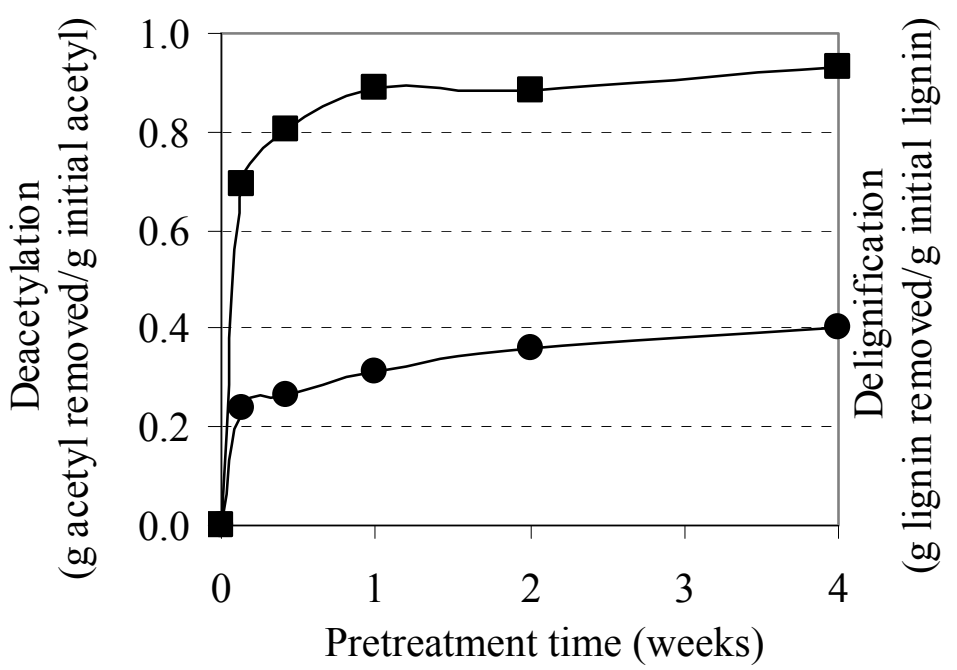

(a)

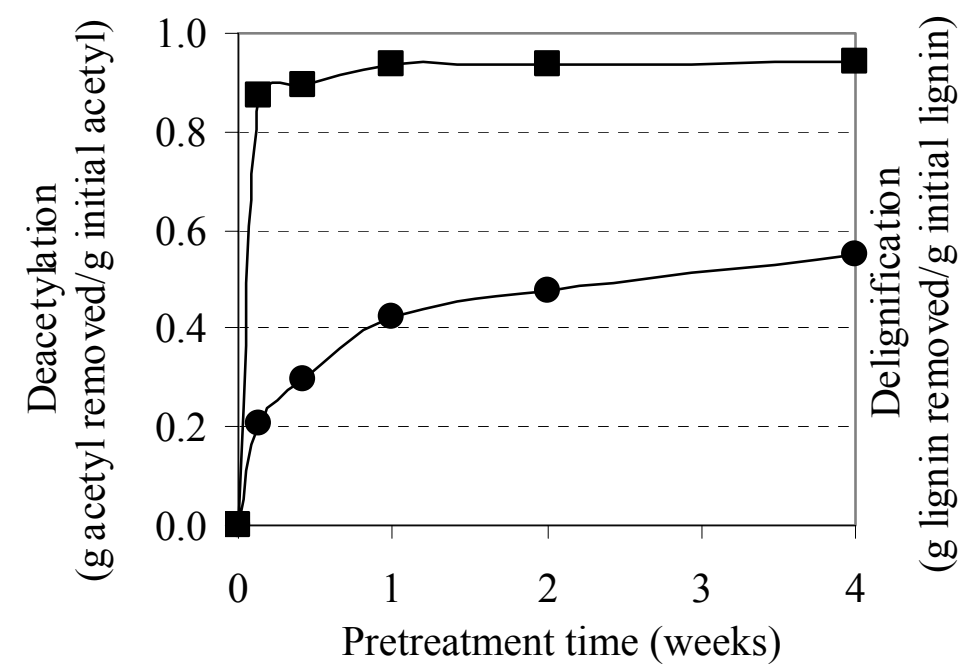

(b)

Figure 56. The profiles of deacetylation ( $\mathbf{\square})$ and delignification (-) during the lime pretreatment in non-oxidative (a) and in oxidative (b) condition at $45^{\circ} \mathrm{C}$. 


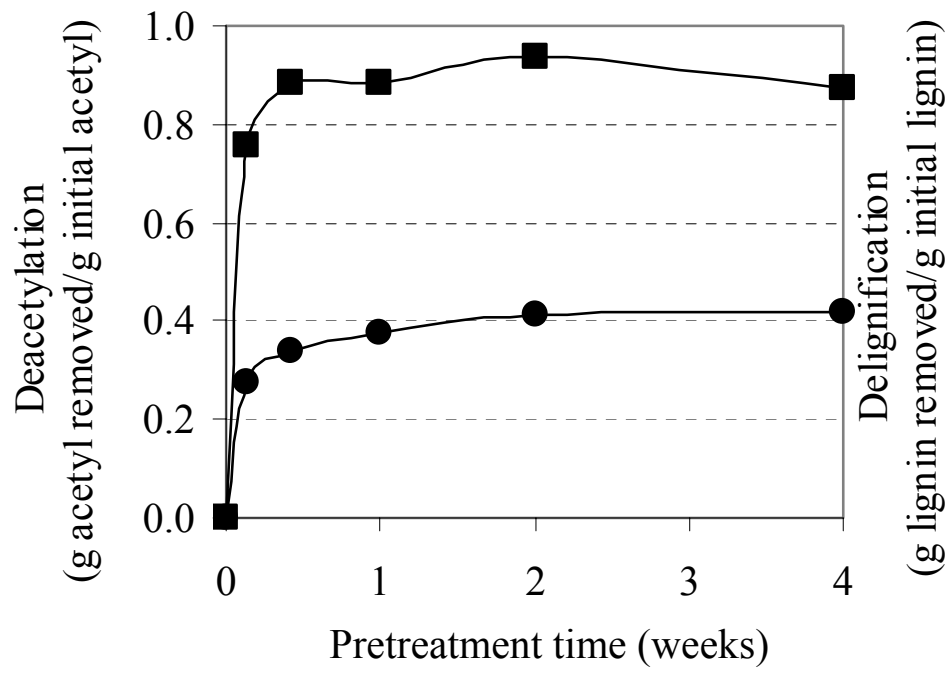

(a)

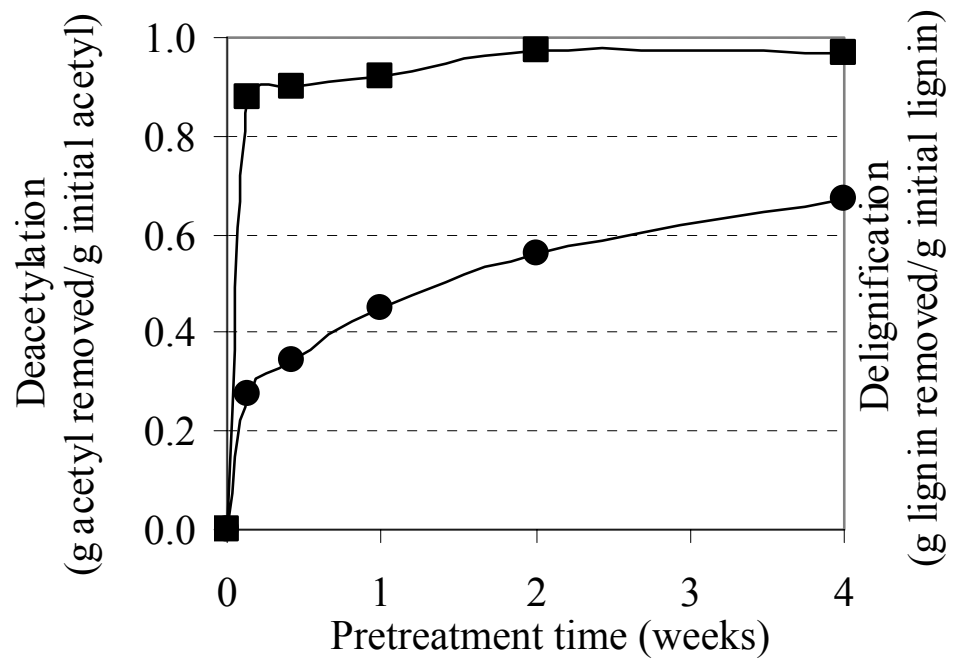

(b)

Figure 57. The profiles of deacetylation ( $\square$ ) and delignification (O) during the lime pretreatment in non-oxidative (a) and in oxidative (b) condition at $55^{\circ} \mathrm{C}$. 
Deacetylation and delignification can affect the enzyme digestibility of biomass. Raw corn stover had no deacetylation and delignification, but pretreated corn stover showed high levels of deacetylation and delignification.

In the early stages of lime pretreatment, when corn stover was highly deacetylated but with little delignification, its 3-d hydrolysis yield of holocellulose at 15 FPU/g cellulose of enzyme loading increased from $0.25 \mathrm{~g}$ holocellulose hydrolyzed/g holocellulose in raw biomass to more than $0.40 \mathrm{~g}$ holocellulose hydrolyzed/g holocellulose in treated biomass due to lime pretreatment. Later in the treatment, complete deacetylation was achieved, and the 3-d enzyme digestibility increased linearly with delignification, as shown in Figure 58 (the linear regression value $\left(\mathrm{R}^{2}\right)$ was 0.7852 ). These plots were made using the entire data set of deacetylation, delignification, and 3-d enzyme digestibility, for all pretreatment conditions and times.

Linear relationships between delignification and 3-d enzyme digestibility at 15 FPU/g cellulose were better for glucan $\left(R^{2}=0.7551\right)$ than for xylan $\left(R^{2}=0.4321\right)$, as shown in Figure 59.

\section{Effect of Crystallinity}

The degree of crystallinity (CrI) of corn stover increased after lime pretreatment. It was related to delignification and the solubilization of hemicellulose - the removal of amorphous components. Regardless of the oxidative treatment, as delignification proceeded due to lime pretreatment, the xylan (hemicellulose) contents slightly decreased whereas the glucan content and the ratio of glucan to xylan $(G / X)$ in the pretreated corn stover increased (Figure 60). This means that lignin and hemicellulose are selectively removed (or solubilized), but cellulose is not affected by lime pretreatment at mild temperatures $\left(25-55^{\circ} \mathrm{C}\right)$, even though corn stover was contacted with alkali for a long time, 16 weeks.

The degree of crystallinity increased with delignification due to the increase of glucan content in the pretreated solid fraction of corn stover, as shown in Figure 61. 

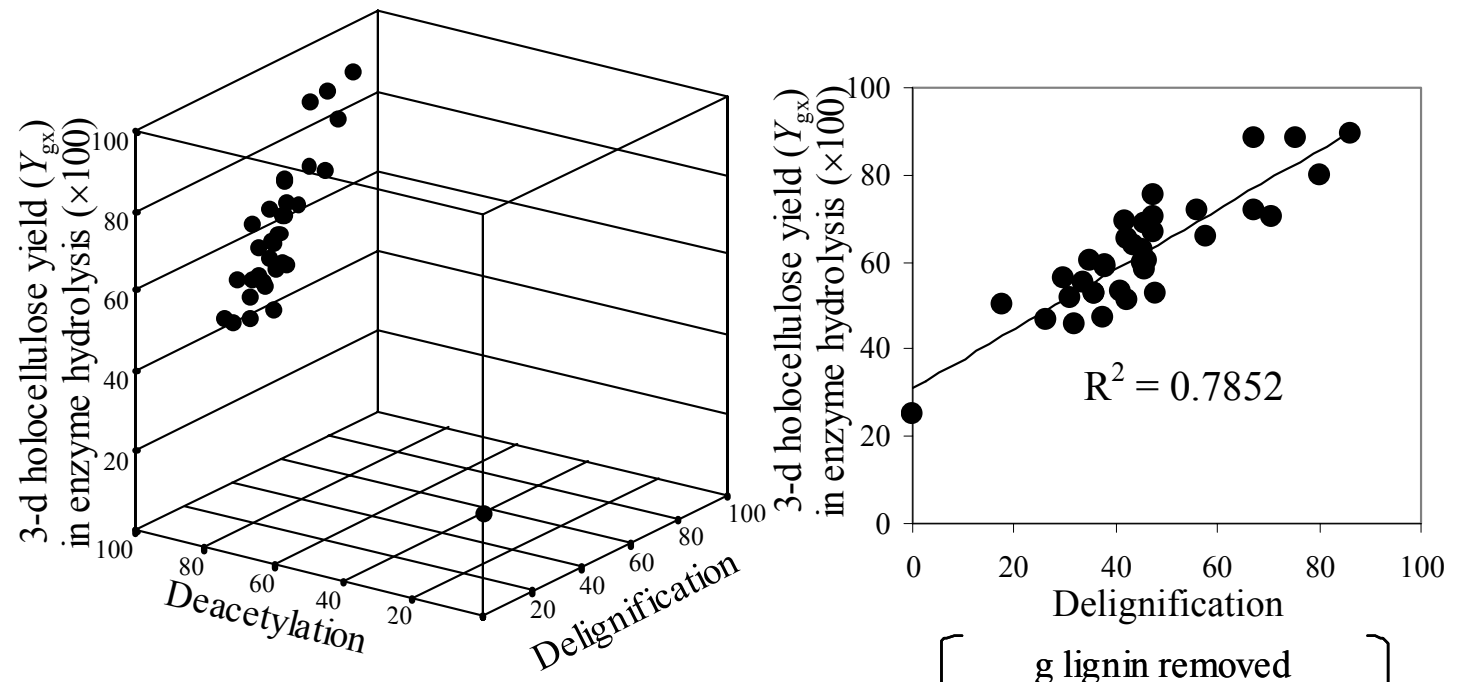

$\left[\frac{\mathrm{g} \text { lignin removed }}{100 \mathrm{~g} \text { lignin in raw biomass }}\right]$
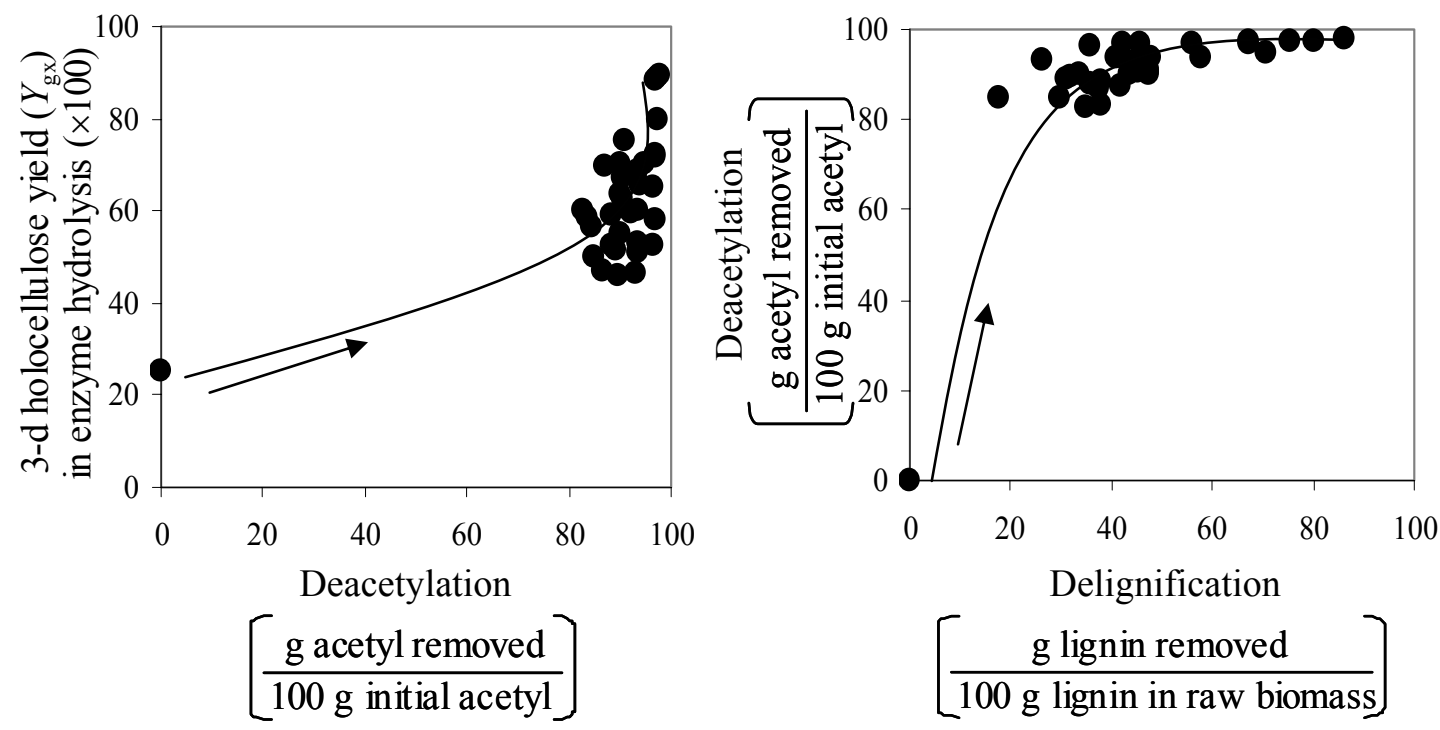

Figure 58. Distribution of deacetylation, delignification, and 3-d sugar yield $\left(Y_{\mathrm{gx}}\right)$ in enzyme hydrolysis for the corn stover treated with lime. 

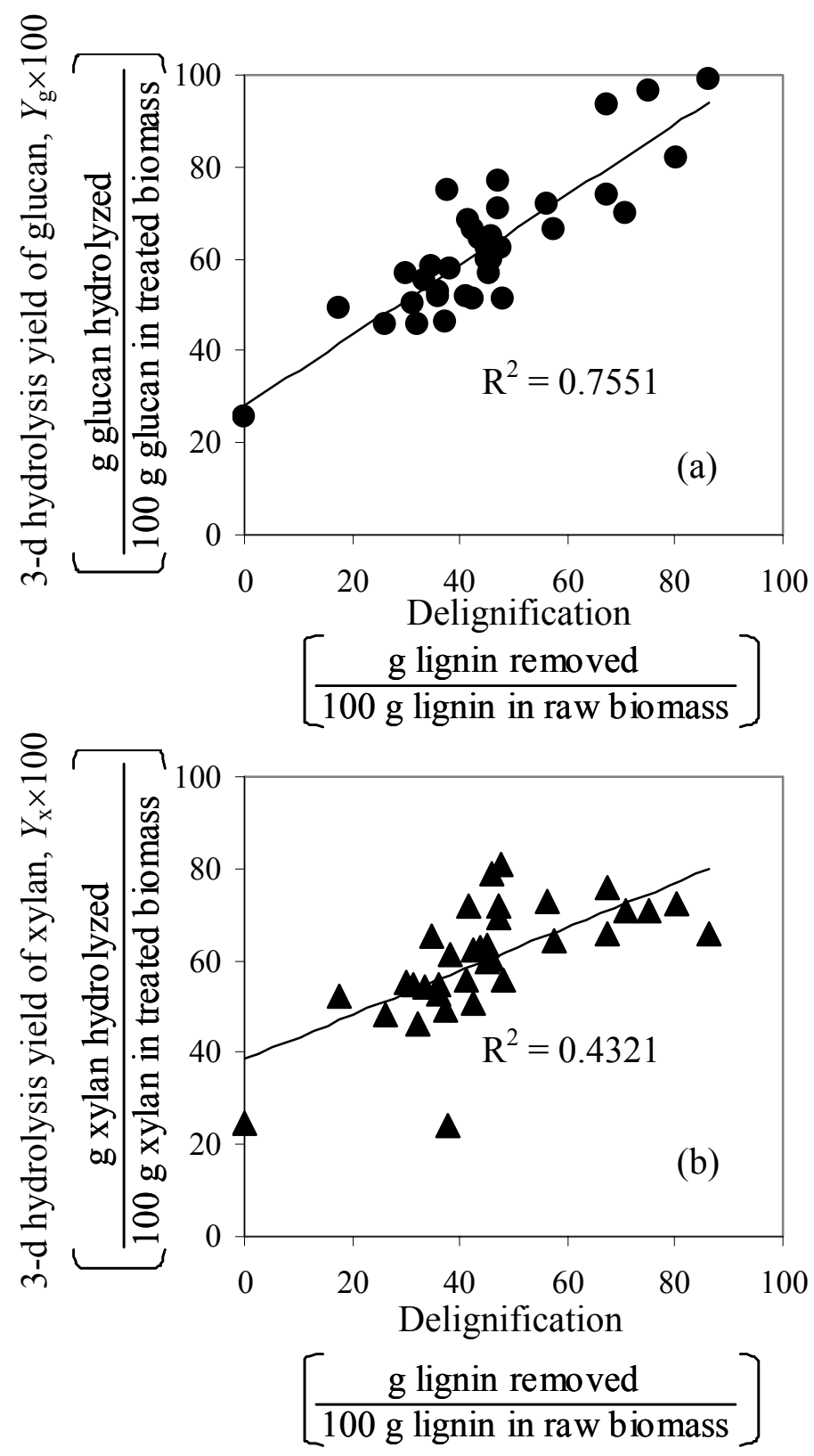

Figure 59. Effect of delignification on the hydrolysis yields of glucan (a) and xylan (b) in 3-d enzyme digestibility at $15 \mathrm{FPU} / \mathrm{g}$ cellulose. 

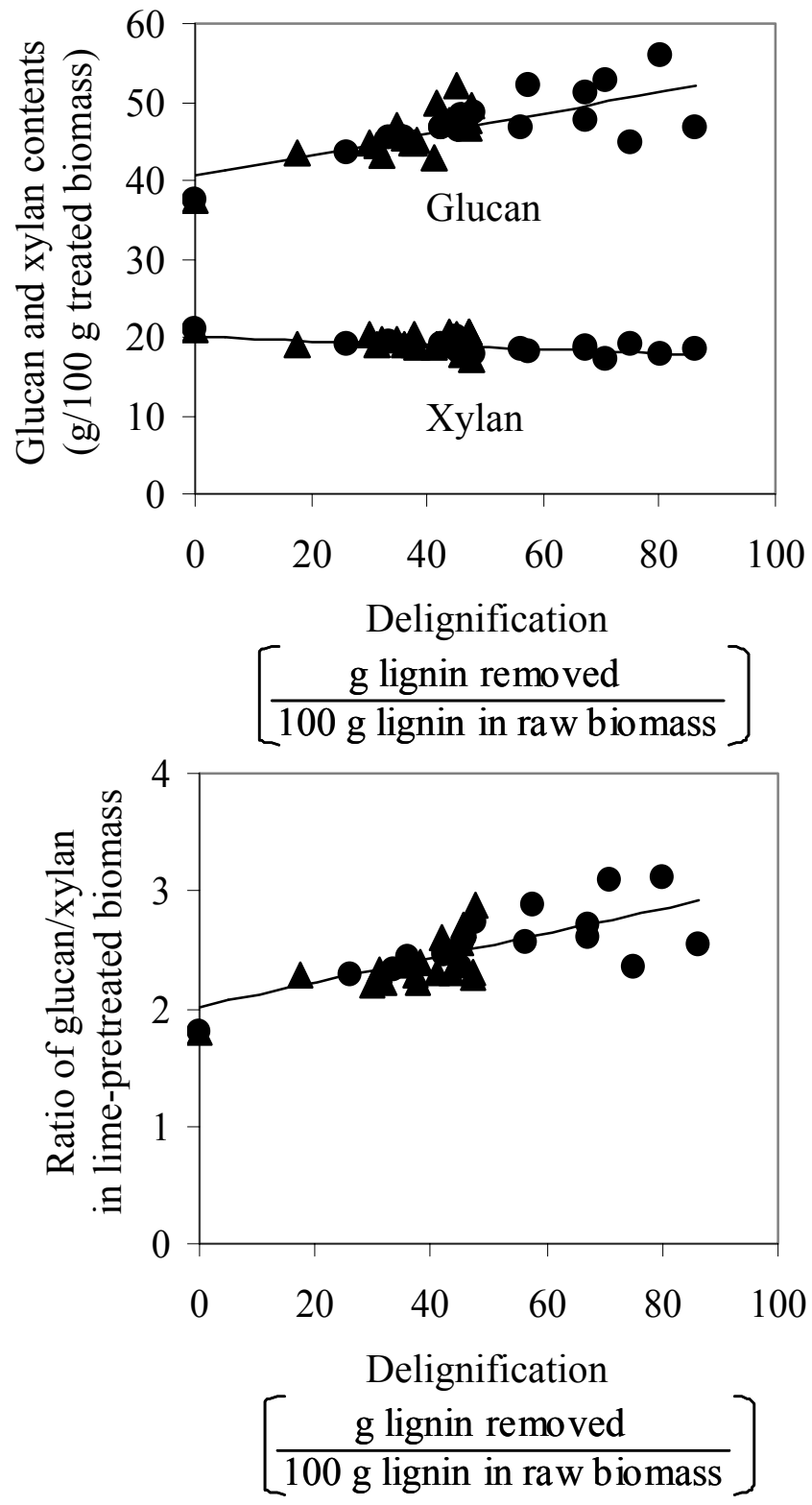

Figure 60. Correlation of delignification with holocellulose (glucan and xylan) content (a) and with the ratio of glucan to xylan (b) of lime-pretreated solid in nonoxidative $(\boldsymbol{\Delta})$ and oxidative $(\boldsymbol{\bullet})$ conditions. 

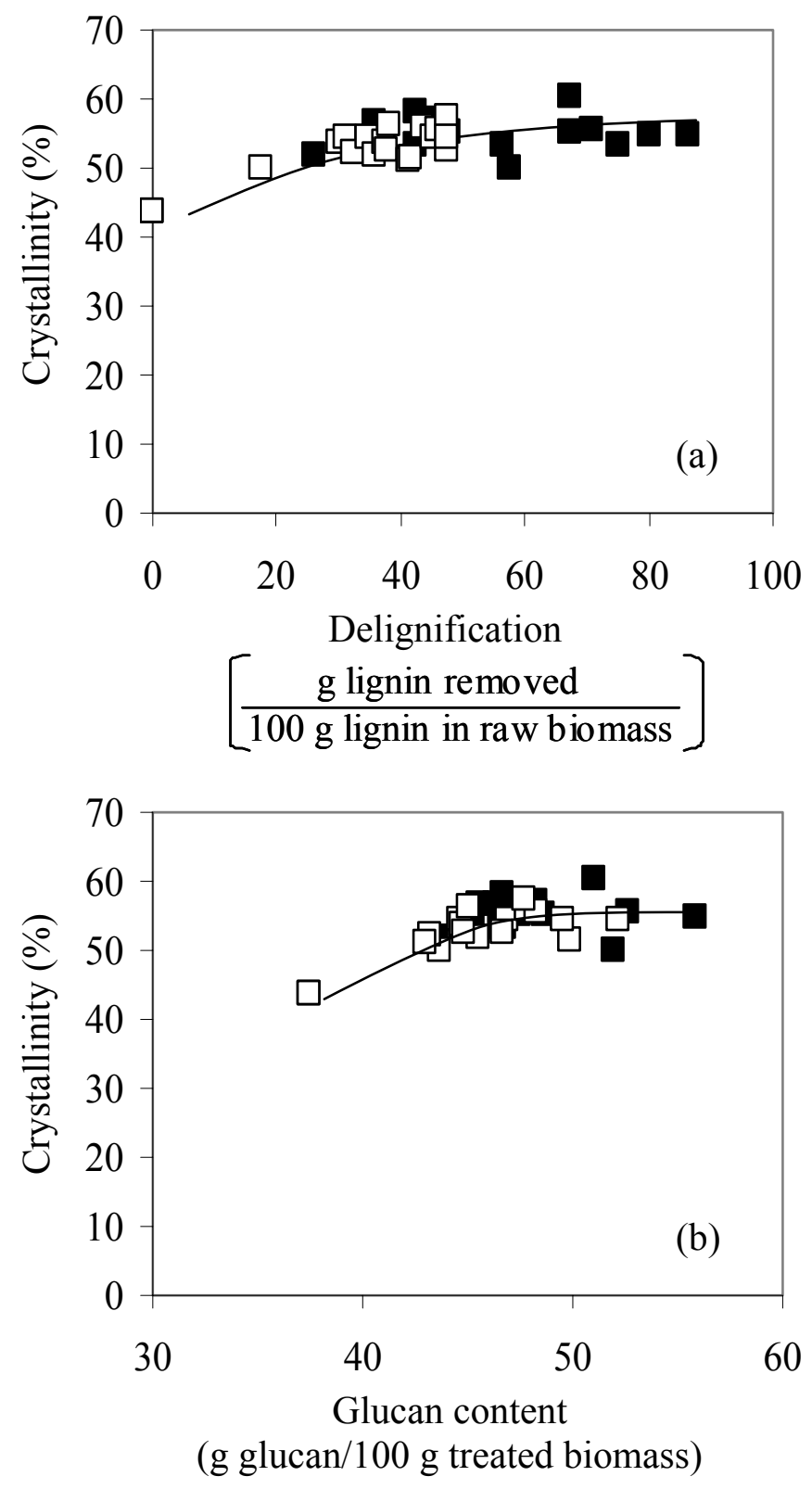

Figure 61. Correlation of crystallinity with delignification (a) and glucan content (b) of lime-pretreated corn stover in non-oxidative ( $\square$ ) and oxidative ( $\square$ ) conditions. 
However, the increased crystallinity did not negatively affect the 3-d sugar yield of enzyme hydrolysis. The conversion efficiency of cellulose and hemicellulose in enzyme hydrolysis significantly depended on the extent of delignification.

\section{Proposed Model for Corn Stover}

Chang et al. 2000 reported that lignin and acetyl groups in hemicellulose are significant barriers for the cellulase enzyme to access the lignocellulosic fiber matrix and that crystallinity affects the efficiency of enzyme contacted with cellulose and hemicellulose. Lime pretreatment significantly removes the acetyl and lignin barriers allowing enzyme to access the substrates, cellulose and hemicellulose. Even though the crystallinity is high, the amount of adsorbed enzyme is sufficient to achieve high digestibility in a 3-d period of enzyme hydrolysis.

Oxidative lime pretreatment lowers the acetyl and lignin contents to obtain high digestibility, regardless of crystallinity. This result agrees with Chang and Holtzapple's (2000) observations of lime pretreatment on poplar wood.

Using 147 data sets of pretreated poplar wood, Chang and Holtzapple (2000) suggested an empirical formula for hydrolysis yields $\left(Y_{\mathrm{g}}, Y_{\mathrm{x}}\right.$, and $\left.Y_{\mathrm{gx}}\right)$ for glucose, xylose, and total sugar (glucose + xylose) that is a function of the contents of lignin $(L)$, acetyl $(A)$, glucan $(G)$, xylan $(X)$, and crystallinity $(\mathrm{CrI})$. Equations 22 and 23 are the full formulas for $Y_{\mathrm{g}}$ and $Y_{\mathrm{x}}$ using 147 data sets.

$$
\begin{aligned}
Y_{\mathrm{g}}= & \frac{a_{0}+a_{1}(A / G)+a_{2}(A / G)^{2}+a_{3}(A / G)^{3}}{1+\exp \left[\frac{b-L / G}{c}\right]}+\frac{d_{0}+d_{1}(A / G)+d_{2}(A / G)^{2}+d_{3}(A / G)^{3}}{1+\exp \left[\frac{e-\mathrm{CrI}}{f}\right]} \\
& +\frac{g_{0}+g_{1}(A / G)+g_{2}(A / G)^{2}+g_{3}(A / G)^{3}}{\left[1+\exp \left[\frac{b-L / G}{c}\right]\right]\left[1+\exp \left[\frac{e-\mathrm{CrI}}{f}\right]\right]} \\
Y_{\mathrm{x}}= & a_{0}{ }^{\prime}+a_{1}{ }^{\prime} \exp \left[a_{2}{ }^{\prime}(A / X)\right]+b^{\prime}(L / X)+c^{\prime} \mathrm{CrI}+d^{\prime}(L / X)^{2}+e^{\prime} \mathrm{CrI}^{2}+f^{\prime}(L / X) \cdot \mathrm{CrI}
\end{aligned}
$$

and the total hydrolysis yield of sugars $\left(Y_{\mathrm{gx}}\right)$ is expressed as follows: 


$$
\begin{aligned}
Y_{\mathrm{gx}} & =\frac{Y_{\mathrm{g}} \times(G / 0.90)+Y_{\mathrm{x}} \times(X / 0.88)}{(G / 0.90)+(X / 0.88)} \\
& =\frac{Y_{\mathrm{g}}}{1+\frac{0.90 X}{0.88 G}}+\frac{Y_{\mathrm{x}}}{1+\frac{0.88 G}{0.90 X}}
\end{aligned}
$$

where, $G=$ glucan content in lime-treated corn stover (g glucan/100 g treated biomass) $X=$ xylan content in lime-treated corn stover (g xylan/100 g treated biomass) $L=$ lignin content in lime-treated corn stover (g lignin/100 g treated biomass) $A=$ acetyl group in lime-treated corn stover (g acetyl/100 g treated biomass) $Y_{\mathrm{g}}=3$-d hydrolysis yield of glucan (g glucan hydrolyzed/100 g treated biomass) $Y_{\mathrm{x}}=3-\mathrm{d}$ hydrolysis yield of xylan (g xylan hydrolyzed/100 g treated biomass) $Y_{\mathrm{gx}}=3-\mathrm{d}$ hydrolysis yield of total sugar ( $\mathrm{g}$ holocellulose hydrolyzed/100 g treated biomass)

$\mathrm{CrI}=$ crystallinity index $(\%)$ $a_{0}-a_{3}, b, c, d_{0}-d_{3}, e, f, g_{0}-g_{3}, a_{0}{ }^{\prime}-a_{2}{ }^{\prime}, b^{\prime}, c^{\prime}, d^{\prime}, e^{\prime}$, and $f^{\prime}$ are constants.

As shown in Figure 62, for fixed values of acetyl content and crystallinity, the profiles of 3-d hydrolysis yield from holocellulose are sigmoidal as a function of lignin content remaining in lime-treated woody biomass with air.

In this study, with lime-treated corn stover, the crystallinity and acetyl contents were assumed to not affect the 3-d hydrolysis yields because the acetyl group content was almost $0 \%$ and $\mathrm{CrI}$ did not change significantly; therefore, it is expected that the 3 -d hydrolysis profiles would be sigmoidal with residual lignin fraction $\left(W_{\mathrm{L}}\right)$ and can be described by the following empirical equations:

$$
Y_{\mathrm{g}}=\frac{a_{0}}{1+\exp \left[\frac{a_{1}-W_{\mathrm{L}}}{a_{2}}\right]}
$$

and 


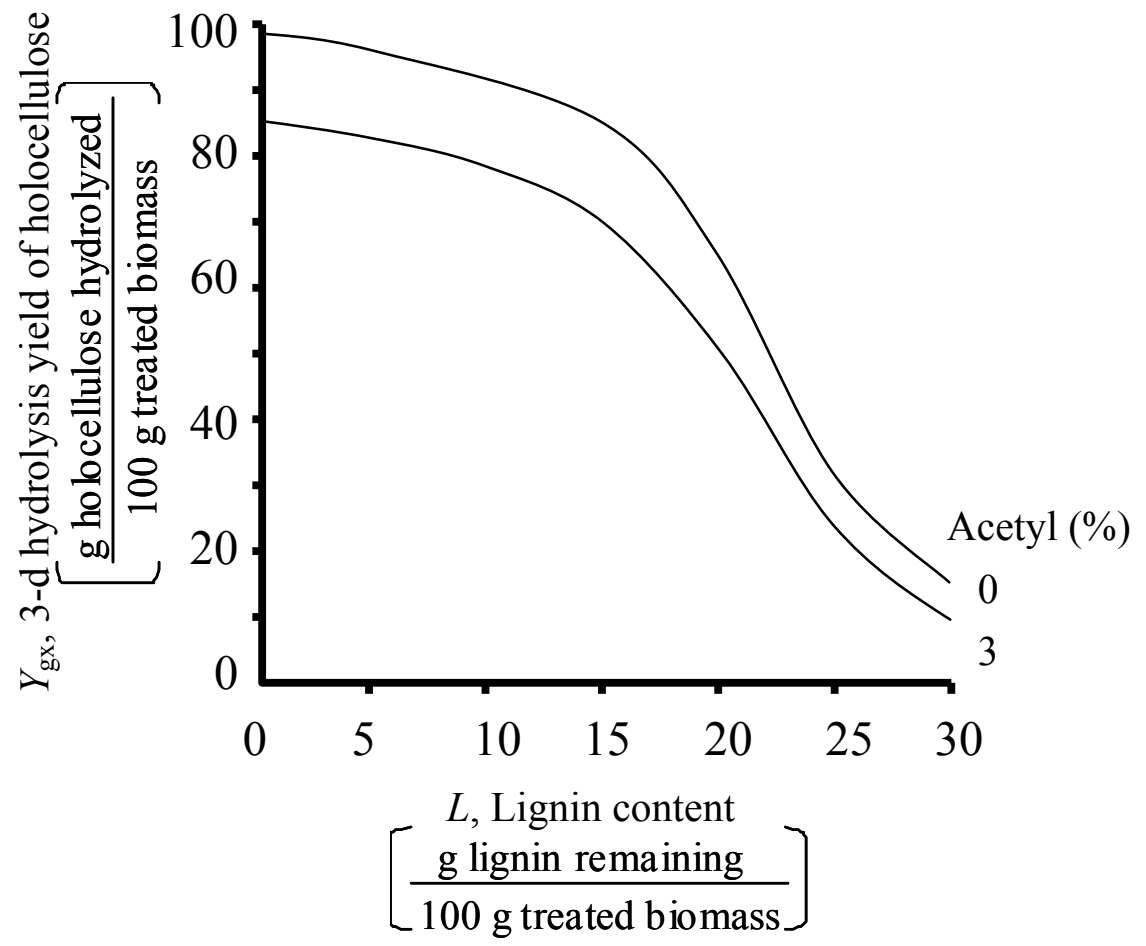

Figure 62. 3-d hydrolysis yield of holocellulose as a function of lignin content in lime-treated woody biomass with air (Chang et al. 2000). 


$$
Y_{\mathrm{x}}=\frac{b_{0}}{1+\exp \left[\frac{b_{1}-W_{\mathrm{L}}}{b_{2}}\right]}
$$

where, $W_{\mathrm{L}}=$ fraction of the residual lignin in lime-treated corn stover

(g lignin remaining/100 g lignin in raw biomass)

$a_{0}-a_{2}$ and $b_{0}-b_{2}$ are constants.

The constants $\left(a_{i}\right.$ and $b_{i}, i=0,1$, and 2$)$ of the models listed in Table 21 were empirically determined from the oxidative lime-pretreatment data by using non-linear regression for parameter estimation by minimizing the root mean square errors in Excel. The plots of Equations 24, 25, and 26 are shown as solid lines in Figure 63. Thus, for oxidative lime-pretreatment, the hydrolysis yields of glucan $\left(Y_{\mathrm{g}}\right)$, xylan $\left(Y_{\mathrm{x}}\right)$, and holocellulose $\left(Y_{\mathrm{gx}}\right)$ of corn stover were fitted well with the predicted values by the simplified non-linear models with the single parameter $\left(W_{\mathrm{L}}\right)$.

\section{Conclusions}

Lime is a very effective chemical for deacetylation. In the presence of lime, deacetylation is not significantly affected by temperature or the presence of oxygen. In the absence of lime, however, deacetylation is influenced by temperature but not affected by oxygen.

Acetyl groups were removed very quickly regardless of temperature and the oxidation condition for lime pretreatment, whereas lignin was removed gradually through the whole period of pretreatment and depended on the pretreatment conditions.

The hydrolysis yield of glucan and xylan to glucose and xylose was affected by deacetylation and linearly depended on delignification.

The degree of crystallinity increased with delignification due to the increase of glucan content in the pretreated solid fraction of corn stover.

Oxidative lime pretreatment lowers the acetyl and lignin contents to obtain high 
Table 21. Parameters of correlations for 3-d hydrolysis yields of glucan ( $Y_{\mathrm{g}}, \mathrm{g}$ glucan hydrolyzed/100 g glucan in treated biomass) and xylan $\left(Y_{\mathrm{x}}, \mathrm{g}\right.$ xylan hydrolyzed/100 g xylan in treated biomass).

\begin{tabular}{|c|c|c|}
\hline Parameters & $\begin{array}{c}Y_{\mathrm{g}} \\
\text { (Equation 25) }\end{array}$ & $\begin{array}{c}Y_{\mathrm{x}} \\
\text { (Equation 26) }\end{array}$ \\
\hline$a_{0}$ or $b_{0}$ & 150.0 & 90.0 \\
\hline$a_{1}$ or $b_{1}$ & 38.06 & 75.0 \\
\hline$a_{2}$ or $b_{2}$ & -40.15 & -30.0 \\
\hline
\end{tabular}



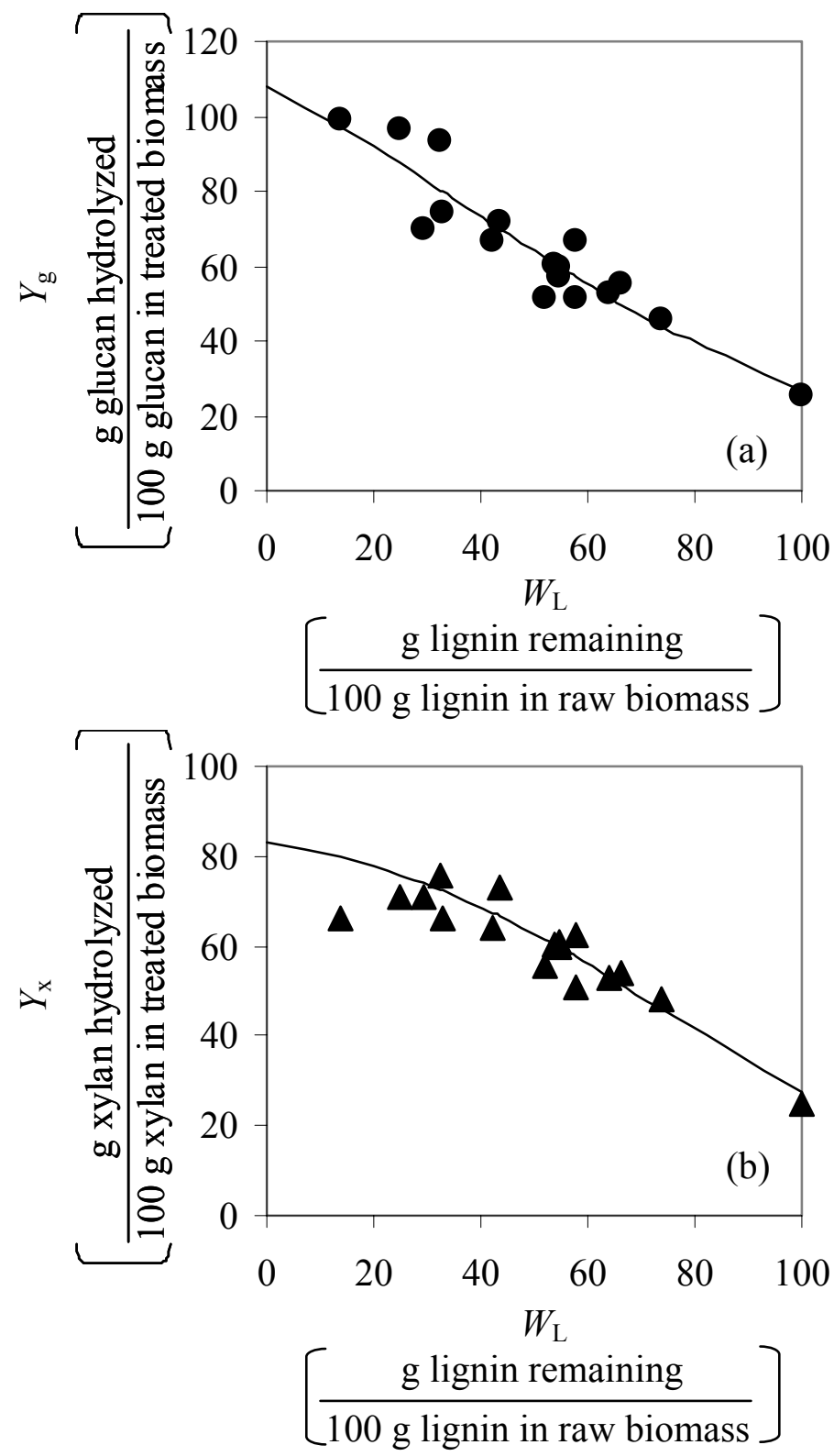

Figure 63. Correlations between the weight fraction of the residual lignin ( $W_{\mathrm{L}}$ ) and 3-d hydrolysis yields: (a) $Y_{\mathrm{g}}$; (b) $Y_{\mathrm{x}}$; (c) $Y_{\mathrm{gx}}$, for corn stover pretreated with lime and air. The enzyme loading rate is 15 FPU/g cellulose. The solid lines show plots of non-linear regressions using Equations 25, 26, and 24, respectively. 


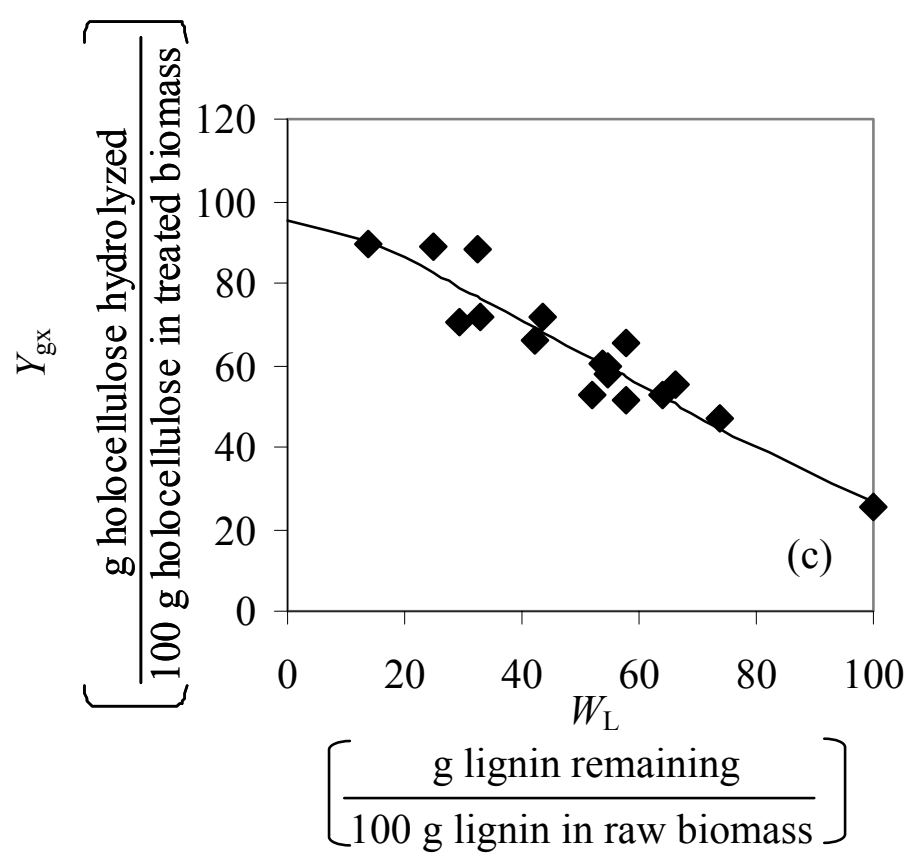

Figure 63. Continued. 
digestibility, regardless of crystallinity.

The non-linear models for 3-d hydrolysis yields of glucan $\left(Y_{\mathrm{g}}\right)$, xylan $\left(Y_{\mathrm{x}}\right)$, and holocellulose $\left(Y_{\mathrm{gx}}\right)$ were empirically established as a function of the residual lignin fraction $\left(W_{\mathrm{L}}\right)$ for the corn stover pretreated with lime and air.

\subsection{Mass Balances from Raw Corn Stover to Enzymatic Hydrolysis}

\section{Introduction}

All components in raw corn stover are fractionated into solid and liquid parts depending on their solubility during lime pretreatment. Most reduction of the solid fraction is caused by delignification, deacetylation, and hemicellulose degradation in the corn stover.

The pretreatment yields of solid, glucan, and xylan - and the enzymatic hydrolysis yields of glucan and xylan to glucose and xylose - were determined in the previous sections. But, these values were obtained from only the solid fraction of the lime pretreatment at each condition.

To determine the mass balances for the whole system, the pretreatment liquor should be considered, because it contains soluble sugars and degradation products from cellulose, hemicellulose, lignin, and other components. Also, the residual solid should be considered after enzymatic hydrolysis of the pretreated corn stover, because it contains the undigested cellulose and hemicellulose, and other residual solids.

Carbohydrates in alkaline solution, in the presence of oxygen, undergo both oxidation and alkaline degradation producing a complex mixture of products (Montgomery 1953, Williams et al. 1982, McGinnis et al. 1984, Klinke et al. 2002). Hydroxy-carboxylic acids, such as glucoisosaccharinic and xylosaccharinic acids, are formed from the degradation of cellulose and hemicellulose by the peeling reaction (or endwise depolymerization) caused by a $\beta$-elimination reaction, which begins at the reducing end of the molecule and proceeds along the chain liberating saccharinate 
molecules (Lai 2001). The formation of low-molecular-mass fragments, such as glycolic and lactic acids, increases at more severe reaction conditions, i.e., high alkaline concentration or high-temperature condition (Sjöström 1991). As intermediates in wet oxidation, monomeric phenols (e.g., 4-hydroxybenzaldehyde, syringaldehyde, and vanillin) and furan derivatives (e.g., 5-hydroxymethylfurfural (5-HMF) and 2-furfural) are formed from the degradation of cellulose and hemicellulose, respectively (Figure 64). Williams et al. (1982) reported that the saccharinic acids reached a maximum about 7 days after treatment of Timothy grass (Phleum pretense) and thereafter decreased due to further degradation to lactic acid and carbon dioxide for a long-term alkaline treatment at mild conditions ( 30 days at $25^{\circ} \mathrm{C}$ ). Some degradation products, such as lactic acid and isosaccharinic acid, in the liquid fraction can be utilized by a mixed-culture of microorganisms after alkaline treatment (Williams et al. 1982).

It is important to know how much cellulose and hemicellulose can be solubilized or degraded after lime pretreatment to perform a total mass balance and determine monosugar yields.

In this study, the amounts of cellulose and hemicellulose that are dissolved and degraded in the liquid fraction of lime-treated corn stover were determined to build a complete mass balance.

If there are no sugars in the pretreatment liquor, the liquid fraction is treated as a waste. But if portions of mono- or oligo-saccharides exist, the liquid fraction can be treated as another carbon source for alcohol fermentation.

The potential ethanol production was estimated for corn stover pretreated at the optimal lime treatment condition and enzymatically hydrolyzed at 15 and $60 \mathrm{FPU} / \mathrm{g}$ cellulose.

Biological inhibitors, such as phenols and furfurals, are produced or released into the hydrolyzate during treatment. To determine whether the pretreatment liquor is fermentable or not, the fermentability was tested for the pretreatment liquor by cultivating Saccharomyces cerevisiae $\mathrm{D}_{5} \mathrm{~A}$ in YPD medium. 


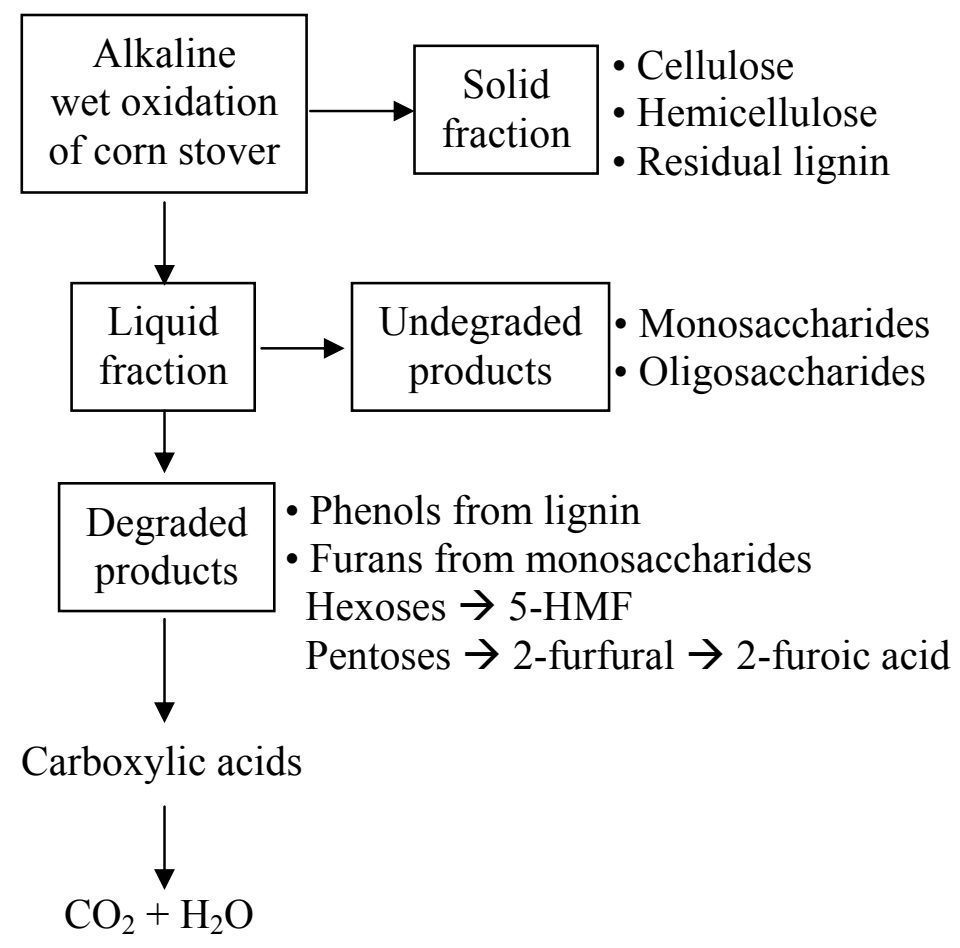

Figure 64. Products of alkaline wet oxidation of corn stover. 


\section{Materials and Methods}

The mass balance from raw corn stover (second batch of corn stover) to enzyme hydrolysis was made for corn stover treated at the recommended condition $\left(55^{\circ} \mathrm{C}, 4\right.$ weeks, and aeration) and treated for a longer time (8 weeks) at the same condition.

The pretreatment liquors were collected from the corn stover slurry by filtration, which was treated with lime and air at $55^{\circ} \mathrm{C}$ for 4 and 8 weeks and then neutralized with hydrochloric acid.

Monosaccharides (glucose, xylose, and arabinose) and disaccharides (cellobiose and xylobiose) in the liquor were analyzed by HPLC using HPX-87C and -87P columns and the refractive index detector, as described in Appendix L, "HPLC analysis of liquid fractions of lime pretreatment for monomeric and dimeric sugars." The total sugars (from monomer to oligomer) and other organic degradation products (e.g., acetic acid, lactic acid, HMF, and furfural) were analyzed by HPLC using HPX-87H column and the refractive index detector, as described in Appendix M, "HPLC analysis of liquid fractions of lime pretreatment to determine total sugars and degradation products."

To characterize the relative fermentability of pretreatment liquor, glucose fermentations were performed using a control sample and various dilutions of hydrolyzates.

Saccharomyces cerevisiae $\mathrm{D}_{5} \mathrm{~A}$ was cultivated in a $125-\mathrm{mL}$ serum bottle with seals containing YPD (10 g/L yeast extract, $20 \mathrm{~g} / \mathrm{L}$ peptone, and $20 \mathrm{~g} / \mathrm{L}$ glucose $)$ medium, as described in Appendix J, "Determination of the fermentability of the pretreatment liquors." One $\mathrm{mL}$ of inoculum cultured for 24 hours was added into $50 \mathrm{~mL}$ of sterilized medium. The fermentability of the pretreatment liquor was characterized by the following equations:

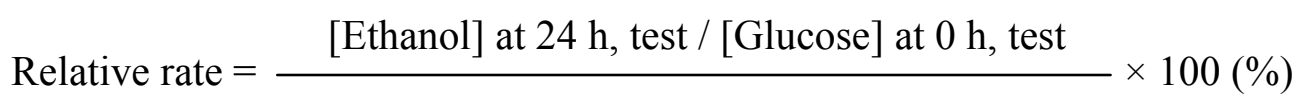

[Ethanol] at $24 \mathrm{~h}$, control / [Glucose] at $0 \mathrm{~h}$, control 


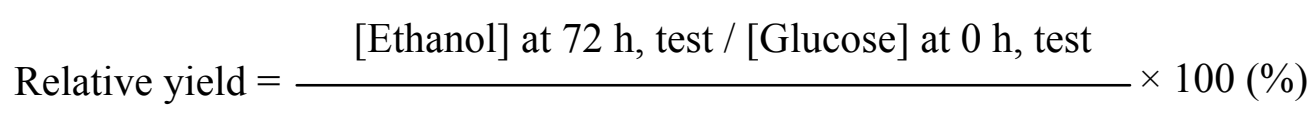

[Ethanol] at $72 \mathrm{~h}$, control / [Glucose] at $0 \mathrm{~h}$, control

The control fermentation was performed at each run with the test fermentations and the results served as the denominator in Equations 27 and 28 for each experiment.

Also, the cell growth yield $\left(Y_{\mathrm{c} / \mathrm{g}}=\right.$ increment of $\mathrm{OD} / \mathrm{g}$ glucose consumed) was compared with the control fermentation. Ethanol concentration was determined by gas chromatography (GC), as described in Appendix K, "Determination of ethanol concentration by GC."

\section{Results and Discussions}

\section{Cellulose and Hemicellulose Recovered in the Solid Corn Stover}

At $55^{\circ} \mathrm{C}$ with air, the pretreatment yields of cellulose $\left(Y_{\mathrm{G}}, \mathrm{g}\right.$ glucan recovered $/ 100$ g glucan in raw biomass) were 97.8 and 85.5 in the solid fraction treated with lime for 4 and 8 weeks, respectively, whereas the pretreatment yields of hemicellulose $\left(Y_{\mathrm{X}}, \mathrm{g}\right.$ xylan recovered/100 g xylan in raw biomass) were 67.8 and 65.7, respectively (Table 22 and Figure 65).

In lime pretreatment, cellulose was recovered in high yield, whereas hemicellulose was not, which is consistent with the results described in Section 3.3, 'Compositional changes of corn stover during lime pretreatment.' In other words, most of the cellulose remained in the solid fraction, whereas hemicellulose was relatively labile and dissolved in pretreatment liquor at mild conditions $\left(25-55^{\circ} \mathrm{C}\right)$.

In enzymatic hydrolysis of the recovered solid, cellulose was more digestible than hemicellulose (Table 23 and Figure 66). At $60 \mathrm{FPU} / \mathrm{g}$ cellulose of cellulase loading, cellulose was almost completely digested $(\geq 97.7 \%)$, but hemicellulose was not completely digested, which might be resulted from a low hemicelluase activity in the enzyme preparation, which was optimized for cellulase activity (Figure 51). 
Table 22. The weight percents of cellulose and hemicellulose degraded and undegraded in the pretreatment liquor, and recovered in the solid stover treated with lime at $55^{\circ} \mathrm{C}$ with aeration for 4 and 8 weeks.

\begin{tabular}{|c|c|c|c|c|}
\hline Component & \multicolumn{2}{|c|}{ Cellulose } & \multicolumn{2}{c|}{ Hemicellulose } \\
\hline Fractions & 4 week & 8 week & 4 week & 8 week \\
\hline Degraded & 0.6 & 13.0 & 7.9 & 11.8 \\
\hline Undegraded & 1.6 & 1.5 & 24.3 & 22.5 \\
\hline Solid & 97.8 & 85.5 & 67.8 & 65.7 \\
\hline
\end{tabular}

Table 23. The weight percents of cellulose and hemicellulose digested and undigested in the recovered solid corn stover treated with lime at $55^{\circ} \mathrm{C}$ with aeration for 4 and 8 weeks, when the enzyme loading rate is 15 and $60 \mathrm{FPU} / \mathrm{g}$ cellulose, respectively, in 3-d enzyme digestibility.

\begin{tabular}{|c|c|c|c|c|}
\hline Component & \multicolumn{2}{|c|}{ Cellulose } & \multicolumn{2}{c|}{ Hemicellulose } \\
\hline Treated Time & 4 week & 8 week & 4 week & 8 week \\
\hline & \multicolumn{4}{|c|}{$15 \mathrm{FPU} / \mathrm{g}$ cellulose } \\
\hline Digested & 92.9 & 96.2 & 75.2 & 70.9 \\
\hline Undigested & 7.1 & 3.8 & 24.8 & 29.1 \\
\hline & \multicolumn{5}{|c|}{$60 \mathrm{FPU} / \mathrm{g}$ cellulose } \\
\hline Digested & 97.7 & 98.8 & 78.6 & 68.0 \\
\hline Undigested & 2.3 & 1.2 & 21.4 & 32.0 \\
\hline
\end{tabular}




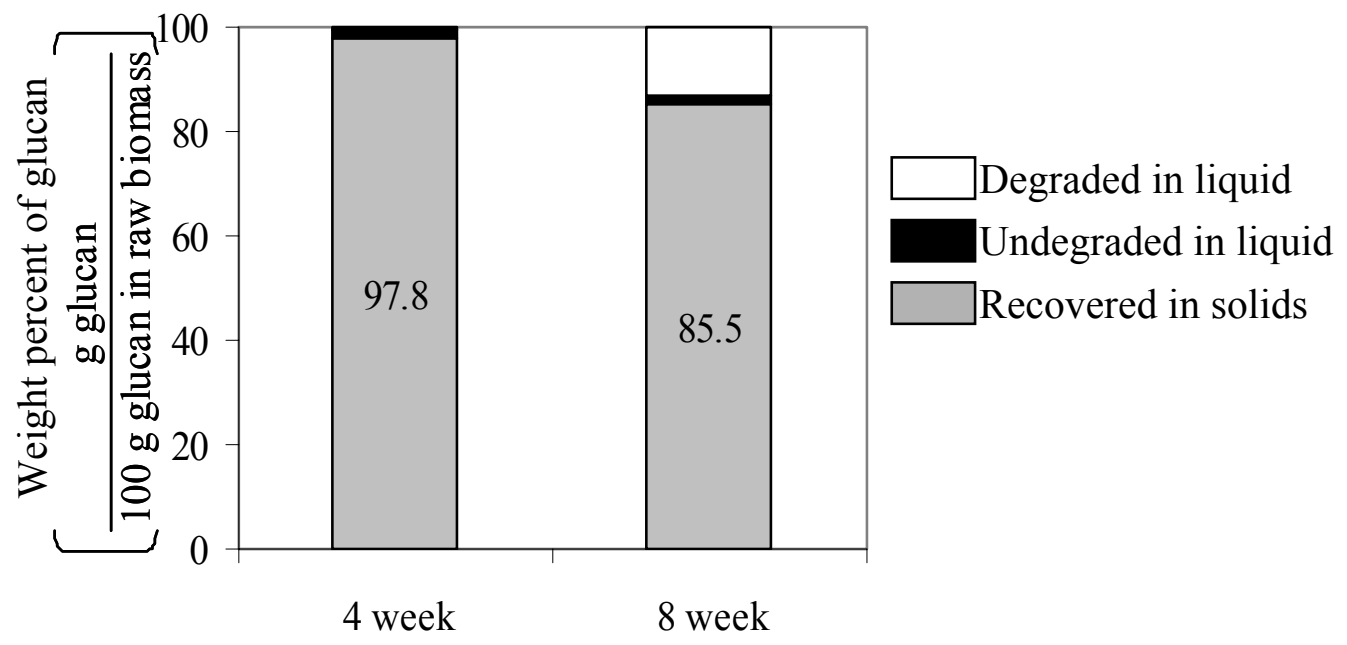

Pretreatment time (weeks)

(a)

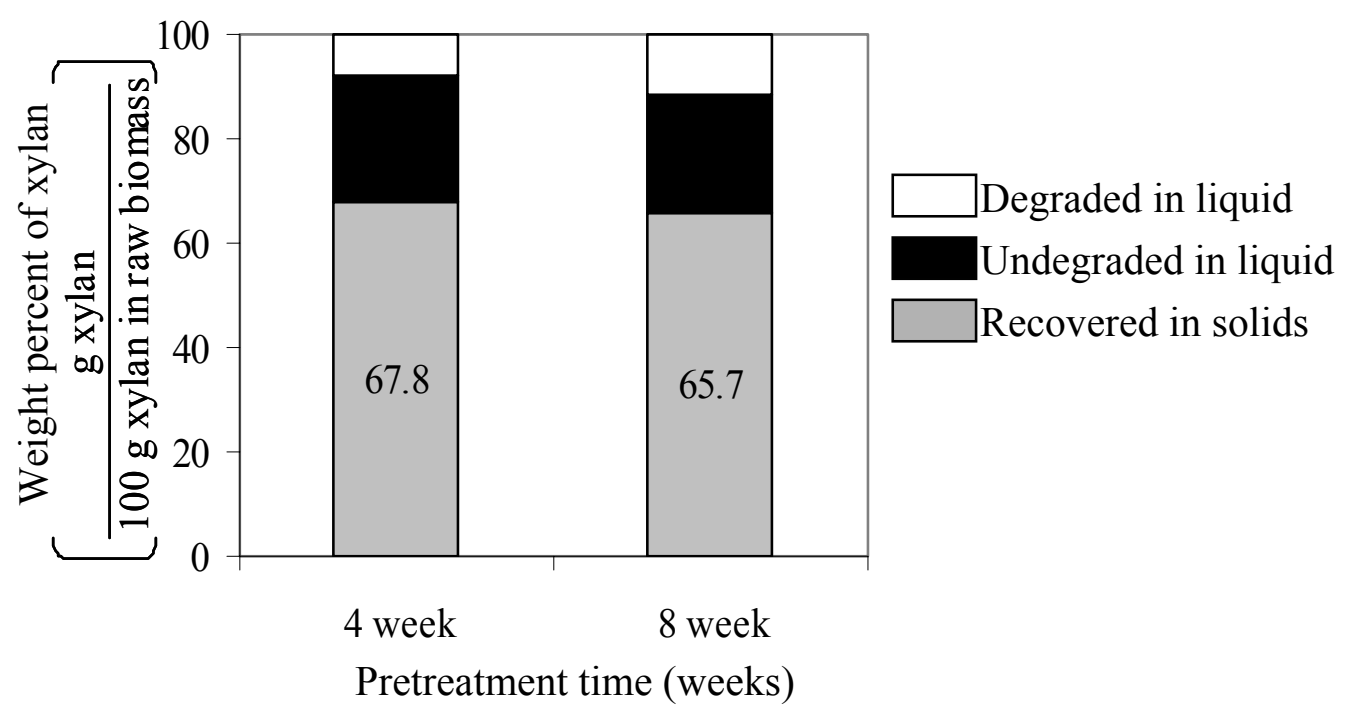

(b)

Figure 65. Weight percents of cellulose (a) and hemicelluose (b) degraded and undegraded in the pretreatment liquor, and recovered in the solid pretreated with lime at $55^{\circ} \mathrm{C}$ in oxidative condition, respectively. 


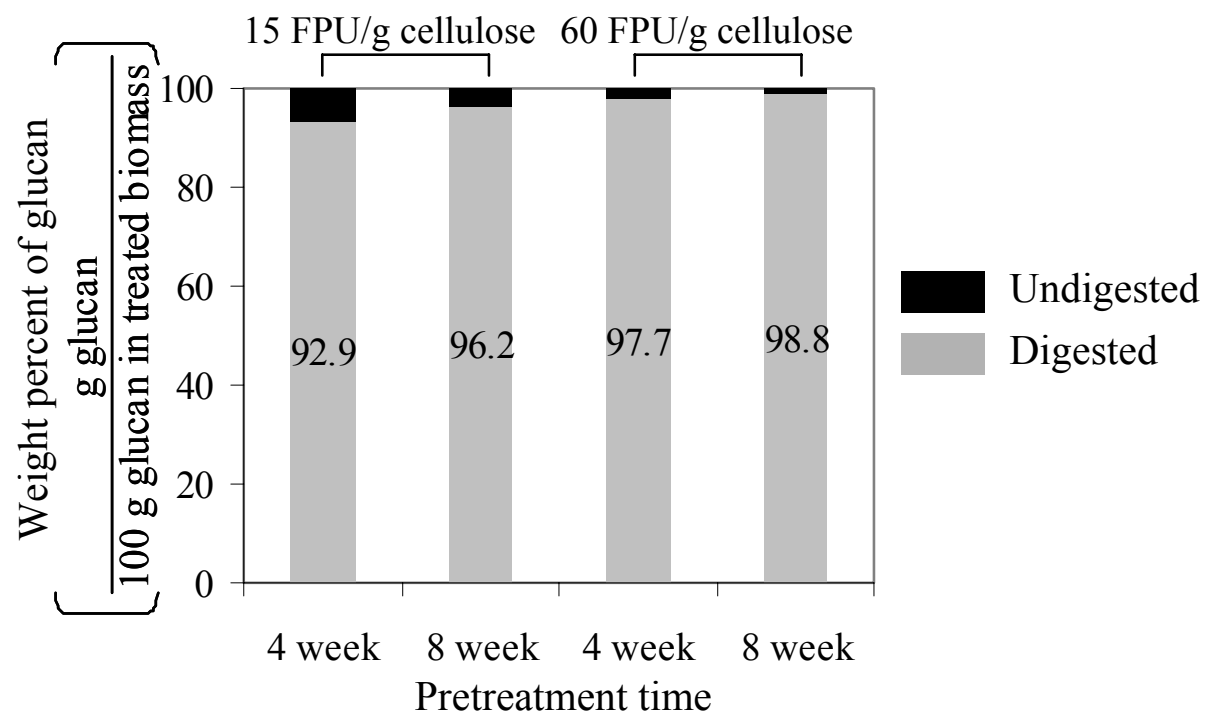

(a)

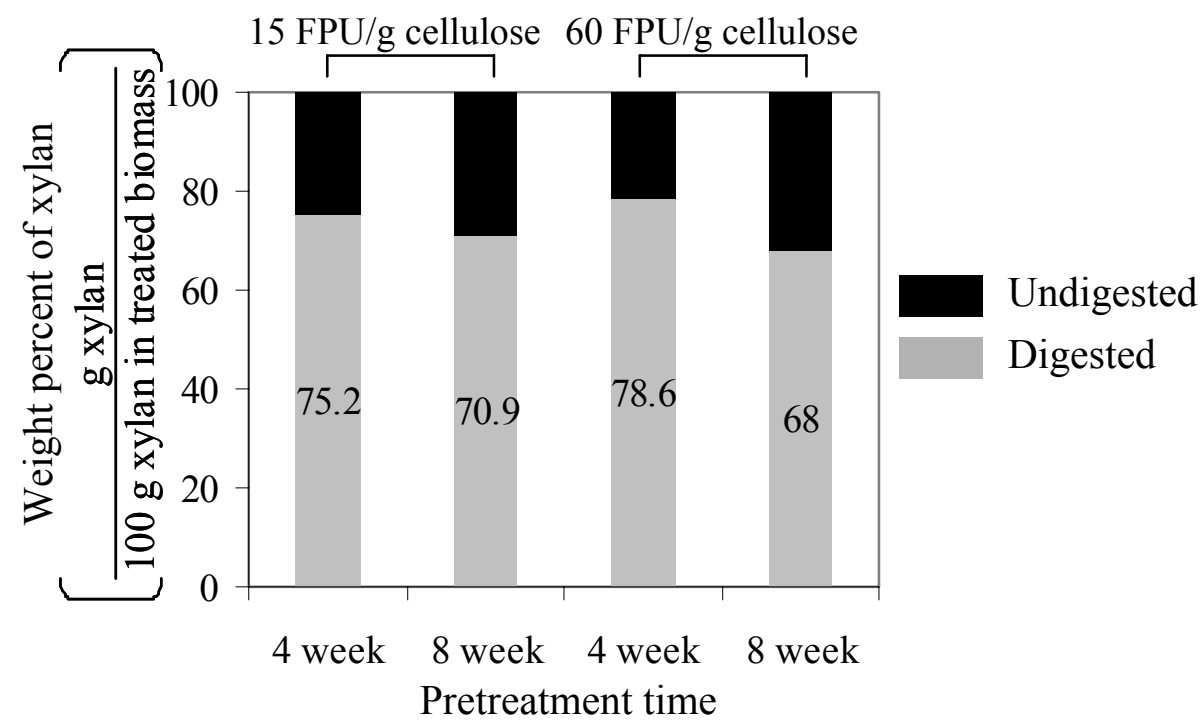

(b)

Figure 66. Weight percents of cellulose (a) and hemicelluose (b) digested and undigested in the recovered solid pretreated with lime at $55^{\circ} \mathrm{C}$ in oxidative condition, respectively, when the enzyme loading rate is 15 and $60 \mathrm{FPU} / \mathrm{g}$ cellulose in 3-d enzyme hydrolysis. 


\section{Cellulose and Hemicellulose Dissolved in the Pretreatment Liquor}

At $55^{\circ} \mathrm{C}$ with aeration, cellulose was not significantly degraded at 4 weeks, as shown in Figure 65 . However, at 8 weeks in this condition, $14.5 \%$ of cellulose in raw corn stover was dissolved into the pretreatment liquor. Most of the cellulose fragments ( $89.8 \%$ of dissolved cellulose) were degraded and only $10.2 \%$ of the cellulose fragments existed as intact glucooligomers (degree of polymerization $\geq 2$ ), as shown in Table 22 .

However, there were no furan intermediates degraded from glucose because 5hydroxymethylfurfural (HMF) peaks (retention time $14.7 \mathrm{~min}$ ) were not detected in the pretreatment liquor. Therefore, the cellulose backbone was broken between 4 and 8 weeks at $55^{\circ} \mathrm{C}$ with air in lime pretreatment and then degraded into small molecules, such as acetic acid and carbon dioxide.

Hemicellulose mainly remained in the solid fraction, but more than $32 \%$ of hemicellulose in raw corn stover was dissolved in the liquid fraction of pretreatment after 4 weeks at $55^{\circ} \mathrm{C}$ using oxidative conditions (see Table 22 and Figure 65). However, $2 / 3$ of the dissolved hemicellulose existed as xylooligomer, and was not degraded into small molecules. It means that hemicellulose degradation is relatively slow compared to cellulose degradation in lime pretreatment of corn stover. The peak of 2-furfural (47.35 min of retention time) was detected as an intermediate product of hemicellulose degradation.

Hemicellulose solubilization in lime pretreatment is closely related with deacetylation and delignification. The residual fraction of hemicellulose in the solid linearly depended on the residual fraction of lignin in the solid, as described in Section 3.4. The removal of acetyl groups from hemicellulose occurred at the very beginning of lime pretreatment. Interestingly, cellulose was much more stable than hemicellulose, but once cellulose dissolved in the pretreatment liquid, it degraded faster than hemicellulose.

\section{Enzymatic Hydrolysis of the Pretreated Corn Stover}

When pretreated corn stover was hydrolyzed enzymatically at $15 \mathrm{FPU} / \mathrm{g}$ cellulose of enzyme loading, cellulose and hemicellulose were digested up to $92.9 \mathrm{~g}$ glucan 
hydrolyzed/100 g glucan in treated biomass and $75.2 \mathrm{~g}$ xylan hydrolyzed/100 $\mathrm{g}$ xylan in treated biomass, respectively, from the solid corn stover pretreated at $55^{\circ} \mathrm{C}$ with aeration for 4 weeks (see Figure 66). At 60 FPU/g cellulose of enzyme loading, the 3-d enzyme digestibility of cellulose and hemicellulose increased up to $97.7 \mathrm{~g}$ glucan hydrolyzed/100 $\mathrm{g}$ glucan in treated biomass and $78.6 \mathrm{~g}$ xylan hydrolyzed/100 $\mathrm{g}$ xylan in treated biomass, respectively, for the same corn stover. For the corn stover treated at the same condition for 8 week, the 3-d enzyme digestibility of cellulose increased, but that of hemicellulose decreased, as shown in Table 23 and Figure 66.

Using the optimal lime pretreatment conditions, the overall yields of glucose and xylose were obtained up to $91.3 \mathrm{~g}$ glucan hydrolyzed/100 g glucan in raw biomass and $51.8 \mathrm{~g}$ xylan hydrolyzed/100 $\mathrm{g}$ xylan in treated biomass at $15 \mathrm{FPU} / \mathrm{g}$ cellulose, and 95.5 g glucan hydrolyzed/100 g glucan in treated biomass and $53.5 \mathrm{~g}$ xylan hydrolyzed/100 g xylan in treated biomass at $60 \mathrm{FPU} / \mathrm{g}$ cellulose, respectively.

For the solid fraction treated at the optimal condition, additionally, the enzyme hydrolysis at 15 and $60 \mathrm{FPU} / \mathrm{g}$ cellulose was performed by another research group (Auburn University) as a member of Biomass Refining Consortium for Applied Fundamentals and Innovation (CAFI). From their results, the overall yields of glucose (g glucan hydrolyzed/100 g glucan in raw biomass) and xylose (g xylan hydrolyzed/100 g xylan in raw biomass) were $103 \%$ and $62 \%$ at $15 \mathrm{FPU} / \mathrm{g}$ cellulose, and $104 \%$ and $66 \%$ at $60 \mathrm{FPU} / \mathrm{g}$ cellulose, respectively. These results from other researchers were not included to calculate the mass balance of the whole process in this study, because these values appeared to be overestimated and did not match well with other values in mass balances.

The corn stover pretreated at optimal conditions hydrolyzed quickly, compared with the hydrolysis rate of $\alpha$-cellulose (SIGMA catalog no. C-8002). When compared to the rate of enzyme hydrolysis of $\alpha$-cellulose, the relative digestibility of the pretreated corn stover reached a maximum value in a short hydrolysis time, as shown in Figure 67.

For a given biomass, the relative digestibility is defined as the ratio of the digestibility at a particular time to its digestibility at $96 \mathrm{~h}$, which is assumed to be the asymptotic maximum (ultimate digestibility). The digestibility (hydrolysis yield) at $96 \mathrm{~h}$ 


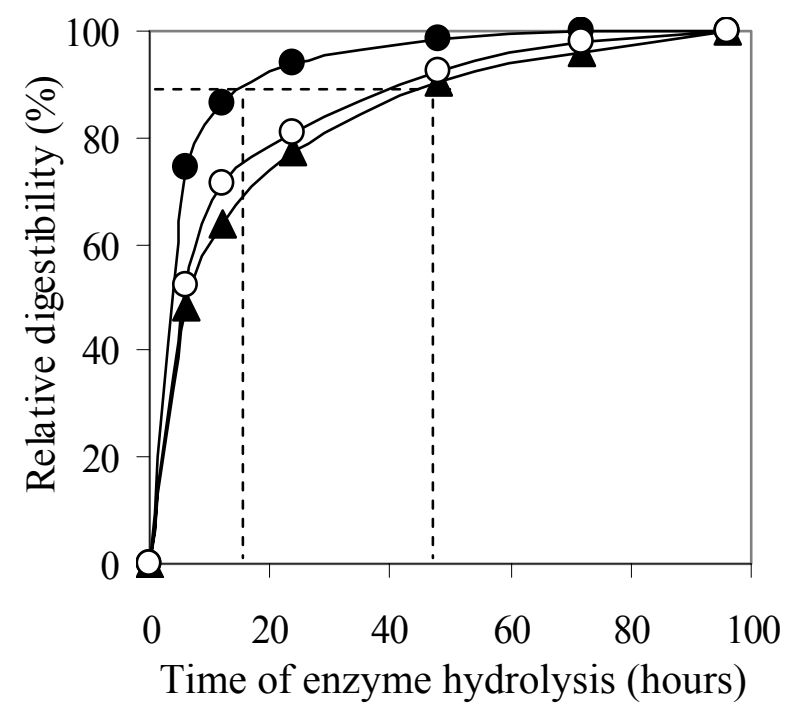

(a)

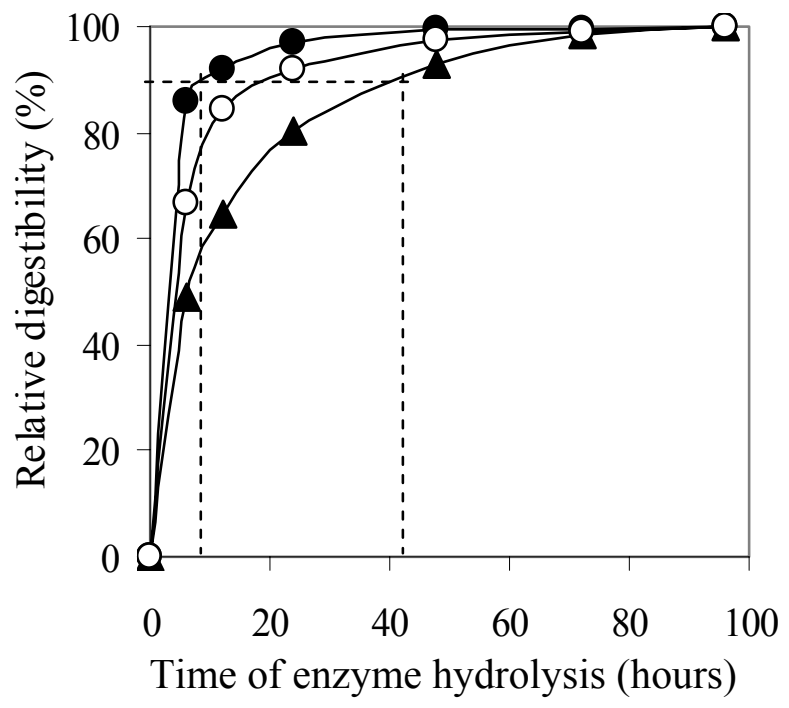

(b)

Figure 67. The relative digestibility of glucan in enzyme hydrolysis of $\alpha$-cellulose $(\boldsymbol{\Delta})$ and the corn stover $(\mathbf{O})$ pretreated with lime at the optimal condition $\left(55^{\circ} \mathrm{C}, 4\right.$ weeks, and aeration), and relative digestibility of xylan $(\mathrm{O})$ for the pretreated corn stover at (a) 15 and (b) $60 \mathrm{FPU} / \mathrm{g}$ cellulose, respectively. 
of hydrolysis was 0.88 and $0.99 \mathrm{~g}$ glucan digested/g glucan in substrate for $\alpha$-cellulose, and 0.98 and $0.99 \mathrm{~g}$ glucan digested/g glucan in treated biomass for the pretreated corn stover, at 15 and $60 \mathrm{FPU} / \mathrm{g}$ cellulose, respectively.

To obtain $90 \%$ of the relative digestibility, $\alpha$-cellulose needs to be enzymatically hydrolyzed over $47 \mathrm{~h}$ and $43 \mathrm{~h}$, whereas the pretreated corn stover just requires $15 \mathrm{~h}$ and $9 \mathrm{~h}$, at 15 and $60 \mathrm{FPU} / \mathrm{g}$ cellulose, respectively. Apparently, xylan in the corn stover requires more time to be completely hydrolyzed than glucan in enzyme hydrolysis, as shown in Figure 67.

\section{Mass Balances from Raw Corn Stover to Enzyme Hydrolysis}

A mass balance for the whole process, from raw corn stover to enzyme hydrolysis, is depicted in Figure 68. The composition of the raw corn stover (second batch) is listed in the second column in Tables 24 and 25. Each component of raw corn stover ('RC') was fractionated into the solid ('PS') and liquid ('PL') fractions after lime pretreatment; the values are listed in Tables 24 and 25.

The largest change in the corn stover composition was the lignin. Of the Klason lignin of raw corn stover, $66.9 \%$ and $79.7 \%$ were dissolved for 4 and 8 weeks, respectively, at $55^{\circ} \mathrm{C}$ in the oxidative lime pretreatment.

The second largest change in the corn stover composition was hemicellulose (mainly xylooligomer), as discussed in the previous sub-sections. More than $62 \%$ of protein and $93 \%$ of acetyl groups in raw biomass were solubilized into the pretreatment liquor.

Total mass was well conserved through the whole process, e.g., mass balance closure was $99.6 \%$ in the optimal pretreatment and the enzyme hydrolysis at $15 \mathrm{FPU} / \mathrm{g}$ cellulose.

\section{Estimation of Ethanol Production}

The ethanol yield from sugars (glucose and xylose) was assumed as $0.45 \mathrm{~g}$ ethanol/g sugar in alcohol fermentation. It was assumed that $100 \mathrm{lb}$ of dry raw corn 


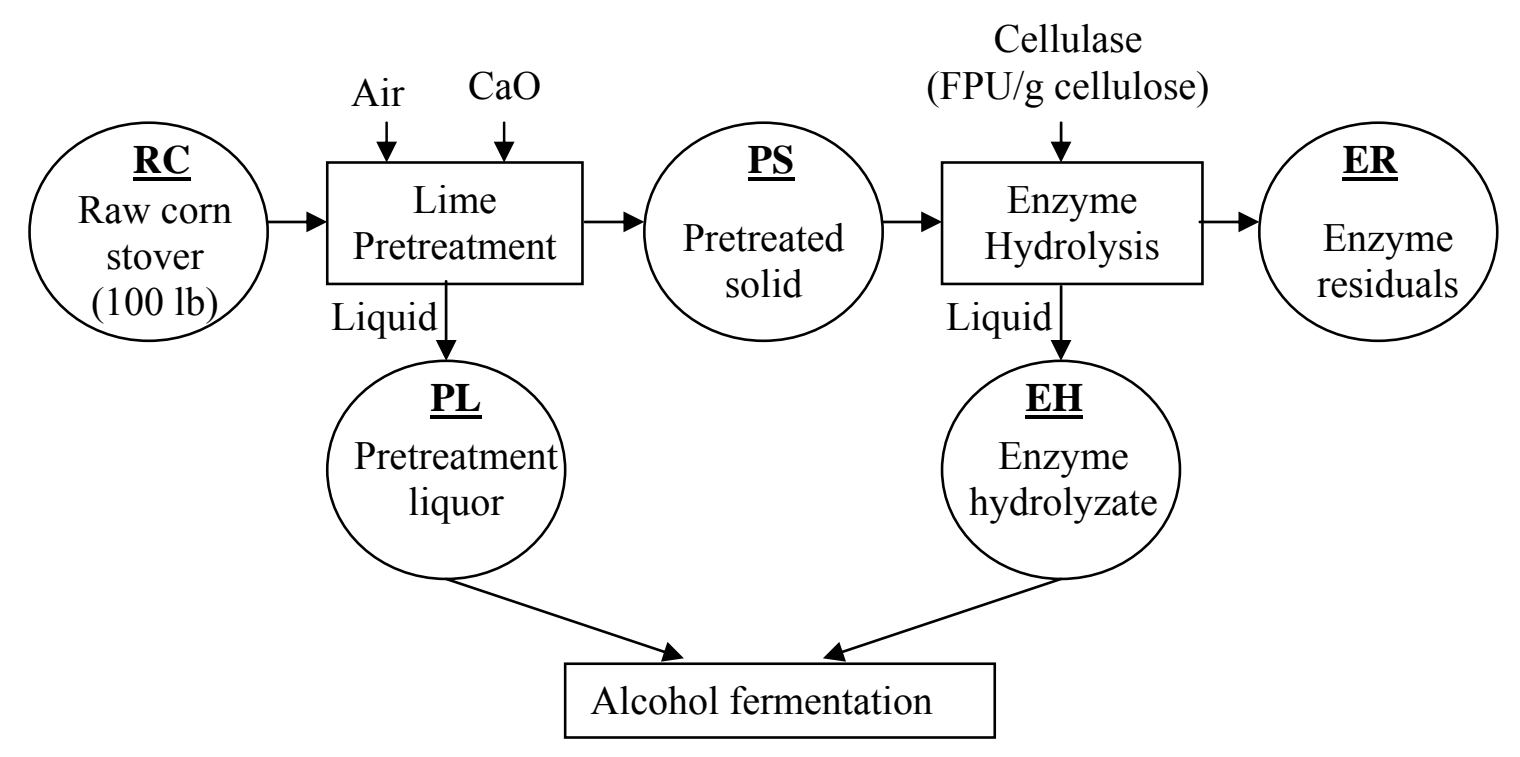

Figure 68. Mass fractions from raw corn stover to enzyme hydrolysis. 
Table 24. Mass balances from raw corn stover (RC) to enzyme hydrolysis (ER and $\mathrm{EH}$ ) of the pretreated corn stover (in Figure 68 ) at $55^{\circ} \mathrm{C}$ with aeration for 4 weeks.

\begin{tabular}{|c|c|c|c|c|c|c|c|}
\hline \multirow{3}{*}{$\begin{array}{c}\text { In } 100 \mathrm{lb} \text { of } \\
\text { raw }(\mathrm{RC})\end{array}$} & \multirow{3}{*}{$\begin{array}{l}\text { Raw } \\
\mathrm{RC}\end{array}$} & \multirow{2}{*}{\multicolumn{2}{|c|}{ Lime pretreatment }} & \multicolumn{4}{|c|}{ Enzyme hydrolysis } \\
\hline & & & & \multicolumn{2}{|c|}{$15 \mathrm{FPU} / \mathrm{g}$ cellulose } & \multicolumn{2}{|c|}{$60 \mathrm{FPU} / \mathrm{g}$ cellulose } \\
\hline & & PS & PL & ER & $\mathrm{EH}$ & ER & $\mathrm{EH}$ \\
\hline Glucan & 36.1 & 35.3 & $0.58^{5)}$ & $2.3^{9)}$ & 33.0 & $0.8^{9)}$ & 34.5 \\
\hline Xylan & 21.4 & 14.5 & $5.2^{6)}$ & $3.4^{9)}$ & 11.1 & $3.1^{9)}$ & 11.4 \\
\hline Arabinan & 3.6 & 1.4 & 2.2 & 1.4 & 0.0 & 1.4 & 0.0 \\
\hline K. Lignin ${ }^{1)}$ & 17.2 & 5.7 & 11.5 & 5.7 & 0.0 & 5.7 & 0.0 \\
\hline A. Lignin ${ }^{2)}$ & 3.6 & 3.6 & 0.0 & 3.6 & 0.0 & 3.6 & 0.0 \\
\hline Protein & 3.5 & 1.3 & 2.2 & 1.3 & 0.0 & 1.3 & 0.0 \\
\hline Acetyl & 3.2 & 0.2 & $3.1^{7)}$ & 0.2 & 0.0 & 0.2 & 0.0 \\
\hline Ash & 6.9 & 8.6 & $\mathrm{NM}^{8)}$ & 6.9 & 0.0 & 6.9 & 0.0 \\
\hline Others $^{3)}$ & 6.1 & 6.4 & $\mathrm{NM}^{8)}$ & 7.6 & 0.0 & 9.8 & 0.0 \\
\hline Total (lb) & 101.6 & 77.0 & 24.8 & $32.4^{10)}$ & 44.1 & $32.8^{10)}$ & 45.9 \\
\hline $\begin{array}{c}\text { Mass } \\
\text { balance } \\
\text { closures }\end{array}$ & \multicolumn{7}{|c|}{$\begin{array}{l}\text { for } 15 \mathrm{PU} / \mathrm{g} \text { cellulose } \\
\qquad\{(77.0+24.8) / 101.6\} \times\{(32.4+44.1) / 77.0\} \times 100=99.6 \% \\
\text { for } 60 \mathrm{FPU} / \mathrm{g} \text { cellulose } \\
\quad\{(77.0+24.8) / 101.6\} \times\{(32.8+45.9) / 77.0\} \times 100=102.4 \%\end{array}$} \\
\hline
\end{tabular}

1) Klason lignin

2) Acid-soluble lignin

3) Others $=$ mannan + galactan + uronic acid + non-structural sugars

4) $[\{$ Mass (PS)+Mass(PL) $\} / \operatorname{Mass}(\mathrm{RC})] \times[\{\operatorname{Mass}(\mathrm{ER})+\operatorname{Mass}(\mathrm{EH})\} / \operatorname{Mass}(\mathrm{PS})] \times 100(\%)$

5) Total glucan dissolved $(\mathrm{lb})=(0.19 \mathrm{lb}$ glucose $+0.44 \mathrm{lb}$ glucooligomer $) \times 0.9$ in the pretreatment liquor

6) Total xylan dissolved $(\mathrm{lb})=(0.19 \mathrm{lb}$ xylose $+5.72 \mathrm{lb}$ xylooligomer $) \times 0.88$ in the pretreatment liquor

7) The amounts of acetic acid in the pretreatment liquor measured by HPLC

8) $\mathrm{NM}=$ not measured

9) Undigested glucan or xylan in enzyme hydrolysis

10) Total amounts of the residual solid in enzyme hydrolysis measured gravimetrically

* It was assumed that the enzyme hydrolyzate contained glucose and xylose only. It is expressed equivalent glucan and xylan. 
Table 25. Mass balances from raw corn stover (RC) to enzyme hydrolysis (ER and $\mathrm{EH}$ ) of the pretreated corn stover (in Figure 68 ) at $55^{\circ} \mathrm{C}$ with aeration for 8 weeks.

\begin{tabular}{|l|c|c|c|c|c|c|c|}
\hline \multirow{2}{*}{$\begin{array}{c}\text { In } 100 \mathrm{lb} \text { of } \\
\text { raw }(\mathrm{RC})\end{array}$} & Raw & \multicolumn{2}{|c|}{ Lime pretreatment } & \multicolumn{5}{|c|}{ Enzyme hydrolysis } \\
\cline { 5 - 8 } & & & & 15 FPU/g cellulose & \multicolumn{2}{c|}{60 FPU/g cellulose } \\
\hline Component & RC & PS & PL & ER & EH & ER & EH \\
\hline Glucan & 36.1 & 30.9 & $0.5^{5)}$ & $1.2^{9)}$ & 29.7 & $0.4^{9)}$ & 30.5 \\
\hline Xylan & 21.4 & 14.1 & $4.8^{6)}$ & $4.1^{9)}$ & 10.0 & $4.5^{9)}$ & 9.6 \\
\hline Arabinan & 3.6 & 1.7 & 1.9 & 1.7 & 0.0 & 1.7 & 0.0 \\
\hline K. Lignin & 17.2 & 3.5 & 13.7 & 3.5 & 0.0 & 3.5 & 0.0 \\
\hline A. Lignin
\end{tabular}

1) Klason lignin

2) Acid-soluble lignin

3) Others $=$ mannan + galactan + uronic acid + non-structural sugars

4) $[\{$ Mass (PS)+Mass(PL) $\} / \operatorname{Mass}(\mathrm{RC})] \times[\{\operatorname{Mass}(\mathrm{ER})+\operatorname{Mass}(\mathrm{EH})\} / \operatorname{Mass}(\mathrm{PS})] \times 100(\%)$

5) Total glucan dissolved $(\mathrm{lb})=(0.00 \mathrm{lb}$ glucose $+0.59 \mathrm{lb}$ glucooligomer $) \times 0.9$ in the pretreatment liquor

6) Total xylan dissolved $(\mathrm{lb})=(0.00 \mathrm{lb}$ xylose $+5.48 \mathrm{lb}$ xylooligomer $) \times 0.88$ in the pretreatment liquor

7) The amounts of acetic acid in the pretreatment liquor measured by HPLC

8) $\mathrm{NM}=$ not measured

9) Undigested glucan or xylan in enzyme hydrolysis

10) Total amounts of the residual solid in enzyme hydrolysis measured gravimetrically

* It was assumed that the enzyme hydrolyzate contained glucose and xylose only. It is expressed equivalent glucan and xylan. 
stover (second batch) was pretreated at the optimal condition $\left(55^{\circ} \mathrm{C}, 4\right.$ weeks, and aeration) and enzymatically hydrolyzed with 15 and $60 \mathrm{FPU} / \mathrm{g}$ cellulose for 3 days.

The previous results were used for yields of glucose and xylose in pretreatment and enzyme hydrolysis (overall conversion), as summarized in Table 26 and 27. On the basis of these assumptions, the amount of ethanol (gallon) in yeast fermentation was estimated by the case studies as follows:

\section{Case 1. Fermentation of enzyme hydrolyzate saccharified from only solid fraction of pretreatment: $\mathrm{R} \rightarrow \mathrm{PS} \rightarrow \mathrm{EH} \rightarrow$ Fermentation}

This case considers glucose and xylose in the enzyme hydrolyzate obtained only from the solid fraction of the pretreated corn stover. Per $100 \mathrm{lb}$ of raw corn stover, 36.6 $\mathrm{lb}$ of glucose (33 lb glucan $\div 0.9$ ) and $12.6 \mathrm{lb}$ of xylose $(11.1 \mathrm{lb}$ xylan $\div 0.88$ ) can serve as carbon sources for yeast fermentation, when the pretreated solid (35.3 lb glucan and $14.5 \mathrm{lb}$ xylan) is hydrolyzed at $15 \mathrm{FPU} / \mathrm{g}$ cellulose of enzyme loading. It gives 3.38 gallons of ethanol. If the same calculation is applied for $60 \mathrm{FPU} / \mathrm{g}$ cellulose, then 3.52 gallons of ethanol can be produced.

\section{Case 2. Fermentation of enzyme hydrolyzate containing the pretreament liquor: $\mathbf{R}$ $\rightarrow$ PS+PL $\rightarrow$ EH $\rightarrow$ Fermentation}

This case considers the total sugars (glucose and xylose) generated in the pretreatment step as carbon source for fermentation. The $0.63 \mathrm{lb}$ of glucose and $5.91 \mathrm{lb}$ of xylose in the pretreatment liquor (PL) were added with the $36.6 \mathrm{lb}$ of glucose and 12.6 $\mathrm{lb}$ of xylose obtained from the enzyme hydrolysis at $15 \mathrm{FPU} / \mathrm{g}$ cellulose in Case 1.

It gives 3.88 gallons of ethanol. For $60 \mathrm{FPU} / \mathrm{g}$ cellulose, 4.02 gallons of ethanol can be produced. Thus, an additional 0.50 gallons of the ethanol can be produced, if the monomers and sugar oligomers in the pretreatment liquor are used. 
Table 26. Yields of glucose and xylose in the pretreatment and the overall process, when the enzyme loading is $15 \mathrm{FPU} / \mathrm{g}$ cellulose.

\begin{tabular}{|c|c|c|c|}
\hline \multicolumn{2}{|c|}{ Process } & $\begin{array}{c}\text { Yield of glucan } \\
\text { (g glucan/100 g } \\
\text { original glucan) }\end{array}$ & $\begin{array}{c}\text { Yield of xylan } \\
\text { (g xylan/100 g } \\
\text { original xylan) }\end{array}$ \\
\hline \multirow{4}{*}{ Pretreatment } & $\mathrm{RC} \rightarrow \mathrm{PS}^{1)}$ & 97.8 & 67.8 \\
\cline { 2 - 4 } & $\mathrm{RC} \rightarrow \mathrm{PL}^{2)}$ & 1.60 & 24.4 \\
\cline { 2 - 4 } Overall process & $\mathrm{RC} \rightarrow \mathrm{PS}+\mathrm{PL}^{3)}$ & 99.4 & 92.1 \\
\hline & $\mathrm{RC} \rightarrow \mathrm{PS} \rightarrow \mathrm{EH}^{4)}$ & 91.3 & 51.8 \\
\cline { 2 - 4 } & $\begin{array}{c}\mathrm{RC} \rightarrow \mathrm{PS}+\mathrm{PL} \rightarrow \\
\mathrm{EH}^{5}\end{array}$ & 93.2 & 79.5 \\
\hline
\end{tabular}

1) The recovery of glucan and xylan in the pretreatment solid

2) The solubilization of glucan and xylan in the pretreatment liquor $($ Total glucose $=$ monomer + glucooligomer; total xylose $=$ monomer + xylooligomer $)$

3) To calculate the yield of total sugars (= monomer + oligomer + polysaccharide)

4) To estimate the ethanol production in Case 1.

5) To estimate the ethanol production in Case 2.

Table 27. Yields of glucose and xylose in the pretreatment and the overall process, when the enzyme loading is $60 \mathrm{FPU} / \mathrm{g}$ cellulose.

\begin{tabular}{|c|c|c|c|}
\hline \multicolumn{2}{|c|}{ Process } & $\begin{array}{c}\text { Yield of glucan } \\
\text { (g glucan/100 g } \\
\text { original glucan) }\end{array}$ & $\begin{array}{c}\text { Yield of xylan } \\
\text { (g xylan/100 g } \\
\text { original xylan) }\end{array}$ \\
\hline \multirow{3}{*}{ Pretreatment } & $\mathrm{RC} \rightarrow \mathrm{PS}^{1)}$ & 97.8 & 67.8 \\
\cline { 2 - 4 } & $\mathrm{RC} \rightarrow \mathrm{PL}^{2)}$ & 1.60 & 24.4 \\
\cline { 2 - 4 } & $\mathrm{RC} \rightarrow \mathrm{PS}+\mathrm{PL}^{3)}$ & 99.4 & 92.1 \\
\hline \multirow{3}{*}{ Overall process } & $\mathrm{RC} \rightarrow \mathrm{PS} \rightarrow \mathrm{EH}^{4)}$ & 95.5 & 53.5 \\
\cline { 2 - 4 } & $\begin{array}{c}\mathrm{RC} \rightarrow \mathrm{PS}+\mathrm{PL} \rightarrow \\
\mathrm{EH}^{5)}\end{array}$ & 97.2 & 80.9 \\
\hline
\end{tabular}

1) -5): same as Table 26 


\section{Fermentability of the Pretreatment Liquor}

In YPD basal medium (10 g/L yeast extract, $20 \mathrm{~g} / \mathrm{L}$ peptone, and $20 \mathrm{~g} / \mathrm{L}$ glucose $)$, the optical density (O.D. measured at $600 \mathrm{~nm}$ with a standard cuvet (1-cm pathlength)) of Saccharomyces cerevisiae $\mathrm{D}_{5} \mathrm{~A}$ reached up to $6.5 \pm 0.2$ at $24 \mathrm{~h}$. In this fermentation, $21 \mathrm{~g} / \mathrm{L}$ of initial glucose was completely consumed and the ethanol production was 11.3 $\pm 1.2 \mathrm{~g} / \mathrm{L}$. After $24 \mathrm{~h}$, the cell growth reduced and the ethanol concentration reduced to $9.9 \pm 1.0 \mathrm{~g} / \mathrm{L}$, as shown in Figure 69 .

When $50 \%(\mathrm{v} / \mathrm{v})$ of pretreatment liquor collected from the optimal pretreatment (4 weeks, $55^{\circ} \mathrm{C}$, and aeration) was contained in the basal medium, the relative rate of fermentation in Equation 26 was $86.1 \%$, but the cell yield from glucose $\left(Y_{\mathrm{c} / \mathrm{g}}\right)$ was $17.9 \%$ higher than that of the control during the 24-h cultivation. The relative ethanol yield of the test medium in Equation 27 was $10.3 \%$ higher than that of the control, and $Y_{\mathrm{c} / \mathrm{g}}$ was still higher after $72 \mathrm{~h}$, as shown in Table 28 .

In this study, there was no reduction in cell yield or ethanol yield from glucose for the oxidative pretreatment liquors of corn stover. As the pretreatment time increased from 4 to 16 weeks, the relative rate of fermentation at $24 \mathrm{~h}$ was slightly lower. However, the relative yield of ethanol fermentation at $72 \mathrm{~h}$ showed higher values in the pretreatment liquor than in control fermentation.

Therefore, it is concluded that there are no inhibitory substances in pretreatment liquor against yeast cell growth and ethanol production.

\section{Applications}

Industrially, one possible implementation of the lime pretreatment technology is a biomass pile that accomplishes both pretreatment and fermentation, as shown in Figure 70. Once the biomass pile is pretreated with lime $\left(0.073 \mathrm{~g} \mathrm{Ca}(\mathrm{OH})_{2} / \mathrm{g}\right.$ raw biomass $)$ or quick lime $(0.058 \mathrm{~g} \mathrm{CaO} / \mathrm{g}$ raw biomass $)$ at the optimal condition $\left(55^{\circ} \mathrm{C}, 4\right.$ weeks, and aeration), the fermentation can be performed in the same pile by direct inoculation and cultivation of acid-forming microorganisms from ruminal or marine sources. 


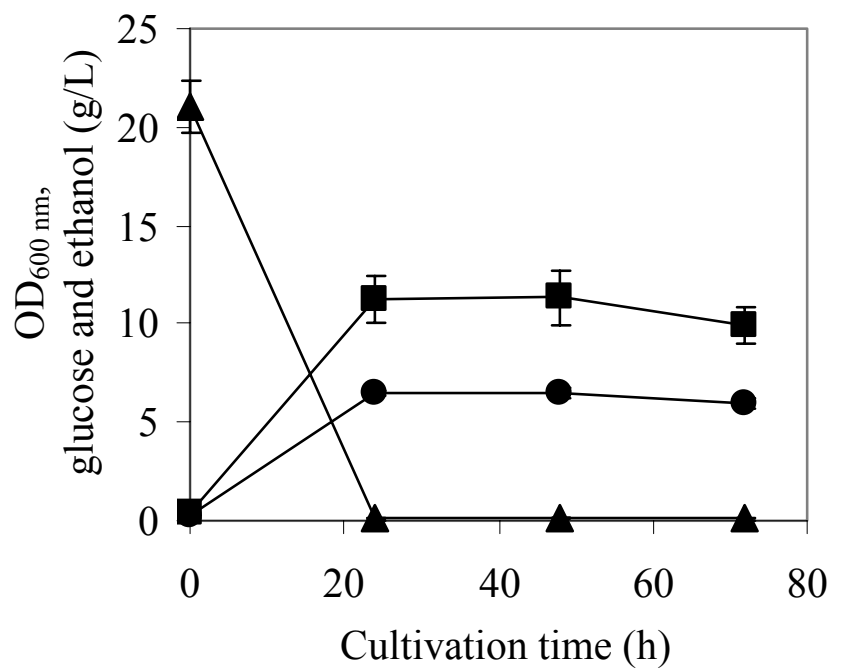

Figure 69. Cultivation of Saccharomyces cerevisiae $\mathrm{D}_{5} \mathrm{~A}$ in YPD basal medium at $37^{\circ} \mathrm{C}$ : OD (-), glucose concentration $(\mathbf{\Lambda})$, and ethanol concentration $(\mathbf{\square})$.

Table 28. Fermentability of the pretreatment liquor collected in the non-oxidative and oxidative conditions at $55^{\circ} \mathrm{C}$.

\begin{tabular}{|c|c|c|c|c|c|c|c|}
\hline \multirow{2}{*}{ Parameters } & \multirow{2}{*}{$\begin{array}{c}\text { Culture } \\
\text { Time } \\
\end{array}$} & (h) & Control & \multicolumn{2}{|c|}{$\begin{array}{c}\text { Non-oxidative } \\
\text { pretreatment }\end{array}$} & \multicolumn{3}{|c|}{$\begin{array}{c}\text { Oxidative } \\
\text { pretreatment }\end{array}$} \\
\cline { 4 - 8 } & & $\begin{array}{c}1 \\
\text { day }^{*}\end{array}$ & $\begin{array}{c}16 \\
\text { week }^{*}\end{array}$ & $\begin{array}{c}4 \\
\text { weeks }^{*}\end{array}$ & $\begin{array}{c}8 \\
\text { weeks }\end{array}$ & $\begin{array}{c}16 \\
\text { weeks }^{*}\end{array}$ \\
\hline$Y_{\mathrm{c} / \mathrm{g}}{ }^{1)}$ & 24 & 0.12 & 0.12 & 0.09 & 0.14 & 0.17 & 0.12 \\
& 72 & 0.11 & 0.10 & 0.09 & 0.15 & 0.16 & 0.12 \\
\hline$Y_{\mathrm{e} / \mathrm{g}}{ }^{2)}$ & 24 & 0.44 & 0.45 & 0.62 & 0.40 & 0.57 & 0.55 \\
0.59 & 72 & 0.35 & 0.43 & 0.51 & 0.41 & 0.55 & 0.59 \\
\hline $\begin{array}{c}\text { Relative } \\
\text { rate }^{3)}\end{array}$ & 24 & 100 & 107.3 & 85.6 & 86.1 & 99.9 & 87.8 \\
\hline $\begin{array}{c}\text { Relative } \\
\text { yield }^{4)}\end{array}$ & 72 & 100 & 112.4 & 94.4 & 110.3 & 115.3 & 108.4 \\
\hline
\end{tabular}

* Pretreatment time.

1) Cell yield for glucose $=\mathrm{g}$ cell increased $/ \mathrm{g}$ glucose consumed $(\mathrm{g}$ cell $=0.414 \times$ O.D. $)$.

2) Ethanol yield for glucose $=\mathrm{g}$ ethanol produced $/ \mathrm{g}$ glucose consumed.

3) Defined in Equation 27.

4) Defined in Equation 28. 


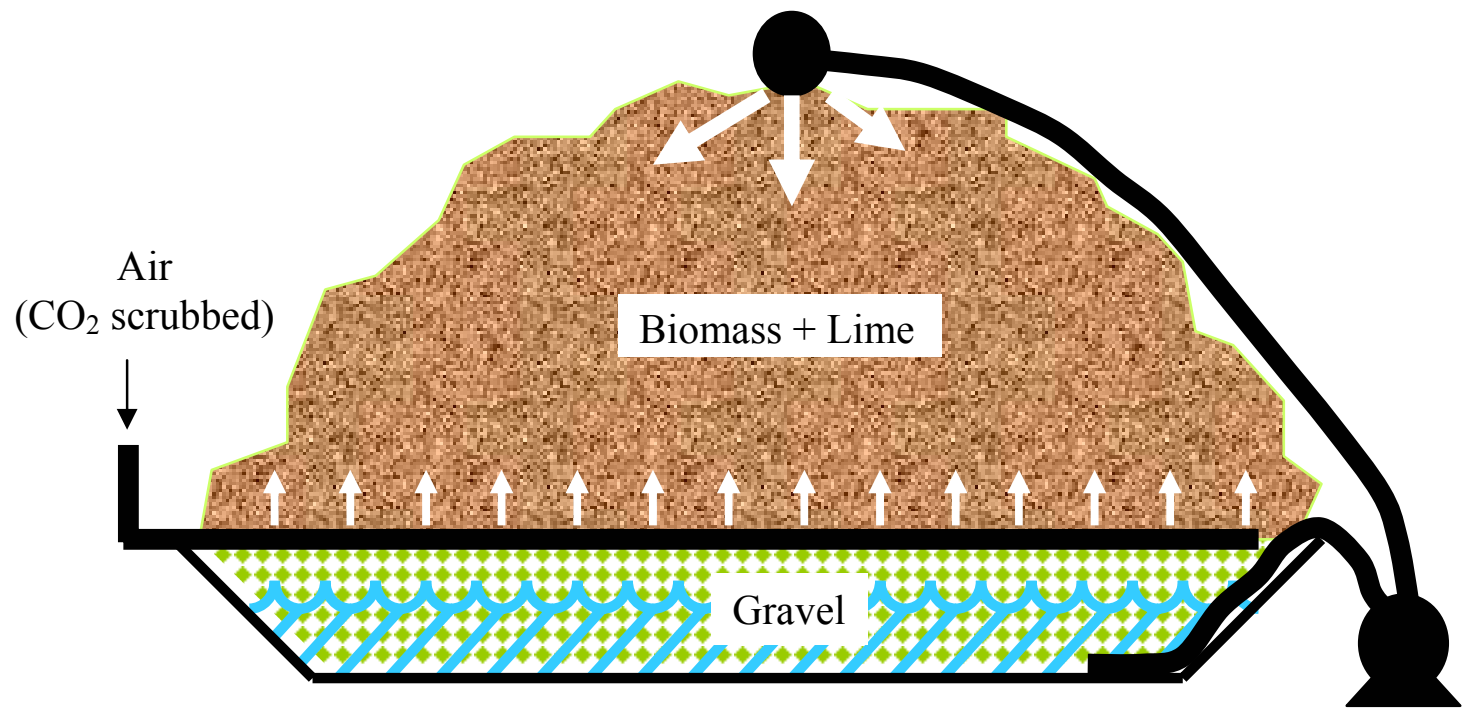

Figure 70. Cross-sectional view of pretreatment and fermentation pile. 
During the lime pretreatment of the biomass pile, water should be circulated through the pile by drawing water from the bottom and pumping it to the top, and air can be blown upward through the pile to enhance lignin removal by alkaline oxidation. The temperature of the pile can be controlled by regulating the temperature of the circulating water using a heat exchanger.

\section{Conclusions}

The solubilization of hemicellulose during lime pretreatment is closely related with deacetylation and delignification. Cellulose was much more stable than hemicellulose, but cellulose degraded faster, once it dissolved in the pretreatment liquid.

Using the optimal pretreatment, the overall yields of glucose and xylose were $91.3 \mathrm{~g}$ glucan hydrolyzed/100 g glucan in raw biomass and $51.8 \mathrm{~g}$ xylan hydrolyzed/100 g xylan in raw biomass at $15 \mathrm{FPU} / \mathrm{g}$ cellulose, and $95.5 \mathrm{~g}$ glucan hydrolyzed/100 $\mathrm{g}$ glucan in raw biomass and $53.5 \mathrm{~g}$ xylan hydrolyzed/100 g xylan in raw biomass at 60 FPU/g cellulose, respectively. Furthermore, when considering the dissolved fragments (monomers and oligomers) of glucan and xylan in the pretreatment liquor, the overall yields of glucose and xylose were $93.2 \mathrm{~g}$ glucan hydrolyzed/100 g glucan in raw biomass and $79.5 \mathrm{~g}$ xylan hydrolyzed/100 g xylan in raw biomass at $15 \mathrm{FPU} / \mathrm{g}$ cellulose, and 97.2 $\mathrm{g}$ glucan hydrolyzed/100 g glucan in raw biomass and $80.9 \mathrm{~g}$ xylan hydrolyzed/100 $\mathrm{g}$ xylan in raw biomass at $60 \mathrm{FPU} / \mathrm{g}$ cellulose, respectively.

When compared to the enzyme hydrolysis rate of $\alpha$-cellulose, pretreated corn stover reacted more quickly.

It is expected that $3.4-4.0$ gallons of ethanol can be produced from $100 \mathrm{lb}$ of raw corn stover by the optimal lime pretreatment ( 4 weeks, $55^{\circ} \mathrm{C}$, and aeration), enzyme hydrolysis (15 - $60 \mathrm{FPU} / \mathrm{g}$ cellulose), and yeast fermentation. There are no inhibitory substances in the pretreatment liquor that affect yeast cell growth and ethanol production. 


\section{CHAPTER IV CONCLUSIONS}

These systematic studies on the effects of lime pretreatment conditions showed that time, temperature, and oxidative treatment had the greatest impact on the enzymatic digestibility of corn stover, a herbaceous lignocellulosic biomass. Low temperatures (25 $-55^{\circ} \mathrm{C}$ ) require a long pretreatment time to achieve high hydrolysis yields of glucose and xylose. The oxidative treatment can be achieved using air instead of pure oxygen to effectively remove lignin.

The recommended conditions for lime pretreatment using mild conditions are determined by the overall hydrolysis yields of sugars (glucose and xylose) and the extent of deacetylation and delignification. The recommended condition is $55^{\circ} \mathrm{C}, 4$ week, and aeration. At this recommended condition, $7.3 \mathrm{~g}$ of lime, $\mathrm{Ca}(\mathrm{OH})_{2}$ (or $5.8 \mathrm{~g}$ of quick lime, $\mathrm{CaO}$ ) is sufficient to pretreat $100 \mathrm{~g}$ of raw biomass. The delignification selectivity is more enhanced due to the oxidative pretreatment.

Using the recommended pretreatment, the overall hydrolysis yields of glucose (g glucan hydrolyzed/100 g glucan in raw biomass) and xylose (g xylan hydrolyzed/100 g xylan in raw biomass) from the pretreated solid were obtained up to 91.3 and 51.8 at $15 \mathrm{FPU} / \mathrm{g}$ cellulose, and 95.5 and 53.5 at $60 \mathrm{FPU} / \mathrm{g}$ cellulose, respectively.

The pretreatment liquor can serve as a source of dissolved sugar instead of being a waste. It contains dissolved sugars, mostly xylooligomer, with other degradation products, but has no inhibitory effects on cell growth and alcohol production in yeast fermentation. Cellulose can be recovered in high yield $(\geq 94 \%)$ whereas hemicellulose shows the relatively low yield in pretreatment.

The overall yield for glucose and xylose can be more improved, when the dissolved sugars in the pretreatment liquor are utilized in alcohol fermentation after converting all oligomers to monomers, either by enzymes or dilute acid treatment.

The oxidative lime treatment significantly reduces the lignin content of corn stover, e.g., it can remove up to $57.8,66.2,80.9$, and $87.5 \%$ of the initial lignin at 25,35 , 
45, and $55^{\circ} \mathrm{C}$, respectively for 16 weeks. Delignification has a linear relationship with the solubilization of hemicellulose (xylan) and is enhanced as the temperature increases in the oxidative lime pretreatment.

Delignification of corn stover in lime pretreatment can be explained by threephase (initial, bulk, and residual) delignification and is mathematically described using an empirical model. The delignification of the initial phase is easily achieved at the beginning of lime pretreatment, but the delignification of the bulk and residual phases depends on time, temperature, and aeration. The activation energy $\left(E_{\mathrm{a}}\right)$ for delignification of these two phases is estimated as 50.15 and $54.21 \mathrm{~kJ} / \mathrm{mol}$, respectively, in oxidative pretreatment, which are similar to bagasse delignification (Sabatier et al. 1993) but much less than in wood kraft delignification (Dolk et al. 1989 and Chiang et al. 1990).

Deacetylation of hemicellulose was almost complete ( $\geq 96.1 \%$ ), which was achieved by the oxidative lime pretreatment within a few weeks.

The lime pretreatment extensively deacetylates, and slightly increases the crystallinity due to the removal of amorphous substances. The removal of acetyl and lignin is sufficient to obtain high digestibility, regardless of crystallinity. This result is in accordance with Chang and Holtzapple (2000)'s observations of pretreated poplar wood.

Empirical correlations between delignification and 3-d sugar yield from enzyme hydrolysis were suggested as a modified and simplified model from the previous model of Chang and Holtzapple (2000).

The ethanol production was predicted from mass balances obtained from enzymatic hydrolysis of lime-treated corn stover. $3.4-4.0$ gallons of ethanol can be produced from $100 \mathrm{lb}$ of raw corn stover by the optimal lime pretreatment (4 weeks, $55^{\circ} \mathrm{C}$, and aeration), enzyme hydrolysis (15 - $60 \mathrm{FPU} / \mathrm{g}$ cellulose), and yeast fermentation.

There are no inhibitory substances in the pretreatment hydrolyzate that affect yeast cell growth and ethanol production. 
For industrial-scale pretreatment, lime has many advantages: it is cheap and safe to handle, easily recovered, and does not require a pressure reactor. Furthermore, the low-temperature $\left(\leq 55^{\circ} \mathrm{C}\right)$ operation reduces the cost of capital and energy. Aeration enhances the selective delignification of biomass and the conversion efficiency of polysaccharides to monosaccharides in a relatively short period (1 -2 months) of lime pretreatment. 


\section{REFERENCES}

Argyropoulos DS. 2001. Oxidative delignification chemistry - fundamentals and catalysis, ACS Symposium series 785, ACS, Washington, DC.

Aurell R. 1964. Kraft pulping of birch, Part I. The changes in the composition of the wood residue during the cooking process. Svensk Papperstidn 67(2):43-49.

Bhandari N, MacDonald DG, Bakhshi NN. 1983. Kinetic studies of corn stover saccharification using sulphuric acid. Biotechnology and Bioengineering 26:320327.

Browning BL. 1967. The isolation and determination of acetyl and methoxyl groups. Methods of Wood Chemistry 2:655-657.

Carrasco F, Roy C. 1992. Kinetic study of dilute - acid prehydrolysis of xylancontaining biomass. Wood Sci Technol 26:189-208.

Chang VS, Burr B, Holtzapple MT. 1997. Lime pretreatment of switchgrass, Applied Biochemistry and Biotechnology 63-65:3-19.

Chang VS, Nagwani M, Holtzapple MT. 1998. Lime pretreatment of crop residues bagasse and wheat straw. Applied Biochemistry and Biotechnology 74:135-159.

Chang VS, Holtzapple MT. 2000. Fundamental factors affecting biomass enzymatic reactivity. Applied Biochemistry and Biotechnology 84-86: 5-37.

Chang VS, Nagwani M, Kim CH, Holtzapple MT. 2001. Oxidative lime pretreatment of high-lignin biomass. Applied Biochemistry and Biotechnology 94:1-28.

Chiang VL, Yu J. 1990. Isothermal reaction kinetics of kraft delignification of Douglasfir. Journal of Wood Chemistry and Technology 10(3):293-310.

Chum HL, Johnson DK, Black SK, Overend RP. 1990. Pretreatment - catalyst effects and the combined severity parameter. Applied Biochemistry and Biotechnology 24/25:1-14.

Costa SM, Gonçalves AR, Esposito E. 2002. Action of white-rot fungus Panus tigrinus on sugarcane bagasse. Applied Biochemistry and Biotechnology 98-100:357-364.

Coward-Kelly G, Aiello-Mazzari C, Kim Sehoon, Granda C, Holtzapple MT. 2003. Suggested improvements to the standard filter paper assay used to measure cellulase activity. Biotechnology and Bioengineering 82(6):745-749.

Crawford DL, Pometto III AL, Crawford RL. 1984. Production of useful lignin polymers by bioconversion of lignocellose with Streptomyces. Biotech Avds 2:217-232. 
DeGroot, BD., van Dam JEG, van't Riet K. 1995. Alkaline pulping of hemp woody core: kinetic modeling of lignin, xylan, and cellulose extraction and degradation. Holzforschung 49(4):332-342.

DeGroot BD, van Dam JEG, van derZwan RP, van't Riet K. 1994. Simplified kinetic modeling of alkaline delignification of hemp woody core. Holzforschung 48(3):207214

Dolk M, Yan JF, McCarthy JL. 1989. Lignin 25. Kinetics of delignification of western Hemlock in flow-through reactors under alkaline conditions. Holzforschung 43(2):91-98.

Fan LT, Gharpuray MM, Lee Y-H. 1987. Cellulose hydrolysis biotechnology monographs. Springer, Berlin, p. 57.

Garrote G, Domínguez H, Parajó JC. 2002. Autohydrolysis of corncob: study of nonisothermal operation for xylooligosaccharide production. Journal of Food Engineering 52:211-218.

Gierer J. 1985. Chemistry of delignification. Part I: general concept and reactions during pulping. Wood Science and Technology 19:289-312.

Gierer J, Norén I. 1980. On the course of delignification during kraft pulping. Holzforschung 34(6):197-200.

Goring DAI. 1971. Part 7. Polymer properties of lignin and lignin derivatives. In: Lignins - occurrence, formation, structure and reactions. Editors: Sarkanen KVand Ludwig CH, pp. 695-768, Wiley-Interscience, New York.

Hahn HB. 1996 Ethanolic fermentation of lignocellulose hydrolysates: a minireview. Applied Biochemistry and Biotechnology 57/58:195-199.

Hettenhaus J, Wiselogel A, Wooley R. 2000. Corn Stover Co-Products, A Course for Commercialization, Ninth Biennial Bioenergy Conference; Buffalo, NY. (Source: http://www.ott.doe.gov/biofuels/newsearchdb.cgi)

Hileman B. 1999. Case grows for climate change. Chemical \& Engineering News 77:1623.

Holtzapple MT. 1993a. Cellulose. In: Encyclopedia of Food Science, Food Technology and Nutrition, vol. 2, pp. 2731-2738, Academic Press, London.

Holtzapple MT. 1993b. Hemicellulose. In: Encyclopedia of Food Science, Food Technology and Nutrition, vol. 2, pp. 2324-2334, Academic Press, London.

Holtzapple MT. 1993c. Lignin. In: Encyclopedia of Food Science, Food Technology and Nutrition, vol. 4, pp. 758-767, Academic Press, London. 
Holtzapple MT, Caram HS, Humphrey AE. 1984. Determining the inhibition constants in $\mathrm{HCH}-1$ model of cellulose hydrolysis. Biotechnology and Bioengineering 26:775780 .

Holtzapple MT, Jun J-H, Ashok G, Patibandla SL, Dale BE. 1991. The ammonia freeze explosion (AFEX) process. A practice al lignocellulose pretreatment. Applied Biochemistry and Biotechnology 28/29:59-74.

Holtzapple MT, Ripley EP, Nikolaou M. 1994. Saccharification, fermentation, and protein recovery from low-temperature AFEX-treated coastal bermudagrass. Biotechnology and Bioengineering 44:1122-1131.

Holtzapple MT, Ross MK, Chang NS, Chang VS, Adelson SK, Brazel C. 1997. Biomass conversion to mixed alcohol fuels using the MixAlco process. In: Fuels and Chemicals from Biomass, Editors: Saha BC and Woodward J., pp. 130-142, ACS Symp. Ser. 666. American Chemical Society, Washington DC.

Ingram LO, Doran JB. 1995. Conversion of cellulosic materials to ethanol. FEMS Microbiology Reviews 16:235-241.

Inventory of U.S. Greenhouse Gas Emissions and Sinks: 1990 - 2001(April 15, 2003). http://www.epa.gov/globalwarming/publications/emissions.

Jeewon L. 1997. Biological conversion of lignocellulosic biomass to ethanol - a review article. Journal of Biotechnology 56:1-24.

Kaar WE, Holtzapple MT. 2000. Using lime pretreatment to facilitate the enzyme hydrolysis of corn stover. Biomass and Bioenergy 00:1-11.

Kadam KL, McMillan JD. 2003. Availability of corn stover as a sustainable feedstock for bioethanol production. Bioresource Technology 88:17-25.

Kerr AJ. 1970. The kinetics of kraft pulping - progress in the development of a mathematical model. Appita 24(3):180-188.

Kleinert TN. 1966. Mechanisms of alkaline delignification: 1. The overall reaction pattern. Tappi 49(2):53-57.

Klinke HL, Ahring BK, Schmidt AS, Thomsen AB. 2002. Characterization of degradation products from alkaline wet oxidation of wheat straw. Bioresource Technology 82:15-26.

Kong F, Engler CR, Soltes EJ. 1992. Effects of cell-wall acetate, xylan backbone, and lignin on enzymatic hydrolysis of aspen wood. Applied Biochemistry and Biotechnology 34/35:23-35. 
Kuznetsov BN, Kuznetsova SA, Danilov VG, Kozlov IA, Taraban'ko VE. et al. 2002. New catalytic processes for a sustainable chemistry of cellulose production from wood biomass. Catalysis Today 75:211-217.

Lai YZ. 2001. Chapter 10. Chemical degradation. In: Wood and Cellulose Chemistry. Editors: Hon DN-S and Shiraishi N., pp. 443 - 512, Marcel Dekker, Inc., New York·Basel.

Lee YH, Fan LT. 1982. Kinetic studies of enzymatic hydrolysis of insoluble cellulose: analysis of the initial rates. Biotechnology and Bioengineering 24:2383-2406.

López R, Poblano VM, Licea-Claveríe A, Avalos M, Alvarez-Castillo A, Castaño VM. 2000. Alkaline surface modification of sugar cane bagasse. Adv Composite Mater 9(2):99-108.

McGinnis GD, Prince SE, Biermann CJ, Lowrimore JT. 1984. Wet oxidation of model carbohydrate compounds. Carbohydrate Research 128:51-60.

Miller GL. 1959. Use of dinitrosalicylic acid reagent for determination of resucing sugars. Analytical Chemistry 31:426-428.

Miller MM. 2001. Lime, U.S. Geological Survey Minerals Yearbook - 2001. pp. 45.1 45.8 (Source: http://minerals.usgs.gov/minerals/pubs)

Mitchell DJ, Grohmann K, Himmel ME. 1990. Effective of the degree of acetylation of the enzymatic digestion of acetylated xylans. Journal of Wood Chemistry and Technology 10(1):111-121.

Montgomery R. 1953. Observation of alkaline degradation of sugars. Industrial and Engineering Chemistry 45(5):1144-1147.

Perry RH, Green D. 1984. Perry's Chemical Engineer's Handbook, $6^{\text {th }}$ edition, McGraw Hill, New York.

Puri VP. 1984. Effect of crystallinity and degree of polymerization of cellulose on enzymatic saccharification. Biotechnology and Bioengineering 26:1219-1222.

Ragg PL, Fields PR. 1987. The development of a process for the hydroysis of lignocellulosic waste. Phil Trans R Soc Lond A321:537-547.

Reczey K, Szengyel S, Eklund R, Zacchi G. 1996. Cellulase production by T. reesei. Bioresource and Technology 57:25-30.

Rivers DB, Emert GH. 1981. Factors affecting the enzymatic hydrolysis of municipalsolid-waste components. Biotechnology and Bioengineering 31:278-281.

Roncero MB, Torres AL, Colom JF, Vidal T. 2003. TCF bleaching of wheat straw pulp using ozone and xylanase. Bioresource Technology 87:315-323. 
Sabatier J, Peniche C, Fernández N. 1993. Soda pulping of bagasse: delignification phases and kinetics. Holzforschung 47(4):313-317.

Sarkanen KV, Ludwig CH. 1971. Definition and nomenclature. In: Lignins - occurrence, formation, structure and reactions. Editors: Sarkanen KV and Ludwig CH., pp. 1-18, Wiley-Interscience, New York.

Segal L, Creely JJ, Martin Jr AE, Conrad CM. 1959. An empirical method for estimating the degree of crystallinity of native cellulose using the X-ray diffractometer. Textile Res J 29:786-794.

Shiraishi A, Sano Y. 2001. Chapter 4. Chemistry of lignin. In: Wood and Cellulosic Chemistry. Editors: Hon DN-S and Shiraishi N., pp.109-173, Marcel Dekker, Inc, New York.

Sinitsyn AP, Gusakov AV, Vlasenko EY. 1991. Effect of structural and physicochemical features of cellulosic substrates on the efficiency of enzymatic hydrolysis. Applied Biochemistry and Biotechnology 30:43-59.

Sjöström E. 1991. Carbohydrate degradation products from alkaline treatment of biomass. Biomass and Bioenergy 1(1):61-64.

Sokhansanj S, Turhollow A, Cushman J, Cundiff J. 2002. Engineering aspects of collecting corn stover for bioenergy. Biomass and Bioenergy 23:347-355.

Vázquez G, Antorrena G, González J, Freire S, López S. 1997. Acetosolv pulping of pine wood. Kinetic modeling of lignin solubilization and condensation. Bioresource Technology 59:121-127.

Vlasenko EY, Ding H, Labavitch JM, Shoemaker SP. 1997. Enzymatic hydrolysis of pretreated rice straw. Bioresource Technology 59:109-119.

Whistler RL, Jeans A. 1943. Quantitative estimation of acetyl in carbohydrate acetates. Industrial and Engineering Chemistry 15(5):317-318.

Williams AG, Morrison IM. 1982. Studies on the production of saccharinic acids by the alkaline treatment of young grass and their effectiveness as substrates for mixed rumen microorganisms in vitro. J Sci Food Agric 33:21-29. 


\section{APPENDIX A}

\section{LIME PRETREATMENT PROCEDURE}

1. Fill water into the water tank to cover the heating element. Turn on the centrifugal pump to circulate water. Fill sufficient water into the tank to maintain a nearly full level.

2. Turn on the temperature controller to heat up the circulating water to the set temperature.

3. Operate the whole system to reach a steady state.

4. Step 1 through 3 can be omitted in the case of pretreatment at $25^{\circ} \mathrm{C}$.

5. Place $15.0 \mathrm{~g}$ dry weight of the raw biomass and $7.5 \mathrm{~g}$ of calcium hydroxide in a beaker. Pour $70 \mathrm{~mL}$ of distilled water into the beaker and thoroughly mix using a spatula.

6. Transfer the mixture of biomass and calcium hydroxide into a reactor using a funnel. Wash the beaker and the spatula with $80 \mathrm{~mL}$ of distilled water to transfer all remnants in the reactor through the funnel.

7. Tightly cap the reactor and connect the bubble indicator (it is filled with $20-25$ $\mathrm{mL}$ of distilled water in $50 \mathrm{~mL}$ of plastic tube) to measure the gas flow rate.

8. Slowly open the appropriate valve to supply nitrogen for non-oxidative pretreatment or air for oxidative pretreatment. Confirm bubble formation in the bubble indicator. Adjust the gas flow rate to achieve at $2-3$ bubbles/second using a clamp, which is placed at the tube in the bottom of the reactor.

9. Regularly check the gas pressure $(4.5-5.0$ psi in the case of nitrogen gas and 60 -80 psi in the case of in-line air), gas flow rate, seals, water levels in the cylinder filled with water and in the tank, and working temperatures.

10. After the pretreatment time has elapsed, remove the reactors and cool down to ambient temperature. 


\section{APPENDIX B}

\section{PARTICLE SIZE DISTRIBUTION OF RAW BIOMASS}

\section{Sieves}

USA standard testing sieves (A.S.T.M.E. -11 Specification)

Table B-1. Specification of Sieves.

\begin{tabular}{|c|c|c|c|}
\hline \multirow{2}{*}{ Sieve number } & Tyler Equivalent & \multicolumn{2}{|c|}{ Opening size } \\
\cline { 3 - 4 } & Mesh & $\mathrm{mm}$ & in \\
\hline 4 & 4 & 4.750 & 0.1870 \\
\hline 20 & 20 & 0.850 & 0.0331 \\
\hline 30 & 28 & 0.600 & 0.0234 \\
\hline 40 & 35 & 0.425 & 0.0165 \\
\hline 50 & 48 & 0.300 & 0.0117 \\
\hline 80 & 80 & 0.180 & 0.0070 \\
\hline 100 & 100 & 0.150 & 0.0059 \\
\hline
\end{tabular}

\section{Procedures}

1. Load $50 \mathrm{~g}$ dry biomass on the No. 100 mesh sieve.

2. Vigorously and horizontally shake the whole set (Lid + Sieve + Bowl for receiving the sieved particle) for $1 \mathrm{~min}$.

3. Carefully disassemble the bowl of the bottom side.

4. Transfer the sieved particle into the pre-weighed aluminum foil pan.

5. Transfer remnant on the sieve of higher mesh number (e.g., 100) into the sieve of lower mesh number (e.g., 80).

6. Repeat Steps 2 to 5 until mesh No. 4.

7. Dry samples at $105^{\circ} \mathrm{C}$ for $24 \mathrm{~h}$.

8. Measure and determine dry weight contents for each collection of the sieved particles. 


\section{APPENDIX C}

\section{DETERMINATION OF LIME UNREACTED AFTER PRETREATMENT}

The amounts of lime in the biomass slurry harvested from the reactor was determined by $\mathrm{pH}$ titration using $\mathrm{HCl}$.

\section{Apparatus and Materials}

Magnetic stirrer

Buret, $50-\mathrm{mL}$

Hydrochloric acid ( $\mathrm{HCl}), 5-\mathrm{N}$ (Certified standard solution)

pH meter (Orion, model 230A, U.S.A)

\section{Procedure}

1. Place the bottle containing pretreated biomass slurry on the magnetic stirrer.

2. Dip the $\mathrm{pH}$ probe inside of the bottle to measure the $\mathrm{pH}$ of the slurry. The probe and $\mathrm{pH}$ meter must be calibrated with standard solutions prior to measurement.

3. Fill 5-N HCl solution in the buret and clamp it over the bottle. Record the volume $\left(V_{i}\right)$.

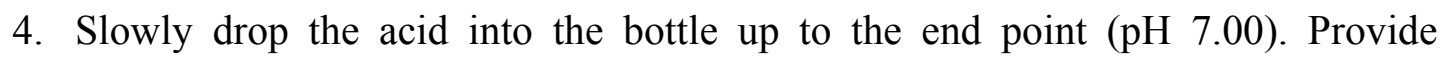
enough time ( $\geq 20 \mathrm{~min}$ ) to ensure the $\mathrm{pH}$ of the slurry is stabilized.

5. Record the volume left in the buret $\left(V_{f}\right)$.

\section{Calculation}

$$
W_{\mathrm{c}}(\mathrm{g})=\frac{1 \mathrm{~mol} \mathrm{Ca}(\mathrm{OH})_{2}}{2 \mathrm{~mol} \mathrm{HCl}} \times \frac{N_{\mathrm{HCl}} \cdot\left(V_{i}-V_{f}\right)}{1000} \times M w_{\mathrm{c}}
$$


where, $W_{\mathrm{c}}=$ The amount of lime, $\mathrm{Ca}(\mathrm{OH})_{2}$, unreacted $(\mathrm{g})$

$$
\begin{aligned}
& N_{\mathrm{HCl}}=\text { Normality of } \mathrm{HCl} \text { solution }(\mathrm{mol} / \mathrm{L}) \\
& V_{i}-V_{f}=\text { Total volume of } \mathrm{HCl} \text { solution to titrate the biomass slurry }(\mathrm{mL}) \\
& M w_{\mathrm{c}}=\text { Molecular weight of } \mathrm{Ca}(\mathrm{OH})_{2}, 74.092 \mathrm{~g} / \mathrm{mol}
\end{aligned}
$$




\section{APPENDIX D}

\section{BIOMASS WASHING PROCEDURE}

\section{Washing Procedure for Material Balances between Raw and Washed-Only Biomass}

1. Dry about $30 \mathrm{~g}$ of untreated biomass at $45^{\circ} \mathrm{C}$ for $24 \mathrm{~h}$ or longer if necessary.

2. Place and cool the biomass dried at $45^{\circ} \mathrm{C}$ in the desiccator until it reaches room temperature.

3. Tare a 1-L centrifuge bottle. Transfer and weigh approximately $20 \mathrm{~g}$ of the biomass dried at $45^{\circ} \mathrm{C}$ in the centrifuge bottle. Record the weight of the biomass dried at $45^{\circ} \mathrm{C}\left(W_{1}\right)$.

4. Using the rest of the biomass dried at $45^{\circ} \mathrm{C}$, determine the moisture content as described in the NREL Standard Procedure No. $001\left(X_{1}\right)$.

5. Place about $500 \mathrm{~mL}$ of distilled water in the centrifuge bottle and stir for 15 minutes.

6. Centrifuge the water-biomass mixture at 4,000 rpm for 10 minutes.

7. During centrifugation, setup a vacuum filtration apparatus using a Buchner funnel and a 9-cm 934/AH glass fiber filter paper (particle retention $=1.5 \mu \mathrm{m}$ ). Weigh the dried filter paper at $45^{\circ} \mathrm{C}$ before setup.

8. After centrifugation, carefully decant the water on the Buchner funnel with vacuum filtration. Decant as much water as possible. Observe the filtrate color.

9. Transfer as much filter cake remained on the filter paper into the centrifuge bottle using water as possible.

10. Repeat Steps 4 through 8 until the filtrate becomes clear. If it takes too long to filter, replace the old filter paper with a new one which has been dried and weighed in advance. 
11. After being completely washed, transfer all the biomass in the centrifuge bottle as well as the filter paper into a container, which has been dried and weighed. Dry the biomass and filter paper at $45^{\circ} \mathrm{C}$ for $72 \mathrm{~h}$ or longer if necessary.

12. Place and cool the biomass and filter papers in the desiccator until it reaches room temperature. Weigh them and record the values $\left(W_{2}\right)$.

13. Using about $5 \mathrm{~g}$ of the $45^{\circ} \mathrm{C}$-dried and washed biomass, determine the moisture content as described in the NREL No. $001\left(X_{2}\right)$. Store the rest of the biomass in the desiccator for analyses of ash, lignin, carbohydrate, and protein later.

14. The total weight loss due to washing is calculated using the following formula:

$$
\text { Total Weight Loss }(\%)=\frac{W_{1} \times\left(1-X_{1}\right)-W_{2} \times\left(1-X_{2}\right)}{W_{1} \times\left(1-X_{1}\right)} \times 100
$$

where $W_{1}=45^{\circ} \mathrm{C}$-dried weight of raw biomass (g)

$X_{1}=$ moisture content of $45^{\circ} \mathrm{C}$-dried raw biomass $\left(\mathrm{g} \mathrm{H}_{2} \mathrm{O} / \mathrm{g}\right.$ dry biomass $)$

$W_{2}=45^{\circ} \mathrm{C}$-dried weight of washed biomass $(\mathrm{g})$

$X_{2}=$ moisture content of $45^{\circ} \mathrm{C}$-dried washed biomass $\left(\mathrm{g} \mathrm{H}_{2} \mathrm{O} / \mathrm{g}\right.$ dry biomass $)$

\section{Washing Procedure for Material Balances between Raw and Pretreated-and- Washed Biomass}

1. Dry about $30 \mathrm{~g}$ of untreated biomass at $45^{\circ} \mathrm{C}$ for $24 \mathrm{~h}$ or longer if necessary.

2. Place and cool the biomass dried at $45^{\circ} \mathrm{C}$ in the desiccator until it reaches room temperature.

3. Weigh approximately $20 \mathrm{~g}$ of the biomass dried at $45^{\circ} \mathrm{C}$ in a plastic weighing dish. Record the weight of the biomass dried at $45^{\circ} \mathrm{C}\left(W_{1}\right)$.

4. Using the rest of the biomass dried at $45^{\circ} \mathrm{C}$, determine the moisture content as described in the NREL Standard Procedure No. $001\left(X_{1}\right)$.

5. Pretreat the biomass as described in Appendix A.

6. Transfer pretreated biomass with $500 \mathrm{~mL}$ distilled water from the reactors to a centrifuge bottle and stir for 15 minute. 
7. Repeat Steps 6 through 11 used in "Washing Procedure for Material Balances between Raw and Washed Only Biomass."

8. Weigh them and record the values $\left(W_{2}\right)$.

9. Using about $5 \mathrm{~g}$ of the air-dried and washed biomass, determine the moisture content as described in the NREL Standard Procedure No. $001\left(X_{2}\right)$. Store the rest of the biomass for analyses of ash, lignin, carbohydrate, and protein later.

10. The total weight loss due to washing is calculated using the following formula:

$$
\text { Total Weight Loss }(\%)=\frac{W_{1} \times\left(1-X_{1}\right)-W_{2}}{W_{1} \times\left(1-X_{1}\right)} \times 100
$$

where $W_{1}=$ air-dried weight of raw biomass $(\mathrm{g})$

$$
\begin{aligned}
X_{1}= & \text { moisture content of air-dried raw biomass }\left(\mathrm{g} \mathrm{H}_{2} \mathrm{O} / \mathrm{g} \text { air-dried biomass }\right) \\
W_{2}= & \text { air-dried weight of pretreated and washed biomass }(\mathrm{g}) \\
X_{2}= & \text { moisture content of air-dried pretreated and washed biomass } \\
& \left(\mathrm{g} \mathrm{H}_{2} \mathrm{O} / \mathrm{g} \text { air-dried biomass }\right)
\end{aligned}
$$




\section{APPENDIX E}

\section{ENZYME HYDROLYSIS}

\section{Enzymatic Hydrolysis Procedure for Lime Pretreatment Studies of Corn Stover}

Lime-pretreated and washed biomass was transferred from the reactors to tubes with distilled water. Citrate buffer (1.0 M, pH 4.8) and sodium azide solution (1 (w/w)\%) were added to the slurry to keep constant $\mathrm{pH}$ and prevent microbial growth, respectively. Glacial acetic acid or saturated sodium hydroxide solution was then added to adjust the $\mathrm{pH}$ 4.8. The total volume of mixture was then made up to the desired volume by adding distilled water. The tube was placed in a rotary shaker at $150 \mathrm{rpm}$ and $50{ }^{\circ} \mathrm{C}$. After $1-\mathrm{h}$ incubation, cellulase (Spezyme CP, Lot No. 301-00348-257, Genencor, USA) and cellobiase (Novozyme 188, activity $\cong 250 \mathrm{CBU} / \mathrm{g}$ ) were added to the test tube, using various loading rates (i.e., 0, 2, 10, 20, 40, and $120 \mathrm{FPU} / \mathrm{g}$ cellulose) and an excess cellobiase loading (i.e., $40 \mathrm{CBU} / \mathrm{g}$ cellulose). Samples were withdrawn at 0,1 , and $72 \mathrm{~h}$ and sugars were measured at each time point. See the following for the complete hydrolysis procedures. The same procedure was also applied to untreated biomass.

1. Prepare 1-M citrate buffer $(\mathrm{pH} 4.3)$ and $10 \mathrm{mg} / \mathrm{mL}$ sodium azide solution.

2. Transfer $1.05 \mathrm{~g}$ dry biomass (this value corresponds to $0.5 \mathrm{~g}$ glucan, if glucan content is $47.5 \%$ ) of lime-pretreated and washed corn stover in the plastic tube (50-mL Falcon tube). Use the wet biomass pre-determined the moisture content as described in the NREL Standard Procedure No. 001.

3. Add $30 \mathrm{~mL}$ of distilled water, $2.5 \mathrm{~mL}$ of $1-\mathrm{M}$ citrate buffer, and $1.5 \mathrm{~mL}$ of $1 \%$ sodium azide into the tube.

4. Measure the current $\mathrm{pH}$ of the mixture and add glacial acetic acid or saturated sodium hydroxide to adjust $\mathrm{pH} 4.8$, if necessary. 
5. Wash pH-electrode with $3.5 \mathrm{~mL}$ of distilled water to transfer all attached biomass on the surface of the electrode.

6. Add the remaining volume of distilled water in the tube to make the final reaction volume be $49.0 \mathrm{~mL}$ in the tube.

7. Incubate the tube in a rotary shaker for $1 \mathrm{~h}$ before adding enzymes.

8. Take out the heated tube from the shaker and start the enzyme hydrolysis reaction by adding $1.0 \mathrm{~mL}$ of the diluted cellulase solution and $80.0 \mu \mathrm{L}$ of cellobiase (this volume corresponds to $40 \mathrm{CBU} / \mathrm{g}$ cellulose). The final volume becomes $50.0 \mathrm{~mL}$. See Table E-1 to prepare the diluted cellulase solutions at different concentrations.

9. Vigorously shake the tube to get a homogenous mixture, immediately open the cap of the tube, take $3.5 \mathrm{~mL}$ sample, and transfer it to glass tube with a screw cap. Use the enlarged pipette tip (cut the end of the tip to make around 5-mm I.D hole) to take the sample. After taking the sample, tightly cap and incubate the tube in the shaker at $100 \mathrm{rpm}$ and $50{ }^{\circ} \mathrm{C}$. Note that the tube has to be placed in the horizontal direction, not be erected in the vertical direction, to get homogenous mixing during the incubation.

10. Tightly seal the cap of the glass tube and vigorously boil the sample tube for 15 min to denature enzymes.

11. Immerse the boiled tube in the ice-bath for $10 \mathrm{~min}$ and transfer the sample to conical tube (14 mL capacity).

12. Centrifuge the sample at 4,000 rpm for 5 min to separate liquid and solid parts.

13. Transfer the liquid part into the tube and store it in the freezer to analyze sugar concentrations by DNS or HPLC later.

14. Repeat Steps 9 through 12 at 1 and $72 \mathrm{~h}$ later to get enzyme digestibility data for $1 \mathrm{~h}$ and $3 \mathrm{~d}$. 
Table E-1. Example of preparation of the diluted cellulase solutions.

\begin{tabular}{|c|c|c|c|c|}
\hline No. & $\begin{array}{c}\text { Final cellulase } \\
\text { concentration in the } \\
\text { reaction tube } \\
\text { (FPU/g cellulose) }\end{array}$ & $\begin{array}{c}\text { Dilution } \\
\text { factor }\end{array}$ & $\begin{array}{c}\text { Addition volume } \\
\text { of the original } \\
\text { cellulase } \\
\text { solution } \\
(\mathrm{mL})\end{array}$ & $\begin{array}{c}\text { Addition volume } \\
\text { of distilled water } \\
(\mathrm{mL})\end{array}$ \\
\hline (1) & 120 & $1 \times$ & 3.0 & 0.0 \\
\hline (2) & 40 & $1 / 3 \times$ & 1.0 & 2.0 \\
\hline (3) & 20 & $1 / 6 \times$ & 0.5 & 2.5 \\
\hline (4) & 10 & $1 / 60 \times$ & $0.5^{\mathrm{b})}$ & 1.5 \\
\hline (5) & 2 & $0.5^{\mathrm{c})}$ & 4.5 \\
\hline
\end{tabular}

a) It is assumed that the activity of the original cellulase solution is $60 \mathrm{FPU} / \mathrm{mL}$.

b) This volume is taken from the (2)-dilution solution.

c) This volume is taken from the (3)-dilution solution 


\section{APPENDIX F}

\section{SUGAR MEASUREMENT}

\section{Dinitrosalicylic Acid (DNS) Assay}

Reducing sugar was measured using the dinitrosalicylic acid (DNS) assay (Miller, 1959). A glucose standard prepared from the Sigma $100 \mathrm{mg} / \mathrm{dL}$ glucose standard solution was used for the calibration, thus the reducing sugars were measured as "equivalent glucose."

\section{Preparation of DNS Reagents}

1. Dissolve $10.6 \mathrm{~g}$ of 3,5-dinitrosalicylic acid crystals and $19.8 \mathrm{~g}$ of $\mathrm{NaOH}$ in 1,416 $\mathrm{mL}$ of distilled water.

2. Add $306 \mathrm{~g}$ of sodium-potassium tartrate (Rochelle salts).

3. Melt phenol crystals under a fume hood at $50^{\circ} \mathrm{C}$ using a water bath. Add $7.6 \mathrm{~mL}$ of the dissolved phenol to the mixture.

4. Add $8.3 \mathrm{~g}$ of sodium meta-bisulfate $\left(\mathrm{Na}_{2} \mathrm{~S}_{2} \mathrm{O}_{4}\right)$.

5. Add $\mathrm{NaOH}$ to adjust the $\mathrm{pH}$ to 12.6 , if required.

\section{Calibration of DNS Reagent}

1. Using $200 \mathrm{mg} / \mathrm{dL}$ Sigma glucose standard, prepare $1 \mathrm{~mL}$ of sample in test tubes according to Table E-1.

2. Place $0.25 \mathrm{~mL}$ of each sample into test tubes.

3. Dispense $0.75 \mathrm{~mL}$ of DNS reagent into each test tube.

4. Place the caps on the tubes and vortex.

5 . Vigorously boil samples in a water bath for $5 \mathrm{~min}$.

6. Cool the test tubes for a few minutes. 
7. Take $0.8 \mathrm{~mL}$ of sample from the tube and dilute it with $8 \mathrm{~mL}$ of distilled water.

8. Zero the spectrophotometer (Milton Roy, Spectronic 1001) at $550 \mathrm{~nm}$ with distilled water.

9. Measure the absorbance and prepare a calibration curve.

\section{Measurement of Reducing Sugar Concentration of Sample}

1. Centrifuge samples at $4,000 \mathrm{rpm}$ for 5 minutes.

2. Dilute the samples into test tubes such that the sugar concentration lies between 0.2 to $1.0 \mathrm{mg} / \mathrm{mL}$. Vortex the diluted samples.

3. Place $0.5 \mathrm{~mL}$ of each diluted sample into test tubes.

4. Repeat Step 3 to 8 used to prepare the calibration curve.

5. Calculate sugar concentration from the absorbance of the samples using the calibration curve.

6. Calculate the reducing sugar yield by the following formula:

$$
Y=S \times D \times V / W
$$

where $Y=$ reducing sugar yield (mg equivalent glucose/g dry biomass)

$S=$ sugar concentration in diluted sample (mg equivalent glucose $/ \mathrm{mL})$

$D=$ dilution factor

$V=$ working volume $(\mathrm{mL})$

$W=$ weight of dry biomass $(\mathrm{g})$

Table F-1. Preparation of glucose standard solutions for DNS assay.

\begin{tabular}{|c|c|c|}
\hline $\begin{array}{c}\text { Glucose Concentration } \\
(\mathrm{mg} / \mathrm{mL})\end{array}$ & $\begin{array}{c}\text { 200 mg/dL Sigma } \\
\text { Standard }(\mathrm{mL})\end{array}$ & Distilled Water $(\mathrm{mL})$ \\
\hline 0.2 & 0.1 & 0.9 \\
\hline 0.4 & 0.2 & 0.8 \\
\hline 0.6 & 0.3 & 0.7 \\
\hline 0.8 & 0.4 & 0.6 \\
\hline 1.0 & 0.5 & 0.5 \\
\hline
\end{tabular}




\section{APPENDIX G}

\section{DETERMINATION OF ACETYL GROUPS IN BIOMASS}

\section{Materials}

Anhydrous methanol $\left(\mathrm{CH}_{3} \mathrm{OH}\right)$

Sodium methoxide $\left(\mathrm{CH}_{3} \mathrm{ONa}\right), 30 \%(\mathrm{w} / \mathrm{w})$

Sodium hydroxide $(\mathrm{NaOH}), 0.1-\mathrm{N}$

Hydrochloric acid ( $\mathrm{HCl}), 0.1-\mathrm{N}$

Phenolphthalein indicator

\section{Procedure}

1. Determine the moisture content of the biomass (NREL standard procedure No. 1).

2. Prepare 0.2-N sodium methoxide: dilute $19.5 \mathrm{~mL}$ of $30 \%(\mathrm{w} / \mathrm{w})$ sodium methoxide in $500 \mathrm{~mL}$ anhydrous methanol.

3. Weigh $0.5 \mathrm{~g}$ dry biomass and transfer it in a $250-\mathrm{mL}$ single-neck round-bottom flask (A). Attach the reaction flask (A) to a distillation apparatus as shown in Figure G-1.

4. Preheat the water bath to around $80{ }^{\circ} \mathrm{C}$.

5. Add $20 \mathrm{~mL}$ of $0.2-\mathrm{N}$ sodium methoxide in the reaction flask (A) through the graduated separatory funnel (B) and add $40 \mathrm{~mL}$ of anhydrous methanol through funnel (B).

6. Collect the distillate in a 500-mL two-neck round-bottom flask (C), which is connected with Drierite ${ }^{\circledR}$ Drying Column (D) containing desiccants. Immerse the flask (C) in ice bath.

7. When most of the liquid in the flask (A) has distilled, add $40 \mathrm{~mL}$ of anhydrous methanol in the reaction flask (A) through the funnel (B). 
8. Repeat Step 7 twice (total $120 \mathrm{~mL}$ of anhydrous methanol is added).

9. When most of the liquid in the reaction flask (A) has distilled, add $25 \mathrm{~mL}$ of 0.1 $\mathrm{N} \mathrm{NaOH}$ to the distillation flask $(\mathrm{C})$ through the side neck. Immediately close the side neck with a glass stopper.

10. Remove the distillation flask (C) from the ice bath and place it in a hot water bath.

11. Boil the flask (C) under reflux for $20 \mathrm{~min}$.

12. Cool the flask (C) to room temperature.

13. Add $50 \mu \mathrm{L}$ of phenolphthalein indicator into the flask (C). Titrate the contents of the flask (C) with $0.1-\mathrm{N} \mathrm{HCl}$ until the color becomes colorless. Record the volume of $\mathrm{HCl}$ used.

14. Repeat Steps 9 to 13 for a blank determination with $120 \mathrm{~mL}$ of anhydrous methanol.

15. The acetyl content in the biomass is estimated as follows:

$$
\% \text { Acetyl content }=\frac{\Delta V \times N \times 0.043}{W} \times 100
$$

where $\Delta V=\mathrm{mL}$ of $\mathrm{HCl}$ for blank $-\mathrm{mL}$ of $\mathrm{HCl}$ for sample

$$
N=\text { normality of } \mathrm{HCl} \text { solution }
$$$$
W=\text { dry weight of sample }
$$

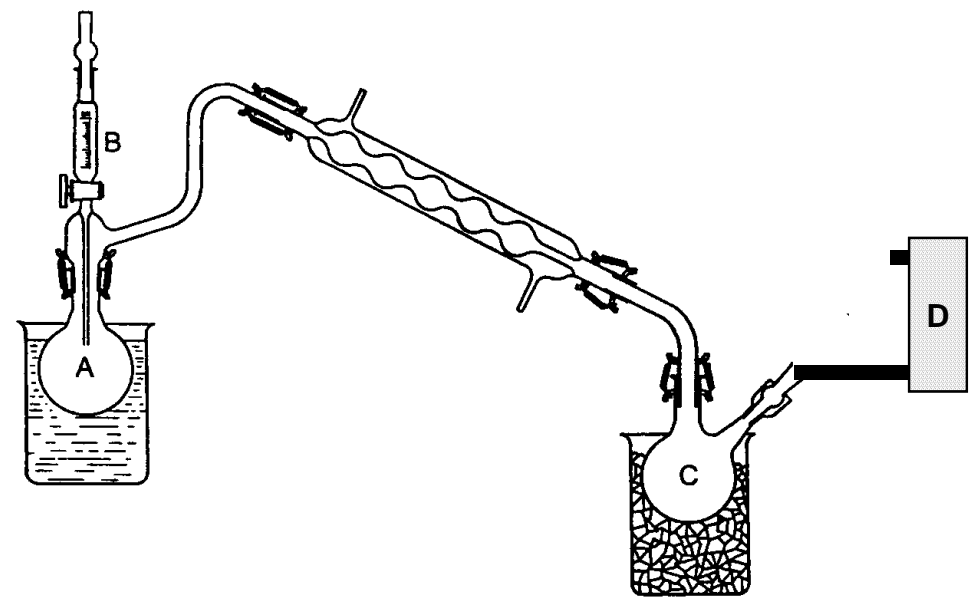

Figure G-1. Schematic diagram of distillation apparatus to determine acetyl groups in biomass (Modified from Whistler and Jeans, 1943). 


\section{APPENDIX $\mathbf{H}$}

\section{DETERMINATION OF CARBOHYDRATES IN BIOMASS}

This method is used to determine the contents of cellulose (glucan) and hemicellulose (xylan) in the untreated and treated corn stover. This method is based on the NREL standard procedure No. 2CS (Determination of structural carbohydrate content in corn stover feedstocks by HPLC).

\section{Apparatus}

HPLC integrator: Spectra-Physics, SP4270.

Autosampler: Spectra-Physics, AS100.

Refractive index detector: RefractoMonitor ${ }^{\circledR}$ III, Model 1109, LDC/MiltonRoy, U.S.A.

HPLC columns, BioRad Aminex 7 HPX-87C and/or Aminex 7 HPX-87P.

Guard columns, cartridges appropriate for the column used.

Analytical balance readable to $0.1 \mathrm{mg}$.

Convection oven $\left(45\right.$ and $\left.105^{\circ} \mathrm{C}\right)$

Autoclave $\left(121^{\circ} \mathrm{C}\right)$

Water bath at $30{ }^{\circ} \mathrm{C}$

\section{Materials}

Standard sugars ( $>98 \%$ purity): set of glucose, xylose, galactose, arabinose, and mannose

$72 \% \mathrm{w} / \mathrm{W} \mathrm{H}_{2} \mathrm{SO}_{4}\left(12.00 \pm 0.02 \mathrm{M}\right.$ or specific gravity 1.6389 at $\left.15.6{ }^{\circ} \mathrm{C}\right)$

Calcium carbonate, ACS reagent grade

Water, 18 megaohm deionized

Glass test tubes, $16 \times 100 \mathrm{~mm}$ 
$125-\mathrm{mL}$ glass serum bottles, crimp top style, with rubber stoppers and aluminum seals to fit

pH paper (pH $4 \sim 7$ )

Disposable nylon syringe filters, $0.2-\mu \mathrm{m}$

Disposable syringes, 3-mL

Autosampler vials, with crimp top seals to fit.

Erlenmeyer flasks, $50-\mathrm{mL}$

\section{Procedure}

1. Determine the moisture content of the biomass (NREL standard procedure No. 1). Total solid content is determined as $T_{f}$.

2. Weigh $0.3 \pm 0.01 \mathrm{~g}$ of the biomass to the nearest $0.1 \mathrm{mg}$ and place in a $16 \times 100$ $\mathrm{mm}$ test tube $\left(W_{1}\right)$.

3. Add $3.00 \pm 0.01 \mathrm{~mL}(4.92 \pm 0.01 \mathrm{~g})$ of $72 \% \mathrm{H}_{2} \mathrm{SO}_{4}$ and mix with a glass stirring rod to wet thoroughly.

4. Place the tubes at room temperature for $2 \mathrm{~h}$ (hydrolysis reaction occurs).

5. Stir the sample every $15 \mathrm{~min}$ to assure complete mixing and wetting.

6. Prepare sugar recovery standards (SRS) as follows: (1) weigh $0.3 \pm 0.01 \mathrm{~g}$ of each sugar (predried at $45^{\circ} \mathrm{C}$ ); (2) place each in its own $16 \times 100 \mathrm{~mm}$ test tube; (3) add acid, hydrolyze, and stir these sugars as described in the Steps $3-5$.

7. The calculated SRSs will be used to correct for losses due to the destruction of sugars during the hydrolysis reaction.

8. After 2-h hydrolysis reaction, transfer each sample to its own serum bottle and dilute to a $4 \%$ acid concentration by adding $84.00 \pm 0.04 \mathrm{~mL}$ deionized water. Carefully transfer all residual solids along with the hydrolyzed liquor.

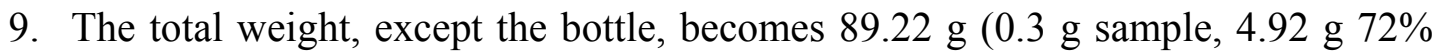
$\mathrm{H}_{2} \mathrm{SO}_{4}$, and $84.00 \mathrm{~g}$ deionized water) and the total volume of solution $\left(V_{f}\right)$ is 87.0 $\mathrm{mL}$ (the specific gravity of the $4 \%$ acid solution is $1.0250 \mathrm{~g} / \mathrm{mL}$ ). 
10. Stopper each of the bottles and crimp aluminum seals into place.

11. Autoclave the samples in their sealed bottles for $1 \mathrm{~h}$ at $121 \pm 3{ }^{\circ} \mathrm{C}$.

12. After autoclaving, allow the samples to cool for about $20 \mathrm{~min}$ at room temperature before removing the seals and stoppers.

13. These autoclaved solutions may also be used for the determination of acidinsoluble and/or acid-soluble lignin, which are described in Appendix I, in parallel with this method.

14. Transfer or filter $20-\mathrm{mL}$ aliquots of each sample into 50-mL Erlenmeyer flasks.

15. Neutralize with calcium carbonate to a $\mathrm{pH}$ between 5 and 6 . Do not overneutralize. Add the calcium carbonate slowly with frequent swirling to avoid problems with foaming. Monitor the $\mathrm{pH}$ of the solution with $\mathrm{pH}$ paper to avoid over-neutralize.

16. Filter the neutralized hydrolyzate using $3-\mathrm{mL}$ syringe with a $0.2-\mu \mathrm{m}$ filter attached. One portion of the hydrolyzate should be filtered directly into a sealed test tube for storage. A second portion should be directly into an autosampler vial if the hydrolyzate is to be analyzed without dilution. Dilute the hydrolyzate and filter into an autosampler vial, if the concentration of the analytes is expected to exceed the validated linear range.

17. Prepare a series of sugar calibration standards in deionized water at concentrations appropriate for creating a calibration curve for each sugar of interest. A suggested scheme for the HPX-87C column is to prepare a set of multi-component standards containing glucose, xylose, and arabinose in the range of $0.2-12.0 \mathrm{mg} / \mathrm{mL}$. For the HPX-87P column, galactose and mannose should be included as additional components in the standards.

18. The instrumental conditions are as follows:

Sample volume: $50 \mu \mathrm{L}$

Eluant: $0.2 \mu \mathrm{m}$ filtered and degassed, deionized water

Flow rate: $0.55 \mathrm{~mL} / \mathrm{min}$

Column temperature: $85^{\circ} \mathrm{C}$ 
Detector: refractive index

Run time: 20 min data collection plus a 15-min post-run

\section{Calculations}

(1) Create calibration curve by linear regression analysis for each sugar to be quantified. From these curves, determine the concentration in $\mathrm{mg} / \mathrm{mL}$ of the sugars present in each solution

(2) Calculate the amount of sugar recovered from each SRS taken through the two-stage hydrolysis. The amount will give an estimate of each individual sugar destroyed during the hydrolysis process.

$$
\% R_{S R S}=C_{2} / C_{1} \times 100(\%)
$$

where: $\% R_{S R S}=\%$ recovery of sugar recovery standard (SRS)

$C_{1}=$ known concentration of SRS before hydrolysis, in $\mathrm{mg} / \mathrm{mL}$

$C_{2}=$ concentration of SRS detected by HPLC after hydrolysis, in $\mathrm{mg} / \mathrm{mL}$

(3) Correct sugar concentration values (in $\mathrm{mg} / \mathrm{mL}$ ) obtained from HPLC for each sugar in the hydrolyzed sample by using the \% recovery of SRS.

$$
C_{c o r r}=C_{s p l} \times 100 / \% R_{S R S}
$$

where: $C_{\text {corr }}=$ concentration of sugar in hydrolyzed sample corrected, in $\mathrm{mg} / \mathrm{mL}$

$C_{s p l}=$ concentration of sugar detected in the hydrolyzed sample by HPLC, in $\mathrm{mg} / \mathrm{mL}$

$\% R_{S R S}=\%$ recovery of sugar recovery standard (SRS)

(4) Calculate the $\%$ of each sugar present in the sample as follows:

$$
\% \text { Sugar }=\frac{C_{c o r r} \times \frac{1 \mathrm{~g}}{1000 \mathrm{mg}} \times V_{f}}{W_{1} \times \frac{\% T_{f}}{100 \%}} \times 100(\%)
$$

where: $W_{1}=$ initial weight of sample, in $\mathrm{g}$ 
$V_{f}=$ volume of filtrate, $87.0 \mathrm{~mL}$

$C_{c o r r}=$ concentration of sugar in hydrolyzed sample corrected for loss on hydrolysis, in $\mathrm{mg} / \mathrm{mL}$

$T_{f}=\%$ total solid content of the prepared sample used in this carbohydrate analysis, as determined by NREL standard procedure No. 001 . 


\section{APPENDIX I}

\section{DETERMINATION OF LIGNIN (ACID-INSOLUBLE AND -SOLUBLE) CONTENTS IN BIOMASS}

This method is based on the NREL standard procedure No. 03 (Determination of acid-insoluble lignin in biomass) and No. 04 (Determination of acid-soluble lignin in biomass).

\section{Apparatus}

Muffle furnace.

Analytical balance readable to $0.1 \mathrm{mg}$.

Convection oven $\left(45\right.$ and $\left.105^{\circ} \mathrm{C}\right)$.

Manifold for reflux condensers.

\section{Materials}

$72 \% \mathrm{w} / \mathrm{w} \mathrm{H}_{2} \mathrm{SO}_{4}\left(12.00 \pm 0.02 \mathrm{M}\right.$ or specific gravity 1.6389 at $\left.15.6{ }^{\circ} \mathrm{C}\right)$

Micro reflux condensers with ground glass joint 24/40

1000-mL Erlenmeyer with ground glass joint 24/40

500-mL graduated cylinder

100-mL graduated cylinder

1000-mL vacuum flask

$20 \mathrm{~mm} \times 150 \mathrm{~mm}$ borosilicate test tubes

200-mm glass stir rods

50-mL glass filtering crucible - medium porosity

Vacuum adapter for crucibles

Crucible tongs 


\section{Procedure}

1. Determine the moisture content of the biomass (NREL standard procedure No. 1). Total solid content is determined as $T_{f}$.

2. Weigh $1.0 \mathrm{~g}$ of the biomass and place in test tubes $\left(W_{\mathrm{i}}\right)$.

3. Add $15 \mathrm{~mL}$ of chilled $\left(15^{\circ} \mathrm{C}\right) 72 \% \mathrm{H}_{2} \mathrm{SO}_{4}$ and stir until thoroughly mixed.

4. Stir the sample every $15 \mathrm{~min}$ for $2 \mathrm{~h}$ at room temperature to assure complete mixing and wetting (hydrolysis reaction occurs).

5. Transfer hydrolyzate to $1000-\mathrm{mL}$ Erlenmeyer flask and dilute to $3 \%$ acid concentration with $560 \mathrm{~mL}$ of distilled water. Carefully transfer all the residual solids along with the hydrolysis liquid.

6. Boil gently for $4 \mathrm{~h}$ under reflux condenser.

7. Rinse the condenser with a small amount of deionized water before disassembling reflux apparatus.

8. Vacuum filter the reflux solution through a filtering crucible that has been ignited and weighed.

9. Record the volume of filtrate collected.

10. Decant $10 \mathrm{~mL}$ of filtrate and save for acid-soluble lignin determination.

11. Wash the particles clinging to the flask with hot deionized water and filter again.

12. Dry the crucible and contents at $105^{\circ} \mathrm{C} \pm 3{ }^{\circ} \mathrm{C}$ until constant weight is achieved \pm $0.1 \%$ upon reheating.

13. Cool in desiccator and weigh as lignin plus ash to the nearest $0.1 \mathrm{mg}\left(W_{1}\right)$.

14. To correct for acid-insoluble ash, the crucible containing the dried residue is ashed at $575 \pm 25^{\circ} \mathrm{C}$.

15. The ashed crucible and contents are then cooled in a desiccator and weighed to the nearest $0.1 \mathrm{mg}\left(W_{2}\right)$.

16. The weight of lignin (\% Klason lignin) will be reported by percent on a dry weight basis as below: 


$$
\% \text { Klason lignin }=\frac{W_{1}-W_{2}}{W_{i} \times \frac{\% T_{f}}{100 \%}} \times 100 \%
$$

where: $W_{1}=$ weight of crucible + acid insoluble residue

$W_{2}=$ weight of crucible + ash

$W_{i}=$ initial sample weight

$T_{f}=$ solid content in the initial sample

17. The filtrate that was saved in the previous Step 10 is used to determine acidsoluble lignin content.

18. Dilute the filtrate with $3 \% \mathrm{H}_{2} \mathrm{SO}_{4}$ solution (normally, dilution factor, $d f$, $=7$ ).

19. Measure the absorbance of the filtrate at $205 \mathrm{~nm}$. A $3 \% \mathrm{H}_{2} \mathrm{SO}_{4}$ solution should be used as a reference blank.

20. Absorbance range should be between 0.2 and 0.7 .

21. Calculation: An absorptivity (extinction coefficient) value of $110 \mathrm{~L} /(\mathrm{g} \cdot \mathrm{cm})$ is used to calculate the amount of acid-soluble lignin present in the filtrate. The percent acid-soluble lignin on a $105^{\circ} \mathrm{C}$ dry weight basis is calculated as follows:

$$
\% \text { Acid-soluble lignin }=\frac{\frac{A}{b \times a} \times d f \times V}{\frac{1000 \mathrm{~mL}}{1 \mathrm{~L}} \times W} \times 100 \%
$$

where: $A=$ absorbance at $205 \mathrm{~nm}$

$d f=$ dilution factor

$b=$ cell path length of $1 \mathrm{~cm}$

$a=$ absorptivity value of $100 \mathrm{~L} /(\mathrm{g} \cdot \mathrm{cm})$

$V=$ filtrate volume, in $\mathrm{mL}$

$W=$ initial sample weight 


\section{APPENDIX $\mathbf{J}$}

\section{DETERMINATION OF THE FERMENTABILITY OF THE PRETREATMENT LIQUORS}

Biomass must be pretreated prior to biological conversion to achieve high yield, and biological inhibitors may be produced or released into the hydrolyzate during treatment. To characterize the relative fermentability of pretreatment hydrolyzates, glucose fermentations are performed using a control sample and various dilutions of hydrolyzates.

\section{Apparatus}

Analytical balance readable to $0.1 \mathrm{mg}$.

Autoclave

Shaking incubator $\left(38^{\circ} \mathrm{C}, 130 \mathrm{rpm}\right)$

Serum bottles $(125-\mathrm{mL})$ with butyl rubber stoppers and aluminum climp seals

\section{Materials}

Saccharomyces cerevisiae $\mathrm{D}_{5} \mathrm{~A}$ provided from NREL

$10 \times \mathrm{YP}$ medium $(100 \mathrm{~g} / \mathrm{L}$ yeast extract, $200 \mathrm{~g} / \mathrm{L}$ peptone $)$

$500 \mathrm{~g} / \mathrm{L}$ of glucose solution

Pretreatment hydrolyzates

\section{Medium preparation}

Deionized water and $20 \% \mathrm{v} / \mathrm{v}, 50 \% \mathrm{v} / \mathrm{v}$ or even higher percentages of fresh pretreatment hydrolysate are used to prepare the control and the test solutions, respectively, as illustrated in the following examples. 
Example 1. Control medium preparation ( $0 \% \mathrm{v} / \mathrm{v}$ of hydrolyzate).

\begin{tabular}{lc}
\hline \multicolumn{1}{c}{ Materials } & Amounts \\
\hline Deionized water & $39.5 \mathrm{~mL}$ \\
10× YP medium & $5.0 \mathrm{~mL}$ \\
$50 \%$ glucose solution & $2.0 \mathrm{~mL}$ \\
1.0-M citrate buffer & $2.5 \mathrm{~mL}$ \\
Inoculum & $1.0 \mathrm{~mL}$ \\
\hline Total volume & $50.0 \mathrm{~mL}$ \\
\hline
\end{tabular}

Example 2. Test medium preparation ( $50 \% \mathrm{v} / \mathrm{v}$ of hydrolyzate).

\begin{tabular}{lc}
\hline \multicolumn{1}{c}{ Materials } & Amounts \\
\hline hydrolyzate & $25.0 \mathrm{~mL}$ \\
Deionized water & $14.5 \mathrm{~mL}$ \\
10× YP medium & $5.0 \mathrm{~mL}$ \\
$50 \%$ glucose solution & $2.0 \mathrm{~mL}$ \\
1.0-M citrate buffer & $2.5 \mathrm{~mL}$ \\
Inoculum & $1.0 \mathrm{~mL}$ \\
\hline Total volume & $50.0 \mathrm{~mL}$ \\
\hline
\end{tabular}

\section{Procedure}

1. Prepare the media without $50 \%$ glucose solution and inoculum as described in above examples.

2. Adjust the medium $\mathrm{pH}$ to 4.8 with $1.0-\mathrm{M}$ citrate buffer.

3. Tightly seal the serum bottle with rubber stopper and aluminum seal.

4. Sterilize the bottles containing medium for $30 \mathrm{~min}$ at $121^{\circ} \mathrm{C}$.

5. After cooling down the bottles, add $2 \mathrm{~mL}$ of $50 \%$ glucose and $1 \mathrm{~mL}$ of $\mathrm{D}_{5} \mathrm{~A}$ inoculum. 
6. Take $3 \mathrm{~mL}$ of sample from each bottle, measure the optical density (O.D $600 \mathrm{~nm}$ ) using spectrophotometer, and then centrifuge them to separate the liquid part (4,000 rpm, $5 \mathrm{~min})$.

7. Store the liquid samples at refrigerator to determine glucose and ethanol concentration later on.

8. Seal the bottles and cultivate them at shaking incubator at $38^{\circ} \mathrm{C}$ and $130 \mathrm{rpm}$.

9. For sampling, insert a sterile syringe needle on the rubber stopper to release gas from the bottle, invert the bottle, and take $2 \mathrm{~mL}$ of sample for analysis.

10. Sampling times are scheduled at $0,24,48$, and $72 \mathrm{~h}$.

11. The fermentability of hydrolysate is characterized by the following equations:

$$
\begin{aligned}
& \text { Relative rate }=\frac{[\text { Ethanol }] \text { at } 24 \mathrm{~h}, \text { test } /[\text { Glucose }] \text { at } 0 \mathrm{~h}, \text { test }}{[\text { Ethanol }] \text { at } 24 \mathrm{~h}, \text { control } /[\text { Glucose }] \text { at } 0 \mathrm{~h}, \text { control }} \times 100(\%) \\
& \text { Relative yield }=\frac{[\text { Ethanol }] \text { at } 72 \mathrm{~h}, \text { test } /[\text { Glucose }] \text { at } 0 \mathrm{~h}, \text { test }}{[\text { Ethanol }] \text { at } 72 \mathrm{~h}, \text { control } /[\text { Glucose }] \text { at } 0 \mathrm{~h}, \text { control }} \times 100(\%)
\end{aligned}
$$




\section{APPENDIX K}

\section{DETERMINATION OF ETHANOL CONCENTRATION BY GC}

For ethanol analysis, at least $1 \mathrm{~mL}$ of liquid should be withdrawn from the fermentor, and placed in a $1.7-\mathrm{mL}$ microcentrifuge tube. If not used immediately, the samples must be stored below $-20^{\circ} \mathrm{C}$. At the moment of analysis, thaw and vortex the sample stored in freezer before beginning the procedure.

\section{Apparatus and Materials}

Gas chromatograph (6890 Series, Agilent Technologies, U.S.A.)

Analytical column HP-5 (dimension: $30 \mathrm{~m} \times 0.32 \mathrm{~mm} \times 0.25 \mu \mathrm{m}$, Agilent Technologies, U.S.A.)

Micro-centrifuge (6,000 rpm, Phenix Research Products, U.S.A.)

Disposable nylon syringe filters, $0.45-\mu \mathrm{m}$

Disposable syringes, 3-mL

Autosampler vials with rubber stoppers and crimp aluminum seals

Standard solution of ethanol (100\% w/w, Ethyl alcohol USP - 200 Proof, AAPER

Alcohol and Chemical Company, Kentucky, U.S.A.)

\section{Procedure}

1. Before starting GC, check the gas cylinders (compressed hydrogen, zero-grade helium, and compressed zero-grade air from Plaxair, Bryan, TX) to insure at least 100 psig pressure in each.

2. Establish gas flow by setting the regulators at $40 \mathrm{psig}$ for hydrogen, $60 \mathrm{psig}$ for helium, and 50 psig for air. 
3. Check the solvent and waste bottles on the injector tower (7683 Series Injector, Agilent Technologies). Fill the solvent bottles with methanol and be sure the waste bottles are empty.

4. Make sure the column head pressure gauge on the GC indicates the proper pressure, 15 psig. Low head pressure usually indicates a worn-out septum in the injector. Replace the septum before starting the GC.

5. Maximally 100 sample vials can be loaded in the autosampler plate. Place the samples in the autosampler racks, not leaving empty spaces between samples.

6. Operation conditions for ethanol analysis are

(1) Oven temperature $=40^{\circ} \mathrm{C}$

(2) $\operatorname{Ramp}=20^{\circ} \mathrm{C} / \mathrm{min}$

(3) Inlet temperature $=230^{\circ} \mathrm{C}$

(4) Detector temperature $=250^{\circ} \mathrm{C}$

(5) $\mathrm{H}_{2}$ flow $=40 \mathrm{~mL} / \mathrm{min}$

(6) He flow $=179 \mathrm{~mL} / \mathrm{min}$

(7) Air flow $=400 \mathrm{~mL} / \mathrm{min}$

(8) Run time $=12.75 \mathrm{~min}$

7. Start the GC on the computer by loading the method. Set and load the sequence of samples to run. After the conditions are reached, the green start signal is on the screen. Select the start icon at the sequence table.

8. When running the sequence is completed, select standby mode from the method list and close air and hydrogen cylinder valves. 


\section{APPENDIX L}

\section{HPLC ANALYSIS OF LIQUID FRACTIONS OF LIME PRETREATMENT FOR MONOMERIC AND DIMERIC SUGARS}

This method is used to determine the soluble monosaccharide content of the liquid fractions of biomass such as pretreatment liquors and liquid fermentation samples.

The soluble sugar content indicates the amount of fermentable sugars available for conversion to ethanol. This procedure is based on the NREL standard procedure No. 13 (HPLC analysis of liquid fractions of process samples for monomeric sugars and cellobiose).

\section{Apparatus and Materials}

Analytical balance, accurate to $0.1 \mathrm{mg}$

$\mathrm{pH}$ meter

HPLC system with refractive index detector (RefractoMonitor ${ }^{\circledR}$ III, Model 1109, LDC/MiltonRoy, U.S.A.)

Autosampler: Spectra-Physics, AS100.

Biorad Aminex HPX-87C and/or HPX-87P columns with the guard column

Standard sugars - cellobiose, glucose, xylose, arabinose, galactose, and mannose

Calcium carbonate, ACS reagent grade

Deionized water, 0.2- $\mu \mathrm{m}$ filtered

$\mathrm{pH}$ paper (range 2-9)

\section{Procedure}

1. Measure the $\mathrm{pH}$ of the liquid sample and adjust the $\mathrm{pH} 5-6$, e.g., if the $\mathrm{pH}$ is less than 5, neutralize with calcium carbonate. 
2. Filter the liquid sample diluted and neutralized with $0.2-\mu \mathrm{m}$ syringe filters into autosampler vials.

3. Prepare the multi-component standard containing glucose, xylose, cellobiose, xylobiose, arabinose, and mannose in the range of $0.2-12.0 \mathrm{mg} / \mathrm{mL}$.

4. If cellobiose, mannose, and galactose are to be determined, only the Biorad Aminex HPX-87P column must be used. The operating conditions are Sample volume: $50 \mu \mathrm{L}$

Mobile phase: HPLC grade deionized water degassed and filtered with $0.2-\mu \mathrm{m}$ nylon-filter

Flow rate: $0.55 \mathrm{~mL} / \mathrm{min}$

Column temperature: $85^{\circ} \mathrm{C}$

Detector: refractive index

Run time: 20 minutes for data collection plus a $15 \mathrm{~min}$ for post-run. 


\section{APPENDIX M}

\section{HPLC ANALYSIS OF LIQUID FRACTIONS OF LIME PRETREATMENT TO DETERMINE TOTAL SUGARS AND DEGRADATION PRODUCTS}

This method is used to determine the total soluble sugars in the liquid sample including monosaccharides and oligosaccharides. To determine the total sugar concentrations in the liquor, all forms of oligomers turn to monosacchrides using $4 \%$ dilute acid (sulfuric acid). This method also can be applied to determine the degradation products of carbohydrates and lignin, which can be generated during the lime pretreatment. This method is based on NREL standard procedure No. 14 (Dilute acid hydrolysis procedure for determination of total sugars in the liquid fraction of process samples) and No. 15 (HPLC analysis of liquid fractions of process samples for organic acids, glycerol, HMF, and furfural.

\section{Apparatus and Materials}

Analytical balance, accurate to $0.1 \mathrm{mg}$.

$\mathrm{pH}$ meter.

Autosampler: Spectra-Physics, AS100.

HPLC system with refractive index detector (RefractoMonitor ${ }^{\circledR}$ III, Model 1109, LDC/MiltonRoy, U.S.A.).

Biorad Aminex HPX-87H column with the guard column.

Standards - xylobiose, glucose, xylose, arabinose, lactic acid, formic acid, glycerol, HMF (5-hydroxy-2-furfuraladehyde), and furfural.

Calcium carbonate, ACS reagent grade

Deionized water, $0.2-\mu \mathrm{m}$ filtered

$\mathrm{pH}$ paper (range 2-9)

$72 \%$ sulfuric acid, ACS grade 


\section{Procedures}

1. Transfer $20 \mathrm{~mL}$ of the liquid sample into the crimp-top bottles.

2. Adjust the $\mathrm{pH}$ to 5.0 with $72 \%$ sulfuric acid $(0.03 \mathrm{~mL})$.

3. Add $0.67 \mathrm{~mL}$ of $72 \%$ sulfuric acid to make $4 \%$ final acid concentration.

4. Seal the crimp-top bottle and place into the autoclave $\left(120^{\circ} \mathrm{C}\right.$ for $\left.1 \mathrm{~h}\right)$.

5. Cool down to room temperature.

6. Filter through $0.2-\mu \mathrm{m}$ syringe filter.

7. Prepare the multi-component standard solution containing xylobiose, glucose, xylose, arabinose, lactic acid, glycerol, formic acid, acetic acid, ethanol, and furfural.

8. The retention times for each component as follows:

\begin{tabular}{lc}
\hline \multicolumn{1}{c}{ Component } & Retention time (min) \\
\hline Xylobiose & 8.7 \\
Glucose & 9.7 \\
Xylose & 10.4 \\
Arabinose & 11.37 \\
Lactic acid & 13.24 \\
Glycerol/Formic acid & 14.7 \\
Acetic acid & 15.99 \\
Ethanol & 22.0 \\
HMF & 29.8 \\
Fufural & 47.35 \\
\hline
\end{tabular}

* HMF: 5-hydroxy-2-furfuraladehyde

9. The operation conditions for HPLC are

Sample volume: $50 \mu \mathrm{L}$

Mobile phase: $0.01-\mathrm{N}$ sulfuric acid $(1.06 \mathrm{~mL}$ of conc. sulfuric acid in $4 \mathrm{~L}$ of deionized water)

Flow rate: $0.6 \mathrm{~mL} / \mathrm{min}$

Column temperature: $60^{\circ} \mathrm{C}$

Detector: refractive index

Run time: 55 min for data collection. 


\section{APPENDIX N}

\section{EXPERIMENTAL DATA}

Table N-1.Specific lime consumption ( $\mathrm{g} \mathrm{Ca}(\mathrm{OH})_{2} / \mathrm{g}$ raw biomass).

\begin{tabular}{|c|c|c|c|c|c|c|c|c|c|}
\hline \multirow{2}{*}{$\begin{array}{c}\text { Temp } \\
\left({ }^{\circ} \mathrm{C}\right)\end{array}$} & $\begin{array}{c}\text { Gas } \\
\text { purge }\end{array}$ & \multicolumn{7}{|c|}{ Pretreatment time (d: day; w: week) } \\
\cline { 2 - 10 } & $0 \mathrm{~d}$ & $1 \mathrm{~d}$ & $3 \mathrm{~d}$ & $1 \mathrm{w}$ & $2 \mathrm{w}$ & $4 \mathrm{w}$ & $8 \mathrm{w}$ & $16 \mathrm{w}^{1)}$ \\
\hline \multirow{4}{*}{25} & $\mathrm{~N}_{2}$ & 0.000 & 0.014 & 0.015 & 0.015 & 0.023 & 0.030 & 0.038 & 0.041 \\
\cline { 2 - 11 } & Air & 0.000 & 0.019 & 0.016 & 0.029 & 0.034 & 0.051 & 0.070 & 0.087 \\
\cline { 2 - 10 } & Air* & 0.000 & - & - & 0.022 & - & 0.047 & 0.064 & 0.097 \\
\hline \multirow{4}{*}{35} & $\mathrm{~N}_{2}$ & 0.000 & 0.012 & 0.026 & 0.027 & 0.027 & 0.042 & 0.046 & 0.040 \\
\cline { 2 - 10 } & Air & 0.000 & 0.017 & 0.024 & 0.047 & 0.057 & 0.076 & 0.105 & 0.112 \\
\cline { 2 - 10 } & Air* & 0.000 & - & - & 0.034 & - & - & 0.082 & 0.118 \\
\hline \multirow{4}{*}{45} & $\mathrm{~N}_{2}$ & 0.000 & 0.020 & 0.021 & 0.033 & 0.036 & 0.040 & 0.047 & 0.052 \\
\cline { 2 - 10 } & Air & 0.000 & 0.017 & 0.032 & 0.067 & 0.074 & 0.096 & 0.151 & 0.220 \\
\cline { 2 - 10 } & Air* & 0.000 & - & - & - & 0.058 & - & 0.100 & 0.160 \\
\hline \multirow{3}{*}{55} & $\mathrm{~N}_{2}$ & 0.000 & 0.017 & 0.027 & 0.037 & 0.038 & 0.045 & 0.058 & 0.053 \\
\cline { 2 - 10 } & Air & 0.000 & 0.025 & 0.039 & 0.066 & 0.092 & 0.195 & 0.228 & 0.319 \\
\cline { 2 - 9 } & Air* & 0.000 & - & - & - & - & 0.073 & 0.148 & 0.176 \\
\hline
\end{tabular}

The first batch data of corn stover for Figures 12 and 13

1) $15 \mathrm{w}$ for $25^{\circ} \mathrm{C}$

* Air scrubbed $\mathrm{CO}_{2}$ 
Table N-2. The fractional changes of lignin solubilized $\left(1-W_{\mathrm{L}}\right)^{1)}$ as a function of the weight fraction of lime consumed $\left(1-W_{\mathrm{C}}\right)^{2)}$.

\begin{tabular}{|c|c|c|c|c|c|c|c|c|c|}
\hline \multirow{2}{*}{$\begin{array}{c}\text { Temp } \\
\left({ }^{\mathrm{o}} \mathrm{C}\right)\end{array}$} & \multirow{2}{*}{$\begin{array}{c}\text { Gas } \\
\text { purge }\end{array}$} & \multirow{2}{*}{$\begin{array}{l}\text { Para- } \\
\text { meter }\end{array}$} & \multicolumn{7}{|c|}{ Pretreatment time (d: day; w: week) } \\
\hline & & & $1 \mathrm{~d}$ & $3 d$ & $1 \mathrm{w}$ & $2 \mathrm{w}$ & $4 \mathrm{w}$ & $8 \mathrm{w}$ & $16 \mathrm{w}^{3)}$ \\
\hline \multirow{6}{*}{25} & \multirow{2}{*}{$\mathrm{N}_{2}$} & $\varphi$ & 0.123 & 0.167 & 0.176 & 0.299 & 0.345 & 0.348 & 0.437 \\
\hline & & $\gamma$ & 0.029 & 0.029 & 0.030 & 0.045 & 0.061 & 0.076 & 0.082 \\
\hline & \multirow{2}{*}{ Air } & $\varphi$ & 0.138 & 0.196 & 0.261 & 0.336 & 0.379 & 0.424 & 0.577 \\
\hline & & $\gamma$ & 0.039 & 0.031 & 0.058 & 0.069 & 0.103 & 0.140 & 0.174 \\
\hline & \multirow{2}{*}{ Air* } & $\varphi$ & - & - & - & - & 0.362 & 0.433 & 0.568 \\
\hline & & $\gamma$ & - & - & - & - & 0.094 & 0.093 & 0.194 \\
\hline \multirow{6}{*}{35} & \multirow{2}{*}{$\mathrm{N}_{2}$} & $\varphi$ & 0.214 & 0.255 & 0.321 & 0.374 & 0.380 & 0.410 & 0.476 \\
\hline & & $\gamma$ & 0.024 & 0.053 & 0.054 & 0.054 & 0.084 & 0.092 & 0.081 \\
\hline & \multirow{2}{*}{ Air } & $\varphi$ & 0.204 & 0.275 & 0.360 & 0.455 & 0.461 & 0.556 & 0.673 \\
\hline & & $\gamma$ & 0.033 & 0.048 & 0.094 & 0.113 & 0.152 & 0.210 & 0.224 \\
\hline & \multirow{2}{*}{ Air* } & $\varphi$ & - & - & 0.368 & - & - & 0.568 & 0.662 \\
\hline & & $\gamma$ & - & - & 0.072 & - & - & 0.164 & 0.235 \\
\hline \multirow{6}{*}{45} & \multirow{2}{*}{$\mathrm{N}_{2}$} & $\varphi$ & 0.236 & 0.267 & 0.311 & 0.360 & 0.401 & 0.457 & 0.473 \\
\hline & & $\gamma$ & 0.040 & 0.042 & 0.066 & 0.072 & 0.080 & 0.094 & 0.103 \\
\hline & \multirow{2}{*}{ Air } & $\varphi$ & 0.204 & 0.297 & 0.424 & 0.479 & 0.551 & 0.708 & 0.801 \\
\hline & & $\gamma$ & 0.033 & 0.064 & 0.134 & 0.148 & 0.192 & 0.302 & 0.440 \\
\hline & \multirow{2}{*}{ Air* } & $\varphi$ & - & - & - & 0.484 & - & 0.712 & 0.790 \\
\hline & & $\gamma$ & - & - & - & 0.116 & - & 0.202 & 0.320 \\
\hline \multirow{6}{*}{55} & \multirow{2}{*}{$\mathrm{N}_{2}$} & $\varphi$ & 0.277 & 0.337 & 0.377 & 0.412 & 0.417 & 0.474 & 0.453 \\
\hline & & $\gamma$ & 0.033 & 0.053 & 0.074 & 0.076 & 0.091 & 0.115 & 0.107 \\
\hline & \multirow{2}{*}{ Air } & $\varphi$ & 0.273 & 0.343 & 0.452 & 0.587 & 0.702 & 0.786 & 0.882 \\
\hline & & $\gamma$ & 0.050 & 0.077 & 0.132 & 0.184 & 0.390 & 0.457 & 0.637 \\
\hline & \multirow{2}{*}{ Air* } & $\varphi$ & - & - & - & - & - & 0.789 & 0.880 \\
\hline & & $\gamma$ & - & - & - & - & - & 0.295 & 0.352 \\
\hline
\end{tabular}

The first batch data of corn stover for Figure 14

1) $\varphi=1-W_{\mathrm{L}}=1-$ weight fraction of the Klason lignin in the pretreated biomass

$[=] \mathrm{g}$ Klason lignin solubilized $(t) / \mathrm{g}$ insoluble lignin $(0)$

2) $\gamma=1-W_{\mathrm{C}}=1-$ weight fraction of lime unused

$[=] \mathrm{g} \mathrm{Ca}(\mathrm{OH})_{2}$ used $(t) / \mathrm{g} \mathrm{Ca}(\mathrm{OH})_{2}(0)$

3) $15 \mathrm{w}$ for $25^{\circ} \mathrm{C}$ experiment

* Air: $\mathrm{CO}_{2}$ scrubbed 
Table N-3. Composition of raw and pretreated corn stover at $25^{\circ} \mathrm{C}$ without air.

\begin{tabular}{|c|c|c|c|c|c|}
\hline \multirow{2}{*}{ Component } & \multicolumn{5}{|c|}{ Contents ${ }^{1)}$ (g/100 g of dry biomass) } \\
\hline & $\operatorname{Raw}^{2)}$ & 1 week* $^{*}$ & 2 weeks* & 8 weeks* & 15 weeks* \\
\hline Glucan & 37.5 & 41.8 & 39.1 & 39.6 & 38.8 \\
\hline Xylan & 20.8 & 18.3 & 17.7 & 16.6 & 16.9 \\
\hline Lignin $^{3)}$ & 21.4 & 17.7 & 14.9 & 13.8 & 12.1 \\
\hline Protein & 3.4 & 3.7 & 2.4 & 2.1 & 1.4 \\
\hline Ash & 9.5 & 7.9 & 7.2 & 6.6 & 6.2 \\
\hline Others ${ }^{4)}$ & 7.4 & 6.5 & 6.1 & 5.7 & 5.9 \\
\hline Total & 100.0 & 95.9 & 87.4 & 84.4 & 81.3 \\
\hline
\end{tabular}

The first batch data of corn stover for Figure 15 (a)

1) Based on dry weight

2) Untreated first batch of corn stover $(t=0)$

3) Lignin $=$ Klason + acid-soluble lignin

4) Others $=$ arabinan + mannan + galactan + acetyl + uronic acid + non-structural sugars

* Pretreatment time

Table N-4. Composition of raw and pretreated corn stover at $35^{\circ} \mathrm{C}$ without air.

\begin{tabular}{|c|c|c|c|c|c|c|}
\hline \multirow[b]{2}{*}{ Component } & \multicolumn{6}{|c|}{ Contents ${ }^{1)}(\mathrm{g} / 100 \mathrm{~g}$ of dry biomass $)$} \\
\hline & $\operatorname{Raw}^{2)}$ & $\begin{array}{c}1 \\
\text { week* }\end{array}$ & $\begin{array}{c}2 \\
\text { weeks* }\end{array}$ & $\begin{array}{c}4 \\
\text { weeks* }\end{array}$ & $\begin{array}{c}8 \\
\text { weeks* }\end{array}$ & $\begin{array}{c}16 \\
\text { weeks* }\end{array}$ \\
\hline Glucan & 37.5 & 38.4 & 38.2 & 37.3 & 38.0 & 38.6 \\
\hline Xylan & 20.8 & 17.3 & 16.8 & 15.6 & 16.5 & 13.4 \\
\hline Lignin $^{3)}$ & 21.4 & 14.5 & 13.3 & 13.3 & 12.6 & 11.2 \\
\hline Protein & 3.4 & 3.0 & 2.6 & 2.4 & 2.2 & 1.4 \\
\hline Ash & 9.5 & 8.6 & 8.2 & 8.1 & 7.3 & 7.3 \\
\hline Others ${ }^{4)}$ & 7.4 & 6.9 & 6.4 & 6.2 & 6.1 & 6.1 \\
\hline Total & 100.0 & 88.7 & 85.5 & 82.9 & 82.7 & 78.0 \\
\hline
\end{tabular}

The first batch data of corn stover for Figure 15 (b)

1) - 4): same as described in Table N-3

* Pretreatment time 
Table N-5. Composition of raw and pretreated corn stover at $45^{\circ} \mathrm{C}$ without air.

\begin{tabular}{|c|c|c|c|c|c|c|}
\hline \multirow{2}{*}{ Component } & \multicolumn{6}{|c|}{ Contents $^{1)}(\mathrm{g} / 100$ g of dry biomass) } \\
\cline { 2 - 7 } & Raw $^{2}$ & $\begin{array}{c}1 \\
\text { week* }\end{array}$ & $\begin{array}{c}2 \\
\text { weeks* }\end{array}$ & $\begin{array}{c}4 \\
\text { weeks* }\end{array}$ & $\begin{array}{c}8 \\
\text { weeks* }\end{array}$ & $\begin{array}{c}16 \\
\text { weeks* }\end{array}$ \\
\hline Glucan & 37.5 & 39.8 & 38.7 & 38.9 & 37.3 & 38.6 \\
\hline Xylan & 20.8 & 17.1 & 16.2 & 16.5 & 13.8 & 16.8 \\
\hline Lignin $^{3)}$ & 21.4 & 14.6 & 13.6 & 12.8 & 11.6 & 11.4 \\
\hline Protein & 3.4 & 3.0 & 2.6 & 2.4 & 2.0 & 1.4 \\
\hline Ash & 9.5 & 8.0 & 7.5 & 7.1 & 6.8 & 6.9 \\
\hline Others & 7.4 & 6.7 & 6.4 & 6.3 & 5.7 & 5.7 \\
\hline Total & 100.0 & 89.2 & 85.0 & 84.0 & 77.2 & 80.8 \\
\hline
\end{tabular}

The first batch data of corn stover for Figure 15 (c)

1) - 4): same as described in Table N-3

* Pretreatment time

Table N-6. Composition of raw and pretreated corn stover at $55^{\circ} \mathrm{C}$ without air.

\begin{tabular}{|c|c|c|c|c|c|c|}
\hline \multirow{2}{*}{ Component } & \multicolumn{6}{|c|}{ Contents $^{1)}(\mathrm{g} / 100$ g of dry biomass) } \\
\cline { 2 - 7 } & Raw $^{2)}$ & $\begin{array}{c}1 \\
\text { week* }\end{array}$ & $\begin{array}{c}2 \\
\text { weeks* }\end{array}$ & $\begin{array}{c}4 \\
\text { weeks* }\end{array}$ & $\begin{array}{c}8 \\
\text { weeks* }\end{array}$ & $\begin{array}{c}16 \\
\text { weeks* }\end{array}$ \\
\hline Glucan & 37.5 & 37.6 & 35.0 & 41.0 & 35.2 & 42.2 \\
\hline Xylan & 20.8 & 17.0 & 15.2 & 15.8 & 15.5 & 16.5 \\
\hline Lignin $^{3)}$ & 21.4 & 13.2 & 12.5 & 12.4 & 11.3 & 11.8 \\
\hline Protein $^{*}$ & 3.4 & 2.8 & 2.6 & 1.5 & 1.2 & 0.6 \\
\hline Ash & 9.5 & 7.1 & 10.0 & 6.3 & 6.1 & 5.5 \\
\hline Others & 4.4 & 6.2 & 6.1 & 5.2 & 6.1 & 4.2 \\
\hline Total & 100.0 & 83.9 & 81.4 & 82.2 & 75.4 & 80.8 \\
\hline
\end{tabular}

The first batch data of corn stover for Figure 15 (d)

1) - 4): same as described in Table N-3

* Pretreatment time 
Table N-7. Composition of raw and pretreated corn stover at $25^{\circ} \mathrm{C}$ with air.

\begin{tabular}{|c|c|c|c|c|c|}
\hline \multirow{2}{*}{ Component } & \multicolumn{5}{|c|}{ Contents ${ }^{1)}$ (g/100 g of dry biomass) } \\
\hline & $\mathrm{Raw}^{2)}$ & 1 week* & 2 weeks* & 8 weeks* & 15 weeks* \\
\hline Glucan & 37.5 & 37.8 & 38.3 & 39.0 & 39.7 \\
\hline Xylan & 20.8 & 16.5 & 16.4 & 15.0 & 13.7 \\
\hline Lignin $^{3)}$ & 21.4 & 15.4 & 13.8 & 12.2 & 9.3 \\
\hline Protein & 3.4 & 3.1 & 2.8 & 1.9 & 1.5 \\
\hline Ash & 9.5 & 7.5 & 7.1 & 7.9 & 6.8 \\
\hline Others $^{4)}$ & 7.4 & 6.4 & 6.1 & 5.8 & 5.4 \\
\hline Total & 100.0 & 86.7 & 84.5 & 81.8 & 76.4 \\
\hline
\end{tabular}

The first batch data of corn stover for Figure 16 (a)

1) - 4): same as described in Table N-3

* Pretreatment time

Table N-8. Composition of raw and pretreated corn stover at $35^{\circ} \mathrm{C}$ with air.

\begin{tabular}{|c|c|c|c|c|c|c|}
\hline \multirow{2}{*}{ Component } & \multicolumn{6}{|c|}{ Contents $^{1)}(\mathrm{g} / 100$ g of dry biomass) } \\
\cline { 2 - 7 } & Raw $^{2)}$ & $\begin{array}{c}1 \\
\text { week* }\end{array}$ & $\begin{array}{c}2 \\
\text { weeks* }\end{array}$ & $\begin{array}{c}4 \\
\text { weeks* }\end{array}$ & $\begin{array}{c}8 \\
\text { weeks* }\end{array}$ & $\begin{array}{c}16 \\
\text { weeks* }\end{array}$ \\
\hline Glucan & 37.5 & 38.5 & 36.5 & 38.0 & 36.6 & 35.3 \\
\hline Xylan & 20.8 & 15.8 & 14.2 & 14.6 & 14.0 & 13.0 \\
\hline Lignin $^{3)}$ & 21.4 & 13.4 & 11.5 & 11.6 & 9.7 & 7.5 \\
\hline Protein & 3.4 & 2.2 & 1.7 & 1.6 & 1.7 & 1.3 \\
\hline Ash & 9.5 & 8.2 & 8.5 & 7.2 & 6.9 & 7.5 \\
\hline Others & 7.4 & 6.6 & 6.4 & 5.9 & 5.3 & 4.5 \\
\hline Total & 100.0 & 84.7 & 78.8 & 78.9 & 74.2 & 69.1 \\
\hline
\end{tabular}

The first batch data of corn stover for Figure 16 (b)

1) - 4): same as described in Table N-3

* Pretreatment time 
Table N-9. Composition of raw and pretreated corn stover at $45^{\circ} \mathrm{C}$ with air.

\begin{tabular}{|c|c|c|c|c|c|c|}
\hline \multirow[b]{2}{*}{ Component } & \multicolumn{6}{|c|}{ Contents ${ }^{1)}(\mathrm{g} / 100 \mathrm{~g}$ of dry biomass $)$} \\
\hline & $\operatorname{Raw}^{2)}$ & $\begin{array}{c}1 \\
\text { week* }\end{array}$ & $\begin{array}{c}2 \\
\text { weeks* }\end{array}$ & $\begin{array}{c}4 \\
\text { weeks* }\end{array}$ & $\begin{array}{c}8 \\
\text { weeks* }\end{array}$ & $\begin{array}{c}16 \\
\text { weeks* }\end{array}$ \\
\hline Glucan & 37.5 & 37.6 & 38.7 & 36.1 & 34.1 & 35.1 \\
\hline Xylan & 20.8 & 15.0 & 14.2 & 14.8 & 11.0 & 11.3 \\
\hline Lignin $^{3)}$ & 21.4 & 12.2 & 11.2 & 9.8 & 6.8 & 5.0 \\
\hline Protein & 3.4 & 2.3 & 2.1 & 2.0 & 1.1 & 1.0 \\
\hline Ash & 9.5 & 7.4 & 7.6 & 6.9 & 6.8 & 6.1 \\
\hline Others ${ }^{4)}$ & 7.4 & 6.0 & 5.9 & 5.5 & 5.0 & 4.4 \\
\hline Total & 100.0 & 80.5 & 79.7 & 75.1 & 64.8 & 62.9 \\
\hline
\end{tabular}

The first batch data of corn stover for Figure 16 (c)

1) - 4): same as described in Table N-3

* Pretreatment time

Table N-10. Composition of raw and pretreated corn stover at $55^{\circ} \mathrm{C}$ with air.

\begin{tabular}{|c|c|c|c|c|c|c|}
\hline \multirow[b]{2}{*}{ Component } & \multicolumn{6}{|c|}{ Contents ${ }^{1)}$ (g/100 g of dry biomass) } \\
\hline & $\operatorname{Raw}^{2)}$ & $\begin{array}{c}1 \\
\text { week* }\end{array}$ & $\begin{array}{c}2 \\
\text { weeks* }\end{array}$ & $\begin{array}{c}4 \\
\text { weeks* }\end{array}$ & $\begin{array}{c}8 \\
\text { weeks* }\end{array}$ & $\begin{array}{c}16 \\
\text { weeks* }\end{array}$ \\
\hline Glucan & 37.5 & 37.1 & 34.8 & 36.4 & 32.1 & 26.6 \\
\hline Xylan & 20.8 & 15.8 & 13.6 & 14.0 & 13.7 & 10.5 \\
\hline Lignin $^{3)}$ & 21.4 & 11.5 & 9.5 & 7.7 & 6.1 & 3.8 \\
\hline Protein & 3.4 & 1.0 & 1.0 & 0.9 & 0.7 & 0.4 \\
\hline Ash & 9.5 & 7.3 & 9.9 & 11.4 & 12.5 & 10.7 \\
\hline Others ${ }^{4)}$ & 7.4 & 5.7 & 5.6 & 6.2 & 6.7 & 5.1 \\
\hline Total & 100.0 & 78.4 & 74.4 & 76.6 & 71.8 & 57.1 \\
\hline
\end{tabular}

The first batch data of corn stover for Figure 16 (d)

1) - 4): same as described in Table N-3

* Pretreatment time 
Table N-11. Effect of lime pretreatment at $25^{\circ} \mathrm{C}$ without air on the pretreatment and hydrolysis yields of glucan and xylan.

\begin{tabular}{|c|c|c|c|c|c|c|}
\hline \multirow{2}{*}{ Process } & \multirow{2}{*}{ Component } & \multicolumn{5}{|c|}{ Pretreatment time (weeks) } \\
\hline & & $0^{11)}$ & 1 & 2 & 8 & 15 \\
\hline \multirow{4}{*}{ Raw } & iS $(g)^{1)}$ & 14.80 & 15.14 & 15.14 & 15.14 & 15.06 \\
\hline & Glucan $(\mathrm{g})$ & 5.55 & 5.68 & 5.68 & 5.68 & 5.65 \\
\hline & Xylan $(\mathrm{g})$ & 3.08 & 3.15 & 3.15 & 3.15 & 3.13 \\
\hline & $\begin{array}{l}\text { Holocellulose } \\
\text { (g) }\end{array}$ & 8.63 & 8.63 & 8.63 & 8.63 & 8.78 \\
\hline \multirow{9}{*}{ Pretreatment } & $\mathrm{fS}(\mathrm{g})^{2)}$ & - & 14.5 & 13.21 & 12.81 & 12.23 \\
\hline & Glucan $(\mathrm{g})$ & - & 6.00 & 5.91 & 6.00 & 5.84 \\
\hline & Xylan (g) & - & 2.76 & 2.68 & 2.54 & 2.54 \\
\hline & $\begin{array}{c}\text { Holocellulose } \\
(\mathrm{g})\end{array}$ & - & 8.77 & 8.58 & 8.54 & 8.38 \\
\hline & $G / X$ ratio $^{3)}$ & 1.80 & 2.17 & 2.21 & 2.36 & 2.30 \\
\hline & $Y_{\mathrm{T}}^{4)}$ & - & 0.96 & 0.87 & 0.85 & 0.81 \\
\hline & $Y_{\mathrm{G}}^{5)}$ & - & 1.05 & 1.04 & 1.06 & 1.03 \\
\hline & $Y_{X}^{6)}$ & - & 0.88 & 0.85 & 0.81 & 0.81 \\
\hline & $Y_{\mathrm{GX}}{ }^{7)}$ & - & 0.99 & 0.97 & 0.97 & 0.95 \\
\hline \multirow{6}{*}{$\begin{array}{l}\text { 3-d enzyme } \\
\text { hydrolysis } \\
\text { at } 15 \mathrm{FPU} / \\
\text { g cellulose }\end{array}$} & Glucan $(\mathrm{g})$ & 1.44 & 3.11 & 3.37 & 3.48 & 3.75 \\
\hline & Xylan (g) & 0.77 & 1.44 & 1.49 & 1.66 & 1.59 \\
\hline & $G / X$ ratio $^{3)}$ & 1.87 & 2.15 & 2.27 & 2.10 & 2.36 \\
\hline & $Y_{\mathrm{g}}^{8)}$ & 0.26 & 0.52 & 0.57 & 0.58 & 0.64 \\
\hline & $Y_{\mathrm{x}}^{9)}$ & 0.25 & 0.52 & 0.56 & 0.65 & 0.63 \\
\hline & $Y_{\mathrm{gX}}{ }^{10)}$ & 0.26 & 0.50 & 0.57 & 0.60 & 0.64 \\
\hline \multirow{6}{*}{$\begin{array}{l}\text { 3-d enzyme } \\
\text { hydrolysis } \\
\text { at } 60 \mathrm{FPU} / \\
\text { g cellulose }\end{array}$} & Glucan $(\mathrm{g})$ & 1.62 & 3.60 & 3.44 & 4.04 & 4.16 \\
\hline & Xylan (g) & 0.87 & 1.65 & 1.48 & 1.78 & 1.59 \\
\hline & $G / X$ ratio $\left.^{3}\right)$ & 1.87 & 2.19 & 2.32 & 2.28 & 2.61 \\
\hline & $Y_{\mathrm{g}}^{(1)}$ & 0.29 & 0.57 & 0.58 & 0.67 & 0.71 \\
\hline & $Y_{\mathrm{x}}^{9)}$ & 0.28 & 0.60 & 0.55 & 0.70 & 0.63 \\
\hline & $Y_{\mathrm{gx}}^{10)}$ & 0.29 & 0.58 & 0.57 & 0.68 & 0.69 \\
\hline
\end{tabular}

The first batch data of corn stover for Figures 17, 30, 41, 42, 43, 44, and 45

1) $\mathrm{iS}=$ initial dry weight of corn stover $(\mathrm{g})$

2) $\mathrm{fS}=$ dry weight of total solid recovered after pretreatment (g)

3) $G / X$ ratio $=$ Glucan $(\mathrm{g}) /$ Xylan $(\mathrm{g})$

4) $Y_{\mathrm{T}}=$ recovery yield of total solid $=\mathrm{fS}(\mathrm{g}) / \mathrm{iS}(\mathrm{g})$

5) $Y_{\mathrm{G}}=$ pretreatment yield of glucan $=\mathrm{g}$ glucan recovered $/ \mathrm{g}$ glucan in raw bioamss

6) $Y_{\mathrm{X}}=$ pretreatment yield of xylan $=\mathrm{g}$ xylan recovered/g xylan in raw biomass

7) $Y_{\mathrm{GX}}=$ pretreatment yield of holocellulose (glucan + xylan)

8) $Y_{\mathrm{g}}=$ hydrolysis yield of glucan $=\mathrm{g}$ glucan hydrolyzed $/ \mathrm{g}$ glucan in treated biomass

9) $Y_{\mathrm{x}}=$ hydrolysis yield of xylan $=\mathrm{g}$ xylan hydrolyzed/g xylan in treated biomass

10) $Y_{\mathrm{gx}}=$ hydrolysis yield of holocellulose (glucan + xylan)

11) This column for the data of the untreated corn stover 
Table N-12. Effect of lime pretreatment at $25^{\circ} \mathrm{C}$ with air on the pretreatment and hydrolysis yields of glucan and xylan.

\begin{tabular}{|c|c|c|c|c|c|}
\hline \multirow{2}{*}{ Process } & \multirow{2}{*}{ Component } & \multicolumn{4}{|c|}{ Pretreatment time (weeks) } \\
\hline & & 1 & 2 & 8 & 15 \\
\hline \multirow{4}{*}{ Raw } & iS $(g)^{1)}$ & 15.14 & 15.14 & 15.14 & 15.06 \\
\hline & Glucan $(\mathrm{g})$ & 5.68 & 5.68 & 5.68 & 5.65 \\
\hline & Xylan (g) & 3.15 & 3.15 & 3.15 & 3.13 \\
\hline & $\begin{array}{l}\text { Holocellulose } \\
\text { (g) }\end{array}$ & 8.63 & 8.63 & 8.63 & 8.78 \\
\hline \multirow{9}{*}{ Pretreatment } & $\mathrm{fS}(\mathrm{g})^{2)}$ & 13.14 & 12.79 & 12.23 & 11.49 \\
\hline & Glucan $(\mathrm{g})$ & 5.73 & 5.80 & 5.69 & 5.97 \\
\hline & Xylan $(\mathrm{g})$ & 2.50 & 2.48 & 2.32 & 2.07 \\
\hline & $\begin{array}{l}\text { Holocellulose } \\
\text { (g) }\end{array}$ & 8.23 & 8.28 & 8.02 & 8.04 \\
\hline & $G / X$ ratio $^{3)}$ & 2.29 & 2.33 & 2.45 & 2.89 \\
\hline & $Y_{\mathrm{T}}^{4)}$ & 0.87 & 0.85 & 0.81 & 0.76 \\
\hline & $Y_{\mathrm{G}}^{5)}$ & 1.01 & 1.02 & 1.00 & 1.06 \\
\hline & $Y_{X}^{6)}$ & 0.80 & 0.79 & 0.74 & 0.66 \\
\hline & $Y_{\mathrm{GX}}{ }^{7)}$ & 0.93 & 0.94 & 0.91 & 0.92 \\
\hline \multirow{6}{*}{$\begin{array}{l}\text { 3-d enzyme } \\
\text { hydrolysis } \\
\text { at } 15 \mathrm{FPU} / \\
\text { g cellulose }\end{array}$} & Glucan (g) & 2.63 & 3.21 & 3.79 & 3.97 \\
\hline & Xylan (g) & 1.21 & 1.35 & 1.45 & 1.33 \\
\hline & $G / X$ ratio $\left.^{3}\right)$ & 2.17 & 2.39 & 2.61 & 2.99 \\
\hline & $Y_{\mathrm{g}}^{8)}$ & 0.46 & 0.56 & 0.67 & 0.67 \\
\hline & $Y_{\mathrm{x}}^{(9)}$ & 0.48 & 0.54 & 0.63 & 0.64 \\
\hline & $Y_{\mathrm{gx}}{ }^{10)}$ & 0.47 & 0.55 & 0.65 & 0.66 \\
\hline \multirow{6}{*}{$\begin{array}{l}\text { 3-d enzyme } \\
\text { hydrolysis } \\
\text { at } 60 \mathrm{FPU} / \\
\text { g cellulose }\end{array}$} & Glucan $(\mathrm{g})$ & 3.59 & 3.40 & 4.22 & 4.60 \\
\hline & Xylan (g) & 1.50 & 1.39 & 1.57 & 1.42 \\
\hline & $G / X$ ratio $\left.^{3}\right)$ & 2.39 & 2.44 & 2.69 & 3.23 \\
\hline & $Y_{\mathrm{g}}^{8)}$ & 0.63 & 0.59 & 0.74 & 0.77 \\
\hline & $Y_{\mathrm{x}}^{9)}$ & 0.60 & 0.56 & 0.68 & 0.69 \\
\hline & $Y_{\mathrm{gx}}^{10)}$ & 0.62 & 0.58 & 0.72 & 0.75 \\
\hline
\end{tabular}

The first batch data of corn stover for Figures 17, 30, 41, 42, 43, and 44

1) -10): same as described in Table N-11 
Table N-13. Effect of lime pretreatment at $35^{\circ} \mathrm{C}$ without air on the pretreatment and hydrolysis yields of glucan and xylan.

\begin{tabular}{|c|c|c|c|c|c|c|}
\hline \multirow{2}{*}{ Process } & \multirow{2}{*}{ Component } & \multicolumn{5}{|c|}{ Pretreatment time (weeks) } \\
\hline & & 1 & 2 & 4 & 8 & 16 \\
\hline \multirow{4}{*}{ Raw } & iS $(g)^{1)}$ & 15.02 & 15.12 & 15.12 & 14.96 & 14.96 \\
\hline & Glucan $(\mathrm{g})$ & 5.63 & 5.67 & 5.67 & 5.61 & 5.61 \\
\hline & Xylan (g) & 3.12 & 3.15 & 3.15 & 3.11 & 3.11 \\
\hline & $\begin{array}{l}\text { Holocellulose } \\
\text { (g) }\end{array}$ & 8.76 & 8.82 & 8.82 & 8.72 & 8.72 \\
\hline \multirow{9}{*}{ Pretreatment } & $\mathrm{fS}(\mathrm{g})^{2)}$ & 13.34 & 12.91 & 12.54 & 12.37 & 11.65 \\
\hline & Glucan $(\mathrm{g})$ & 5.77 & 5.78 & 5.65 & 5.68 & 5.77 \\
\hline & Xylan $(\mathrm{g})$ & 2.61 & 2.54 & 2.36 & 2.47 & 2.00 \\
\hline & $\begin{array}{l}\text { Holocellulose } \\
\text { (g) }\end{array}$ & 8.38 & 8.31 & 8.00 & 8.15 & 7.77 \\
\hline & $G / X$ ratio $^{3)}$ & 2.22 & 2.28 & 2.39 & 2.30 & 2.89 \\
\hline & $Y_{\mathrm{T}}^{4)}$ & 0.89 & 0.85 & 0.83 & 0.83 & 0.78 \\
\hline & $Y_{\mathrm{G}}^{5)}$ & 1.03 & 1.02 & 1.00 & 1.01 & 1.03 \\
\hline & $Y_{X}^{6)}$ & 0.83 & 0.81 & 0.75 & 0.79 & 0.64 \\
\hline & $Y_{\mathrm{GX}}{ }^{7)}$ & 0.96 & 0.94 & 0.91 & 0.94 & 0.89 \\
\hline \multirow{6}{*}{$\begin{array}{l}\text { 3-d enzyme } \\
\text { hydrolysis } \\
\text { at } 15 \mathrm{FPU} / \\
\text { g cellulose }\end{array}$} & Glucan $(\mathrm{g})$ & 2.63 & 2.67 & 3.26 & - & 3.60 \\
\hline & Xylan (g) & 1.21 & 1.25 & 1.45 & - & 1.61 \\
\hline & $G / X$ ratio $\left.^{3}\right)$ & 2.18 & 2.13 & 2.25 & - & 2.23 \\
\hline & $Y_{\mathrm{g}}^{8)}$ & 0.46 & 0.46 & 0.58 & - & 0.62 \\
\hline & $Y_{\mathrm{x}}^{9)}$ & 0.46 & 0.49 & 0.61 & - & 0.81 \\
\hline & $Y_{\mathrm{gx}}^{10)}$ & 0.46 & 0.47 & 0.59 & - & 0.67 \\
\hline \multirow{6}{*}{$\begin{array}{l}\text { 3-d enzyme } \\
\text { hydrolysis } \\
\text { at } 60 \mathrm{FPU} / \\
\text { g cellulose }\end{array}$} & Glucan (g) & 3.50 & 3.44 & 3.83 & - & 3.95 \\
\hline & Xylan (g) & 1.56 & 1.53 & 1.73 & - & 1.74 \\
\hline & $G / X$ ratio $\left.^{3}\right)$ & 2.25 & 2.25 & 2.21 & - & 2.27 \\
\hline & $Y_{\mathrm{g}}^{8)}$ & 0.61 & 0.60 & 0.68 & - & 0.69 \\
\hline & $Y_{\mathrm{x}}^{9)}$ & 0.60 & 0.60 & 0.74 & - & 0.87 \\
\hline & $Y_{\mathrm{gx}}{ }^{10)}$ & 0.60 & 0.60 & 0.60 & - & 0.73 \\
\hline
\end{tabular}

The first batch data of corn stover for Figures 18, 30, 41, 42, 43, and 46

1) -10): same as described in Table N-11 
Table N-14. Effect of lime pretreatment at $35^{\circ} \mathrm{C}$ with air on the pretreatment and hydrolysis yields of glucan and xylan.

\begin{tabular}{|c|c|c|c|c|c|c|}
\hline \multirow{2}{*}{ Process } & \multirow{2}{*}{ Component } & \multicolumn{5}{|c|}{ Pretreatment time (weeks) } \\
\hline & & 1 & 2 & 4 & 8 & 16 \\
\hline \multirow{4}{*}{ Raw } & iS $(g)^{1)}$ & 15.02 & 15.12 & 15.12 & 14.96 & 14.96 \\
\hline & Glucan $(\mathrm{g})$ & 5.63 & 5.67 & 5.67 & 5.61 & 5.61 \\
\hline & Xylan $(\mathrm{g})$ & 3.12 & 3.15 & 3.15 & 3.11 & 3.11 \\
\hline & $\begin{array}{l}\text { Holocellulose } \\
\text { (g) }\end{array}$ & 8.76 & 8.82 & 8.82 & 8.72 & 8.72 \\
\hline \multirow{4}{*}{ Pretreatment } & $\mathrm{fS}(\mathrm{g})^{2)}$ & 12.73 & 11.89 & 11.93 & 11.10 & 10.34 \\
\hline & Glucan $(\mathrm{g})$ & 5.79 & 5.51 & 5.75 & 5.47 & 5.28 \\
\hline & Xylan $(\mathrm{g})$ & 2.37 & 2.14 & 2.21 & 2.10 & 1.95 \\
\hline & $\begin{array}{l}\text { Holocellulose } \\
\text { (g) }\end{array}$ & 8.16 & 7.66 & 7.97 & 7.57 & 7.23 \\
\hline \multirow{5}{*}{ Parameters } & $G / X$ ratio $^{3)}$ & 2.44 & 2.57 & 2.60 & 2.60 & 2.71 \\
\hline & $Y_{\mathrm{T}}^{4)}$ & 0.85 & 0.79 & 0.79 & 0.74 & 0.69 \\
\hline & $Y_{\mathrm{G}}^{5)}$ & 1.03 & 0.97 & 1.01 & 0.98 & 0.94 \\
\hline & $Y_{X}^{6)}$ & 0.76 & 0.68 & 0.70 & 0.68 & 0.63 \\
\hline & $Y_{\mathrm{GX}}{ }^{7)}$ & 0.93 & 0.87 & 0.90 & 0.87 & 0.83 \\
\hline \multirow{6}{*}{$\begin{array}{l}\text { 3-d enzyme } \\
\text { hydrolysis } \\
\text { at } 15 \text { FPU/ } \\
\text { g cellulose }\end{array}$} & Glucan (g) & 3.04 & 3.14 & 3.45 & - & 3.91 \\
\hline & Xylan (g) & 1.26 & 1.30 & 1.34 & - & 1.29 \\
\hline & $G / X$ ratio $^{3)}$ & 2.42 & 2.41 & 2.58 & - & 3.04 \\
\hline & $Y_{\mathrm{g}}^{8)}$ & 0.53 & 0.57 & 0.60 & - & 0.74 \\
\hline & $Y_{\mathrm{x}}^{9)}$ & 0.53 & 0.61 & 0.61 & - & 0.66 \\
\hline & $Y_{\mathrm{gx}}^{10)}$ & 0.53 & 0.58 & 0.60 & - & 0.72 \\
\hline \multirow{6}{*}{$\begin{array}{l}\text { 3-d enzyme } \\
\text { hydrolysis } \\
\text { at } 60 \text { FPU/ } \\
\text { g cellulose }\end{array}$} & Glucan (g) & 3.39 & 3.27 & 4.13 & - & 4.17 \\
\hline & Xylan (g) & 1.37 & 1.33 & 1.72 & - & 1.32 \\
\hline & $G / X$ ratio $\left.^{3}\right)$ & 2.48 & 2.46 & 2.40 & - & 3.15 \\
\hline & $Y_{\mathrm{g}}^{8)}$ & 0.59 & 0.59 & 0.72 & - & 0.79 \\
\hline & $Y_{\mathrm{x}}^{5}$ & 0.58 & 0.62 & 0.78 & - & 0.68 \\
\hline & $Y_{\mathrm{gx}}{ }^{10)}$ & 0.58 & 0.60 & 0.74 & - & 0.76 \\
\hline
\end{tabular}

The first batch data of corn stover for Figures 18, 30, 41, 42, 43, and 46

1) -10): same as described in Table N-11 
Table N-15. Effect of lime pretreatment at $45^{\circ} \mathrm{C}$ without air on the pretreatment and hydrolysis yields of glucan and xylan.

\begin{tabular}{|c|c|c|c|c|c|}
\hline \multirow{2}{*}{ Process } & \multirow{2}{*}{ Component } & \multicolumn{4}{|c|}{ Pretreatment time (weeks) } \\
\hline & & 1 & 2 & 8 & 16 \\
\hline \multirow{4}{*}{ Raw } & iS $(g)^{1)}$ & 15.02 & 14.86 & 14.93 & 14.93 \\
\hline & Glucan $(\mathrm{g})$ & 5.63 & 5.57 & 5.60 & 5.60 \\
\hline & Xylan (g) & 3.12 & 3.09 & 3.11 & 3.11 \\
\hline & $\begin{array}{l}\text { Holocellulose } \\
\text { (g) }\end{array}$ & 8.76 & 8.66 & 8.71 & 8.71 \\
\hline \multirow{9}{*}{ Pretreatment } & $\mathrm{fS}(\mathrm{g})^{2)}$ & 13.41 & 12.63 & 11.53 & 12.06 \\
\hline & Glucan $(\mathrm{g})$ & 5.98 & 5.75 & 5.57 & 5.76 \\
\hline & Xylan $(\mathrm{g})$ & 2.57 & 2.40 & 2.06 & 2.50 \\
\hline & $\begin{array}{l}\text { Holocellulose } \\
\text { (g) }\end{array}$ & 8.55 & 8.16 & 7.62 & 8.26 \\
\hline & $G / X$ ratio $^{3)}$ & 2.32 & 2.39 & 2.71 & 2.30 \\
\hline & $Y_{\mathrm{T}}^{4)}$ & 0.89 & 0.85 & 0.77 & 0.81 \\
\hline & $Y_{\mathrm{G}}^{5)}$ & 1.06 & 1.03 & 0.99 & 1.03 \\
\hline & $Y_{\mathrm{X}}^{6)}$ & 0.82 & 0.77 & 0.66 & 0.81 \\
\hline & $Y_{\mathrm{GX}}{ }^{7)}$ & 0.98 & 0.94 & 0.88 & 0.95 \\
\hline \multirow{6}{*}{$\begin{array}{l}\text { 3-d enzyme } \\
\text { hydrolysis } \\
\text { at } 15 \mathrm{FPU} / \\
\text { g cellulose }\end{array}$} & Glucan $(\mathrm{g})$ & 3.00 & 2.99 & 3.62 & 4.07 \\
\hline & Xylan (g) & 1.41 & 1.31 & 1.62 & 1.73 \\
\hline & $G / X$ ratio $\left.^{3}\right)$ & 2.13 & 2.28 & 2.23 & 2.35 \\
\hline & $Y_{\mathrm{g}}^{8)}$ & 0.50 & 0.52 & 0.65 & 0.71 \\
\hline & $Y_{\mathrm{x}}^{59}$ & 0.55 & 0.55 & 0.79 & 0.69 \\
\hline & $Y_{\mathrm{gx}}^{10)}$ & 0.52 & 0.53 & 0.69 & 0.70 \\
\hline \multirow{6}{*}{$\begin{array}{l}\text { 3-d enzyme } \\
\text { hydrolysis } \\
\text { at } 60 \mathrm{FPU} / \\
\text { g cellulose }\end{array}$} & Glucan (g) & 3.58 & 3.59 & 3.95 & 4.23 \\
\hline & Xylan (g) & 1.60 & 1.68 & 1.78 & 1.93 \\
\hline & $G / X$ ratio $\left.^{3}\right)$ & 2.25 & 2.13 & 2.22 & 2.19 \\
\hline & $Y_{\mathrm{g}}^{8)}$ & 0.60 & 0.62 & 0.71 & 0.74 \\
\hline & $Y_{\mathrm{x}}^{9)}$ & 0.62 & 0.70 & 0.87 & 0.77 \\
\hline & $Y_{\mathrm{gx}}{ }^{10)}$ & 0.61 & 0.65 & 0.75 & 0.75 \\
\hline
\end{tabular}

The first batch data of corn stover for Figures 19, 30, 41, 42, 43, and 47

1) -10): same as described in Table N-11 
Table N-16. Effect of lime pretreatment at $45^{\circ} \mathrm{C}$ with air on the pretreatment and hydrolysis yields of glucan and xylan.

\begin{tabular}{|c|c|c|c|c|c|}
\hline \multirow{2}{*}{ Process } & \multirow{2}{*}{ Component } & \multicolumn{4}{|c|}{ Pretreatment time (weeks) } \\
\hline & & 1 & 2 & 8 & 16 \\
\hline \multirow{4}{*}{ Raw } & iS $(g)^{1)}$ & 15.02 & 14.86 & 14.93 & 14.93 \\
\hline & Glucan $(\mathrm{g})$ & 5.63 & 5.57 & 5.60 & 5.60 \\
\hline & Xylan $(\mathrm{g})$ & 3.12 & 3.09 & 3.11 & 3.11 \\
\hline & $\begin{array}{l}\text { Holocellulose } \\
\text { (g) }\end{array}$ & 8.76 & 8.66 & 8.71 & 8.71 \\
\hline \multirow{9}{*}{ Pretreatment } & $\mathrm{fS}(\mathrm{g})^{2)}$ & 12.09 & 11.82 & 9.66 & 9.40 \\
\hline & Glucan $(\mathrm{g})$ & 5.64 & 5.75 & 5.09 & 5.25 \\
\hline & Xylan (g) & 2.26 & 2.11 & 1.64 & 1.69 \\
\hline & $\begin{array}{l}\text { Holocellulose } \\
\text { (g) }\end{array}$ & 7.90 & 7.86 & 6.73 & 6.93 \\
\hline & $G / X$ ratio $^{3)}$ & 2.50 & 2.72 & 3.10 & 3.11 \\
\hline & $Y_{\mathrm{T}}^{4)}$ & 0.81 & 0.80 & 0.65 & 0.63 \\
\hline & $Y_{\mathrm{G}}^{5)}$ & 1.00 & 1.03 & 0.91 & 0.94 \\
\hline & $Y_{X}^{6)}$ & 0.72 & 0.68 & 0.53 & 0.54 \\
\hline & $Y_{\mathrm{GX}}{ }^{7)}$ & 0.90 & 0.91 & 0.77 & 0.80 \\
\hline \multirow{6}{*}{$\begin{array}{l}\text { 3-d enzyme } \\
\text { hydrolysis } \\
\text { at } 15 \text { FPU/ } \\
\text { g cellulose }\end{array}$} & Glucan (g) & 2.90 & 2.96 & 3.57 & 4.31 \\
\hline & Xylan (g) & 1.15 & 1.18 & 1.17 & 1.22 \\
\hline & $G / X$ ratio $^{3)}$ & 2.52 & 2.51 & 3.06 & 3.54 \\
\hline & $Y_{\mathrm{g}}^{8)}$ & 0.51 & 0.52 & 0.70 & 0.82 \\
\hline & $Y_{\mathrm{x}}^{9)}$ & 0.51 & 0.56 & 0.71 & 0.72 \\
\hline & $Y_{\mathrm{gx}}{ }^{10)}$ & 0.51 & 0.53 & 0.70 & 0.80 \\
\hline \multirow{6}{*}{$\begin{array}{l}\text { 3-d enzyme } \\
\text { hydrolysis } \\
\text { at } 60 \text { FPU/ } \\
\text { g cellulose }\end{array}$} & Glucan (g) & 3.48 & 3.68 & 3.70 & 3.81 \\
\hline & Xylan (g) & 1.36 & 1.49 & 1.23 & 1.68 \\
\hline & $G / X$ ratio $\left.^{3}\right)$ & 2.56 & 2.47 & 3.01 & 2.27 \\
\hline & $Y_{\mathrm{g}}^{8)}$ & 0.62 & 0.64 & 0.73 & 0.73 \\
\hline & $Y_{\mathrm{x}}^{5}$ & 0.60 & 0.71 & 0.75 & 0.99 \\
\hline & $Y_{\mathrm{gx}}{ }^{10)}$ & 0.61 & 0.66 & 0.73 & 0.79 \\
\hline
\end{tabular}

The first batch data of corn stover for Figures 19, 30, 41, 42, 43, and 47

1) -10): same as described in Table N-11 
Table N-17. Effect of lime pretreatment at $55^{\circ} \mathrm{C}$ without air on the pretreatment and hydrolysis yields of glucan and xylan.

\begin{tabular}{|c|c|c|c|c|c|c|}
\hline \multirow{2}{*}{ Process } & \multirow{2}{*}{ Component } & \multicolumn{5}{|c|}{ Pretreatment time (weeks) } \\
\hline & & 1 & 2 & 4 & 8 & 16 \\
\hline \multirow{4}{*}{ Raw } & iS $(g)^{1)}$ & 15.09 & 15.05 & 15.09 & 15.05 & 14.97 \\
\hline & Glucan $(\mathrm{g})$ & 5.66 & 5.64 & 5.66 & 5.64 & 5.61 \\
\hline & Xylan (g) & 3.14 & 3.13 & 3.14 & 3.13 & 3.11 \\
\hline & $\begin{array}{l}\text { Holocellulose } \\
\text { (g) }\end{array}$ & 8.80 & 8.78 & 8.80 & 8.78 & 8.73 \\
\hline \multirow{9}{*}{ Pretreatment } & $\mathrm{fS}(\mathrm{g})^{2)}$ & 12.65 & 12.24 & 12.41 & 11.35 & 12.09 \\
\hline & Glucan $(\mathrm{g})$ & 5.67 & 5.26 & 5.99 & 5.29 & 6.31 \\
\hline & Xylan $(\mathrm{g})$ & 2.56 & 2.28 & 2.38 & 2.34 & 2.47 \\
\hline & $\begin{array}{l}\text { Holocellulose } \\
\text { (g) }\end{array}$ & 8.23 & 7.54 & 8.56 & 7.63 & 8.78 \\
\hline & $G / X$ ratio $^{3)}$ & 2.22 & 2.30 & 2.52 & 2.27 & 2.56 \\
\hline & $Y_{\mathrm{T}}^{4)}$ & 0.84 & 0.81 & 0.82 & 0.75 & 0.81 \\
\hline & $Y_{\mathrm{G}}^{5)}$ & 1.00 & 0.93 & 1.05 & 0.94 & 1.06 \\
\hline & $Y_{X}^{6)}$ & 0.82 & 0.73 & 0.76 & 0.75 & 0.79 \\
\hline & $Y_{\mathrm{GX}}{ }^{7)}$ & 0.94 & 0.86 & 0.97 & 0.87 & 1.00 \\
\hline \multirow{6}{*}{$\begin{array}{l}\text { 3-d enzyme } \\
\text { hydrolysis } \\
\text { at } 15 \mathrm{FPU} / \\
\text { g cellulose }\end{array}$} & Glucan $(\mathrm{g})$ & - & 2.73 & 4.24 & 4.08 & 3.95 \\
\hline & Xylan (g) & - & 1.27 & 1.71 & 1.68 & 1.57 \\
\hline & $G / X$ ratio $\left.^{3}\right)$ & - & 2.14 & 2.49 & 2.43 & 2.52 \\
\hline & $Y_{\mathrm{g}}^{8)}$ & - & 0.52 & 0.71 & 0.77 & 0.63 \\
\hline & $Y_{\mathrm{x}}^{9)}$ & - & 0.56 & 0.72 & 0.72 & 0.64 \\
\hline & $Y_{\mathrm{gx}}^{10)}$ & - & 0.53 & 0.69 & 0.75 & 0.63 \\
\hline \multirow{6}{*}{$\begin{array}{l}\text { 3-d enzyme } \\
\text { hydrolysis } \\
\text { at } 60 \mathrm{FPU} / \\
\text { g cellulose }\end{array}$} & Glucan (g) & - & 3.53 & 4.22 & 4.09 & 4.32 \\
\hline & Xylan (g) & - & 1.66 & 1.63 & 1.67 & 1.78 \\
\hline & $G / X$ ratio $^{3}$ & - & 2.13 & 2.59 & 2.45 & 2.43 \\
\hline & $Y_{\mathrm{g}}^{8)}$ & - & 0.67 & 0.68 & 0.77 & 0.69 \\
\hline & $Y_{\mathrm{x}}^{9)}$ & - & 0.73 & 0.69 & 0.71 & 0.72 \\
\hline & $Y_{\mathrm{gx}}{ }^{10)}$ & - & 0.69 & 0.68 & 0.75 & 0.70 \\
\hline
\end{tabular}

The first batch data of corn stover for Figures 20, 30, 41, 42, 43, 44, and 48

1) -7): same as described in Table N-11 
Table N-18. Effect of lime pretreatment at $55^{\circ} \mathrm{C}$ with air on the pretreatment and hydrolysis yields of glucan and xylan.

\begin{tabular}{|c|c|c|c|c|c|c|}
\hline \multirow{2}{*}{ Process } & \multirow{2}{*}{ Component } & \multicolumn{5}{|c|}{ Pretreatment time (weeks) } \\
\hline & & 1 & 2 & 4 & 8 & 16 \\
\hline \multirow{4}{*}{ Raw } & iS $(g)^{1)}$ & 15.09 & 15.05 & 15.09 & 15.05 & 14.97 \\
\hline & Glucan $(\mathrm{g})$ & 5.66 & 5.64 & 5.66 & 5.64 & 5.61 \\
\hline & Xylan (g) & 3.14 & 3.13 & 3.14 & 3.13 & 3.11 \\
\hline & $\begin{array}{l}\text { Holocellulose } \\
(\mathrm{g})\end{array}$ & 8.80 & 8.78 & 8.80 & 8.78 & 8.73 \\
\hline \multirow{9}{*}{ Pretreatment } & $\mathrm{fS}(\mathrm{g})^{2)}$ & 11.83 & 11.20 & 11.55 & 10.80 & 8.55 \\
\hline & Glucan $(\mathrm{g})$ & 5.60 & 5.24 & 5.49 & 4.83 & 3.99 \\
\hline & Xylan $(g)$ & 2.38 & 2.05 & 2.11 & 2.06 & 1.57 \\
\hline & $\begin{array}{c}\text { Holocellulose } \\
(\mathrm{g})\end{array}$ & 7.98 & 7.29 & 7.60 & 6.89 & 5.55 \\
\hline & $G / X$ ratio $^{3)}$ & 2.36 & 2.56 & 2.60 & 2.34 & 2.55 \\
\hline & $Y_{\mathrm{T}}^{4)}$ & 0.78 & 0.74 & 0.77 & 0.72 & 0.57 \\
\hline & $Y_{\mathrm{G}}^{5)}$ & 0.99 & 0.93 & 0.97 & 0.86 & 0.71 \\
\hline & $Y_{X}^{6)}$ & 0.76 & 0.65 & 0.67 & 0.66 & 0.50 \\
\hline & $Y_{\mathrm{GX}}{ }^{7)}$ & 0.91 & 0.83 & 0.86 & 0.79 & 0.64 \\
\hline \multirow{6}{*}{$\begin{array}{l}\text { 3-d enzyme } \\
\text { hydrolysis } \\
\text { at } 2.1 \mathrm{FPU} / \\
\text { g cellulose }\end{array}$} & Glucan (g) & 2.52 & 2.63 & 3.90 & 3.76 & 3.41 \\
\hline & Xylan (g) & 1.07 & 1.04 & 1.22 & 1.18 & 0.83 \\
\hline & $G / X$ ratio $\left.^{3}\right)$ & 2.35 & 2.51 & 3.22 & 3.19 & 4.09 \\
\hline & $Y_{\mathrm{g}}^{(8)}$ & 0.45 & 0.50 & 0.71 & 0.78 & 0.86 \\
\hline & $\left.Y_{\mathrm{x}}^{9}\right)$ & 0.45 & 0.51 & 0.58 & 0.57 & 0.53 \\
\hline & $Y_{\mathrm{gx}}{ }^{10)}$ & 0.45 & 0.50 & 0.67 & 0.72 & 0.77 \\
\hline \multirow{6}{*}{$\begin{array}{l}\text { 3-d enzyme } \\
\text { hydrolysis } \\
\text { at } 15 \text { FPU/ } \\
\text { g cellulose }\end{array}$} & Glucan (g) & 3.35 & 3.76 & 5.13 & 4.66 & 3.94 \\
\hline & Xylan (g) & 1.42 & 1.49 & 1.60 & 1.46 & 1.03 \\
\hline & $G / X$ ratio $\left.^{3}\right)$ & 2.35 & 2.52 & 3.21 & 3.19 & 3.82 \\
\hline & $Y_{\mathrm{g}}^{8)}$ & 0.60 & 0.72 & 0.93 & 0.96 & 0.99 \\
\hline & $Y_{\mathrm{x}}^{9)}$ & 0.60 & 0.73 & 0.76 & 0.71 & 0.66 \\
\hline & $Y_{\mathrm{gx}}{ }^{10)}$ & 0.60 & 0.72 & 0.89 & 0.89 & 0.90 \\
\hline \multirow{6}{*}{$\begin{array}{l}\text { 3-d enzyme } \\
\text { hydrolysis } \\
\text { at } 60 \text { FPU/ } \\
\text { g cellulose }\end{array}$} & Glucan (g) & 3.99 & 4.04 & 6.00 & 5.30 & 4.37 \\
\hline & Xylan (g) & 1.79 & 1.79 & 1.91 & 1.59 & 1.18 \\
\hline & $G / X$ ratio $\left.^{3}\right)$ & 2.28 & 2.30 & 3.21 & 3.41 & 3.79 \\
\hline & $Y_{\mathrm{g}}^{8)}$ & 0.64 & 0.69 & 0.98 & 0.99 & 0.99 \\
\hline & $Y_{\mathrm{x}}^{9)}$ & 0.66 & 0.77 & 0.80 & 0.68 & 0.66 \\
\hline & $Y_{\mathrm{gx}}^{10)}$ & 0.65 & 0.72 & 0.93 & 0.90 & 0.90 \\
\hline
\end{tabular}

The first batch data of corn stover for Figures 20, 30, 41, 42, 43, 44, 48, and 49

1) -10): same as described in Table N-11 
Table N-19. Overall yields for glucose $\left(Y_{\mathrm{g}}^{\mathrm{T}}\right)$ and xylose $\left(Y_{\mathrm{x}}^{\mathrm{T}}\right)$ of corn stover pretreated at the recommended condition $\left(55^{\circ} \mathrm{C}, 4\right.$ week, and aeration) and hydrolyzed enzymatically at different enzyme loadings.

\begin{tabular}{|c|c|c|}
\hline $\begin{array}{c}\text { Enzyme loading } \\
\text { (FPU/g cellulose) }\end{array}$ & $\begin{array}{c}\text { Overall yield for glucose, } \\
Y_{\mathrm{g}}^{\mathrm{T}} \text { 1) }\end{array}$ & $\begin{array}{c}\text { Overall yield for xylose, } \\
Y_{\mathrm{x}}^{\mathrm{T}} \text { 2) }\end{array}$ \\
\hline 2.1 & 0.69 & 0.39 \\
\hline 3.0 & 0.74 & 0.41 \\
\hline 7.0 & 0.81 & 0.45 \\
\hline 15.0 & 0.91 & 0.51 \\
\hline 60.0 & 0.96 & 0.54 \\
\hline
\end{tabular}

The first batch data of corn stover for Figure 50

1) g glucan hydrolyzed/g glucan in raw biomass

2) g xylan hydrolyzed/g xylan in raw biomass

Table N-20. Hydrolysis efficiency of Spezyme CP (cellulase: Lot No. 301-00348-257) on $\alpha$-cellulose (Sigma C-8002) and pure xylan (Sigma X-4252) at 5 FPU/g cellulose and $5 \mathrm{FPU} / \mathrm{g}$ xylan of enzyme loadings, respectively.

\begin{tabular}{|c|c|c|}
\hline $\begin{array}{c}\text { Time of enzyme hydrolysis } \\
\text { (hours) }\end{array}$ & $\begin{array}{c}\alpha \text {-Cellulose digested } \\
\text { (g cellulose digested/g } \\
\text { initial cellulose) }\end{array}$ & $\begin{array}{c}\text { Xylan digested } \\
\text { (g xylan digested/g initial } \\
\text { xylan) }\end{array}$ \\
\hline 0 & 0.000 & 0.000 \\
\hline 6 & 0.280 & 0.323 \\
\hline 12 & 0.440 & 0.401 \\
\hline 24 & 0.578 & 0.461 \\
\hline 48 & 0.714 & 0.549 \\
\hline 72 & 0.771 & 0.580 \\
\hline 96 & 0.813 & 0.590 \\
\hline
\end{tabular}

Data for Figure 51 
Table N-21. Effect of lime pretreatment at $25^{\circ} \mathrm{C}$ without air on delignification.

\begin{tabular}{|c|c|c|c|c|c|}
\hline $\begin{array}{c}\text { Batch No. } \\
\text { of Corn } \\
\text { stover }\end{array}$ & $\begin{array}{c}\text { Pretreatment } \\
\text { time } \\
(\text { weeks })\end{array}$ & $\begin{array}{c}\text { Klason } \\
\text { lignin } \\
\text { content (\%) }\end{array}$ & $\begin{array}{c}\text { Acid- } \\
\text { soluble } \\
\text { lignin (\%) }\end{array}$ & $\begin{array}{c}Y_{\mathrm{T}}{ }^{1)} \\
(\mathrm{g} / \mathrm{g})\end{array}$ & $\begin{array}{c}W_{\mathrm{L}}^{2)} \\
(\mathrm{g} / \mathrm{g})\end{array}$ \\
\hline \multirow{5}{*}{1} & $0^{3)}$ & 19.62 & 1.80 & 1.00 & 1.00 \\
\cline { 2 - 6 } & $1 / 7$ & 17.33 & 1.48 & 0.99 & 0.88 \\
\cline { 2 - 6 } & $3 / 7$ & 16.84 & 1.42 & 0.97 & 0.83 \\
\cline { 2 - 6 } & 1 & 16.88 & 1.56 & 0.96 & 0.82 \\
\cline { 2 - 6 } & 2 & 15.76 & 1.35 & 0.87 & 0.70 \\
\cline { 2 - 6 } & 4 & 14.94 & 1.29 & 0.85 & 0.65 \\
\hline \multirow{5}{*}{2} & 15 & 15.12 & 1.22 & 0.85 & 0.65 \\
\cline { 2 - 6 } & 0 & 13.62 & 1.25 & 0.81 & 0.56 \\
\cline { 2 - 6 } & 1 & 14.20 & 3.60 & 1.00 & 1.00 \\
\cline { 2 - 6 } & 2 & 13.47 & 1.25 & 0.99 & 0.81 \\
\cline { 2 - 6 } & 4 & 13.19 & 1.45 & 0.92 & 0.72 \\
\cline { 2 - 6 } & 16 & 12.49 & 1.38 & 0.83 & 0.66 \\
\hline
\end{tabular}

Data for Figures 17, 23, 24, 25, 30, 31, and 36

1) $Y_{\mathrm{T}}=$ recovery yield of total solid $=\mathrm{g}$ solid recovered/g raw biomass

2) $W_{\mathrm{L}}=$ the fraction of the insoluble lignin: defined as Equation 5

3) Data for the untreated corn stover

Table N-22. Effect of lime pretreatment at $35^{\circ} \mathrm{C}$ without air on delignification.

\begin{tabular}{|c|c|c|c|c|c|}
\hline $\begin{array}{c}\text { Batch No. } \\
\text { of Corn } \\
\text { stover }\end{array}$ & $\begin{array}{c}\text { Pretreatment } \\
\text { time } \\
(\text { weeks })\end{array}$ & $\begin{array}{c}\text { Klason } \\
\text { lignin } \\
\text { content }(\%)\end{array}$ & $\begin{array}{c}\text { Acid- } \\
\text { soluble } \\
\text { lignin }(\%)\end{array}$ & $\begin{array}{c}Y_{\mathrm{T}}^{1)} \\
(\mathrm{g} / \mathrm{g})\end{array}$ & $\begin{array}{l}W_{\mathrm{L}}{ }^{2)} \\
(\mathrm{g} / \mathrm{g})\end{array}$ \\
\hline \multirow[t]{9}{*}{ Dever } & $0^{3)}$ & 19.62 & 1.80 & 1.00 & 1.00 \\
\hline & $1 / 7$ & 16.96 & 1.26 & 0.91 & 0.79 \\
\hline & $3 / 7$ & 16.46 & 1.33 & 0.89 & 0.75 \\
\hline & 1 & 15.00 & 1.28 & 0.89 & 0.68 \\
\hline & 2 & 14.39 & 1.17 & 0.85 & 0.63 \\
\hline & 4 & 14.68 & 1.41 & 0.83 & 0.62 \\
\hline & 8 & 14.00 & 1.28 & 0.83 & 0.59 \\
\hline & 12 & 13.80 & 1.06 & 0.82 & 0.57 \\
\hline & 16 & 13.21 & 1.17 & 0.78 & 0.52 \\
\hline \multirow{5}{*}{2} & $0^{3)}$ & 17.20 & 3.60 & 1.00 & 1.00 \\
\hline & 2 & 13.31 & 1.39 & 0.81 & 0.62 \\
\hline & 4 & 13.12 & 1.35 & 0.78 & 0.60 \\
\hline & 8 & 12.72 & 1.37 & 0.78 & 0.58 \\
\hline & 16 & 12.68 & 1.33 & 0.75 & 0.55 \\
\hline
\end{tabular}

Data for Figure 18, 23, 24, 25, 30, 31, and 36

1) - 3) same as described in Table N-21 
Table N-23. Effect of lime pretreatment at $45^{\circ} \mathrm{C}$ without air on delignification.

\begin{tabular}{|c|c|c|c|c|c|}
\hline $\begin{array}{c}\text { Batch No. } \\
\text { of Corn } \\
\text { stover }\end{array}$ & $\begin{array}{c}\text { Pretreatment } \\
\text { time } \\
\text { (weeks) }\end{array}$ & $\begin{array}{c}\text { Klason } \\
\text { lignin } \\
\text { content }(\%)\end{array}$ & $\begin{array}{c}\text { Acid- } \\
\text { soluble } \\
\text { lignin }(\%)\end{array}$ & $\begin{array}{c}Y_{\mathrm{T}}^{1}{ }^{1} \\
(\mathrm{~g} / \mathrm{g})\end{array}$ & $\begin{array}{l}W_{\mathrm{L}}{ }^{2)} \\
(\mathrm{g} / \mathrm{g})\end{array}$ \\
\hline \multirow{9}{*}{ 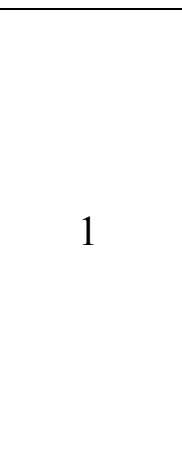 } & $0^{3)}$ & 19.62 & 1.80 & 1.00 & 1.00 \\
\hline & $1 / 7$ & 16.88 & 1.24 & 0.89 & 0.76 \\
\hline & $3 / 7$ & 16.30 & 1.39 & 0.89 & 0.73 \\
\hline & 1 & 15.14 & 1.23 & 0.89 & 0.69 \\
\hline & 2 & 14.78 & 1.27 & 0.85 & 0.64 \\
\hline & 4 & 14.01 & 1.23 & 0.84 & 0.60 \\
\hline & 8 & 13.79 & 1.22 & 0.77 & 0.54 \\
\hline & 12 & 12.30 & 1.16 & 0.84 & 0.53 \\
\hline & 16 & 12.80 & 1.37 & 0.81 & 0.53 \\
\hline \multirow{6}{*}{2} & $0^{3)}$ & 17.20 & 3.60 & 1.00 & 1.00 \\
\hline & 1 & 13.70 & 1.41 & 0.84 & 0.67 \\
\hline & 2 & 14.04 & 1.40 & 0.75 & 0.61 \\
\hline & 4 & 12.59 & 1.37 & 0.80 & 0.59 \\
\hline & 8 & 12.06 & 1.37 & 0.79 & 0.55 \\
\hline & 16 & 11.13 & 1.37 & 0.78 & 0.51 \\
\hline
\end{tabular}

Data for Figures 19, 23, 24, 25, 30, 31, and 36

1) - 3) same as described in Table N-21

Table N-24. Effect of lime pretreatment at $55^{\circ} \mathrm{C}$ without air on delignification

\begin{tabular}{|c|c|c|c|c|c|}
\hline $\begin{array}{c}\text { Batch No. } \\
\text { of Corn } \\
\text { stover }\end{array}$ & $\begin{array}{c}\text { Pretreatment } \\
\text { time } \\
\text { (weeks) }\end{array}$ & $\begin{array}{c}\text { Klason } \\
\text { lignin } \\
\text { content }(\%)\end{array}$ & $\begin{array}{c}\text { Acid- } \\
\text { soluble } \\
\text { lignin }(\%)\end{array}$ & $\begin{array}{c}Y_{\mathrm{T}}^{1)} \\
(\mathrm{g} / \mathrm{g})\end{array}$ & $\begin{array}{l}\left.W_{\mathrm{L}}{ }^{2}\right) \\
(\mathrm{g} / \mathrm{g})\end{array}$ \\
\hline \multirow{8}{*}{1} & $0^{3)}$ & 19.62 & 1.80 & 1.00 & 1.00 \\
\hline & $1 / 7$ & 16.34 & 1.30 & 0.87 & 0.72 \\
\hline & $3 / 7$ & 15.34 & 1.29 & 0.85 & 0.66 \\
\hline & 1 & 14.57 & 1.19 & 0.84 & 0.62 \\
\hline & 2 & 14.20 & 1.15 & 0.81 & 0.59 \\
\hline & 4 & 13.89 & 1.21 & 0.82 & 0.58 \\
\hline & 8 & 13.70 & 1.34 & 0.75 & 0.53 \\
\hline & 16 & 13.30 & 1.33 & 0.81 & 0.55 \\
\hline \multirow{5}{*}{2} & $0^{3)}$ & 17.20 & 3.60 & 1.00 & 1.00 \\
\hline & 2 & 13.23 & 1.48 & 0.80 & 0.61 \\
\hline & 4 & 12.48 & 1.48 & 0.80 & 0.58 \\
\hline & 8 & 12.10 & 1.43 & 0.79 & 0.56 \\
\hline & 16 & 11.03 & 1.70 & 0.78 & 0.50 \\
\hline
\end{tabular}

Data for Figures 20, 23, 24, 25, 30, 31, and 36

1) - 3) same as described in Table N-21 
Table N-25. Effect of lime pretreatment at $25^{\circ} \mathrm{C}$ with air on delignification.

\begin{tabular}{|c|c|c|c|c|c|}
\hline $\begin{array}{c}\text { Batch No. } \\
\text { of Corn } \\
\text { stover }\end{array}$ & $\begin{array}{c}\text { Pretreatment } \\
\text { time } \\
(\text { weeks) }\end{array}$ & $\begin{array}{c}\text { Klason } \\
\text { lignin } \\
\text { content (\%) }\end{array}$ & $\begin{array}{c}\text { Acid- } \\
\text { soluble } \\
\text { lignin (\%) }\end{array}$ & $\begin{array}{c}Y_{\mathrm{T}}{ }^{1)} \\
(\mathrm{g} / \mathrm{g})\end{array}$ & $\begin{array}{c}W_{\mathrm{L}}^{2)} \\
(\mathrm{g} / \mathrm{g})\end{array}$ \\
\hline \multirow{4}{*}{1} & $0^{3)}$ & 19.62 & 1.80 & 1.00 & 1.00 \\
\cline { 2 - 6 } & $1 / 7$ & 17.21 & 1.56 & 0.95 & 0.86 \\
\cline { 2 - 6 } & $3 / 7$ & 16.59 & 1.48 & 0.92 & 0.80 \\
\cline { 2 - 6 } & 1 & 16.17 & 1.61 & 0.87 & 0.74 \\
\cline { 2 - 6 } & 2 & 14.93 & 1.43 & 0.85 & 0.66 \\
\cline { 2 - 6 } & 4 & 14.22 & 1.49 & 0.83 & 0.62 \\
\cline { 2 - 6 } & 8 & 13.55 & 1.54 & 0.81 & 0.58 \\
\hline \multirow{4}{*}{2} & 15 & 10.54 & 1.62 & 0.76 & 0.42 \\
\cline { 2 - 6 } & $0^{3)}$ & 17.20 & 3.60 & 1.00 & 1.00 \\
\cline { 2 - 6 } & 1 & 14.13 & 1.61 & 0.90 & 0.74 \\
\cline { 2 - 6 } & 2 & 13.37 & 1.57 & 0.86 & 0.67 \\
\cline { 2 - 6 } & 4 & 12.68 & 1.65 & 0.81 & 0.60 \\
\cline { 2 - 6 } & 16 & 11.96 & 1.67 & 0.74 & 0.51 \\
\hline
\end{tabular}

Data for Figures 17, 23, 24, 26, 30, 32, and 36

1) - 3) same as described in Table N-21

Table N-26. Effect of lime pretreatment at $35^{\circ} \mathrm{C}$ with air on delignification.

\begin{tabular}{|c|c|c|c|c|c|}
\hline $\begin{array}{l}\text { Batch No. } \\
\text { of Corn } \\
\text { stover }\end{array}$ & $\begin{array}{l}\text { Pretreatment } \\
\text { time } \\
\text { (weeks) }\end{array}$ & $\begin{array}{c}\text { Klason } \\
\text { lignin } \\
\text { content }(\%)\end{array}$ & $\begin{array}{c}\text { Acid- } \\
\text { soluble } \\
\text { lignin }(\%)\end{array}$ & $\begin{array}{c}Y_{\mathrm{T}}{ }^{1)} \\
(\mathrm{g} / \mathrm{g})\end{array}$ & $\begin{array}{l}W_{\mathrm{L}}^{2)} \\
(\mathrm{g} / \mathrm{g})\end{array}$ \\
\hline \multirow[t]{9}{*}{ Devrer } & $0^{3)}$ & 19.62 & 1.80 & 1.00 & 1.00 \\
\hline & $1 / 7$ & 16.68 & 1.30 & 0.91 & 0.80 \\
\hline & $3 / 7$ & 15.86 & 1.41 & 0.87 & 0.73 \\
\hline & 1 & 14.36 & 1.44 & 0.85 & 0.64 \\
\hline & 2 & 13.17 & 1.43 & 0.79 & 0.55 \\
\hline & 4 & 12.98 & 1.66 & 0.79 & 0.54 \\
\hline & 8 & 11.36 & 1.74 & 0.74 & 0.44 \\
\hline & 12 & 9.50 & 1.65 & 0.79 & 0.40 \\
\hline & 16 & 8.99 & 1.82 & 0.69 & 0.33 \\
\hline \multirow{5}{*}{2} & $0^{3)}$ & 17.20 & 3.60 & 1.00 & 1.00 \\
\hline & 2 & 12.66 & 1.65 & 0.84 & 0.62 \\
\hline & 4 & 11.54 & 1.83 & 0.74 & 0.50 \\
\hline & 8 & 10.04 & 1.87 & 0.73 & 0.43 \\
\hline & 16 & 8.08 & 2.00 & 0.74 & 0.35 \\
\hline
\end{tabular}

Data for Figures 18, 23, 24, 26, 30, 32, and 36

1) - 3) same as described in Table N-21 
Table N-27. Effect of lime pretreatment at $45^{\circ} \mathrm{C}$ with air on delignification.

\begin{tabular}{|c|c|c|c|c|c|}
\hline $\begin{array}{l}\text { Batch No. } \\
\text { of Corn } \\
\text { stover }\end{array}$ & $\begin{array}{c}\text { Pretreatment } \\
\text { time } \\
(\text { weeks })\end{array}$ & $\begin{array}{c}\text { Klason } \\
\text { lignin } \\
\text { content }(\%)\end{array}$ & $\begin{array}{c}\text { Acid- } \\
\text { soluble } \\
\text { lignin }(\%)\end{array}$ & $\begin{array}{c}Y_{\mathrm{T}}^{1)} \\
(\mathrm{g} / \mathrm{g})\end{array}$ & $\begin{array}{l}W_{\mathrm{L}}{ }^{2)} \\
(\mathrm{g} / \mathrm{g})\end{array}$ \\
\hline \multirow{9}{*}{ 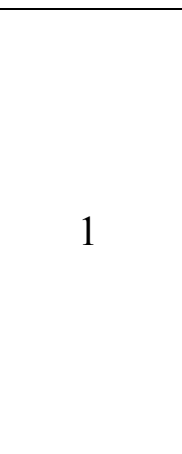 } & $0^{3)}$ & 19.62 & 1.80 & 1.00 & 1.00 \\
\hline & $1 / 7$ & 16.92 & 1.36 & 0.89 & 0.80 \\
\hline & $3 / 7$ & 15.52 & 1.51 & 0.86 & 0.70 \\
\hline & 1 & 13.60 & 1.53 & 0.81 & 0.58 \\
\hline & 2 & 12.45 & 1.61 & 0.80 & 0.52 \\
\hline & 4 & 11.35 & 1.72 & 0.75 & 0.45 \\
\hline & 8 & 8.58 & 1.90 & 0.65 & 0.29 \\
\hline & 12 & 6.40 & 1.79 & 0.64 & 0.22 \\
\hline & 16 & 6.00 & 1.94 & 0.63 & 0.20 \\
\hline \multirow{6}{*}{2} & $0^{3)}$ & 17.20 & 3.60 & 1.00 & 1.00 \\
\hline & 1 & 12.86 & 1.76 & 0.78 & 0.58 \\
\hline & 2 & 12.47 & 1.46 & 0.68 & 0.49 \\
\hline & 4 & 9.91 & 1.85 & 0.72 & 0.42 \\
\hline & 8 & 7.74 & 2.13 & 0.68 & 0.31 \\
\hline & 16 & 5.83 & 2.06 & 0.54 & 0.18 \\
\hline
\end{tabular}

Data for Figures 19, 23, 24, 26, 30, 32, and 36

1) - 3) same as described in Table N-21

Table N-28. Effect of lime pretreatment at $55^{\circ} \mathrm{C}$ with air on delignification.

\begin{tabular}{|c|c|c|c|c|c|}
\hline $\begin{array}{c}\text { Batch No. } \\
\text { of Corn } \\
\text { stover }\end{array}$ & $\begin{array}{c}\text { Pretreatment } \\
\text { time } \\
\text { (weeks) }\end{array}$ & $\begin{array}{c}\text { Klason } \\
\text { lignin } \\
\text { content }(\%)\end{array}$ & $\begin{array}{c}\text { Acid- } \\
\text { soluble } \\
\text { lignin }(\%)\end{array}$ & $\begin{array}{c}Y_{\mathrm{T}}^{1)} \\
(\mathrm{g} / \mathrm{g})\end{array}$ & $\begin{array}{l}W_{\mathrm{L}}{ }^{2)} \\
(\mathrm{g} / \mathrm{g})\end{array}$ \\
\hline \multirow{8}{*}{1} & $0^{3)}$ & 19.62 & 1.80 & 1.00 & 1.00 \\
\hline & $1 / 7$ & 16.22 & 1.43 & 0.85 & 0.73 \\
\hline & $3 / 7$ & 14.82 & 1.50 & 0.84 & 0.66 \\
\hline & 1 & 13.27 & 1.44 & 0.78 & 0.55 \\
\hline & 2 & 11.18 & 1.64 & 0.74 & 0.44 \\
\hline & 4 & 8.11 & 1.90 & 0.77 & 0.33 \\
\hline & 8 & 6.56 & 1.89 & 0.72 & 0.25 \\
\hline & 16 & 4.52 & 2.20 & 0.57 & 0.14 \\
\hline \multirow{5}{*}{2} & $0^{3)}$ & 17.20 & 3.60 & 1.00 & 1.00 \\
\hline & 2 & 10.44 & 2.02 & 0.72 & 0.44 \\
\hline & 4 & 8.55 & 2.01 & 0.65 & 0.33 \\
\hline & 8 & 5.56 & 2.05 & 0.62 & 0.20 \\
\hline & 16 & 4.42 & 2.35 & 0.51 & 0.13 \\
\hline
\end{tabular}

Data for Figures 20, 23, 24, 26, 30, 32, and 36

1) - 3) same as described in Table N-21 
Table N-29. Correlation of the residual lignin $\left(W_{\mathrm{L}}\right)$ with the pretreatment yields of holocellulose $\left(Y_{\mathrm{GX}}\right)$, glucan $\left(Y_{\mathrm{G}}\right)$, and xylan $\left(Y_{\mathrm{X}}\right)$ in lime pretreatment.

\begin{tabular}{|c|c|c|c|c|c|c|c|c|c|}
\hline \multirow{2}{*}{$\begin{array}{l}\text { Temp. } \\
\left({ }^{\circ} \mathrm{C}\right)\end{array}$} & \multirow{2}{*}{$\begin{array}{c}\text { Time } \\
\text { (weeks) }\end{array}$} & \multicolumn{4}{|c|}{ Without air } & \multicolumn{4}{|c|}{ With air } \\
\hline & & $W_{\mathrm{L}}$ & $Y_{\mathrm{GX}}$ & $Y_{\mathrm{G}}$ & $Y_{\mathrm{X}}$ & $W_{\mathrm{L}}$ & $Y_{\mathrm{GX}}$ & $Y_{\mathrm{G}}$ & $Y_{\mathrm{X}}$ \\
\hline \multirow{5}{*}{25} & $0^{1)}$ & 1.00 & 1.00 & 1.00 & 1.00 & 1.00 & 1.00 & 1.00 & 1.00 \\
\hline & 1 & 0.82 & 1.03 & 1.05 & 0.88 & 0.74 & 0.93 & 1.01 & 0.80 \\
\hline & 2 & 0.70 & 0.97 & 1.04 & 0.85 & 0.66 & 0.94 & 1.02 & 0.79 \\
\hline & 8 & 0.65 & 0.97 & 1.06 & 0.81 & 0.58 & 0.91 & 1.00 & 0.74 \\
\hline & 15 & 0.56 & 0.95 & 1.03 & 0.81 & 0.42 & 0.92 & 1.06 & 0.66 \\
\hline \multirow{5}{*}{35} & 1 & 0.68 & 0.96 & 1.03 & 0.83 & 0.64 & 0.93 & 1.03 & 0.76 \\
\hline & 2 & 0.63 & 0.94 & 1.02 & 0.81 & 0.55 & 0.87 & 0.97 & 0.68 \\
\hline & 4 & 0.62 & 0.91 & 1.00 & 0.75 & 0.54 & 0.90 & 1.01 & 0.70 \\
\hline & 8 & 0.59 & 0.94 & 1.01 & 0.79 & 0.44 & 0.87 & 0.98 & 0.68 \\
\hline & 16 & 0.52 & 0.89 & 1.03 & 0.64 & 0.33 & 0.83 & 0.94 & 0.63 \\
\hline \multirow{5}{*}{45} & 1 & 0.69 & 0.98 & 1.06 & 0.82 & 0.58 & 0.90 & 1.00 & 0.72 \\
\hline & 2 & 0.64 & 0.94 & 1.03 & 0.78 & 0.52 & 0.91 & 1.03 & 0.68 \\
\hline & 4 & 0.60 & 0.95 & 1.04 & 0.79 & 0.45 & 0.87 & 0.96 & 0.71 \\
\hline & 8 & 0.54 & 0.88 & 0.99 & 0.66 & 0.29 & 0.77 & 0.91 & 0.53 \\
\hline & 16 & 0.53 & 0.95 & 1.03 & 0.81 & 0.20 & 0.80 & 0.94 & 0.54 \\
\hline \multirow{5}{*}{55} & 1 & 0.62 & 0.94 & 1.00 & 0.82 & 0.55 & 0.91 & 0.99 & 0.76 \\
\hline & 2 & 0.59 & 0.86 & 0.93 & 0.73 & 0.44 & 0.83 & 0.93 & 0.65 \\
\hline & 4 & 0.58 & 0.97 & 1.05 & 0.76 & 0.33 & 0.86 & 0.97 & 0.67 \\
\hline & 8 & 0.53 & 0.87 & 0.94 & 0.75 & 0.25 & 0.79 & 0.86 & 0.66 \\
\hline & 16 & 0.55 & 1.01 & 1.06 & 0.79 & 0.14 & 0.64 & 0.71 & 0.50 \\
\hline
\end{tabular}

The first batch data of corn stover for Figure 30

1) Data of the untreated corn stover 
Table N-30. Enzymatic hydrolysis (mg equiv. glucose/g dry biomass) for the first bacth of untreated corn stover.

\begin{tabular}{|c|c|c|c|}
\hline \multirow{2}{*}{$\begin{array}{c}\text { Enzyme loading } \\
\text { (FPU/g dry } \\
\text { biomass) }\end{array}$} & 1 & 5 & 72 \\
\cline { 2 - 4 } & $11.01 \pm 1.61$ & $41.16 \pm 9.43$ & $114.01 \pm 10.12$ \\
\hline 1 & $38.16 \pm 1.45$ & $59.39 \pm 1.81$ & $153.06 \pm 15.98$ \\
\hline 5 & $45.74 \pm 0.81$ & $78.60 \pm 15.71$ & $172.12 \pm 1.41$ \\
\hline 10 & $56.67 \pm 8.17$ & $92.14 \pm 6.14$ & $185.91 \pm 5.75$ \\
\hline 20 & $68.97 \pm 0.05$ & $108.55 \pm 7.68$ & $192.81 \pm 22.12$ \\
\hline 60 & & \multicolumn{3}{|c|}{ Time of enzyme hydrolysis (hr) } \\
\hline
\end{tabular}

Data of DNS assay for Figure 37

Error band $( \pm)$ indicates 1 standard deviation

Table N-31. 3-d sugar yield (mg equiv. glucose/g dry biomass) for the first batch of the lime-pretreated corn stover at 25 and $55^{\circ} \mathrm{C}$ in non-oxidative condition.

\begin{tabular}{|c|c|c|c|c|c|c|}
\hline \multicolumn{2}{|c|}{ Enzyme } & \multirow{2}{*}{$\begin{array}{c}\text { Untreated } \\
(0)^{*}\end{array}$} & Enzyme & $\mathrm{T}\left({ }^{\circ} \mathrm{C}\right)$ & Enzyme & $\mathrm{T}\left({ }^{\circ} \mathrm{C}\right)$ \\
\hline $\begin{array}{c}\text { FPU/g dry } \\
\text { biomass }\end{array}$ & $\begin{array}{c}\mathrm{FPU} / \mathrm{g} \\
\text { cellulose }\end{array}$ & & $\begin{array}{c}\mathrm{FPU} / \mathrm{g} \\
\text { cellulose }\end{array}$ & $\begin{array}{c}25 \\
(15)^{*}\end{array}$ & $\begin{array}{c}\mathrm{FPU} / \mathrm{g} \\
\text { cellulose }\end{array}$ & $\begin{array}{c}55 \\
(16)^{*}\end{array}$ \\
\hline 1 & 2.7 & 114.01 & 2.1 & 412.79 & 1.9 & 445.20 \\
\hline 5 & 13.3 & 153.06 & 10.5 & 431.23 & 9.6 & 535.56 \\
\hline 10 & 26.7 & 172.12 & 20.9 & 526.86 & 19.2 & 515.07 \\
\hline 20 & 53.3 & 185.91 & 41.9 & 508.31 & 38.3 & 557.00 \\
\hline 60 & 160.0 & 192.81 & 125.6 & 529.23 & 115.0 & 569.92 \\
\hline
\end{tabular}

Data of DNS assay for Figure 38

* Pretreatment time (weeks) 
Table N-32. Relative 3-d sugar yield (mg equiv. glucose/g dry biomass) for the first batch of the lime-pretreated corn stover without air at $25^{\circ} \mathrm{C}$ for 15 week.

\begin{tabular}{|c|c|c|c|c|}
\hline \multirow{2}{*}{$\begin{array}{c}\text { Pretreatment time } \\
\text { (weeks) }\end{array}$} & \multicolumn{2}{|c|}{$\begin{array}{c}\text { 3-d sugar yield (mg equiv. } \\
\text { glucose/g dry biomass) }\end{array}$} & \multicolumn{2}{|c|}{ Relative 3-d sugar yield } \\
\cline { 2 - 5 } & $2.1^{*}$ & $125.6^{*}$ & $2.1^{*}$ & $125.6^{*}$ \\
\hline 0 & 114.01 & 192.81 & 0.28 & 0.36 \\
\hline 1 & 306.39 & 412.48 & 0.74 & 0.78 \\
\hline 2 & 290.07 & 455.68 & 0.70 & 0.86 \\
\hline 4 & 341.71 & 500.46 & 0.83 & 0.95 \\
\hline 8 & 356.60 & 522.53 & 0.86 & 0.99 \\
\hline 15 & 412.79 & 529.23 & 1.00 & 1.00 \\
\hline
\end{tabular}

Data of DNS assay for Figure 39

* Enzyme loading (FPU/g cellulose)

Table N-33. 3-d sugar yield (mg equiv. glucose/g dry biomass) for the first batch of the lime-pretreated corn stover in non-oxidative condition for 16 weeks*.

\begin{tabular}{|c|c|c|c|c|c|c|}
\hline \multirow{2}{*}{ Untreated } & Enzyme (FPU/g cellulose) & 2.7 & 13.3 & 26.7 & 53.3 & 160.0 \\
\cline { 2 - 7 } & $3-d$ sugar yield & 114.0 & 153.1 & 172.1 & 185.9 & 192.8 \\
\hline \multirow{2}{*}{$25^{\circ} \mathrm{C}$} & Enzyme (FPU/g cellulose) & 2.1 & 10.5 & 20.9 & 41.9 & 125.6 \\
\cline { 2 - 7 } & $3-d$ sugar yield & 412.8 & 431.2 & 526.9 & 508.3 & 529.2 \\
\hline \multirow{2}{*}{$35^{\circ} \mathrm{C}$} & Enzyme (FPU/g cellulose) & 2.0 & 10.1 & 20.2 & 40.3 & 121.0 \\
\cline { 2 - 7 } & $3-d$ sugar yield & 444.5 & 504.1 & 511.0 & 524.0 & 570.4 \\
\hline \multirow{2}{*}{$45^{\circ} \mathrm{C}$} & Enzyme (FPU/g cellulose) & 2.1 & 10.5 & 21.0 & 41.9 & 125.7 \\
\cline { 2 - 7 } & $3-d$ sugar yield & 436.5 & 521.5 & 543.3 & 560.5 & 592.8 \\
\hline \multirow{2}{*}{$55^{\circ} \mathrm{C}$} & Enzyme (FPU/g cellulose) & 1.9 & 9.6 & 19.2 & 38.3 & 115.0 \\
\cline { 2 - 7 } & $3-d$ sugar yield & 445.2 & 535.6 & 515.1 & 557.0 & 569.9 \\
\hline
\end{tabular}

Data of DNS assay for Figure 40

* 15 weeks for $25^{\circ} \mathrm{C}$ experiment. 
Table N-34. 3-d sugar yield (mg equiv. glucose/g dry biomass) for the first batch of the lime-pretreated corn stover in oxidative condition for 16 weeks*.

\begin{tabular}{|c|c|c|c|c|c|c|}
\hline \multirow{2}{*}{ Untreated } & Enzyme (FPU/g cellulose) & 2.7 & 13.3 & 26.7 & 53.3 & 160.0 \\
\cline { 2 - 7 } & 3-d sugar yield & 114.0 & 153.1 & 172.1 & 185.9 & 192.8 \\
\hline \multirow{2}{*}{$25^{\circ} \mathrm{C}$} & Enzyme (FPU/g cellulose) & 1.9 & 9.6 & 19.2 & 38.5 & 115.4 \\
\cline { 2 - 7 } & $3-d$ sugar yield & 490.0 & 554.3 & 558.4 & 560.2 & 573.9 \\
\hline \multirow{2}{*}{$35^{\circ} \mathrm{C}$} & Enzyme (FPU/g cellulose) & 2.0 & 9.8 & 19.6 & 39.2 & 117.5 \\
\cline { 2 - 7 } & $3-d$ sugar yield & 511.7 & 548.3 & 566.4 & 607.1 & 602.9 \\
\hline \multirow{2}{*}{$45^{\circ} \mathrm{C}$} & Enzyme (FPU/g cellulose) & 1.8 & 9.0 & 17.9 & 35.8 & 107.5 \\
\cline { 2 - 7 } & $3-d$ sugar yield & 558.2 & 567.9 & 608.1 & 606.9 & 608.1 \\
\hline \multirow{2}{*}{$55^{\circ} \mathrm{C}$} & Enzyme (FPU/g cellulose) & 2.2 & 10.7 & 21.5 & 42.9 & 128.7 \\
\cline { 2 - 7 } & $3-d$ sugar yield & 554.3 & 578.3 & 624.7 & 644.2 & 627.9 \\
\hline
\end{tabular}

Data of DNS assay for Figure 41

* 15 weeks for $25^{\circ} \mathrm{C}$ experiment.

Table N-35. Deacetylation for the first batch of the lime-pretreated corn stover.

\begin{tabular}{|c|c|c|c|c|c|c|c|c|}
\hline \multirow{4}{*}{ Process } & \multirow{2}{*}{$\begin{array}{c}\text { Temp } \\
\left({ }^{\circ} \mathrm{C}\right)\end{array}$} & \multicolumn{7}{|c|}{ Pretreatment time (weeks) } \\
\cline { 3 - 9 } & 25 & 58.48 & 79.96 & 84.87 & 84.64 & 86.65 & 82.78 & 90.14 \\
\hline \multirow{3}{*}{$\begin{array}{c}\text { No } \\
\text { air }\end{array}$} & 35 & 83.44 & 83.41 & 89.63 & 86.78 & 83.41 & 89.84 & 90.63 \\
\cline { 2 - 9 } & 45 & 69.32 & 80.62 & 89.03 & 88.16 & 93.24 & 93.74 & 90.25 \\
\cline { 2 - 9 } & 55 & 74.60 & 82.96 & 92.98 & 90.04 & 96.68 & 96.69 & 93.82 \\
\hline \multirow{4}{*}{ Air } & 25 & 75.84 & 88.30 & 88.42 & 93.61 & 87.27 & 91.05 & 90.43 \\
\cline { 2 - 9 } & 35 & 81.65 & 84.01 & 96.53 & 96.85 & 93.56 & 96.94 & 97.17 \\
\cline { 2 - 9 } & 45 & 87.16 & 89.63 & 93.46 & 93.76 & 93.99 & 94.89 & 97.51 \\
\cline { 2 - 9 } & 55 & 87.72 & 89.74 & 92.24 & 97.12 & 96.94 & 97.23 & 97.73 \\
\hline
\end{tabular}

Data for Figure 53

* 15 weeks for $25^{\circ} \mathrm{C}$ experiment. 
Table N-36. Delignification $(\varphi)$ and deacetylation $(\zeta)$ of the lime-pretreated corn stover.

\begin{tabular}{|c|c|c|c|c|c|}
\hline \multirow{2}{*}{ Temp $\left({ }^{\circ} \mathrm{C}\right)$} & \multirow{2}{*}{$\begin{array}{l}\text { Pretreatment } \\
\text { time (weeks) }\end{array}$} & \multicolumn{2}{|c|}{ Non-oxidative pretreatment } & \multicolumn{2}{|c|}{ Oxidative pretreatment } \\
\hline & & $\varphi^{1)}$ & $\zeta^{2)}$ & $\varphi^{1)}$ & $\zeta^{2)}$ \\
\hline \multirow{6}{*}{25} & 0 & 0.000 & 0.000 & 0.000 & 0.000 \\
\hline & $1 / 7$ & 0.123 & 0.585 & 0.138 & 0.746 \\
\hline & $3 / 7$ & 0.167 & 0.800 & 0.196 & 0.830 \\
\hline & 1 & 0.176 & 0.848 & 0.261 & 0.930 \\
\hline & 2 & 0.299 & 0.846 & 0.336 & 0.900 \\
\hline & 4 & 0.353 & 0.867 & 0.379 & 0.967 \\
\hline \multirow{6}{*}{35} & 0 & 0.000 & 0.000 & 0.000 & 0.000 \\
\hline & $1 / 7$ & 0.214 & 0.834 & 0.204 & 0.817 \\
\hline & $3 / 7$ & 0.255 & 0.834 & 0.275 & 0.840 \\
\hline & 1 & 0.321 & 0.896 & 0.360 & 0.965 \\
\hline & 2 & 0.374 & 0.868 & 0.455 & 0.969 \\
\hline & 4 & 0.380 & 0.834 & 0.461 & 0.936 \\
\hline \multirow{6}{*}{45} & 0 & 0.000 & 0.000 & 0.000 & 0.000 \\
\hline & $1 / 7$ & 0.236 & 0.693 & 0.204 & 0.872 \\
\hline & $3 / 7$ & 0.267 & 0.806 & 0.297 & 0.896 \\
\hline & 1 & 0.311 & 0.890 & 0.424 & 0.935 \\
\hline & 2 & 0.360 & 0.882 & 0.479 & 0.938 \\
\hline & 4 & 0.401 & 0.932 & 0.551 & 0.940 \\
\hline \multirow{6}{*}{55} & 0 & 0.000 & 0.000 & 0.000 & 0.000 \\
\hline & $1 / 7$ & 0.277 & 0.758 & 0.273 & 0.877 \\
\hline & $3 / 7$ & 0.337 & 0.883 & 0.343 & 0.897 \\
\hline & 1 & 0.377 & 0.884 & 0.452 & 0.922 \\
\hline & 2 & 0.412 & 0.936 & 0.562 & 0.971 \\
\hline & 4 & 0.474 & 0.873 & 0.673 & 0.969 \\
\hline
\end{tabular}

The first batch data of corn stover for Figures 54, 55, 56, and 57

1) $\varphi=$ weight fraction of delignification $\left(1-W_{\mathrm{L}}\right)$

$=1-$ weight fraction of the insoluble lignin in the pretreated biomass

$[=] \mathrm{g}$ insoluble lignin solubilized $(t) / \mathrm{g}$ insoluble lignin $(0)$

2) $\zeta=$ weight fraction of deacetylation $\left(1-W_{\mathrm{A}}\right)$

$=1-$ weight fraction of acetyl groups in the pretreated biomass

$[=] \mathrm{g}$ acetyl groups removed $(t) / \mathrm{g}$ acetyl groups $(0)$ 
Table N-37. Correlation of structural features (delignification, deacetylation, and crystallinity) with the hydrolysis yields of glucan and xylan for the lime pretreatment without air.

\begin{tabular}{|c|c|c|c|c|c|c|c|c|c|}
\hline \multirow[t]{2}{*}{$\begin{array}{l}\text { Temp } \\
\left({ }^{\circ} \mathrm{C}\right)\end{array}$} & \multirow{2}{*}{$\begin{array}{l}\text { Pretreat- } \\
\text { ment } \\
\text { time } \\
\text { (weeks) }\end{array}$} & \multirow[t]{2}{*}{$\varphi^{1)}$} & \multirow[t]{2}{*}{$\zeta^{2)}$} & \multirow[t]{2}{*}{$\mathrm{CrI}^{3)}$} & \multicolumn{2}{|c|}{$\begin{array}{c}\text { Content }(\%) \text { in } \\
\text { the pretreated } \\
\text { corn stover }\end{array}$} & \multicolumn{3}{|c|}{$\begin{array}{l}\text { Hydrolysis yields at } \\
15 \mathrm{FPU} / \mathrm{g} \text { cellulose }\end{array}$} \\
\hline & & & & & glucan & xylan & $Y_{\mathrm{g}}$ & $Y_{\mathrm{x}}$ & $Y_{\mathrm{gx}}$ \\
\hline \multirow{5}{*}{25} & $0^{4)}$ & 0.00 & 0.00 & 43.59 & 37.50 & 20.80 & 0.26 & 0.25 & 0.26 \\
\hline & 1 & 0.18 & 0.85 & 50.09 & 43.64 & 19.06 & 0.49 & 0.52 & 0.50 \\
\hline & 2 & 0.30 & 0.85 & 53.85 & 44.72 & 20.27 & 0.57 & 0.56 & 0.57 \\
\hline & 8 & 0.35 & 0.83 & 54.46 & 46.85 & 19.83 & 0.58 & 0.65 & 0.60 \\
\hline & 15 & 0.44 & 0.90 & 55.99 & 47.72 & 20.77 & 0.64 & 0.63 & 0.60 \\
\hline \multirow{4}{*}{35} & 1 & 0.32 & 0.90 & 52.22 & 43.27 & 19.53 & 0.46 & 0.46 & 0.46 \\
\hline & 2 & 0.37 & 0.87 & 53.79 & 44.76 & 19.64 & 0.46 & 0.49 & 0.47 \\
\hline & 4 & 0.38 & 0.83 & 56.16 & 45.01 & 18.80 & 0.58 & 0.61 & 0.59 \\
\hline & 16 & 0.48 & 0.91 & 54.49 & 49.57 & 17.16 & 0.62 & 0.81 & 0.67 \\
\hline \multirow{4}{*}{45} & 1 & 0.31 & 0.89 & 54.42 & 44.59 & 19.20 & 0.50 & 0.55 & 0.52 \\
\hline & 2 & 0.36 & 0.88 & 51.94 & 45.55 & 19.02 & 0.52 & 0.55 & 0.53 \\
\hline & 8 & 0.46 & 0.94 & 55.68 & 48.30 & 17.83 & 0.65 & 0.79 & 0.69 \\
\hline & 16 & 0.47 & 0.90 & 57.57 & 47.74 & 20.75 & 0.71 & 0.69 & 0.70 \\
\hline \multirow{5}{*}{55} & 1 & 0.38 & 0.88 & 52.53 & 44.84 & 20.22 & - & - & - \\
\hline & 2 & 0.41 & 0.94 & 51.23 & 42.98 & 18.65 & 0.52 & 0.56 & 0.53 \\
\hline & 4 & 0.42 & 0.87 & 51.31 & 49.85 & 19.15 & 0.69 & 0.72 & 0.70 \\
\hline & 8 & 0.47 & 0.91 & 52.76 & 46.64 & 20.58 & 0.77 & 0.72 & 0.75 \\
\hline & 16 & 0.45 & 0.91 & 54.56 & 52.19 & 20.42 & 0.63 & 0.64 & 0.63 \\
\hline
\end{tabular}

The first batch data of corn stover for Figures 58, 59, 60, and 61

1) $\varphi=$ weight fraction of delignification $\left(1-W_{\mathrm{L}}\right)$

$=1-$ weight fraction of the insoluble lignin in the pretreated biomass

$[=] \mathrm{g}$ insoluble lignin solubilized $(t) / \mathrm{g}$ insoluble lignin $(0)$

2) $\zeta=$ weight fraction of deacetylation $\left(1-W_{\mathrm{A}}\right)$

$=1-$ weight fraction of acetyl groups in the pretreated biomass

$[=]$ g acetyl groups removed $(t) / \mathrm{g}$ acetyl groups $(0)$

3) $\mathrm{CrI}=$ crystallinity index

4) Untreated corn stover 
Table N-38. Correlation of structural features (delignification, deacetylation, and crystallinity) with the hydrolysis yields of glucan and xylan for the lime pretreatment with air.

\begin{tabular}{|c|c|c|c|c|c|c|c|c|c|}
\hline \multirow[t]{2}{*}{$\begin{array}{l}\text { Temp } \\
\left({ }^{\circ} \mathrm{C}\right)\end{array}$} & \multirow{2}{*}{$\begin{array}{c}\text { Pretreat- } \\
\text { ment } \\
\text { time } \\
\text { (weeks) }\end{array}$} & \multirow[t]{2}{*}{$\varphi^{1)}$} & \multirow[t]{2}{*}{$\zeta^{2)}$} & \multirow[t]{2}{*}{$\mathrm{CrI}^{3)}$} & \multicolumn{2}{|c|}{$\begin{array}{l}\text { Content }(\%) \text { in } \\
\text { the pretreated } \\
\text { corn stover }\end{array}$} & \multicolumn{3}{|c|}{$\begin{array}{l}\text { Hydrolysis yields at } \\
15 \mathrm{FPU} / \mathrm{g} \text { cellulose }\end{array}$} \\
\hline & & & & & glucan & xylan & $Y_{\mathrm{g}}$ & $Y_{\mathrm{x}}$ & $Y_{\mathrm{gx}}$ \\
\hline \multirow{5}{*}{25} & $0^{4)}$ & 0.00 & 0.00 & 43.59 & 37.50 & 20.80 & 0.26 & 0.25 & 0.26 \\
\hline & 1 & 0.26 & 0.93 & 51.89 & 43.57 & 19.04 & 0.46 & 0.48 & 0.47 \\
\hline & 2 & 0.34 & 0.90 & 53.55 & 45.31 & 19.41 & 0.56 & 0.54 & 0.55 \\
\hline & 8 & 0.42 & 0.97 & 53.40 & 46.55 & 19.01 & 0.67 & 0.63 & 0.65 \\
\hline & 15 & 0.58 & 0.94 & 50.00 & 51.99 & 18.00 & 0.67 & 0.64 & 0.66 \\
\hline \multirow{4}{*}{35} & 1 & 0.36 & 0.97 & 56.69 & 45.49 & 18.63 & 0.53 & 0.53 & 0.53 \\
\hline & 2 & 0.46 & 097 & 56.67 & 46.37 & 18.04 & 0.57 & 0.61 & 0.58 \\
\hline & 4 & 0.46 & 0.94 & 57.10 & 48.22 & 18.55 & 0.60 & 0.61 & 0.60 \\
\hline & 16 & 0.67 & 0.97 & 60.23 & 51.07 & 18.83 & 0.74 & 0.66 & 0.72 \\
\hline \multirow{4}{*}{45} & 1 & 0.42 & 0.94 & 57.98 & 46.68 & 18.66 & 0.51 & 0.51 & 0.51 \\
\hline & 2 & 0.48 & 0.94 & 55.07 & 48.61 & 17.87 & 0.52 & 0.56 & 0.53 \\
\hline & 8 & 0.71 & 0.95 & 55.47 & 52.66 & 17.00 & 0.70 & 0.71 & 0.70 \\
\hline & 16 & 0.80 & 0.98 & 54.68 & 55.84 & 17.93 & 0.82 & 0.72 & 0.80 \\
\hline \multirow{5}{*}{55} & 1 & 0.45 & 0.92 & 55.41 & 47.37 & 20.11 & 0.60 & 0.60 & 0.60 \\
\hline & 2 & 0.56 & 0.97 & 53.26 & 46.82 & 18.26 & 0.72 & 0.73 & 0.72 \\
\hline & 4 & 0.67 & 0.97 & 55.35 & 47.52 & 18.26 & 0.93 & 0.76 & 0.89 \\
\hline & 8 & 0.75 & 0.97 & 53.36 & 44.74 & 19.08 & 0.96 & 0.71 & 0.89 \\
\hline & 16 & 0.86 & 0.98 & $\underline{0}$ & 46.61 & 1 & 9 & 6 & 0.90 \\
\hline
\end{tabular}

The first batch data of corn stover for Figures 58, 59, 60, 61, and 63 1) - 4): same as described in Table N-37. 
Table N- 39. Relative digestibility of glucan and xylan in the lime pretreatment of corn stover at the optimal condition and the enzyme hydrolysis at 15 and 60 FPU/g cellulose.

\begin{tabular}{|c|c|c|c|c|c|c|c|c|}
\hline \multirow{3}{*}{ Sample } & \multirow{2}{*}{ Component } & \multirow{2}{*}{$\begin{array}{c}\text { FPU/g } \\
\text { cellulose }\end{array}$} & \multicolumn{6}{|c|}{ Relative digestibility } \\
\cline { 4 - 9 } & & & 6 & 12 & 24 & 48 & 72 & 96 \\
\hline \multirow{2}{*}{$\begin{array}{c}\alpha- \\
\begin{array}{c}\alpha \\
\text { ellulose } \\
1)\end{array}\end{array}$} & \multirow{2}{*}{ Glucan } & 15 & 48.1 & 63.8 & 77.4 & 90.6 & 96.1 & 100.0 \\
\cline { 3 - 9 } & \multirow{2}{*}{ Xylan } & 60 & 48.9 & 64.5 & 80.5 & 92.8 & 98.5 & 100.0 \\
\cline { 3 - 9 } & & 60 & - & - & - & - & - & - \\
\hline \multirow{2}{*}{$\begin{array}{c}\text { Corn } \\
\text { stover } \\
2)\end{array}$} & \multirow{2}{*}{ Glucan } & 15 & 74.4 & 86.6 & 94.1 & 98.5 & 100.1 & 100.0 \\
\cline { 3 - 9 } & \multirow{2}{*}{ Xylan } & 60 & 86.0 & 91.9 & 97.0 & 99.3 & 99.5 & 100.0 \\
\cline { 3 - 9 } & & 60 & 66.8 & 84.6 & 91.7 & 97.3 & 99.0 & 100.0 \\
\hline
\end{tabular}

Data for Figure 67

1) SIGMA (C-8002)

2) The second batch of corn stover treated at the optimal condition $\left(55^{\circ} \mathrm{C}, 4\right.$ weeks, and aeration). 
Table N-40. Data of acetyl group determination for the samples from CAFI group.

\begin{tabular}{|c|c|c|c|}
\hline $\begin{array}{c}\text { CAFI } \\
\text { member }\end{array}$ & $\begin{array}{l}\text { Sample } \\
\text { number }\end{array}$ & Pretreatment conditions & $\begin{array}{c}\text { Acetyl } \\
\text { group }(\%)\end{array}$ \\
\hline \multirow{3}{*}{$\begin{array}{l}\text { Purdue } \\
\text { University }\end{array}$} & $\mathrm{P} 1$ & Untreated corn stover & $2.26 \pm 0.15$ \\
\hline & P2-1 & Pretreated, filtered and dried solid & $1.73 \pm 0.08$ \\
\hline & $\mathrm{P} 2-2$ & Pretreated and filtrate (liquid fraction) & $0.10 \pm 0.02$ \\
\hline \multirow{2}{*}{$\begin{array}{l}\text { Dartmouth } \\
\text { College }\end{array}$} & D1 & $\begin{array}{l}140^{\circ} \mathrm{C} \text { for } 40 \mathrm{~min} \\
\text { with } 1 \% \text { acid and } 10 \% \text { sol. }\end{array}$ & $0.90 \pm 0.05$ \\
\hline & D2 & $\mathrm{N} / \mathrm{A}$ & $0.82 \pm 0.05$ \\
\hline \multirow{9}{*}{$\begin{array}{l}\text { Auburn } \\
\text { University }\end{array}$} & $\mathrm{J} 1$ & $170^{\circ} \mathrm{C}, 60 \mathrm{~min}, 15 \mathrm{wt} \% \mathrm{NH}_{3}$ & $0.29 \pm 0.05$ \\
\hline & $\mathrm{J} 2$ & $170^{\circ} \mathrm{C}, 14 \mathrm{~min}, 15 \mathrm{wt} \% \mathrm{NH}_{3}$ & $0.38 \pm 0.05$ \\
\hline & $\mathrm{J} 3$ & $170^{\circ} \mathrm{C}, 10 \mathrm{~min}, 15 \mathrm{wt} \% \mathrm{NH}_{3}$ & $0.30 \pm 0.02$ \\
\hline & $\mathrm{J} 4$ & $170^{\circ} \mathrm{C}, 20 \mathrm{~min}, 15 \mathrm{wt} \% \mathrm{NH}_{3}$ & $0.19 \pm 0.05$ \\
\hline & $\mathrm{J} 5$ & $25^{\circ} \mathrm{C}, 1 \mathrm{~d}, 30 \mathrm{wt} \% \mathrm{NH}_{3}$ & $0.43 \pm 0.00$ \\
\hline & $\mathrm{J} 6$ & $25^{\circ} \mathrm{C}, 3 \mathrm{~d}, 30 \mathrm{wt} \% \mathrm{NH}_{3}$ & $0.38 \pm 0.07$ \\
\hline & $\mathrm{J} 7$ & $25^{\circ} \mathrm{C}, 6 \mathrm{~d}, 30 \mathrm{wt} \% \mathrm{NH}_{3}$ & $0.31 \pm 0.06$ \\
\hline & $\mathrm{J} 8$ & $25^{\circ} \mathrm{C}, 10 \mathrm{~d}, 30 \mathrm{wt} \% \mathrm{NH}_{3}$ & $0.35 \pm 0.01$ \\
\hline & J9 & Untreated corn stover & $2.24 \pm 0.08$ \\
\hline \multirow{4}{*}{$\begin{array}{l}\text { Michigan } \\
\text { State } \\
\text { University }\end{array}$} & M1 & $60 \% \mathrm{MC}^{*}, 1: 1\left(\mathrm{NH}_{3}:\right.$ biomass $), 90^{\circ} \mathrm{C}$ & $0.60 \pm 0.05$ \\
\hline & M2 & $60 \% \mathrm{MC}^{*}, 1.3: 1\left(\mathrm{NH}_{3}:\right.$ biomass $), 90^{\circ} \mathrm{C}$ & $0.53 \pm 0.02$ \\
\hline & M3 & $40 \% \mathrm{MC}^{*}, 1: 1\left(\mathrm{NH}_{3}:\right.$ biomass $), 90^{\circ} \mathrm{C}$ & $0.40 \pm 0.06$ \\
\hline & M4 & $40 \% \mathrm{MC}^{*}, 1.3: 1\left(\mathrm{NH}_{3}:\right.$ biomass $), 90^{\circ} \mathrm{C}$ & $0.49 \pm 0.05$ \\
\hline \multirow{6}{*}{ NREL } & Control 1\&2 & $\begin{array}{l}\text { Pretreated, held in Jago (1) \& without } \\
\text { filtering \& washing (2) }\end{array}$ & $0.53 \pm 0.03$ \\
\hline & CS-030117-A & $\begin{array}{c}\text { Pretreated, hot washed with } \mathrm{Fe}^{3+} \\
\text { catalyst }\end{array}$ & $0.45 \pm 0.01$ \\
\hline & CS-030124-C & $\begin{array}{l}\text { Pretreated, hot washed with } 0.1 \% \\
\mathrm{NaOH}\end{array}$ & $0.56 \pm 0.05$ \\
\hline & CS-030128-B & $\begin{array}{l}\text { Pretreated, hot washed with hot water } \\
\text { only }\end{array}$ & $0.46 \pm 0.03$ \\
\hline & CS-030128-C & $\begin{array}{l}\text { Pretreated, hot washed with } 0.5 \% \\
\text { ethanol }\end{array}$ & $0.47 \pm 0.04$ \\
\hline & P030312CS & $\begin{array}{c}\text { Taken directly from SUNDS reactor } \\
\text { without further treatment }\end{array}$ & $0.63 \pm 0.05$ \\
\hline
\end{tabular}

*MC: moisture content ( $\mathrm{wt} \%$ )

Error band $( \pm)$ indicates 1 standard deviation 


\section{VITA}

Born in Busan, the Republic of Korea, Se Hoon Kim graduated with B.S. (1989) and M.S. (1991) degrees in chemical technology from Seoul National University, Seoul, Korea. He worked at Biotech Research Institute of LG Chemical Co. Ltd. (the current name is LG Life Science Ltd.) in Taejon, Korea for 10 years (1991 - 2000). He graduated from Texas A\&M University with a Ph.D. degree in chemical engineering in 2004.

Correspondence can be mailed to:

\section{SE HOON KIM}

(Current address) 301 Ball Street, Apt. 2109, College Station, TX 77840, U.S.A.

(Permanent address) Sinbanpo Hansin Apt. 119-911, Jamwon-dong, Seocho-gu, Seoul 137 - 797, Republic of Korea

(E-mail addresses) bioskim@netian.com sehoonkim@tamu.edu 